\title{
Embodying Voice: \\ singing Verdi, singing Wagner
}

\author{
Margaret Medlyn
}

\begin{abstract}
A thesis
submitted to Victoria University of Wellington in fulfilment of the requirements for the degree of Doctor of Philosophy
\end{abstract}

Victoria University of Wellington

2016 


\section{Contents}

List of diagrams 5

List of musical examples 5

Acknowledgements 6

Abstract 7

Introduction: Sheer Voice 9

Chapter One

The Singer's Ineffability 25

Introduction - Paving the Way for the Performative Turn - Philosophers,

Musicology and Vocality - The Performer's Perspective - Gender and Feminism -

Verdi and Wagner - Body - The Diva - Listener Ecstasy - Jouissance

Chapter Two

Voice in Negotiation between the Material and the Ineffable 69

Embodiment - The Breath - The Complexity of Embodiment

Chapter Three

Verdi, Wagner and the Lowered Larynx 105

Overview of singing technique - Verdi's Vocalità - Wagner's Wörter - Verdi contra Wagner - Jouissance from Verdi and Wagner

Chapter Four

Verdi Il trovatore: the Imperative of Passion 145

Il trovatore - Azucena/La Zingara - Leonora/La primadonna - Leonora and

Azucena

Chapter Five

Wagner's Body: Wagner, the Singer and Sieglinde 193

Wagner's Body - The Singer's Body - Sieglinde's Body

Chapter Six

Kundry: Embodiment as metaphor? 225

Body - Kundry - Voice and Body in Parsifal - Metamorphosis - The

Shamaness/The Wanderer - The Mother/The Seductress - The Virago - The

Magdalen - Conclusion

Conclusion: Voice Unleashed 273

Bibliography 285 


\section{Diagrams}

Model of Embodiment, 2.1 [page 79]

Diagram of the Vocal Apparatus, 2.2 [80]

Diagram of Epiglottis, 3.1 [132]

\section{Music Examples}

Il trovatore by Giuseppe Verdi, Ricordi

Example 4.1 'Stride la vampa', bb. 89-94 [page 165]

Example 4.2 'La mano convulsa stendo', bb. 107-111 [167]

Example 4.3 'Sul capo mio le chiome', bb. 154-8 [168]

Example 4.4 'Ah! Tu la spremi dal cor!' bb. 202-209 [169]

Example 4.5 'Giorni povera vivea' bb. 54-67 [171]

Example 4.6 'È questo un sogno, un'estasi' bb. 102-4 [179]

Example 4.7 'Lo desta alle memorie' bb. 49-56 [181]

Example 4.8 'Deh! Non dirgli, improvvido, le pene del mio cor.' bb. 57-61 [183]

Example 4.9 'Di te?' bb. 122-126 [182]

Example 4.10 'A te davante' bb. 22-33 [185]

Example 4.11 'M'avrai, ma fredda, esanime spoglia!' bb. 147-149 [186]

Example 4.12 'Prima che d'altri vivere', bb. 323-332 [188]

Die Walküre by Richard Wagner, Edition Peters

Example 5.1 'Müde liegt er von Weges Mühn' [208]

Example 5.2 'Der Männer Sippe' [210]

Example 5.3 'O fänd' ich ihn heut' [211]

Example 5.4 'ich hörte sie neulich' [213]

Example 5.5 'Grauen und Schauder' [215]

Example 5.6 'Nicht sehre dich Sorge' [218]

Example 5.7 'O hehrstes Wunder!' [219]

Parsifal by Richard Wagner, Edition Peters

Example 6.1 'Nicht Dank!' [246]

Example 6.2 'Den Vaterlosen gebar die Mutter' [247]

Example 6.3 'Nie tu ich Gutes' [248]

Example 6.4 'Ich will nicht.' [251]

Example 6.5 'Parsifal, Weile!' [254]

Example 6.6 'Nur Sorgen war sie' [256]

Example 6.7 'Grausamer' [260]

Example 6.8 'Ich sah ihn' [262]

Example 6.9 'So war es meing Kuss' [265]

Example 6.10 'Dienen, dienen' [268] 


\section{Acknowledgements}

A huge thank you to my two supervisors, Elizabeth Hudson and Inge van Rij. Elizabeth challenged and provoked me, suggesting I delve into my professional experience to devise a truly creative project. Inge, with her consummate care and attention to detail, stimulated a love of writing in me. In addition, she has quite rightly toppled me from my position of the Queen of the Colon. Both have worked tirelessly to help me shape and finesse my ideas.

Many thanks to my colleagues at the New Zealand School of Music, particularly those in Classical Voice: Jenny Wollerman, Lisa Harper-Brown, Richard Greager and Mark Dorrell. Musicologists Kimberley Cannady and David Cosper read and had suggestions, and graduate student Lynne Wenden helped with the music examples. Bianca Andrew, always supportive and morale boosting, was a proofreader. My husband, Roger Joyce, was a brilliant editor.

Thank you to my children, Jess and Tom Deacon, for their love and constant encouragement. 


\section{Abstract}

\section{Embodying Voice: singing Verdi, singing Wagner}

Writers from diverse disciplines have rhapsodised over the impact of the operatic voice on the listener, while musicologists such as Abbate, Duncan, and Risi have explored the effect that concepts of voice and bodily engagement have had on our critical readings of opera. Yet although perspectives on performance have become an increasingly vital aspect of operatic criticism, no one has laid out how opera singers experience performance in relation to the ideas of embodiment that scholars write about. The discourse on embodiment and voice is theoretical; most discussions of female voice can be mapped on to any historical period and on to any voice, so that all voices end up being treated the same; paradoxically, in addition it is a discourse that largely omits the body.

Indeed, the complexity of connecting many different layers of mind and bodily engagement, that is, the embodiment, is a task that requires detailed and specialised training. Without attempting to speak for all singers at all times, I propose that by acknowledging that different singers achieve and think about particular elements of embodiment in different ways, we can start to come to terms with an individual singer's creative agency, as a co-creator of the composer's music.

In this dissertation I outline key characteristics of the type of embodied voice that has become the basis of operatic singing today, how that operatic voice is produced in performance, and the importance of the singer's own bodily engagement in making that sound and constituting the performance itself. By juxtaposing operatic criticism and readings of voice and vocality with an interrogation of my own physical engagement in singing a few particular roles (as a singer specialising in nineteenth and twentieth-century operatic repertoire), I demonstrate how a singer "creates" roles. My detailed analyses illustrate how a singer's fully conscious bodily engagement, in and through the breath, is inextricably linked with musical and dramatic interpretation, and sets up the vocal spectacle and embodied agency so central to our modern experience of opera. 
Moreover, in the context of specific readings of particular operatic roles, I argue that particular composers set up specific ways in which singers manipulate elements of body and mind - so that the score can influence and even control how a singer can or cannot breathe. As I will demonstrate in detailed studies of four roles by Verdi and Wagner (all of which I have sung in performance), some scores set up an almost physical collaboration between the singer herself and the way in which text, breath and music are shaped and moulded in performance by particular features of the vocal writing. While a large number of roles could be explored in those terms, the demands placed upon body and voice are individual and each role of every opera is always distinct; Verdi and Wagner roles provide particularly valuable examples because of the complex intersection between a rich psychological framework for interpretative engagement and a complex vocal and bodily collaboration. In addition, my focus on a particular timeframe in the historical development of vocal practice suggests fascinating correlations with the case studies I discuss from Il trovatore, Die Walküre and Parsifal. The new type of singer developing the skills and voice to sing these roles predicates today's vocal and stage practices that in turn have influenced my own experience. Offering an in-depth examination of the complex tasks an opera singer undertakes, I also examine differences in the vocality in singing Wagner and Verdi roles, culminating in a detailed exposition of my chosen roles.

This dissertation, therefore, sets up a complex picture of the ways in which vocal performance is constructed and controlled by Verdi and Wagner, on the one hand, and how particular scores also set up the conditions that allow singers in these texts to unleash their voice to achieve "wildness" and expression that lies beyond the text. Through these case studies, I establish a discourse of vocality that allows detailed readings of aspects of vocal performance that seemingly bypass rational communication. In the end, I build a case for understanding how singers' embodiment contributes to the creativity of the performance in ways hitherto intuited but not analysed. Thus I offer a counterbalance and reinterpretation of traditional perspectives on the reality of performance, addressing singers and scholars alike. 


\section{Introduction:}

\section{Sheer Voice}

Voice fascinates and seduces. It is of us and yet not. A paradox, it extends our bodies into space, and can manifest our most hidden feelings. It is all pervasive. We talk about voice in many ways, both metaphorical and literal: the style of an author or poet is their "voice"; individuals or groups of people can have a voice. Used in myriads of ways, the voice has been scrutinised from many perspectives since antiquity, and the effect of its heightened use by way of chanting, orating, shouting, incanting and singing still intrigues and disturbs today. The female voice has long held a particular fascination. The voices of the sirens were suspected of calling and fatally seducing the listener. Similarly dangerous was the abandon induced when the listeners' own voices were raised to music and used to alter states of mind, body and soul, a frenzy of rapture. ${ }^{1}$ When words and music are brought together, the sound of the voice adds to both in crucially significant ways.

The operatic singer has always been the focus of much public attention. On the stage they could be highly seductive, - there is a history of audience fixation on the dramatic, more-than-life-sized personalities of the diva, and the divo, and on their voices. Operatic performances and specific performers have a well-documented history of driving their listeners to enthusiastic, some might say, excessive, displays of gratitude, of catharsis, of diva and divo worship. Much has been written about singers both in an anecdotal, non-scholarly way, and as the focus of scholarly writing. To a professional singer inevitably fascinated by voice, the relationship of scholarly work to the realities of singing can be perplexing. There is often a disjunct between the understandings and interpretations of many scholars and the act of performance (with notable exceptions), and this disjunct poses many questions.

\footnotetext{
${ }^{1}$ Judith A. Peraino, Listening to the Sirens: Musical Technologies of Queer Identity from Homer to Hedwig (Berkeley: University of California Press, 2006), 20. In ancient Greece, and surely before, dance and song accompanied religious rituals, and sexual rites of passage - voices raised with passion and abandon roused parallel feelings in the listener.
} 
These relationships and questions are my focus for research in this dissertation. I aim to share aspects of what happens on the inside of performance, and examine the considerable amount of intense practice and knowledge required to build the embodiment that must necessarily be in place before the singer sets foot before an audience. This is bound to be of interest to singers and students of singing. However, my greater intention is to lay claim to the creative act of performance, and to impress on scholars that the text and music are merely marks on paper until they are subject to a performer's vitality and creativity.

The collision of disciplines that is so much at the frontline of opera performance demands consideration with respect to the operatic embodied voice. However, the actual physical presence of the operatic singer coupled with the impact of the sound can tend to confuse the critics in regard to the vocality of a performance. ${ }^{2}$ As a performer of many of the operatic works that have been the subject of scholarly discourse, I have been intrigued that the act of performance as I experience it seems to have very little connection to what is written. A number of external factors can be understood to be primary drivers of the act of performance. To cite two examples: the director and conductor can wield considerable influence in shaping the singer's performing style; and historical precedents and sociological contexts are crucial factors that influence the development of the professional careers of singers and the way they go about gaining performance experience. ${ }^{3}$ Furthermore, despite a myriad of disparate backgrounds most operatic singers today would agree that their primary focus (that is, the aspect of performance that occupies the bulk of their efforts), lies in

\footnotetext{
2 This is a subject worthy of further research.

${ }^{3}$ Susan Rutherford The Prima Donna and Opera 1815-1930 (Cambridge: Cambridge University Press 2006); Verdi, Opera, Women (Cambridge, Cambridge University Press, 2013) and John Rosselli Singers of Italian Opera: The history of A Profession (Cambridge: Cambridge University Press, 1992) amongst others, provide a wonderful sociological and historical background to the roles of that I have tended to specialise in.
} 
the sheer physicality of singing itself, and the pre-eminence of those physical demands when singing.

I take as my starting point my personal experience of performance and the physical demands of singing and use that experience to interrogate and weave together a number of seemingly disparate strands of research in several fields and apply that knowledge as a filter to those performances. When comparing scholarly approaches with my own performance-based knowledge, I found that most scholarly discourse has tended to approach and examine "voice" in a generic way, often with little acknowledgement of the individuality of each singer's voice, body, and character and personality. The accretion and application of experiential knowledge has, of course, completely different motivations, goals and sets of responses. In engaging in operatic performance, the end focus is on what does or does not work on stage, what affects one when one is singing, and how the variables can be controlled. The excitement of performance is driven by the immediacy of voice and music and how the uncertainties and exigencies of the stage are dealt with.

Even though my experience of scholarship has been positive and rewarding, the extent of the gulf between actuality and the commentary has meant that the impact of this literature on performance practice is virtually nil. Because of this lack of contiguity it is easy to see why professional singers have resisted delving into the separate, specialist field of scholarly literature.

However, as scholars increasingly encroach on the contexts of performance for their critical framework, the gap between theory and practice is narrowing. Scholars who write well about performance are beginning to offer a number of different perspectives that I believe have the power to enhance and enrich the work of performers. This new scholarship has the potential to bridge the gap between theory and practice. A case in point is the engagement with notions of "embodiment". Scholars (with the notable exception of Suzanne Cusick) have written as outsiders as listeners/viewers for other listeners/viewers, on what they see of whatever type of embodiment they are focusing on. I, the singer, am the embodier, and therefore my experience of 
embodiment is from the inside out. My own, non-academic, performance-based experience is a form of knowledge that is completely opaque to even the most sophisticated scholars, and it is this opacity I wish to address in my dissertation.

I base my dissertation on a notion of embodiment that is fully centred on and encapsulates vocal performance. The nature of embodiment is in and of the body and connects cognition, emotion and the nature of the vocal sound itself. Operatic singing in particular is a detailed engagement of mind and body, and the singer experiences this as enacted meaning in real time, resulting in embodiment as a creative act. A singer's embodiment interacts with musicological aspects of performance, framing performance through, and incorporating musicological thought.

Like many voice specialists, I am irrationally in love with voices in performance and have an immediate and subjective reaction to them. I love them, hate them, or am indifferent to them if the sound does not call me. There is nothing better in my world than to be enveloped aurally by a voice I love to hear; my greatest sensual musical experiences have been in Sitzprobe rehearsals - first rehearsals with the orchestra before stage rehearsals - which are often held in a small and resonant rehearsal space, and where the singers are so close that their sound inhabits your body, a very intimate experience.

I understand voices and how they work in performance. They speak to me: I can hear the state of health of the vocalis muscle, the state of health of the body. I can even gather some sense of the state of mind of the singer. Operatic singing, of course, is not naturalistic: it is a heightened way of expressing texts. The extra volume helps the opera singer's voice to reach out and touch the audience in a meaningful and cathartic way -it not only conveys a sense of the singer, but must also communicate the direct expression of the character and the public persona. The listener experiences the whole entity - it is not just the physical sound and feeling, but also the visual and musical. Some singers have extra qualities in the harmonic structure in the voice that compel one's attention and make it an imperative to listen to it. I call this quality "extra textual". 
The harmonic structure of each voice is individual to the singer's body and is a function of the vocal resonator tract - the reasonably small space in the oro-pharynx -the throat (see Diagram Chapter 2.1 p. 85) above the vocal folds to the top of the lifted soft palate. The judicious and subtle muscular movements enhance the harmonic structure of the sound initiated by the vocal folds. These muscular movements are part of the embodiment of the singer, and require a great deal of control to achieve the compelling qualities of extra-textual communication.

In first delving into scholarly perspectives on voice and vocality, it was seminal for me to discover the (well-known) work of the philosopher Roland Barthes. He recognised what I think of as this extra-textual quality of singers - he called it the "grain of the voice" - as something that masked the technique of singing and gave the listener a sensual connection to the singer. Michel Poizat's work also helped me to bridge the gap between what I experience and what commentators write about: the exploration of the listener's pleasure, their jouissance, was deeply resonant; to give pleasure is after all why singers sing. Jouissance is a French word meaning enjoyment or pleasure that can combine mental, physical and spiritual aspects. It can also be taken to mean sexual orgasm, but more often, enhanced and enlarged upon by the writings of a number of French philosophers and writers to mean excessive pleasure, including pleasure at the level of pain. Writers about the voice especially Poizat suggest that certain voices give the listener a metaphysical fulfilment of desire, a fusion of the mystical and the erotic.

Barthes and Poizat talk in evocative detail about the listener's pleasure. For me, though, these texts prompted an initial challenge and posed a crucial gap in perspective, because without the singer's pleasure in their own singing, we would have no vocal performance. Understanding the embodiment of what I do as a performer to give jouissance, and making sense of the effort involved in singing entails also raising the question of how that jouissance is invoked for both listener and singer. 
The idea that the singer might enjoy jouissance is one that has remained mostly unexplored. ${ }^{4}$ Yet singers get physical pleasure from their bodies working intensely to produce sound. They also, naturally, have some satisfaction from singing well, and also the enjoyment in assuming an interesting role. Indeed, there is some intersection between the way vocal pleasure is crafted in certain roles - it emerges at certain points, it is not just constant - that can become a key aspect of the interpretation of that role. In this way it is intriguing to contemplate how much composers like Verdi and Wagner were in fact crafting the physical experience of singing.

My case studies, centred on roles I have sung, are discussed in Chapters Four to Six. In the case study on Wagner's Kundry, I discuss the particular and unusual jouissance that is available to me as an actor. If jouissance captures the kind of ecstasy that happens at key moments, in fact it is the illusive working together of body and mind in the production of voice, and in vocal performance, that my research aims to elucidate. Indeed, I suggest that many singers sing for the bodily joy of making their sound, for the physical release of the concentrated bodily engagement, of the embodiment. My voice is me. I try hard to keep the vocal mechanism separated from myself, as I always need to be objective about the sound and how I train it. However, the feeling of it is within me and it gives me a great deal of mental and physical pleasure, jouissance, when my voice is working well and is healthy.

By calling on and articulating my professional experience, in this dissertation I will investigate in detail how these ingenious and individual performances of singers are created - how the body is involved in engaging with the operatic voice in live performance. Each performer has his or her own modus operandi and varying abilities to deal with external influences that distract them from singing. My reading of singers' individualised technique and an understanding of my own process will be the key to engagement with my research. Given the centrality of my own experience of vocality to this

\footnotetext{
${ }^{4}$ Clemens Risi has noted the expression on singers' faces when, for instance, they get through a particularly difficult passage well, or without incident. Clemens Risi, "The Diva's Fans: Opera and Bodily Participation" (Performance Research 16, (3) 2011).
} 
perspective, then, it will be helpful to lay out some of my own context. Singers are notoriously diffident about articulating their processes; I hope that articulating my experiences as a performer will lead to a greater understanding by scholars of what we singers do on stage, and how we are judged in the moment of vocalising, under tremendous pressure.

Although acknowledging that memory can mislead, I have an excellent visual and kinaesthetic recall, and can re-run performances in my head. I use this recall in my case studies as a type of fabricated recollection, assisted by video and sound recordings, interspersing in-the-moment comments on performance with critical reflections.

As my research and approach has been shaped by my own experience, it seems necessary to lay out how my perspective was formed and shaped; the ways in which my own training and experience has informed my view on performance and inspired me to search out answers to the effect of operatic vocality.

I grew up surrounded by music and voices. I knew instinctively as a child that my voice was me, that one was one's voice and that it was of one's body. Engaging in the regular family music-making sessions and singing communally continued into my teens, as did involvement in the theatre. Though amateur music- and theatre-making, it was real, visceral. It never occurred to me that this was an extraordinary life for a child and teenager, it was just what our family did, and what my grandparents did, and what their families in the north of England, through the church and choral societies, had done in turn. Always part of my life, despite brief excursions into the sciences, music and voice became the subjects I studied, then what I taught, and finally how I earned money to live, and, along the way, a career developed.

At some point I realised how much I didn't know technically, but I still had enough instinctive vocal, musical and theatrical drive to keep myself going until I could find the people and knowledge I needed to inform myself. My career did not have the ideal or standard trajectory. I studied singing at tertiary level but was initially subject to uninformed vocal teaching, from which I was rescued by 
Anthea Moller. ${ }^{5}$ However, I was put off tertiary institutions for a considerable time. Moving to the UK and vowing not to darken the doors of any music college there, I found myself a chorus position and picked up valuable contacts and experiences that way. Commuting backwards and forward between New Zealand and England, I found a niche in singing mezzo roles, lots of interesting music and unexpectedly found myself as a fully-fledged professional singer.

After singing professionally for a number of years, it wasn't until a coach challenged me in London that I ever thought about whether the fach I was singing actually suited my voice and character. ${ }^{6}$ True enough, lyric mezzo roles were rather tedious: singing the boy, the maid, or at a pinch, the old lady. But the coach pointed out that my voice, through sustained use, was developing its true dramatic potential, and he suggested I look at some heavier roles. I did and as I had been singing zwischenfach roles already, I was immediately employed for them. ${ }^{7}$ As an experiment, I also started to move into the lower dramatic soprano roles. In this I had no guidance from a teacher; rightly or wrongly I felt I could work through this fach change myself, and I had found no-one at that point who seemed really to understand what my voice needed. With the benefit of experience and hindsight, I realise now that my voice, had it been trained initially with basic Italian vocal concepts, would have kept its large range available to me, rather than shutting it down. As I explain further in Chapter Three, the Italian way of training concentrates on focusing the voice on the pure Italian vowels and in finding its character through an open and unconstricted sound. Many vocalises are employed to develop the chiaroscuro (light and shade) of the colouring and timbre. My voice is a difficult, unwieldy instrument, large and wild, dark and

\footnotetext{
5 Then a New Zealand-based contracted teacher.

${ }^{6}$ Fach: a German word denoting the type and weight of a voice. The classification is broadly used to indicate to singers what roles they should (or should not be) be singing. I started singing professionally in 1982 in London in the Kent Opera Chorus. I progressed to small roles in the company, then after going freelance sang freelance mezzo roles in New Zealand and Australia. The coach was Phillip Thomas at the English National Opera, in 1996.
}

${ }^{7}$ Zwischenfach: literally between two types of voices. Used to denote a high mezzo who sings some lower soprano roles, or a role that can be sung by either a soprano or a mezzo for example, Oktavian in Der Rosenkavalier by Richard Strauss. 
powerful with a top extension - a European voice (by this I mean it didn't fit into an Anglophile soundscape) very like the "falcon" voice of the nineteenth century. ${ }^{8}$ My body needed to be very strong to support and protect it and allow it to work efficiently, and this musculature took time to develop.

Within a few years I had sung all the big Verdi mezzo roles, and in $2000 \mathrm{I}$ switched to sing the Verdi soprano roles followed closely by many Wagner roles. ${ }^{9}$ The music of Verdi and Wagner had captured me from a young age: the Met broadcasts entranced me and it was a matter of some disappointment to me as a young singer that my voice was not suitable to sing at that time any of their repertoire. It was the dramatic nature of the music and the thrilling nature of the vocality that drew me in to their world. I was in my late thirties before I was given the opportunity of singing a Verdi role and it felt like coming home, not only for my personality but also for my voice. What was immediately noticeable to me was the difference in the use of my body, which I learned through the experience of singing on stage, and from listening to the good colleagues around me, of whom I also asked advice. It took singing Marie in Wozzeck, though, to set me off on the exploration about my body and how it helped define my voice. ${ }^{10}$ Because the production was tricky and the music challenging, singing Marie demanded an instinctive way of using my body; the intensity of focus on the musical difficulties allowed my body to perform free of monitoring and work naturally. It interested me that people were very complimentary about the actual sound and expressivity I was able to access.

\footnotetext{
${ }^{8}$ Named after opera singer Marie-Cornélie Falcon (1814-1897), a falcon voice is a very rare intermediate voice type between the dramatic soprano and mezzo-soprano: a darker-coloured dramatic soprano with a strong lower register.

${ }^{9}$ I first sang my first Verdi mezzo role, Azucena from Il trovatore, in 1994 for State Opera of Victoria in Australia, followed by Amneris from Aida in 1996 and 1998 for that company and various others in the Pacific Basin. My first Wagner roles were the Rhinemaidens in 1995 and 1998, and Sieglinde from Die Walküre in 1998 for State Opera of South Australia. In 1999 I understudied Kundry from Parsifal and Salome for the English National Opera; I sang Kundry in my own right with Jeffrey Tate in 2001, State Opera of South Australia.

10 I sang Marie in Wozzeck for Opera Australia in Melbourne in 2000.
} 
In view of this response, I felt I needed to formalise what I had done instinctively to be able to replicate and build on my experience. On advice, I went to Germany and worked extensively with a retired singer there, Evelyn Dahlberg. I then studied with well-known dramatic soprano Elizabeth Connell and Italian coach Renato Fresia in Australia and London. ${ }^{11}$ Along the way I read a lot about the theories of Alfred Tomatis - a trained ear, nose and throat specialist, who realised that if you couldn't hear a pitch and its colour, then you could not replicate it. ${ }^{12}$ As I felt that the harmonic structure of my voice was not balanced between the upper and low harmonics, Elizabeth Connell and I concentrated on correcting my vocal sound in a way that I could hear. I also worked with Renato Fresia on engaging the body in such a way to support the desired stable harmonic structure. In many respects, singing teaching is about teaching the student to hear a vocal sound that is shaped by the teacher; in this way I felt that Elizabeth Connell shaped my voice in a way that suited the fach. Finally, I worked with Professor Paul Farrington in London, whose technical and physiological knowledge corroborated all I had worked out and put into place myself. ${ }^{13}$

From 2006 to 2008 I shifted the focus of my career and spent more time in New Zealand and Australia, concentrating on teaching and on learning how to set up voices in a better way than I myself had experienced. Whilst previously I had taught out of financial necessity, my new practice-based knowledge meant I could now derive considerable satisfaction from teaching, as I was able to solve and mould the sound I wanted to hear from students, making me very successful and in demand as a voice teacher. Full-time employment in a comprehensive

${ }^{11}$ Renato Fresia was for many years the Italian coach for Opera Australia. Elizabeth Connell, the noted dramatic soprano, started as a mezzo and moved to dramatic soprano roles in her late thirties - a perfect person for me to learn from. She also studied extensively in Italy.

12 Dr Alfred Tomatis applied his theories to the psychological process, helping children with psychological and autistic disorders, and applying his method to language teaching and singers. http://www.tomatis.com/en/tomatis-method/a-listening-program.html

13 Professor Paul Farrington is a noted voice teacher based in London. He has given masterclasses throughout the world, is a vocal consultant to Covent Garden in London and Göteborgs Operan in Sweden. He is a Vanguard practitioner of the Estill Voice Method. http://www.paulfarrington.org/about; http://www.estillvoice.com/ 
tertiary level music school put me into contact with a range of scholars as well as performers, while university requirements pushed me into thinking about more formal postgraduate degree qualifications. My Bachelor's degree (years before) had been practice based, with some basic skills in theory and analysis and historical context through a few survey courses. Critical thinking and application of that thinking was not at that time central to a typical conservatory education. I found academic study (that is, an introduction to recent musicology) opened up many new areas of interest for me, and I was particularly taken with the interdisciplinarity of abutting areas of focus. As will be seen in the next chapter, these scholarly approaches provide an important jumping off point for my own attempts to insert the singer's voice into dialogues about the voice.

Articulating my experience in performance and in scholarship provided an evocative and compelling area of focus within which I identified my main areas of interest, and finally crafted the whole into this dissertation. Here, bringing the strands of my research together I summarise my findings and show that the body is a major contributor to the whole that is a singer's art. It is in delving into the conscious use of the body that we can start to unpack that notion of the "grain of the voice", that "extra" communication that the voice has been so broadly invoked to represent. Crucially, it is in understanding the use of the body/mind voice that we can begin to understand the creative act of singing in performance. Thus my research proposes a matrix of embodiment, and suggests investigating that matrix in the context of the changing aspects of vocal technique in the mid-nineteenth century. In addition, I consider more recent vocal technique that is (now) typically applied to repertoire of the midnineteenth century. In applying this framework to specific Verdi and Wagner roles that I have performed, I suggest that the body has considerable importance in the actual sound of the operatic voice, and is indeed an essential part of the effect of the voice - where vocality is more important than orality - and how it communicates to the listener.

In Chapter One, I lay the foundations for a discourse on voice, first by confronting the difficulties in dealing with the existing literature on embodiment and voice. By exploring a range of scholarly discourse and performers' 
experiences, I lay out the essential gulf between theoretical discourses on voice and performative experiences of singing. Scholars such as Suzanne Cusick and Michelle Dunn articulate how ephemeral voice is and relate how any descriptions of voice are in themselves heavily influenced by the subjective responses of the author. As noted above, most scholars are not operatic singers, and therefore are commenting from the outside, many without understanding the process and effort involved in performing on stage. With my stage and performance experience, on the other hand, I can elucidate the more particular aspects of performance. Placing my commentaries into the context of existing frameworks of the critical literature, with ventures into philosophical ideas of the body, I set up a framework for considering notions of embodiment in the context of vocal performance.

In Chapter Two I explore the process of embodiment itself, comparing the literature applying to the metaphysical aspects of embodiment and of theatre studies to what singers do on stage in performance. How we articulate the role of the body in creating operatic voice and character is explored in depth, and I lay out a framework for considering how effective operatic singing must have the mind and body act together synergistically. Fundamentally, I challenge the remnants of the discourse of the Cartesian split between mind and body, suggesting that a scholarly emphasis on the intellectual and the abstract aspects of vocality (such that even the focus of work on embodiment and on voice and body still operates in the realm of theory) has ended up reinserting that dichotomy long after it has been established as artificial. ${ }^{14}$ To counteract the separation of mind and body I present my own detailed articulation of aspects of the embodied experience of performance, which sets up a clear synergy between mind and body at multiple levels of consciousness. Moreover, in the final section

\footnotetext{
14 See Elizabeth Grosz, Volatile Bodies: Towards a Corporeal Feminism (Bloomington: Indiana University Press, 1994). Interesting texts expounding on the mind/body split are: Antonio Damasio, Descartes' Error: Emotion, Reason and the Human Brain (U.S.: G.F.Putnam's Sons, 1994); Richard L. Amoroso, Complementarity of Mind and Body: Realizing the Dream of Décartes, Einstein and Eccles (New York: Nova Science Publications, 2010).
} 
of the chapter, by investigating the details of how a singer performs and involves their body, I demonstrate that layers of bodily engagement are intrinsically linked to various notions of mental awareness and subjective analyses of the text. This extended chapter also looks at the importance of the singing breath in bringing together the many layers of engagement, awareness and subjectivity inherent in a singer's embodiment.

To demonstrate how synergy can come about through the similarities and differences in engagement of the body in performance, in Chapter Three I describe singing particular roles by Verdi and Wagner. I describe the vocal characteristics needed to sing these roles successfully, with an emphasis on the need for a stable technique, and how the technical advancements immediately prior to the composition of these works depended on the coming together of a number of developments in a short space of time. In addition, my chosen roles, all composed within a tight timeframe, highlight the development of forcing the employment of new kinds of embodied relationships in singing. This itself is a critical aspect, both of how those two composers' works function in performance, and of how a particular type of voice engages both listeners, and, as described earlier, the singer herself. Though essentially the vocal emission of the singer's sound should remain the same, there are individual and professionally sanctioned differences in timbres and styles between the two composers. Out of my wide and disparate repertoire I chose to focus on particular roles of Verdi and Wagner because they illustrate a certain progression in the difficulty of performative aspects. While a large number of roles could be explored in these terms, Verdi and Wagner supply roles that provide both a rich psychological framework for interpretative engagement and a complex vocal and bodily collaboration. Moreover, the bodily expectation and the use of the voice for each composer are very different. Indeed, while is not my focus, my exploration of these issues raises many questions for further consideration around individual composers' relationships to singers and singing.

Developing my evidence for the importance of bodily engagement, I engage in four detailed case studies, all in relation to roles I have sung on stage. The first two, in Chapter Four, are an investigation into the vocality of Verdi's Il 
trovatore, and especially of the two main female characters, Leonora and Azucena. Not only do I discuss my own performance technique, but I also comment on the voice types for which Verdi wrote these roles - somewhat unusual ones with special qualities that are much fêted today. The roles of Azucena and Leonora are distinctly different, and are seminal, I suggest, in Verdi's developing vocality. I suggest specific ways in which one's employment of the body aids and abets the differing vocalities, resulting in interesting developments in the perception of the prima donna.

Following this in Chapter Five, I delve into Wagner's concept of the actor and singer's body and talk about the role of Sieglinde, from Die Walküre. Sieglinde is, of course, a major player in Wagner's tetralogy Der Ring des Nibelungen. However, her vocality is still lyric and not in the full-blown style of major Wagner roles. I suggest that the particular way in which Sieglinde is written vocally, indicates that she might represent a transition in Wagner's compositional lexicon.

In my final case study in Chapter Six, I turn to the complex role of Kundry from Parsifal. The pinnacle for many singer-actors, the role requires a particularly elaborate and idiosyncratic embodiment in order to convey the effect for which I believe Wagner had hoped. Kundry highlights the way in which embodied experience provides a challenge to the discourse around the operas of Wagner. I suggest a new way of understanding the character of Kundry by allying her to a number of feminist perspectives that provide a deeper understanding of the libretto, and elucidates key aspects of the experience of her character in live performance.

In my conclusion I suggest that an examination of embodiment from the singer's perspective might illuminate the listener's pleasure with which so many writers engage and that the relationship between the singer's communicative tools and the embodied cognition, or the term that I suggest, embodied continuum, practised over many years, in turn sets up ideal conditions for eliciting an audience reaction. Most importantly though, as a performer, I offer what I believe is an important counterbalance and reinterpretation of traditional 
scholarly perspectives, by explaining the ways in which an embodied approach can lay claim to a very specific creative force, one that is both moulded and shaped by the composer's text, and yet also exceeds it. 


\section{Chapter One:}

\section{The Singer's Ineffability}

\section{Introduction}

The voice in operatic performance can be both disturbing and addictive. As Ralph Locke points out in his article "What are these women doing in opera?", the body in opera has often been figured as voice, the voice being a cipher for the body's disturbed psyche and troubling physical presence, in some way negating the body and intensifying the effect of the voice. ${ }^{15}$ The concentration on powerful and compelling voices, as a fusion of the body and voice, has itself become the focus of a range of investigations: Terry Castle in "In Praise of Brigitte Fassbaender" led the way to renounce the intellectual and academic embarrassment associated with diva worship and explore the rhapsodic impact of voice on the imagination of the listener. The investigation what it is that so compels and binds us to vocal sound and to the singers that produce them has become a fascinating scholarly topic. ${ }^{16}$

The many areas of research that can contribute fruitfully to these issues reflect the multi-faceted nature of opera itself: not only is vocality a focus of study, as well as performance perspectives, but also theatre practitioners and scholars have much to say about the use of body and voice in ways that shed light on both in opera. In addition, new work by neuroscientists on the cognitive

\footnotetext{
${ }^{15}$ Ralph Locke, "What are these women doing in opera?", in Corinne E. Blackmer and Patricia Juliana Smith, eds. En Travesti: Women, Gender Subversion, Opera (New York: Columbia University Press, 1995), 65. Terry Castle, "In Praise of Brigitte Fassbaender", En Travesti: Women, Gender Subversion, Opera (New York: Columbia University Press, 1995), 48-9. Castle was a part of a wave of writing about singers that included Wayne Koestenbaum The Queen's Throat (London: Penguin, 1993); and Michel Poizat, The Angel's Cry, trans. Arthur Denner (Paris: Métailié, 1986).

${ }^{16}$ In the last decade there has been a surge of interest in the prima donna, the diva, and their importance in the field of performance studies. Their intriguing lifestyles and personalities have always held a fascination for their listeners, but it has been the in depth investigations of Mary Ann Smart, "The Lost Voice of Rosine Stolz", Cambridge Opera Journal (6,1, 1994, 31-50); Mimomania (California: University of California Press, 2006); and Susan Rutherford, The Prima Donna and Opera 1815-1930 (Cambridge: Cambridge University Press 2006), of hard to find resources that have opened up the field.
} 
processes of the brain is proving to be exciting, and has a number of potential implications for operatic singers. In this dissertation I present the viewpoint of an opera singer: performance plays out with live, changeable bodies, and my professional experience has given me a very clear perspective on the complexity of the processes of staged performance.

The amount of literature that can relate to staged performance is formidable, but the most pertinent areas for this thesis are writings on the body, theatre practice, gender, voice and body issues and applications of these to performative issues. The influence of feminist musicology, and subsequent focus on the diva, is one of the most important areas of research and has essentially opened up the path for the approach I outline in this dissertation, and which brings to this discourse a new perspective on the very act of performance.

A pivotal background to my entire dissertation is the recent musicological literature that engages with the "performative turn". This chapter will present the key theoretical frameworks pertinent to my study of opera singers' embodiment; I am particularly interested in the variety of attempts to incorporate the aspects of liveness, immediacy, and physicality in performance into the theoretical discourse. Carolyn Abbate in "Music-Drastic or Gnostic?" is of course seminal in laying out some of the complexities of performance and encouraging further engagement. By separating the drastic (the experience of performance in the live moment) from the gnostic (the intellectual interpretation and knowledge of the text), she acknowledges the duality of the process. ${ }^{17}$ Though Abbate acknowledges that the binary is basically a forced one and that the two fields are inseparable, her retention of the two terms ultimately emphasises the estrangement of the drastic from the gnostic, and in the end encourages the scholarly to adhere to the gnostic, to shy away from the drastic as something that cannot be articulated. My experience has shown that the reality of performance is far more complex: live performance is multi-dimensional, and

17 Carolyn Abbate, "Music -Drastic or Gnostic?", Critical Enquiry (30/3, 2004), 505-536. 
for performers, at least, separating the gnostic from the drastic simply does not work. ${ }^{18}$

In scholarly terms, the complexity of voice and operatic singing as a scholarly trope and their fruitfulness as theoretical categories and foundation in physical realities, cannot be engaged without acknowledging the work by two seminal French writers, Roland Barthes and Michel Poizat. In his much quoted work "The Grain of the Voice", Barthes listens for the signification of the body in the vocal sound of the singer. By appreciating the materiality of the voice and including the diction of language in the timbral qualities of the sound, Barthes raised the potential of focussing critical attention on the vocal sound itself. ${ }^{19}$ With that sound we receive information from the body and the intentions of the singer; moreover, he connects the traces of the body in the sound with the pleasure, or jouissance, that we receive from the act of listening. That the body influences the vocal sound and is also a carrier of the body's messages is of vital significance to my work. Nevertheless, while stimulating much creative engagement, Barthes' provocative statements still pose questions that scholars and performers have yet fully to investigate.

Pleasure itself is the focus of Michel Poizat: in his influential book The Angel's Cry, Poizat engages with voice from the perspective of operatic fans' pleasure, both aural and bodily, investigating why listeners receive so much pleasure from the operatic voice. ${ }^{20}$ Basing his work on the psychoanalytic work of Lacan, he stimulated investigation into why the human voice, and particularly the operatic voice, has such an effect on the listener - a sound and effect that is

\footnotetext{
18 Michele Binnie suggests an empirical way of looking at practice and performance, certainly an approach more in tune with my own, even though coming from a pianoplaying perspective (and thus not addressing the particular components of vocal performance). See Michele Binnie, Finding the Drastic: Exploring Forms of Attention in Piano Performance, MMA Exegesis, Victoria University of Wellington, 2014.

${ }^{19}$ Roland Barthes, "The Grain of the Voice", Image, Music, Text (Glasgow: William Collins and Sons, 1977), 179-189. Barthes is referred to in many discourses; for a recent discussion see Laura Wahlfors in "Resonances and Dissonances" (Walther Bernhart and Lawrence Kramer, eds., On Voice (New York: Rodopi, 2014), 57-76, who discusses Barthes in some detail in connection with operatic sound.
}

20 Michel Poizat, The Angel's Cry, trans. Arthur Denner (Paris: Métailié, 1986), 76. 
not notated on the page, nor expressed in the text. The cry, the sound in the voice that arouses the listener is, according to Poizat, "a paroxysmal vocal emission beyond the range of music, and out of the reach of the word". ${ }^{21} \mathrm{He}$ also raises the issue of jouissance and its affect on the listener. His is not a musicological point of view: Poizat's questions and hypotheses focus on the development of the voice from song to cry, reflecting his training in Lacanian psychoanalysis. Most importantly he distinguishes between the ordinary pleasure of hearing a role well sung, and the orgasmic pleasure of jouissance, the pleasure beyond selfcontrol, possibly painful, experienced when a vocal sound or cry seemingly touches a deeply seated psychological need. ${ }^{22}$ Concentrating on the listener's experience, Poizat does not mention the performer's perspective. And yet, as I will suggest in this dissertation, the performer's perspective offers a distinctly different potential elaboration on his ideas.

\section{Paving the Way for the Performative Turn}

Of course neither Barthes nor Poizat were musicologists, and famously it took some time for musicologists to investigate these provocative areas of research

\footnotetext{
${ }^{21}$ Poizat, The Angel's Cry, 76. Poizat suggests that the vocal sound of a voice in extremis, at any pitch, can contain a sound that is emotionally expressive and of an intensity that arouses unbearable emotions in the listener.
}

22 The French psychoanalyst Jacques Lacan's proposal that the voice was an important embodiment of the psychoanalytic object was developed by Poizat and enlarged upon and applied to the singing voice by him. Most Lacanian influenced writing about voice focuses on an abstraction of voice and is concerned with the absence of the materiality of voice, and voice as theory. Among other writers about opera who invoke Lacanian theory are Slavoj Žižek,: "The Wound is Healed Only by the Spear that Smote You: The Operatic Subject and its Vicissitudes" in David Levin, ed. Opera Through Other Eyes (Stanford: Stanford University Press 1994), 177-214; and with Mladen Dolar Opera's Second Death (London: Routledge, 2001). Mladen Dolar's book A Voice and Nothing More (Cambridge, Mass.: MIT Press, 2006) examines in depth the concept of voice, and develops the theory of voice as a Lacanian object-cause, concentrating on areas such as the paradoxical relationship between the voice and the body. Stanley Cavell, $A$ Pitch of Philosophy: Autobiographical Exercises (Cambridge, Mass.: Harvard University Press, 1994) and Michel, Grover-Friedlander, Vocal Apparitions (Princeton: Princeton University Press, c.2005) further elaborate on a Lacanian framework. Guy Rosolato, in 'La Voix: entre corps et langage" Revue Française de Psychoanalyse (1; XXXV111, Janvier, 1974), 75-94, though basing his work on Lacanian theory, sparked much writing and interest in the voice and body together. 
and to develop alternative discourses from within musicology and ethnomusicology. As is well known, the work on opera and voice ran roughly parallel to a more general shift in the field of musicology, most commonly marked by Joseph Kerman's call for the application of critical approaches to the study of music in $1986 .{ }^{23}$ Commenting on the relationship between fields of study in music (music history, theory and analysis and ethnomusicology), Kerman placed the study of music in the main stream of modern intellectual history and suggested a turn to what he called criticism in musicology. Applying the methods of critical theory to music scholarship opened up larger fields of enquiry and allowed exciting frameworks and connections to be proposed between many different fields, among them, inviting new responses to feminist thought.

Recently Fabrizio Della Seta has articulated a useful list of the attributes of the "new musicology" launched by Kerman's call: (1) rejection of what was referred to as musicological "positivism," meaning scholarly studies and archive research; (2) rejection of the ideology of "absolute music," expressed above all in analysis and music theory viewed as autonomous disciplines, separating the musical datum from the person producing it; (3) an aspiration to place the musical experience in its cultural context and relate it to the "life experience" of those producing it; (4) assertion of a "critical," hermeneutic, and indeed, subjective dimension to musicological discourse, in opposition to the claims to scientific objectivity made by "old" musicology. ${ }^{24}$ Not coincidentally, these attributes of musical discourse legitimise a much broader range of musical experiences and perspectives than traditional musicology had been set up for; as a singer, I find a fascinating overlap between these new areas of focus and many aspects of what I do, as a performer.

Stimulated by writing from other disciplines, opera studies became situated at the vanguard of the new musicology, offering new methodological

\footnotetext{
${ }^{23}$ Joseph Kerman, Contemplating Music: Challenges to Musicology (Cambridge: Massachusetts, Harvard University Press, 1985).

${ }^{24}$ Fabrizio Della Seta, Not Without Madness : Perspectives on Opera (Chicago: University of Chicago Press, 2012). ProQuest ebrary. Web. 20 January 2015.
} 
challenges and approaches to scholarship on music. Because of its essentially interdisciplinary nature and its well-documented effect on its listeners, opera was a field of study that lent itself particularly strongly to a reorientation of music in relation to other systems of signification. Opera Studies, with its variety of methodologies and repertoire, grew into a very large field, and one that in various ways was continually influenced by provocative thought from a range of other humanities disciplines. ${ }^{25}$

The interdisciplinarity of the discussions was particularly beneficial in promoting a new dialogue on performance itself. For my present purpose, it is helpful to recognise two strands of thought that emerged from these discussions: new critical interdisciplinary work, and an interest in the experience of opera, with Michel Poizat, Catherine Clément, Terry Castle and Wayne Koestenbaum leading the way. Once investigation of the construction of operatic meaning moved beyond musical analysis of the text, inevitably those investigations opened up perspectives on performance, and voice itself. The incorporation of these ideas into the field of musicology was signalled by Roger Parker's critical, and at the time of its publication in 1988, provocative book, Reading Opera. ${ }^{26}$ In addition, the founding of the periodical Cambridge Opera Journal initiated a scholarly discourse in opera; the invitation to focus on the field of opera led in turn to an interaction with voice and performance, and eventually the performative aspects of voice. ${ }^{27}$

\footnotetext{
${ }^{25}$ In particular, Pierluigi Petrobelli opened the field of enquiry into why and how music in the theatre works, with a particular focus on historical context, musical organisation and dramaturgical conventions. It was he who suggested that scholars must understand all the systems of opera, and how they interacted. Pierluigi Petrobelli, Music in the Theater: Essays on Verdi and Other Composers, trans. Roger Parker (Princeton: Princeton University Press, 2004).

${ }^{26}$ Roger Parker, Reading Opera, edited by Arthur Groos and Roger Parker (Princeton: Princeton University Press, 1988).

27 Cambridge Opera Journal http://journals.cambridge.org/action/displayJournal?jid=OPR The other major opera journal, the reformatted Opera Quarterly, came into existence fifteen years later; Opera Quarterly: http://oq.oxfordjournals.org/
} 
The various approaches opened up by new musicology and the new opera studies led in turn to a wide range of musicological research on singers, singing and vocality, both theoretical and historical. David J. Levin's books, for example, the edited volume Opera through Other Eyes, and the later set of essays Unsettling Opera, investigate the whole range of activities and influences on opera - in other words, the world of the dramaturg. ${ }^{28}$ Carolyn Abbate's books provocatively started a dialogue between music's perceived purpose of telling a narrative, and its sensual properties that resist such confines; it is telling that her subsequent book In Search of Opera focused on operatic performance itself. ${ }^{29}$ Significantly, she makes her reader think about how they hear music and what it signifies. ${ }^{\mathbf{3 0}}$

It is not coincidental that the new interest in feminist approaches to musical criticism also had an important relationship with opera studies. ${ }^{31}$ In this context, Clément's controversial look at the disempowered female heroines in Opera and the Undoing of Women engendered a wide range of important new approaches. ${ }^{32}$ In reply to Clément's assertion of the disempowerment of the women in opera, Kathy Bergeron's review of Clément's book countered some of her claims by asserting that opera is not only about plots, and that the music and indeed the power of female vocality itself - redresses the balance. Led by

${ }^{28}$ David J. Levin Opera through Other Eyes, ed. David J Levin (California: Stanford University Press, 1994); Unsettling Opera (Chicago: The University of Chicago Press, 2007).

${ }^{29}$ Carolyn Abbate, Unsung Voices-Opera and Musical Narrative in the Nineteenth Century (Princeton N.J. : Princeton, c 1991); In Search of Opera (Princeton N.J.: Princeton, 2001).

${ }^{30}$ Her history of opera, co-written with Roger Parker, can be seen as the culmination of this particular strand of research, reorienting a more traditional view of the progression of music history Carolyn Abbate and Roger Parker, A History of Opera: the last four hundred years (New York: Penguin Group, 2012).

${ }^{31}$ See Susan McClary, Feminine Endings: Music, Gender and Sexuality, Minneapolis: University of Minnesota Press, 1991).

32 Catherine Clément, Opera and the Undoing of Women, trans. Betty Wing (Minneapolis: University of Minnesota Press,1988). Clément's work, though still of interest has been challenged by the less than reverent essays of Ralph Locke "What are these Women doing in Opera?", En Travesti: Women, Gender Subversion, Opera (New York: Columbia University Press,1995), and Terry Castle, "Breath's End: Opera and Mortality", The Arts of the Prima Donna in the Long Nineteenth century (Oxford: Oxford University Press, 2009). 
Carolyn Abbate in "Opera, or the Envoicing of Women", a fascination with how women can sing their way to control and power, despite the inadequacies of their situation in the opera plot, helped to establish an understanding of the construction of operatic meaning in a variety of ways. ${ }^{33}$

As musicology continued to expand its methodological frameworks and repertoire, these developments in opera studies mirrored - or sparked - a growing interest more generally in understanding performance. Carolyn Abbate's "Music-Drastic or Gnostic?" was the most specific launching of the expansion of these operatic discourses into the field of musicology, and Elisabeth Le Guin's Boccherini's Body furthered the interest in the performer's body and the connection from her body through the cello to the composer's intentions. The complexity of these issues as they come together to be examined in relation to the act of performance is considerable; thus, inevitably, I have been selective in putting forward the themes that have the greatest relevance for my research. Although these strands of research clearly interconnect and stimulate each other in a number of ways, by separating them, I can explain the various facets more clearly, especially in terms of how they relate to my interests. Firstly, I will lay out how vocality came to be described in musicological terms, in order to raise questions about the ramifications of such descriptions for the performer. Then, by enquiring about what it might mean to investigate performance from the performer's standpoint, I reveal how the discourse on gender and the rise in feminist thought, through its contribution to conceptions of the body itself, suggests important considerations for accounting for the body in performance. Describing these larger themes allows me to offer a brief summary of how my case studies on Verdi and Wagner roles set up a detailed investigation of how important those bodily expectations were in the actual singing of these large

\footnotetext{
33 Katherine Bergeron (1990). Review of Catherine Clément's Opera and the Undoing of Women, Cambridge Opera Journal (1990, Vol 2/1), 93-98; Ralph Locke, "What are these women doing in opera?", in Corinne E. Blackmer and Patricia Juliana Smith, eds. En Travesti: Women, Gender Subversion, Opera (New York: Columbia University Press, 1995); Terry Castle," In Praise of Brigitte Fassbaender", En Travesti: Women, Gender Subversion, Opera (New York: Columbia University Press, 1995), 20-58; Carolyn Abbate, "Opera, or the Envoicing of Women" Musicology and Difference: Gender and Sexuality in Music Scholarship, ed. Ruth Solie (Berkeley: University of California Press, 1993) 225259.
} 
operatic roles. It is the bringing of these strands together with my own experience as a singer that enables me to posit my principal thesis. The very development of this type of voice, at the time of Verdi and Wagner, relied on harnessing specific bodily and cognitive processes, first to sing these roles, and then to protect those voices so that singers could repeatedly do so without destroying their voices and their careers. By positioning the singer as central to the creative process, I also need to acknowledge the substantive work around "divadom", which exposes the unreality of the constructed personality, contrasted with the reality of the person and the voice. In the final strand of my introduction, I look briefly at the link between the intensity of operatic fandom and the elusive quality of jouissance. This last also raises crucial issues about the singer's experience of performance which suggests that my in-depth engagement with the singer's perspective could offer some interesting insights for a range of writers in operatic studies centering, as they do, around voice itself.

\section{Philosophers, Musicology and Vocality}

A different discourse by non-musicologists has continued to examine vocality on their own terms. Interestingly, despite the lack of specific training and the immense scope of this field, - ranging from philosophical musing to in-depth studies, - some of the work lays out some very provocative frameworks for voice. Voice and its communicative aspects has puzzled and defied classification. Many philosophers and scholars have described its effect on the listener, and the power of vocal expression has inspired writers from many disciplines, who have commented in a variety of ways on its ephemerality. ${ }^{34}$

The fascination with the nature of voice itself - the sound of the voice, not the text that it carries- has puzzled philosophers and lovers of voice for a considerable time. Interestingly it is the sound of the voice that is most

\footnotetext{
34 Philosophers have tended to be attracted by the idea of voice, but those involved with voice and opera are especially: Slavoj Žižek, "The Wound is Healed Only by the Spear that Smote You: The Operatic Subject and its Vicissitudes" in David Levin, ed. Opera Through Other Eyes (Stanford: Stanford University Press 1994); Mladen Dolar and Slavoj Žižek, Opera's Second Death (London: Routledge, 2001).
} 
compelling, not the text that it carries. Philosophers rhapsodise on the sound and its effect in the same way that the Greeks glorified the undeniable call of the sirens. Philosopher Adriana Cavarero's For More Than One Voice covers a range of applications of voice. ${ }^{35}$ Invoking the Greek philosophers, feminism and political tyrants, she investigates the uniqueness of every voice: she demonstrates how the western tradition has been subject to the privileging of the mind over body, speech over sound. Perceptively, by a simple reversal of a hegemonic statement, she reminds us of the extra qualities inherent in a voice, which we all listen for: "The voice is sound, not speech; but speech is its essential destination. Significantly, this can also be reversed. Speech carries in itself that which the voice has destined to it."36 Philosopher Corrado Bologna, in his exposition of different types of performed voice, Flatus Vocis: Metafisica e antropologica della voce, quotes medievalist and linguist Paul Zumthor's distinction between orality and vocality: he defines orality as "the functioning of the voice as the bearer of language" and vocality as "the whole of the activities and values that belong to the voice as such, independently of language." 37 This distinction is useful from a singer's perspective, as the separation of vocality from orality further invites us to concentrate on the importance of the vocal sound for carrying information. ${ }^{38}$

The philosophical import of the sound of the voice has been brought into the realm of musicology first and foremost by Carolyn Abbate, who, particularly in Unsung Voices, In Search of Opera and "Music: Drastic or

\footnotetext{
35 Adriana Cavarero For More than One Voice (Stanford: Stanford University Press, 2005).

${ }^{36}$ Cavarero, For More than One Voice, 209.

37 Definisco 'oralità' il funzionamento della voce in quanto portatrice di linguaggio; 'vocalità' l'insieme delle attività e dei valori che le sono propri, indipendemente dal linguaggio.Paul Zumthor, in preface to Corrado Bologna Flatus Vocis: Metafisica e antropologica della voce (Bologna: Il Mulino, 2000, vii); trans. Paul Kottman, in Adriana Cavarero's: For More than One Voice (Stanford: Stanford University Press, 2005), 12.

38 How the values of the sound are made, and how the activities needed to make that sound are inherent in the body, are of vital importance to an operatic singer. While there will always be a conflict for a singer between the two, to read a discourse with the elements of both orality and vocality taken into account, is enlightening.
} 
Gnostic", has discussed the metaphysical aspects of voice and touched on the transcendence of the listening experience. ${ }^{39}$ Abbate's evocation of the uncanny and of wildness suggests a link connecting the listeners of that voice to the invisible perceptions of music and emotion. This interest in the theoretical emphasis of these ineffable qualities of music encouraged the turn to both performance and the performative, and in vocality itself.

Again it was Carolyn Abbate who was one of the first to put forward a call for the attention to performance: "to write about opera ... is to add to the architecture of its necropolis...the first and enduring bases for a passion about opera are not operatic works in the abstract, as intentional objects, but opera and their singers in performances." 40 By acknowledging that in opera we are not just talking about an abstraction but, in fact, live singers on stage, she turns critical attention to the unexpected and fortuitous happenings of performance; she also acknowledges the thrill the listener has in watching singers negotiate, (and sometimes fall off) the tightrope of the live show. Invoking the drastic, she calls this extra quality "wildness"- the uncontainable and unpredictable of live performance, the extra information that enhances a musical performance's strangeness. ${ }^{41}$

Establishing the notion of "wildness" as an essential quality for a communicative singer, is deeply evocative. These readings also point to the ways in which power is also important to the performer - the power of the text as it

${ }^{39}$ Gary Tomlinson, too, in Metaphysical Song, has placed this interest on vocality in the context of western philosophical thought. Carolyn Abbate, Unsung Voices-Opera and Musical Narrative in the Nineteenth Century (Princeton N.J. : Princeton, c 1991); In Search of Opera (Princeton N.J. : Princeton, 2001); “Drastic or Gnostic?” Critical Enquiry (30, 2004), 505-36; Gary Tomlinson, Metaphysical Song (New Jersey: Princeton University Press, 1999); Parker, Roger, A History of Opera; the last four hundred years (New York: Penguin Group, 2012); Vladimir Jankélévitch, Music and the Ineffable, trans. Carolyn Abbate (Princeton: Princeton University Press, 2003).

${ }^{40}$ Abbate, In Search of Opera, ix.

${ }^{41}$ Abbate, "Music-Drastic or Gnostic?" (Critical Inquiry, Vol 30,3, 2004), 505-536.

Michel Poizat, The Angel's Cry, trans. Arthur Denner (New York: Cornell University Press 1992). As Michal Grover-Friedlander puts it -"It is the specific quality of a voice as voice - not the melody sung or the words set-that is crucial in opera". Michal GroverFriedlander, "Prompting Voice in Opera" (The Opera Quarterly, Volume 27, Number 4, Autumn 2011). 
stands and the power of a charismatic performer, one who might take over a performance completely. Abbate suggests that "power may reside in the transcendent aspect of the music that rests above its own precipitation into live performance. Or it may reside in the performer, who produces the immanent matter of the moment", taking over authorial control. ${ }^{42}$ By positioning the power of the performer as such a central aspect of the systems of operatic meaning is deeply provocative, and calls into question the standing of "gnostic" readings, taken by themselves. This emphasis on performance evokes the power of the vocal spectacle, the power of voice and the embodiment of that voice that is vital to a performer - and that is implicit as part of the evocative power of opera itself. Transient and individual, it is, I suggest, the ephemeral communicative aspect that makes the audience listen and pay attention to the singer, and hence to the music. But what do singers do to evoke the uncanny? Is it somehow instinctual and implied, or do they work explicitly beyond the text to deliberately set up vocal sounds that affect the listener?

A recent set of collected essays on vocal performance (On Voice, edited by Walther Bernhart and Lawrence Kramer, published in 2014), helps to illustrate the broad and wide-ranging impact of the field of "voice" as an area of fascinating intersection between theory and bodily performance. ${ }^{43}$ It also serves to illustrate the ways in which these discussions end up raising more issues than answers, when viewed from a singer's perspective. The volume covers various aspects of voice, concentrating on text in some cases and voice in others, and a number of essays are very interesting, particularly Lawrence Kramer's introduction and essay “The Voice of/in Opera”. While Kramer's articulation of the challenges of making a vocal sound resonates with me as a singer, some statements seem to be contradictory: "voice may begin with a cry but its destiny is language", for instance, or, "heightened voice, voice that permeates or saturates language, and that obscures and exceeds language." 44 From a singer's perspective these

\footnotetext{
${ }^{42}$ Abbate, In Search of Opera, 51, 40.

${ }^{43}$ Walther Bernhart and Lawrence Kramer, eds., On Voice (New York: Rodopi, 2014).

${ }^{44}$ Kramer, On Voice, x., i.
} 
statements appear inconsistent: it seems that Kramer feels that the quality of the vocal sound (aside from the issue of diction) can obscure the meaning and yet also elucidate it. In performance it is important that the sound of the voice carries the extra meaning that the text does not elaborate upon; singers are well aware of this necessity. They are also acutely aware of the ways in which a lack of clear diction can make the text hard to understand; and that this is more a question of good or bad technique, rather than something fundamental to the concept of vocality itself.

Building on work by Poizat and the rich discourse about vocality, Kramer and his colleagues also raise some compelling points to acknowledge that the nature of this "extra" communication of vocality rests in the body. Establishing that voice invokes body, and detailing the relationship between body and voice, Kramer's recognition of the performative aspect of operatic voice, the primal quality conveyed, and the importance of the body in making that appropriate naked operatic vocal sound, cries out for further elucidation. He poses one crucial question, in particular, that he sets up as an opportunity for further research: "How do the elements of artifice and expressive primacy stand to each other on the high ground of operatic voice?"45 He intimates that the answer to that question lies in the quality of the vocal sound, and suggests that operatic voice is a form of vocal pleasure that is best taken live, proposing that recordings remove something of the voice and performativity. This would seem to pinpoint the issue that so much of the new scholarship on performativity and vocality points towards: can we formulate a more productive and specific methodology for a critical discourse around the quality of the vocal sound, other than the mere fact that it is crucial and ephemeral?

The fact that vocality is tied to - produced by- the body has been widely acknowledged in voice scholarship (no doubt in part because of Barthes' seminal essay, discussed above); but the discussion seems to end with that acknowledgement. I have not found more specific conclusions on the nature of the engagement between body and voice. From a singer's perspective, though,

\footnotetext{
${ }^{45}$ Kramer, On Voice, 50.
} 
vocality very much depends on the support and engagement of the body in very specific ways. ${ }^{46}$ Some scholars do understand the complexity involved in producing the sound, albeit by commenting on the difficulty in holding on to the sound itself. Michelle Duncan in her article "The operatic scandal of the singing body: Voice, presence, performativity" has suggested the metaphor of water for understanding voice, attempting to describe its quicksilver, ephemeral quality:

Voice is like water, a material that can be held in the hand, but never fast. In its magical fluidity, voice is inextricably bound up with the condition of language, and yet is something more than the language that is impossible to pin down or to control. ${ }^{47}$

The fugitive and volatile qualities of the sound suggested by Dunn are also rhapsodised by philosopher Roland Barthes in $S / Z$ :

Voice is a diffusion, it passes through the whole extent of the body, the skin, insofar as it is passage, abolition of limits, of classification, of names ... it possesses a particular power of hallucination. 48

While focusing solely on the fugitive voice in this case and its ability to take one over, Barthes reiterates the intangibility of the voice and its effects in a live performance. Scholars have long accepted that there is some quality about the human singing voice that is "uncanny" "wild" or "ineffable", but do not emphasise that it is the "liveness" that enhances these memorable aspects of voice. ${ }^{49}$ The notion of the ineffable qualities of voice itself have become the focus of a number of scholars intrigued with the nature of live operatic experience.

\footnotetext{
${ }^{46} \mathrm{~A}$ number of other scholars address these issues, particularly Michel Poizat, The Angel's Cry, 37. The discussion of music vs text is an age-old debate at the heart of the operatic genre.

47 Michelle Duncan, 'The operatic scandal of the singing body: Voice, presence, performativity' (Cambridge Opera Journal, 16, 3, 283-306), 285, Footnote 8.

48 Roland Barthes, S/Z, translation Richard Miller (New York: Hill and Wang, 1974), 110.

49 See Carolyn Abbate, "Drastic or Gnostic?" Critical Enquiry (30, 2004), 505-36; Gary Tomlinson, Metaphysical Song (New Jersey: Princeton University Press, 1999); Vladimir Jankélévitch, Music and the Ineffable, trans. Carolyn Abbate (Princeton: Princeton University Press, 2003).
} 
Lydia Goehr in The Quest for Voice: Music, Politics, and the Limits of Philosophy places music and its performance as the central focus in her book. ${ }^{50}$ Not only does she talk about starting with "a basic idea about human performance and voiced expression" but she also goes on to suggest that our thinking should shift to freedom of expression in performing the work. And, in Goehr's formulation, it is the performance and the imperfections of that liveness that add to its meaning. Taken from a performer's perspective, these descriptions of the performance space are deeply suggestive of what performers tend to take for granted: that performance is nothing without taking creative and emotional risks.

If the imperfections of liveness can either add to the meaning of music in performance, as per Goehr, or add a frisson of thrill for the listener, it is useful to step back for a moment and think about these same features from a singer's point of view. What these commentators do not acknowledge is the transient nature and risk of making a powerful and compelling sound. That lack of perspective, that gap between the reality of producing operatic vocality and receiving it as a listener, has a number of profound implications for identifying fruitful new approaches to understanding vocality in operatic performance.

\section{The Performer's Perspective}

Historically, there are very few singers who have described their experience in a formal and enlightening way. The instances of a singer's perspective raising questions or inspiring further elaborations of the theoretical discourse are almost non-existent. One notable exception is Reynaldo Hahn (1874-1947) a composer and salon singer. In his book On Singers and Singing, he described his experience of what it is like to produce a sound:

The singer creates the material he uses, shapes it and exhibits it at the same moment ... That shape must be definitive - he has no time to modify it, to

\footnotetext{
50 Lydia Goehr, The Quest for Voice: Music, Politics, and the Limits of Philosophy (Oxford: Oxford University Press, 1998), 111.
} 
transform it ... He shapes it, gives it a plastic beauty... a sonorous beauty, but he must also infuse it with emotion, poetry, thought. 51

This rare first-hand account gives some idea of the singer's sense of the fragile and transient nature of singing. ${ }^{52}$

For a singer, though, there is a clear consciousness of the fact that the vocal sound is created in the moment. At the same time, however, the years of preparation and training make such moments not at all spontaneous but suggest that they are premeditated to a great extent. Inevitably to be a performer at a professional level requires daily practice over many years, and the accumulation of deep empirical knowledge. This knowledge, the production of voice itself, is completely dependent on, and intertwined with the body.

Ironically, despite the concurrent literature in which the focus on materiality continues to evoke the body (as I lay out below), the scholarly discourse actually omits the body: the scholarship discusses the body as an external object, rather than thinking from within and through the body. Yet as a singer, it is the relationship between body and voice that is key, and which is no way merely theoretical. Interestingly, though, there is also a large theoretical

${ }^{51}$ Reynaldo Hahn, On Singers and Singing, trans. Léopold Simoneau (reprint: Portland, Oregon, Amadeus Press, 1990), 46.

52 Although Hahn is one of the few singers who have written eloquently about the act of singing, there is of course a large literature on singing and singers. Vocal treatises - the "how to sing" books, from the sixteenth century to the present day-abound. An excellent overview of the historical vocal treatises is given by Berton Coffin in Historical Vocal Pedagogy Classics (Maryland: The Scarecrow Press, 2002). Coffin's breadth of pedagogical knowledge is demonstrated in a valuable survey of historical texts, some very difficult to find today. His critiques are succinct and informative. While a detailed account of vocal treatises lies outside the scope of this dissertation, treatises do raise some important issues that indicate ways of talking about voice, especially when read through the filter of the knowledge of voice science.

Although Manuel Garcia (A Complete Treatise on the Art of Singing Part 11, trans. Donald Paschke (New York: Da Capo Press, 1975) is often referred to as the "father" of modern voice science. The major investigators and developers of voice science in the twentieth century have been Johan Sundberg, The Science of the Singing Voice (Illinois: Northen Illinois University Press, 1989) and Ingo R. Titze, The Principles of Voice Production (New Jersey: Prentice Hall, 1994). An excellent overview of vocal pedagogy from the sixteenth century masters until the present day is James Stark's Bel Canto: A History of Vocal Pedagogy (Toronto: University of Toronto Press, 1999). However, as will become clear, issues about a specific voice are decidedly very different from the typical discussion of opera singers. I will discuss the vocal treatises and vocal methods more thoroughly in Chapter Three, focussing on a particular voice type. 
discourse on the body: a discourse that arose first and foremost with the rise of feminist writing in the field of literary criticism, as a way to engage critically with the female body in the larger context of patriarchal society.

\section{Gender and Feminism}

The development of gender politics and the rise in interest in feminist thought, revitalised thinking in many subjects, not least in the engagement of a new literature about the body. Seminal writers such as Simone de Beauvoir in the The Second Sex elegantly posited the premise of female subordination: it took the first feminist uprising and the rise of feminist writing in the field of literary criticism to break through a male-centric mode of thinking. ${ }^{53}$ Theorising the body as a subject was also the focus of the group of French feminists building on de Beauvoir's work; but it was Judith Butler's seminal work in Gender Trouble: Feminism and the Subversion of Identity and Bodies that Matter: On the Discursive Limits of Sex that took issue with the concept of the body as a blank slate on which culture inscribes itself. ${ }^{54}$ Butler proposed that by allowing the body to define itself as a signifying entity, embodiment was a social, gendered performance rather than a reality imposed from without. Clarifying the notion of performativity, she goes on to describe in Bodies that Matter how the materiality

\footnotetext{
53 Simone de Beauvoir, The Second Sex (1953), trans. Constance Borde, Sheila Malovaney-Chevallier (London: Vintage, 2011).
}

54 Judith Butler,"Performative Acts and Gender Constitution", The Twentieth Century Performance Reader, $2^{\text {nd }}$ Ed., eds Michael Huxley and Noel Witts (Oxford: Routledge, 2002); Gender Trouble: Feminism and the Subversion of Identity (New York: Routledge 1990); Bodies That Matter: On the Discursive Limits of Sex (Oxford: Routledge, 1993). Also see Kaja Silverman The Acoustic Mirror: the female voice in psychoanalysis and cinema (Bloomington: Indiana University Press, 1988); Silverman discusses female subjectivity in reference to sexual difference; and Susan Bordo, Unbearable Weight: Feminism, Western Culture and the Body (Berkeley: University of California Press, 1993) explicating the many constructed interpretations of the female body. Luce Irigaray in Speculum of the Other, Woman, trans. Gillian C. Gill (New York: Cornell University Press,1985) challenges the frameworks of critical theory where all assessment of the female is done on male terms. The assumption that we have no permanent identity, that our identity is always developing and changing, is taken up by a number of writers including Rosi Braidotti, who proposes the idea of the nomadic, lived body. Rosi Braidotti, Nomadic Subjects: Embodiment and Sexual Difference in Contemporary Feminist Theory (New York: Columbia University Press 1994), 23. 
of sex and heterosexual hegemony must be countered by an identity that needs to be fluid, reactive and transformative. This theoretical writing about the body has inspired a range of new writing not just on the body, but on the nature of performance and performativity itself.

Just as theorising the body has a vast literature, so also has the physicality of the body been used in/as a site of negotiations of power within social and cultural frameworks. Early feminists in particular turned to critical tropes around the body, to set the mind/body dynamic on its head. The musicological turn towards performance studies elucidated above was in part a case of musicologists engaging in fruitful debates about how these issues interact with music, challenging the traditional ways of writing history, theory and ethnography. Developing the work of Butler and Ruth Solie, Susan McClary brought the general issues of feminist research into the discourse of musicology. Other scholars, notably Elizabeth Le Guin and Suzanne Cusick, have followed with more nuanced approaches investigating the embodied experience of music. ${ }^{55}$

The most provocative interactions with this literature on the body from the perspective of my study (in relation to the musicological turn outlined above) open up some important avenues of inquiry. Suzanne Cusick's interest in embodiment focuses on the performer/listener relationship and how the musician overcomes the mind/body split. Although Elizabeth Le Guin's Boccherini's Body: An Essay in Carnal Musicology is in no way concerned with vocal music or voice, her approach to using her (cello-playing) body as a critical lens to view the music of Boccherini is a suggestive model for the singer: she

\footnotetext{
55 Susan McClary, Feminine Endings: Music, Gender and Sexuality (Minneapolis: University of Minnesota Press, 1991); Ruth Solie, ed., Musicology and Difference: Gender and Sexuality in Music Scholarship (Berkeley: University of California Press 1993); Suzanne G. Cusick,. "On Musical Performances of Gender and Sex" Audible Traces: Gender, Identity and Music, eds. Elaine Barking and Lydia Hamessley (Los Angeles: Carficioli, c.1999); "Feminist Theory, Music Theory, and the Mind/Body Problem", Perspectives of New Music (32 1994) 8-27. For a further discussion about the body in music see Bruce W. Holsinger, Music, Body and Desire in Medieval Culture: Hildegard of Bingen to Chaucer (Stanford: Stanford University Press, 2001), and also Richard Leppert, The Sight of Sound: Music, Representation, and the History of the Body (Berkeley, University of California Press, 1993).
} 
articulates her connection to the composer through engaging with her body as she plays her cello. ${ }^{56}$

It is partially through understanding the way a singer engages with her body that the female singer has been found to gain a kind of authorial power - in Roland Barthes' inimitable words, "she (the singer) is a figure who not only carries and conquers the semantic in her voice, but also takes on the active 'masculine' part of one who penetrates and inundates, or inseminates the listener." ${ }^{57}$ It is, as I suggest, the vocal power of the singer, aided and abetted by the power of the body that usurps compositional authority. Critically, authors such as Mary Ann Smart point out that a singer's power on stage is not only manifest though the voice but also through their presence and embodiment. Indeed, Smart's book emphasises the physical presence and gesture, rather than voice - though I feel that the two are connected. ${ }^{58}$ The physicality of the effort involved in the engagement of the body in singing helps support the sense that the power of female operatic singing lies in part in the physical engagement itself. In investigating the realities of voice, and how much extra information can be gained from studying the embodied operatic voice's physical attributes, George Lakoff and Mark Johnson, in Philosophy in the Flesh: The Embodied Mind and Its Challenge to Western Thought, apply new theories of the body as the source of dominant metaphors that shape consciousness. ${ }^{59}$ These theories transcend the idea that reason is only held in the brain and suggests that our bodies also hold the knowledge of bodily experience as well as the

\footnotetext{
56 Elisabeth Le Guin, Boccherini's Body: An Essay in Carnal Musicology, California, University of California Press, 2006. Le Guin, Elisabeth, Boccherini's Body: An Essay in Carnal Musicology, California, University of California Press, 2006.

${ }^{57}$ Roland Barthes, S/Z, translation Richard Miller (New York, Hill and Wang, 1970), 118.

58 Mary Ann Smart, Mimomania (California: University of California Press, 2006); see also Melina Esse “'Chi piange, qual forza m'arretra?': Verdi's Interior Voices.” Cambridge Opera Journal (14, nos. 1-2 (March 2002): 59-78;"Sospirare, tremare, piangere: conventions of the body in Italian opera" (ProQuest Dissertations and Theses, 2003).
} 
information from our brains and bodies interwoven. Moreover, it is the processes of our embodied cognition that shapes the elements into a whole.

Feminist musicology continues to inspire and provoke narratives of the body within operatic singing; yet from a singer's perspective, this further work does not engage with the core of what is most interesting and provocative in the earlier work, and still does not explain the mechanisms of using those bodies. ${ }^{60}$ Most crucial, for my purposes, is the work of Michelle Duncan and Clemens Risi, as they both acknowledge the fleeting and transitory nature of operatic performance, while attempting to refine the specificity with which we engage with it. 61

The juxtaposition of the varying strands of interesting areas - voice work, body work and performance work in relation to the field of operatic criticism can be fruitful in explicating the concept of embodiment of an operatic role. The fundamental shortcoming of discussions of body and voice from my perspective is that they remain so theoretical and thence are removed from our engagement in singing. The advances of voice science, though vital and interesting, cannot yet articulate the extra-textual qualities of voice that are only apparent in performance. My perspective as a singer offers a new way to intertwine and

59 George Lakoff and Mark Johnson Philosophy in the Flesh: The Embodied Mind and Its Challenge to Western Thought (New York: Basic Books, 1999), 45.

${ }^{60}$ A number of collected essays explores these themes of body and have remained seminal approaches that still invite further exploration: En Travesti, Queering the Pitch and Embodied Voices develop the idea of the body in performance, including the gendered performance of day-to-day living. Within these, Elizabeth Wood in her essay "Sapphonics" describes what she calls a "sapphonic" voice: a voice that is "a vessel of self expression and identity, a channel for a fluid stream, that 'speaks' for desire in living human form, a lure that arouses listening desires ... characteristically powerful, and problematic, defiant and defective." Wood talks with authority about voices that engender a relationship between the performer and the listener, and their bodies, and that relationship, and I feel, epitomises the vital one when voice and body are combined in live performance.

61 The importance of live performance cannot be over estimated: Martin Katz's book Capturing Sound: How technology has changed music (Berkeley: University of California Press, 2010) and Philip Auslander's Liveness: Performance in a Mediatised Culture (Oxford: Routledge, $2^{\text {nd }}$ ed, 2008), discuss the influences of enhancement and recorded music. 
interpret these various discourses, as I seek to articulate my experiences on the stage in scholarly terms.

\section{Verdi and Wagner}

In order to close the gap in theoretical discourse, and to develop a methodology for a more specific discourse of vocality, I have set up case studies in relation to particular repertoire. Accordingly, using and developing the theories and writings I have mentioned, in Chapters Three to Six, I compare the vocalities of Verdi and Wagner. Within the context of a number of original case studies drawn from my own experience, I consider the challenges posed by each composer and suggest ways in which this particular singer and teacher overcomes them.

In choosing my case studies, I was not only interested in those roles that I have sung on stage, but also those that show a progression in the status of the diva or prima donna. Moreover, these particular two composers offer a richly contrasting field of study within the context of a fairly narrow historical timeframe. In the case of Richard Wagner, because of his interest in musical and dramatic authenticity of his works (something that concerned him greatly, though not suggesting how), he lays out what he expects from singers, and the sort of communication he needed; accordingly in the context of the huge Wagner literature, the most important works for me are his own writings describing the process of his operas, Opera and Drama and Actor and Singers. ${ }^{62}$ Further, writers such as Barry Millington and Stewart Spencer, while not directly commenting on singers, are particularly interested in the performance and effect of Wagner's operas, and what makes them work, and they offer interesting commentary. ${ }^{63}$

\footnotetext{
62 Richard Wagner, Actors and Singers trans. W. Ashton Ellis, (London: University of Nebraska Press, 1995); Opera and Drama, trans. W. Ashton Ellis, (London: University of Nebraska Press, 1995).

${ }^{63}$ Stewart Spencer and Barry Millington, Wagner's Ring of the Nibelungen-A Companion (London: Thames and Hudson 1993); Wagner in Performance eds. Millington and Spencer (New Haven: Yale University Press, 1992); Barry Millington, Richard Wagner: The Sorcerer of Bayreuth (London: Thames and Hudson, 2012).
} 
Unlike Wagner, Verdi never wrote formally about singers, and many of his comments about performers of his works are buried in other literature, and are only partially published within collections of letters and articles. The most interesting commentary lies in detailed letters, which discuss which singer to hire, and why. ${ }^{64}$ John Rosselli's rich writings provide a useful context, both in his illuminating if brief, Verdi biography, and in his seminal writings on nineteenthcentury singers: the realities of building a professional career, what the conditions in theatres were, the positions of women in society and as professional singers, and even the pecuniary rewards of the life. Verdi's own comments on singers and the difficulties of dealing with his librettists are also a rich resource; Marcello Conati's Interviews \& Encounters with Verdi offers a useful summary. ${ }^{65}$ Outside of the focus on biography, most of the literature on Verdi focuses on the dramatic or musical structure of his music; in that context, there has been little exploration on the actuality of Verdian performance, or singing. Roger Freitas in "Towards a Verdian ideal of Singing" is one of the very few scholars who has some insight into the actual singing of Verdi. ${ }^{66}$

While comprehensive research into the performance practice of either Verdi or Wagner's performance practice lies beyond the scope of this dissertation, a brief consideration of some historical expectations of vocal sound, combined with the technical writings of the famous voice teacher of the time, Manuel García II, will lead to some suggestive observations about current

64 Marcello Conati, Interviews \& Encounters with Verdi, edited, introduced \& annotated by Marcello Conati, trans. Richard Stokes (London:Victor Gollancz Ltd.,1984).

${ }^{65}$ John Rosselli The Life of Verdi (Cambridge: Cambridge University Press, 2000); Singers of Italian Opera: The history of a profession (Cambridge, Cambridge University Press, 1992); Marcello Conati, Interviews \& Encounters with Verdi, edited, introduced \& annotated by Marcello Conati, trans. Richard Stokes (London: Victor Gollancz Ltd, 1984).

${ }^{66}$ Roger Freitas, "Towards a Verdian Ideal of Singing", Journal of the Royal Musical Association (Vol 127, No 2 (2002)), 226-257; See also Will Crutchfield, "Vocal ornamentation in Verdi: The Phonographic Evidence" Nineteenth Century Music (Vol 7, No.1, Summer, 1983), 3-54; Rodolfo Celletti, History of Bel Canto (Oxford: Clarendon Press, 1991). 
operatic singing style, which have some relevance to my contemporary case studies. ${ }^{67}$

By pulling together these diverse strands of inquiry, I juggle and combine a rich literature in opera studies that has a crucial importance and relevance to my dissertation. In all cases, these theoretical discourses -on the body, the diva, listener ecstasy and fandom and finally jouissance - point towards the areas that have had relevance to my actual singing in performance. Nonetheless, however provocative these discussions are for me, as a singer, they remain speculative and theoretical: as I have stated above, the production of voice is completely dependent on the interactive support and engagement of the body. It is important, then, for me also to consider some of the ways in which scholars have investigated the body, although these discourses, too, have remained surprisingly disembodied exacerbated, no doubt, by a Western asceticism that has been built on a cult of denying the body.

\section{Body}

The mind/body opposition and its role in Western thought have been well traversed in the literature, alongside a number of other binaries: reason and emotion, self and other, and transcendence and immanence, to name a few. Since the inception of philosophy in ancient Greece, the body has been the subject of much discourse as a source of interference in, and a danger to, the operations of reason. Elizabeth Grosz' summary in Volatile Bodies observes that the body, in Plato's eyes, was seen as a betrayal of and a prison for the soul, reason, or mind. ${ }^{68}$ René Descartes' dualism of the seventeenth century further worked to establish an unbridgeable gulf between mind and matter. Grosz' summary lays out three lines of thought that emerged from Cartesianism: where the body is

${ }^{67}$ Freitas also critiques recordings made of singers that Verdi worked with and professed himself happy with, to back up his research. Above all, these recordings make clear the change in the taste for voice quality and style between Verdi's time and in contemporary practice.

68 Elizabeth Grosz, Volatile Bodies: Towards a Corporeal Feminism (Bloomington: Indiana University Press, 1994), 122-124. 
generally regarded as an object for the natural sciences; where the body is regarded in the terms of metaphors which construe it as an instrument, and where the body is considered a signifying medium, a vehicle of expression. ${ }^{69}$

Grosz' critique itself reflects the increased focus on the body introduced by twentieth-century feminists. As she sums up, it takes the inherited thought and work of Nietzsche, Foucault and Deleuze to arrive at a concept that is the direct antecedent of the philosophy of the body today. ${ }^{70}$ In academic circles this scholarship has been discussed intensively; in the twenty-first century, the divisive effects of this traditional mind/body binary have been supposedly addressed. Nevertheless, the remnants of the mind/body split, together with the subtle primacy that the "mind" portion of the binary manages to continue to assert, is surprisingly prevalent - even in academia, and certainly more broadly in general culture. ${ }^{71}$ Thus, the turn to the body in feminist writing continues to provide an interesting corrective to many of the seemingly innate presuppositions that infuse our discourse.

Western thought's historic engagement with a mind/body split is being further countered by a new strand of scholarship, one that takes as its basis a new scientific understanding of the nature of mind and of how mind is embodied: see Mark Johnson in his books The Body in the Mind and The Meaning of the Body, for example, and George Lakoff, Metaphors We Live By and The Philosophy of the Flesh. ${ }^{72}$ Building on and developing the concepts of Maurice Merleau-Ponty's Phenomenology of Perception, Johnson emphasises that meaning

${ }^{69}$ Grosz, Volatile Bodies, 11-13

${ }^{70}$ Preceding Foucault's idea of the body being penetrated and displayed in sections and the manipulation of those passive areas instigating networks and regimes of powerknowledge, Nietzsche regarded the body as a total integrated organism. (Grosz, Volatile Bodies, 11-13)

${ }^{71}$ As an example, take the split in singing between the vocal treatises and their focus on the sound of the voice and its training, and the tracts on the interpretation of the music that the vocality is used for, not to mention the musicological background of the works.

72 Mark Johnson, The Meaning of the Body (Chicago: University of Chicago Press, 2007); The Body in the Mind (Chicago: University of Chicago Press, 1987); George Lakoff, and Mark Johnson, Philosophy in the Flesh (New York: Basic Books 1999); Metaphors We Live By (Chicago: University of Chicago Press, 2003). 
must always be grounded in bodily experience, feelings and emotions. ${ }^{73}$ Therefore, in the embodied view of mind, thought is both the result of the effect of the environment while at the same time it shapes and influences and interacts with it. The mind uses image schemata, and metaphors to understand the world, and imagination plays a large part in ordering these. Johnson says that:

the way we experience our world as a comprehensive reality ... involves our whole being ... It is the way we are meaningfully situated in our world through our bodily interactions, our cultural institutions our linguistic tradition, and our historical context.74

Grosz, in setting up a new way to approach the body in her work, has laid out a particular intellectual trajectory for this new focus on the body, starting with Marcel Mauss and leading through Michel Foucault's historicisation of those perspectives. Mauss, a French sociologist and anthropologist, examined and noted the varying bodily habits of differing peoples in "Body Techniques", and his work also contributes to the concept that not only our behaviour, but our stance and gait are culturally constructed. Michel Foucault took up his theories and developed them, focusing attention on the ever-changing historical aspects of embodiment, particularly in his three volume History of Sexuality. ${ }^{75}$ Distilling her ideas from others before her, Elizabeth Grosz writes in Volatile Bodies,

Human bodies ... stretch and extend the notion of physicality that dominates the physical sciences ... they are materialities that are uncontainable in physicalist terms alone. ... If bodies are like objects or things, they are like no others, for they are the centres of perspective, insight, reflection, desire and agency... Every body is marked by the history and specificity of its existence. 76

Through Grosz's comment on the historicity of bodies we can see that the attempts to join real living bodies with theory suggest the notion of embodied

\footnotetext{
73 Maurice Merleau-Ponty, Phenomenology of Perception, trans. Colin Smith (Oxford: Routledge, 2004).

${ }^{74}$ Johnson, The Body in the Mind, 100-102.

75 Marcel Mauss, "Body Techniques", Sociology and Psychology: Essays (1950), trans. Ben Brewster (London: Routledge, Kegan and Paul, 1979); Michel Foucault, History of Sexuality Vols 1-3, trans. Robert Hurley (London: Allen Lane, 1979).

${ }^{76}$ Elizabeth Grosz, Volatile Bodies: Towards a Corporeal Feminism (Bloomington: Indiana University Press 1994), xi, 142.
} 
cognition: the result of many layers of knowledge, including societal and personal histories.

A variety of disciplines have been seeking to demonstrate that there is a mind/body connection. The sciences are now driving the discussion, with research in neuroscience and neuroplasticity leading the way with fascinating discoveries about the human mind and cognition. Antonio Damasio's books have informed the discourse on embodiment; The Feeling of What Happens sets the scene, but it is in Self Comes to Mind where he examines human consciousness, and shows how consciousness is linked to emotion. These links extend into memory, reason and language. ${ }^{77}$ By rejecting the idea that consciousness is separate from the body he reminds us that our mind/body is part of the world. Our thoughts are part of the complex system of our entire environment, continually being shaped by that environment while at the same time shaping and influencing and interacting with it in important ways.

Embodied cognition is a hotly debated area, and the research is developing very quickly. The article "How Embodied is Cognition?” by Daniel D. Hutto and Patrick McGivern sets up an important questioning of the framework of embodiment, by asking if the mental representations of embodiment can ever be tested. ${ }^{78}$ What is clear is that a number of elements involved in cognition cannot yet be quantified. However, there is hope that this research will develop in ways that might provide further insights on the effects that music has on our bodies and minds.

The implications of this research for understanding and critiquing the nature of vocality are intriguing. As a specialist in voice, it is impossible for me to talk about voice without body; and as a practitioner, it is also impossible to talk about body without invoking mind and cognition. To train the voice (my own and

\footnotetext{
77 Antonio Damasio, Descartes' Error: Emotion, Reason and the Human Brain (U.S.: G.F.Putnam's Sons, 1994); The Feeling of What Happens: Body and Emotion in the Making of Consciousness (New York: Harcourt Inc, 1999); Self Comes to Mind (London: Heinemann 2010).

78 Daniel D. Hutto and Patrick McGivern, "How Embodied is Cognition?" http://www.academia.edu/9614435/How_Embodied_Is_Cognition Accessed 5/01/2015.
} 
those of others) is essentially to train the mind,to de-habituate and re-habituate muscular patterns in relation to readings of both music and text. With the mind initiating the vocal sound, the body is the resonator, enhancing and providing the physical presence of the voice: to comment on the interaction between these resources one needs a keen sense of bodily processes that are put into play. Some scholars are reaching towards exploring this territory. A body, as Paul Atkinson writes in "Opera and the Embodiment of Performance", is both a set of resources and a set of constraints; it is the good management of those resources that produces a compelling performer. ${ }^{79}$ Providing an ethnography of a rehearsal process, Atkinson gives us a good example of how performance practice dictates how the voice and body of the performer should be controlled, but again without articulating how those processes are engaged. Perhaps not surprisingly, it is in the field of dance that the performative use of the body has led to a deep and interesting discourse on the physicalities of embodiment. ${ }^{80}$ In dance, and indeed in the theatre, kinaesthetic and corporeal meaning is similar to vocality in singing, and much importance is placed on the practice of performance: though conceptualised as a "natural object" it is interesting how the body's fascination resides in its responsiveness as an instrument of expression. ${ }^{81}$

Theatre practitioners have long recognised the body as an instrument of expression: the focus and concentration needed to discipline it is as thorough as that needed for the voice. The extra information that the voice picks up from the body, its movement and absence of movement, are all vital elements in the production of theatrical presence. Interestingly, the material covered in theatre studies is rarely addressed in singer training, although it is deeply relevant. All theatre practitioner training contains voice work, and theatre director Eugenio

\footnotetext{
79 Paul Atkinson, 'Opera and the Embodiment of Performance' from Body/Embodiment; Symbolic Interaction and the Sociology of the Body eds. Dennis Waskul and Phillip Vannini (Burlington: Ashgate, 2006).

${ }^{80}$ The Twentieth-Century Performance Reader, $2^{\text {nd }}$ Edition, eds. Michael Huxley and Noel Witts (Oxford: Routledge, 2012), has a good range of articles about dance, including Susan Leigh Foster's "Choreographing History" and Merce Cunningham's "You have to love dancing to stick to it".

81 Susan Leigh Foster, “Choreographing History”, The Twentieth-Century Performance Reader, 201-211, 202.
} 
Barba's evocation of how the voice becomes an extension of the body relates strongly to the experiences of an opera singer. His description of his theatre practice encapsulates how the involvement with physical processes is consciously engaged and edited in rehearsal:

We began to talk about vocal action. That which for us had once been a postulate - the voice as a physiological process- now became a tangible reality which engaged the entire organism and projected it in space. The voice was a prolongation of the body which, through space, hit, touched, caressed, encircled, pushed, searched far away or close by: an invisible hand which stretched out from the body to act in space or renounce action. ${ }^{82}$

Barba's description of a voice that needs the body to support it suggests the way in which we should think of the singing body, alluding potently to the multilayered aspects of performance.

Actors have long been aware of the importance of this need to elucidate aspects of bodily experience, and practitioners have developed many techniques to access bodily experience. When voice is relied upon in performance, it becomes increasingly vital to maintain the authenticity of the mind-body connection by allowing the voice freedom to pick up its bodily sound. One of the most influential teachers in this area has been Kristin Linklater, and in her book Freeing the Natural Voice she offers an insightful and many-levelled exposition of voice in the context of performance. Linklater suggests ways to shape the voice with the mind to have a direct emotional connection free from physical and psychological blocks. ${ }^{83}$ In her introduction she explains that:

The result of the work will be to produce a voice that will be in direct contact with emotional impulses, shaped by the intellect but not inhibited by it. Such a

82 Eugenio Barba, "Words or Presence", from The Twentieth-Century Performance Reader, 2nd Edition, eds. Michael Huxley and Noel Witts (Oxford: Routledge, 2012), 46. For further discourses on theatre and dance practise, in combination with theorising the body The Twentieth-Century Performance Reader offers a valuable overview and essay from leading scholars on performance.

${ }^{83}$ Kristin Linklater, Freeing the Natural Voice: Imagery and Art in the practise of voice and language (London: Nick Hern Books, 2006). Other books that have been used successfully with actors, and by me with singers, are applying the performance techniques and principles of Mihaly Csikszentmihalyi, Flow: The Psychology of Optimal Experience (New York: Harper and Row, 1990) and Creativity ( New York: HarperCollins Publishers, 1996). 
voice will be a built-in attribute of the body. It will have an innate potential for a wide pitch range, intricate harmonies and kaleidoscopic textural qualities and will be articulated into clear speech in response to clear thinking and a desire to communicate. The natural voice is transparent, it reveals, not describes, inner impulses of emotion and thought, directly and spontaneously. The person is heard, not the person's voice. ${ }^{84}$

On reading Linklater's book, it is clear that this articulation, with a focus on a particular type of practitioner, helps to bridge the gap between the theoretical discourse on voice, body, and operatic performance, and the actual experience of voice and body that an opera singer has in performance. Singer/actors who have the ability to make a direct emotional connection are those whose voices touch us most deeply and communicate their text: we hear the person and their history not the voice.

A number of actor training texts build on Linklater's ideas and contain useful concepts and exercises for singers, including Michael McCallion's The Voice Book, and Cicely Berry's Voice and the Actor. ${ }^{85}$ Even more relevant, perhaps, is the growing interest in the ever-burgeoning research in cognitive neuroscience, which takes some of the more theoretical work outlined above and examines it in specific practitioner contexts. In The Actor, Imagination and Action - Acting and Cognitive Neuroscience, Rhonda Blair examines the physiological relationship between bodily action and emotional experience, in order to explicate the actor's process in more depth. ${ }^{86}$ Building on the work of Lakoff and Johnson, and interweaving that of Damasio, she presents theories of mind and suggests ways

${ }^{84}$ Linklater, Freeing the Natural Voice, 8. My emphasis.

85 Cicely Berry, Voice and the Actor (London: Harrap and Co, 1973); Michael McCallion, The Voice Book (London: Faber and Faber, 1988). Breathwork is also important and useful texts are: Jane Boston, and Rena Cook, eds. Breath in Action, (London: Jessica Kingsley Publishers, 2009); Blandine Calais-Germain, Anatomy of Breathing, trans. Regine Mackenzie, (Paris; Editions DésIris, 2006)

${ }^{86}$ Rhonda Blair, The Actor, Imagination and Action - Acting and Cognitive Neuroscience (New York: Routledge 2008). Other interesting discourses around theatre studies issues are: Hans Ulrich Gumbrecht, Production of Presence (Stanford: Stanford University Press 2004); David Zinder, Body-Voice -Imaginaton: A Training for the Actor (New York: Routledge, 2002); John Howard, Breathing Embodiment: A Study of Middendorf Breathwork (Germany: Verlag Dr. Müller, 2009); Don Ihde, Listening and Voice: Phenomenologies of Sound, $2^{\text {nd }}$ Edition. (New York: State University of New York Press, 2007). 
of integrating the use of them into actorly practise. Blair comments that, "Body and consciousness - or body, mind and feelings is a singular thing: everything that comprises consciousness derives from our physical being." ${ }^{87}$ Blair relies heavily on research into mirror neurons in detailing her exploration into the use of cognitive neuroscience in acting. ${ }^{88}$ Currently called the most hyped concept in neuroscience, she quotes Vittorio Gallese, an important researcher into mirror neuron states, who posits that Damasio's research can be taken further to create a fundamental physical bridge between ourselves and others:

The other's emotion is constituted, experienced and therefore directly understood by means of an embodied simulation producing a shared direct experiential understanding. By means of a shared neural state realised in two different bodies that nevertheless obey the same morpho-functional rules, the 'objectual' other becomes 'another' self. 89

However a "minireview" in December 2013 by James Kilner and Roger Lemon, which critiques the most recent research and literature about mirror neurons, suggests otherwise:

The functional role(s) of mirror neurons and whether mirror neurons arise as a result of a functional adaptation and/or of associative learning during development are important questions that still remain to be solved. In answering these questions we will need to know more about the connectivity of mirror neurons and their comparative biology across different species. ${ }^{90}$

Despite the lack of evidence, the existence of some sort of emotional connectivity has not been ruled out: Damasio and Gallese's proposals may still be proved, and

87 Blair, The Actor, Imagination and Action, 2.

88 The concept of mirror neurons is still controversial and not proven in relation to human subjects.

89 Jarrett, C.B. (2012). Mirror neurons: the most hyped concept in Neuroscience? Psychol. Today [Blog] http://www.psychologytoday.com/blog/brainmyths/201212/mirror-neurons-the-most-hyped-concept-in-neuroscience.; Vittorio Gallese, "Intentional Attunement". The Mirror Neuron System and its role in interpersonal relations," Interdisciplines: What do Mirror Neurons Mean? Mirror Systems, Social Understanding and Social Cognition, www.interdisciplines.org/mirror/papers/1., quoted in Blair,The Actor, Imagination and Action, 107.

90 James.M. Kilner and Roger.N. Lemon, "What We Know Currently about Mirror Neurons", Current Biology, Volume 23, Issue 23, pR1057-R1062, 2 December 2013. http://www.cell.com/current-biology/fulltext/S0960-9822(13)01326-2, accessed $26 / 8 / 2014$. 
help to explain some aspects of the attraction the operatic singing voice has for its listeners.

The recognition of the importance of the singer's physical representation in operatic performance has been acknowledged by numerous composers and recently by a number of scholars such as Melina Esse. ${ }^{91}$ But it is Peter Brooks, a scholar whose interdisciplinary interests include comparative literature, law, and opera, and particularly melodrama, who emphasises how identity is derived from both mind and body. In his article "Body and Voice in Melodrama and Opera" he discusses meaning that is represented bodily: "meaning which becomes lyrical self-expression, aria, song, that conveys a state of being". ${ }^{92}$ Although Brooks lingers on a discussion of the heightened emotions inherent in the operatic body and voice, his comments about the difficulty of the genre have credence: "Opera is the impossible genre, where we are estranged into a heightened element in which emotions make claim in some version of the Romantics' understanding of the original language, which - according to Rousseau, Herder and others - was song and gesture."93 However, he goes on to say that

Opera achieves ... the spectacularisation of both body and voice ... We know we are in the realm of the highest artifice, witnessing the most professional, highly trained imitation of a passion imaginable. Yet we are, while the song lasts, inhabited by that passion in a manner that few other art forms can realise. ${ }^{94}$

Brooks' work emphasises that so complicated an activity as operatic singing can communicate in the most direct visceral way, body to body.

\footnotetext{
${ }^{91}$ Verdi and Wagner, whose music and attitudes to and comments on singers I discuss more fully in Chapter Three, had very strong opinions of what, to them, was a good singer. See Melina Elizabeth Esse, "Sospirare, tremare, piangere: conventions of the body in Italian opera", (PhD dissertation, University of California at Berkeley), 2003.

92 Peter Brooks, "Body and Voice in Melodrama and Opera", Siren Songs: Representations of Gender and Sexuality in Opera, ed. Mary Ann Smart (Princeton: Princeton University Press, 2000), 121.

93 Brooks, "Body and Voice in Melodrama and Opera,122.

94 Brooks, "Body and Voice in Melodrama and Opera, 123.
} 
Coming from a different perspective and building on Peter Brook's work by investigating the added complication of operatic singing into the synergistic work of the body and voice, Linda and Michael Hutcheon are researchers (one a medical doctor and the other a literary critic) who again focus on the effect of the voice on the listener. In their book Bodily Charms, they also build on Wayne Koestenbaum's work in The Queen's Throat, underlining the reactions a listener has to a singer and how much the audience's bodily presence affects a singer's performance. Most of all, the Hutcheons emphasise that it is a singer's individual talent that enables and exemplifies the composer's written role, to bring the music and role to life in a way that ensures that some works gain popularity over others at certain historical times, according to the talents of the predilections of the singers who sing and communicate through them. ${ }^{95}$

In discussing the larger scientific and practitioner discourses I have found many explore roughly parallel issues to those in operatic criticism, and though the body figure more strongly, the definitive research on the task of the body in operatic singing is lacking. The focus on the body for performers- and particularly singers- is crucial and it is only by analysing the effect of its workings that I am able to begin to articulate its importance.

\section{The Diva}

The diva phenomenon has invited some fascinating explorations of singers in historical settings following the divergence of research in the wake of the new musicology. Sociologically interesting work on the aspects of their careers, their lives and the way that they were received, proved to be an engrossing topic for many scholars, and much of the public. This new research builds on the longstanding fascination with female singers going back to the eighteenth and nineteenth centuries, mostly concentrating on the prima donna, and encompasses both serious scholarly investigation of particular singers, and the

\footnotetext{
${ }^{95}$ Again, Mary Ann Smart's discussion on gesture and the use of the body in communication is of vital interest. Mary Ann Smart, Mimomania (California: University of California Press, 2006).
} 
phenomenon of fandom itself - the fascination and admiration of the diva across different eras.

It was Wayne Koestenbaum's book The Queen's Throat that opened up the doors of the rich and diverse world of opera fandom literature, and invited us to celebrate the different aspects of the performances of the diva, their "divadom", and their effect on their listeners. ${ }^{96}$ His personal and detailed critiques of Maria Callas's performances brought into a focus a new way of perceiving the diva as a whole entity, as a woman with a body, not just a powerful and extraordinary voice. Although Koestenbaum commented directly on what the effect of such a contemporary voice was on his body, historically all that is left of the diva is the visual evidence of their body, allowing us to recover a sense of their body, when the voice is no longer available, but also contributing yet again to the separation of body and voice.

Since the eighteenth century when the female singer gradually replaced the role - and the nexus of fandom - formerly occupied by the castrato, most of the attention has been on the female diva - and on diva worship: Maria Malibran, Henriette Sontag and Jenny Lind, for example, provided their public with voices and personalities to incite and inflame their imaginations and worship. ${ }^{97} \mathrm{John}$ Rosselli in Singers of Italian Opera: The history of a profession particularly highlights the exigencies of making a living in that world. Susan Rutherford has contributed further to this sociological record, in Prima Donna and Opera 1815-

\footnotetext{
96 Wayne Koestenbaum, The Queen's Throat (London: Penguin, 1993). His work invited the efforts of a number of authors, such as Sam Abel in Opera in the Flesh, to detail the effect operatic voices had on them. However it is the more critically focused and nuanced work of sociologist Claudio Benzecry in The Opera Fanatic, that has posed questions for musicology by expounding the reactions of the listener and how they react to the live performance. Benzecry's interviews with the opera fans of the Teatro Colón in Buenos Aires provide some interesting and useful descriptions of the operatic voice, and describes listener reaction and interaction. Sam Abel, Opera In the Flesh: Sexuality in Opera Performance (Colorado: Westview Press, 1996); Claudio Benzecry, The Opera Fanatic: Ethnography of an Obsession (Chicago: University of Chicago Press, 2011); Also fascinating is Susan J. Leonardi, and Rebecca A. Pope, The Diva's Mouth: Body, Voice Prima Donna Politics (New Jersey: Rutgers University Press, 1996).

${ }^{97}$ Susan Rutherford, The Prima Donna and Opera 1815-1930 (Cambridge: Cambridge University Press 2006).
} 
1930 and Verdi, Opera, Women, elucidating the life of female artists at that time in new and intriguing ways. ${ }^{98}$ Mary Ann Smart's article about Rosine Stolz not only describes her singing career but also the way in which her own narratives of her life were as much of a construction as her performances: as Smart says, it seemed that a diva was driven to create a persona when she realised she was marked by the compelling voice that incomprehensibly emanates from her body. ${ }^{99}$

The more critical stance by writers like Mary Ann Smart, outlined above, suggest a lens through which this less critically presented material becomes useful: a way to start looking at the Diva on her terms, to understand the "false" construction of facts as part of the persona of, the performance of the diva and as such encouraged a new focus on the diva as a kind of female author otherwise missing from music history. ${ }^{100}$ By asking us to rethink from whose perspective we should view history, and how verifiable "facts" are, it has become possible to challenge the deep ambivalence towards female power/female voices that is entangled in so many investigations into the lives and careers of the divas. ${ }^{101}$ Rachel Cowgill and Hilary Poriss's edited collection, The Arts of the Prima Donna in the Long Nineteenth Century, offers a range of new thinking on the representation and articulation of the presence of female singers, and on the idea of the Diva as a figure of power. ${ }^{102}$ Adding to the growing critical investigations

${ }^{98} \mathrm{John}$ Rosselli, Singers of Italian Opera: The history of a profession (Cambridge: Cambridge University Press, 1992); Susan Rutherford, The Prima Donna and Opera 1815-1930 (Cambridge: Cambridge University Press, 2006); Verdi, Opera, Women (Cambridge: Cambridge University Press, 2013).

${ }_{99}$ Mary Ann Smart, "The Lost Voice of Rosine Stolz", Cambridge Opera Journal (6,1, 1994, 31-50) 40 (after Wayne Koestenbaum, The Queen's Throat, 20).

100 Mary Ann Smart, “The Lost Voice of Rosine Stolz”, Corinne E. Blackmer and Patricia Juliana Smith, eds. En Travesti: Women, Gender Subversion, Opera (New York, Columbia University Press, 1995);

101 Mary Ann Smart, “The Lost Voice of Rosine Stolz", "Verdi sings Erminina Frezzolini”, Women and music $(1,1997) 33-45$; Melina Elizabeth Esse, "'Chi piange, qual forza m'arretra?': Verdi's interior voices”, Cambridge Opera Journal, $(14,1 \& 2,2002)$ 59-78.

102 Rachel Cowgil and Hilary Poriss, eds The Arts of the Prima Donna in the Long Nineteenth Century (Oxford: Oxford University Press, 2012). 
of these singers' histories, Susan Rutherford's monograph on Giuditta Pasta is a valuable addition to her other work, and is striking for the way in which it moves beyond critical biography to investigate the power of her performance in more specific ways. ${ }^{103}$

The long tradition of focus on divas has taken a variety of forms, historically, resulting in a vast trove of resources: in fiction, autobiographical or biographical, or gleaned from comments and letters from listeners. It also inspired several authors (not coincidentally female authors) to write thinly disguised, fictionalised accounts of divas' lives. ${ }^{104}$ The lionising of divas continued through into the twentieth century and means that rich public records and recordings abound with additional autobiographical and biographical material for a range of divas such as Mary Garden and Geraldine Farrar. ${ }^{105}$

In the less scholarly arena, books such as Rupert Christiansen's Prima Donna: A History and Henry Pleasant's The Great Singers reflect the obsessive way in which the idea of the diva was fixed in the public imagination. This material, despite its lack of critical thought, can also bring to light some interesting reflections: Helena Matheopoulos' books, Divo, Diva and Diva: The New Generation, for instance, consisting of interviews with her pick of the well

\footnotetext{
103 Susan Rutherford, “La cantante delle passioni': Giuditta Pasta and the idea of operatic performance" (Cambridge Opera Journal, 19, 2, 107 -138, 2007); "Unnatural gesticulation' or 'un geste sublime'?: Dramatic performance in opera." (Arcadia, (36.2 (2001) 236-255); Mary Ann Smart, Mimomania (California: University of California Press, 2006). Susan Rutherford's other books are invaluable documents: The Prima Donna and Opera 1815-1930 (Cambridge: Cambridge University Press, 2006); Verdi, Opera, Women (Cambridge: Cambridge University Press, 2013).

104 Willa Cather The Song of the Lark originally published in 1915 (London: Cassell, 1938); George Sand Consuelo, originally published in 1842 (London: Norilana Books, 2007).

105 Geraldine Farrar, Geraldine Farrar: The Story of an American Singer (New York: Houghton Mifflin and Co, 1916); Mary Garden and L. Biancolli: Mary Garden's Story (New York, 1951); not to mention the number of biographies of Maria Callas.
} 
known divas and divos (of our time), can offer useful biographical and even sociological background. ${ }^{106}$

In a myriad of ways, then, a wealth of critical discourse has firmly established the notion that the "diva" is a subject worth listening to and writing about. What is fascinating, though, is that the "diva" is still not speaking for herself. While it is all very well as a "diva", to find so much literature that outlines the importance and power of one's performance, there is strikingly little resonance between my sense of my communicative power in performance and these theoretical constructions that work to "envoice" the diva, to make her powerful. However interesting that work on singers is, including the interviews of audiences and fans, the perspective is still from the outside. ${ }^{107}$ It seems that the personality of the diva in opera at times supersedes the vocality, and almost becomes the true power behind the voice. My own experience is that both aspects - the voice and the persona - make up the whole, and that there are in fact a variety of approaches in which we can write more specifically about the way in which vocal power is constructed in performance. My own critical perspective as a performer thus offers a new kind of "voice" to the discourse and an alternative voice for the diva. ${ }^{108}$

In establishing a new focus for discussion on the construction of vocal performance itself, though, I want to retain a few aspects of how the diva has been such a focus of attention, both critical and popular. The veneration of the diva's voice, and why that diva's voice is so affecting and moving, is a fascinating puzzle and it is easy to see why it has been the focus of much renewed research. One facet that intrigues me is how certain female voices have seemed to affect people and been the focus of frenzied admiration. There is such a wide range of

\footnotetext{
106 Rupert Christiansen's Prima Donna: A History ( London: Pimlico,1995); Henry Pleasants, The Great Singers (New York: Simon and Schuster 1966); Helena Matheopoulos Divo (New York: Harper and Row, 1986); Diva (London: Victor Gollancz,1991); Diva: The New Generation (London: Little, Brown and Co., 1998).

${ }^{107}$ Hilary Poriss, Changing the score: arias, prima donnas, and the authority of performance (Oxford: Oxford University Press, 2009).

108 Hilary Poriss, Changing the score: arias, prima donnas, and the authority of performance (Oxford: Oxford University Press, 2009).
} 
fandom that one must be careful not to generalise; nevertheless, in a variety of contexts it is interesting to note how much it has been either the higher voices of sopranos, tenors and the castrati that have enthralled people, or the lower voices of women, particularly those who use chest resonance, that have been celebrated.109 Why should one woman's voice affect people more than another?

If, from the singer's point of view, the complex interaction with the body is the starting point, it is interesting to note that one strand of writing about the operatic voice has also focused on the physicality of response that seems to govern listener ecstasy. These notions of physicality for both listener and singer carry a rich set of implications for my readings of performance, so I will turn now to a brief consideration of the most important work which enhances subtle harmonic structures in the sound, that can lead to, as Clemens Risi puts it, an "addiction" to certain vocal sounds that can precipitate some emotional response to the sound, the music and the words. ${ }^{110}$

\section{Listener Ecstasy}

As a singer it is the corporeality and emotion of the fandom response that most fascinates me. Emotion is, of course, hard to quantify in relation to music, but over the last few years psychologists, neurologists and musicologists have come together to consider emotion in a multidisciplinary way. From a musicological and critical stance, Lydia Austern's edited collection Music, Sensation and Sensuality investigates how the sense of hearing works through the filter of the mind and body. Another set of collected essays, Tom Cochrane, Bernadino Fantini and Klaus Scherer's The Emotional Power of Music: Multidisciplinary perspectives on musical arousal, expression and social control, is exceptional in its

${ }^{109}$ See Terry Castle, "In Praise of Brigitte Fassbaender", in En Travesti: Women, Gender Subversion, Opera eds. Corinne E. Blackmer and Patricia Juliana Smith (New York: Columbia University Press, 1995).

110 Clemens Risi, 'The Diva's Fans: Opera and Bodily Participation', Performance Research (16 (3) 2011), 50. 
breadth, with invaluable reports from performers and composers. ${ }^{111}$ The complexities that arise from the study of the emotional elements of music are many: emotion means many different things to different people, and is so far, despite the efforts of neuroscientific research, unquantifiable. However, the numerous theories regarding the mechanisms of emotional arousal raise interesting questions when viewed from the context of a fan's attraction to the diva.

Music, as we know, is experienced in and through the body, through our contact with the acoustic environment. Musical performance, singing, and staging opera require the use of bodies - a voice does not exist without the body and its breath. The bodies of singers are also important visually (the corporeality of opera singers has been a subject of much discussion in recent years particularly in relation to how it affects the listener's appreciation of the spectacle). ${ }^{112}$ As we have seen, the rise of feminist perspectives and the discourse of the body facilitated considerations of performance, and so opened avenues of enquiry into not only the meaning of the body but the impact of it in communication.

The intricate knitting together of outer and inner worlds in vocal sounds heavily influences how and what we hear: how do we hear the singer's body in the voice that we hear; and how does listening affect our own bodies? These questions of course bring us back to Barthes' "grain of the voice", and illustrate

\footnotetext{
111 Tom Cochrane, Bernadino Fantini and Klaus Scherer, eds., The Emotional Power of Music: Multidisciplinary perspectives on musical arousal, expression and social control (Oxford: OUP, 2013); Linda Phyllis Austern, ed. Music, Sensation and Sensuality (New York: Routledge, 2002).

112 Critics seem very happy to criticise singers' appearances and singing without understanding the process of the staging and/or costume elements they have been subjected to. The criticism of Glyndebourne's Octavian in Der Rosenkavalier is a case in point. See the New York Times article "Too Much Looking, Not Enough Listening?" 22 May 2014. The size of opera singers has been discussed in detail by many commentators particularly journalists, after Deborah Voigt was fired from the Covent Garden production of Strauss' Ariadne auf Naxos in 2004. See Sam Abel, Opera in the Flesh (Colorado, Westview Press, 1996), 19-20. Another to mention size includes Matthew Wilson Smith, "Laughing at the Redeemer: Kundry and the Paradox of Parsifal", Modernist Cultures (Issue 5, 2007), 5-25, 5; Linda Hutcheon and Michael, Hutcheon Bodily Charm: Living Opera (Lincoln: University of Nebraska, 2000).
} 
the basic ways in which we still have not been able to develop any clear progression from his provocative essay. Expanding on the pleasure of listening, philosopher Jean-Luc Nancy poses some interesting questions, asking that if we listen with all our being, as we commonly say, what is it that we hear in the sound? He suggests that the very act of listening opens up a space between sound and sense: the theoretical articulation of that space may provide one way for us to figure the pleasure and other heightened emotions that ensue in performance. ${ }^{113}$ Developing the work of philosopher José Gil, Clemens Risi, on the other hand, expands the discourse on the empathy between singer and audience by pointing out that the experience of a singer has more relevance to the audience than people have otherwise understood: he again asserts that the quality of the voice, the physicality of it, impacts the listener. In describing the experience of the "voice-perceiver", he writes of "co-presence or, more precisely, co-vibration." 114 In this formulation, the connection with the listener, and how the extra textual content of the voice is made that provides that connection, is intimately connected with the workings and engagement of the body and mind of both singer and listener. Risi's work underlines the importance of understanding in more depth the singer's bodily connection: not just to fill in another aspect of the picture, but potentially to unlock a key aspect of what governs the nature of the operatic experience for the listener, as well.

I also find an interesting correlation between the types of voices that elicit the biggest reactions from listeners and the development of a particular kind of physical relation to voice. I will be positioning this relationship in terms of my own understanding of vocal production in the chapters that follow; but it is

113 Jean-Luc Nancy, Listening, trans. Charlotte Mandell (New York: Fordham University Press, 2007), 58. There are a considerable number of books that lay out theories of listening, of how we listen and hear and how that affects the brain and our emotions. I found the most interesting to be: Don Ihde, Listening and Voice: Phenomenologies of Sound, $2^{\text {nd }}$ Edition (New York: State University of New York Press, 2007), and David Michael Levin The Listening Self: Personal Growth, Social Change and the Closure of Metaphysics (New York: Routledge, 1989).

114 Clemens Risi, 'Opera in Performance-In Search of New Analytical Approaches' The Opera Quarterly (Vol 27 No 2-3), 283-295; Clemens Risi, "The Diva's Fans: Opera and Bodily Participation", Performance Research (16 (3) 2011), 49-54, 50. 
intriguing to point in this context towards the historical development of this type of vocal production in the nineteenth century (not coincidentally, the period in which much of the core repertoire that drives the singer-fan synergy), as indicated by James Davies, in his book on nineteenth-century vocal performance Romantic Anatomies of Performance. Calling this style of singing "vocal essentialism" Davies says "...(it) was an example to those who dared to imagine what might happen when voice obeyed raw function alone, when, freed from the artificial categories of communication, voices were unleashed to go their own way." 115 Although Davies calls this vocally communicative style of singing a whim, in fact the ongoing construction of this style of singing is something consciously embarked on even today; and we surely must acknowledge the rational choices in the framing of the vocal production itself that contributes to the creativity of the performance. It is the way a singer wields this "raw function" of vocal sound, as an amalgam of the embodied communication of body, mind and emotion that is the topic of this dissertation. And while my focus is on the singers' act(s) of construction, this larger literature also indicates that it is this function that is also key to listener response to performance. ${ }^{116}$

The bodily reaction to voices calls on a variety of other critical discourses on voice, body, and performance, and starts to articulate some very important insights that will have further implications for my deconstruction of performance. Crucially, the relationship to intense fan reactions brings the question of listener ecstasy to the forefront of attention, in the context of a variety of work initiated by Poizat and Koestenbaum. What is missing from this discourse is an articulation of the circularity of the process of how the diva may also participate - even generate - those moments of ecstasy. Just as Risi suggests that fans feed off the singer's energy, so also can the singer crave and feed off the audience's response. The mirror that Heather Hadlock talks of in "Peering into the Queen's Throat", transforming the diva into a fantastic echoing mirror of the

\footnotetext{
115 James Q. Davies, Romantic Anatomies of Performance (Berkeley: University of California Press, 2014), 98.

116 De Van, Verdi's Theatre, 49.
} 
fan's (fantasy) life, giving the fan the thrill of jouissance, can also be reversed.117 The engagement of the body and voice together, the hard physical work of the singer combined with the pleasure of the fans' reaction creates a specific physical and mental pleasure for singers - indeed, in my experience, one of the key drivers of singers' experience.

\section{Jouissance}

Which brings us to jouissance. While jouissance may seem like an ephemeral concept, it is has been evoked so frequently in the scholarly literature around opera that it can be defined quite succinctly. I suggest that the bodily engagement of the singer can elicit jouissance in the listener, and I will explain how in the next chapter. Moreover, as listeners listening to an operatic voice sing, we can be inhabited by a passion that is formed by a highly trained imitation of passion. Indeed, as José Gil in Metamorphoses of the Body writes, the word itself points towards the visceral connection between the voice and its flesh, the presence and power of the voice, and can be powerfully addictive. ${ }^{118}$ Gil elaborates on that connection, saying,

What happens with certain phenomena of "correspondence" or of "silent communication" between and audience and a speaker, for instance, or in a more general way between spectators and actors on a stage, between a singer and those in the concert hall? 119

The embodiment of the voice is also the embodiment of the emotions expressed by the voice.

That music and voice have sensual qualities that communicate to the listener is clear; Linda Austern in Music, Sensation and Sensuality, reminds us that sound and language reaches outwards to the other senses, and towards the

\footnotetext{
117 Heather Hadlock "Peering into the Queens' Throat" Cambridge Opera Journal (5, 3, 265-275).

118 José Gil, Metamorphoses of the Body (Minnesota: University of Minnesota Press 1998). 187. Gil also talks about the importance of the breath, a reference I shall return to in the next chapter, Chapter Two.
}

119 Gil, Metamorphoses of the Body, 187. 
senses of others. ${ }^{120}$ While Austern seems to suggest that this is a process of disembodiment, for me, just as it is for the theatre practitioner, Eugene Barba, it is an enlargement of the body by the voice that constitutes a state of embodiment. The sound of a particular voice type that gives jouissance, I believe, is central to our understanding of operatic voice and, as I will show through my case studies on Verdi and Wagner, is transmuted into a more meaningful version of the diva's power. Pleasure that is created and received by singer and listener can be appreciated on two levels: it can either be mindless and non-rational, as in many of the fans of the operatic voice, who react bodily and emotionally to the singing; or, the vocal sound, its embodiment, the technical choices the singer makes can enhance a more critical perspective of the drama. However, instead of predicating a separation between mind and body in this way, I suggest that exploring these "mindless" responses can itself lead to valuable critical observations. The voice brings words and music together and yet the sound of the voice exceeds both by enhancing, through embodied cognition, a state of communication that can bypass rational communication: wildness, the uncanny, the ineffable and jouissance. Most listeners and singers, I suggest, seek jouissance as the fundamental operatic end.

There are, however, fundamental differences: a listener's jouissance is metaphysical and intangible whereas a singer's jouissance is embodied, physical and tangible.

My thesis then will both illuminate a new aspect of what lies behind those moments of jouissance for the listener, and also articulate - actually envoice what the singers' active role in creating meaning in performance, is. By developing a new methodology to discuss voice, body and performance, my work can move the discourse of voice and vocality forward in new ways. I also suggest the possibility that the connection, my "oneness" with the music and my own vocal sound, may be a source of pleasure or jouissance, to the listener (although demonstrating that connection lies beyond my purview). By laying out exactly

120 Linda Austern ed., Music, Sensation and Sensuality (New York, Routledge, 2002), 5; Clemens Risi, 'The Diva's Fans: Opera and Bodily Participation', Performance Research $(16(3,2011), 50$. 
what I, as an opera singer do in relation to making a compelling vocal sound and managing a connection between the singer and audience in live performance, I will show how the seemingly small elements in a complex engagement of the body and mind facilitate the pleasure of voice. ${ }^{121}$.

As this chapter demonstrates, then, not only does the performance perspective have a valuable contribution to make in a range of discourses around opera, voice, and vocality; it also has the potential to illuminate some ways of delving into a deeper understanding of how voice is not just a vocality - it is both from the support of the body, and of the body. In the next chapter I will suggest a model of embodiment of the singer's range of bodily/vocal/cognitive choices that coexist at various levels of consciousness in the context of operatic performance. I will also suggest that there are certain parameters to be met to produce a particular sound.

Firstly though to that troubling cipher, the body.

121 Phenomenal -that which is apparent and real. 'Loop of connection' refers here to a psychological state, see Paul J. Eslinger, "Neurological and Neuropsychological Bases of Empathy", European Neurology $(39,1998), 193-199$. 


\section{Chapter Two:}

\section{Voice between the Material and the Ineffable}

In order to explain my assertion of the intricate relationship of body and voice necessary for the singer's creative engagement, in this chapter I will articulate my own explanation of the role the body plays in the physical, cognitive and musical aspects of operatic singing. Illustrating the complexity of what most singers take for granted, I lay out an abstract model of the various layers of physical and mental engagement of embodiment in performance, which aims to make explicit some of the crucial aspects of the multiple intersecting forces that interact to form the opera singer's physical, intellectual, and creative experience. Overall, it is the singer's breath that activates all the physical requirements I lay out, and that facilitates the multiple layers of engagement. By disassembling some of the invisible and seemingly instinctive tasks that a singer achieve (more or less successfully) for performance, I provide a framework for thinking in more detail how we might engage critically with this experience of singing in the context of specific scores/performances. This then allows reflection on what the possible ramifications for the operatic experience of both singer and listener might be. It is the elaboration of the physical and mental engagement of embodiment that articulates many of the elements that determine and enhance creative agency when bringing an operatic character to life on stage.

As a singer performing nineteenth-century operas in the twentieth- and twenty-first centuries, I have learned a tremendous amount from my experiences in performance itself. I have had the benefit of guidance from experts, and I have worked with innovative directors and scholars who have enlarged my experience by suggesting a variety of critical perspectives. In this dissertation, I use this experience to offer an account of what actually happens to one singer's mind and body, in the context of performing demanding Verdi and Wagner operatic roles. 
Before I can turn to particular roles, though, it is crucial to lay out the details of an operatic singer's training and preparation, to understand the ways in which body, cognition, and vocality are linked together to produce a voice, before a singer ever performs a particular role on a specific stage. Indeed, I propose that a detailed understanding of what singers actually do to perform can transform our understanding of the singer's collaborative creative role in creating and shaping our experience of the character. Further, it will be my contention that the greatest operatic composers, such as Verdi and Wagner, composed in ways that shape and allow particular types of "singerly" creativity. The fundamental framework of embodied cognition I outline in this chapter, however, has the potential to be applied in a wide range of contexts and a wide range of repertoire.

The act of singing and staging opera requires bodies: a voice does not exist without the body and its breath. An operatic singer engages in the bodily production of sound, in and through the breath, which in turn shapes an interpretation of text and influences the very formulation of the dramatic character. This bodily involvement is crucial for vocal expression, which is the result of a finely tuned and highly expressive body and voice, combined with a communicative imagination. It is this synthesis, I believe, which creates intense operatic vocal experiences for singers and their listeners. Obviously bodies have changed over time: one cannot say with any surety that our bodies are the same as that type for which Verdi and Wagner were writing music. In addition, the meaning of "the body" both in performance and in life shifts across different cultures. However, in this chapter, I will concentrate on the meanings of the operatic body, and its engagement, to help to counteract effectively disembodied voice that has dominated many discussions of opera. ${ }^{122}$

The operatic body, like the operatic voice, is not natural. Rather, it is a combination of a living human body and a cultural construct conveying literal and metaphorical meanings. To create the operatic body, the operatic "package"

\footnotetext{
122 See Linda Hutcheon and Michael Hutcheon, Bodily Charm, Living Opera (Lincoln: University of Nebraska Press, 2000), 25.
} 
if you like, involves long training and the absorption of difficult concepts. The creative abilities of singers are not generally understood to be an amalgam of body and mind elements: singers are often treated much more as "body" than as creative mind. Lydia Goehr in The Imaginary Museum of Musical Works: An Essay in the Philosophy of Music points to the general issue of performer ideology in the twentieth century suggesting that in relation to the "work concept", performers are reduced to bodies that merely "reproduce" what the composer has created. 123 Perhaps, as she has further noted in The Quest for Voice: Music, Politics, and the Limits of Philosophy, contemplating musical performance beyond the immortal work means understanding a performance simultaneously as an exemplification of the work and as theatre, where an act in which an "expression of spontaneity, immediacy, and freedom, of feeling and breathing, of conviction and commitment" is conveyed by the mute actor-musician. ${ }^{124}$ She is, of course, referring to instrumentalists. However, what is little understood is the myriad ways in which the harnessing and management of the bodily aspects of performance involve choosing which of the physical and mental aspects of the embodiment to emphasise - a much more intellectual and creative process than is often acknowledged. In my own experience, singing an opera in performance allows me, for reasons that will become clear in the case studies, a kind of "authorial" creative power, not only in the way I use my body, but also through the extra textual content I choose to use in the sound. ${ }^{125}$

${ }^{123}$ Lydia Goehr in The Imaginary Museum of Musical Works: An Essay in the Philosophy of Music (Oxford: Oxford University Press, 1992) Mary Hunter's article," To play as if from the Soul of the Composer: The Idea of the Performer in Early Romantic Aesthetics" Uournal of the American Musicological Society, Vol 58, No 2 (Summer 2005) 357-398) promotes firstly the idea that interpretative performance involves a spiritual transformation on the part of the performer, requiring the merging of his own soul with that of the composer; and secondly, the idea of performance that both establishes and collapses apparently intractable dualism.

124 Lydia Goehr The Quest for Voice : Music, Politics, and the Limits of Philosophy (Oxford: Oxford University Press, 1998), 148.

125 In using "extra textual" as a descriptor (following Roland Barthes) I mean the qualities of voice and empathy beyond the basic sound and expression of the text, the undefinable qualities described by Michelle Duncan, Clemens Risi and possibly the "uncanny" qualities of voice noted by Gary Tomlinson and Carolyn Abbate. 


\section{Embodiment}

My exploration of the role of body in vocal performance stands on the rich and significant thinking developed across the twentieth century on the role of embodiment as a key aspect of knowing, being, and constructing cultural meaning. In the context of myriad complex discussions of embodiment as a philosophical and performative concept, Maurice Merleau-Ponty stands out because of the way he placed the body, rather than consciousness, as primary in experiencing the world. ${ }^{126}$ Building on the work of Hegel, Husserl and Heidegger and others in the mid twentieth-century, Merleau-Ponty developed his work to articulate the authority of embodiment. ${ }^{127}$ Drawing on the fields of perception, the empirical sciences and psychology he extended aspects of the field of phenomenology, so that the body can be understood to be the active process of embodying certain cultural and historical possibilities. ${ }^{128}$ In Phenomenology of Perception, Merleau-Ponty says,

My body is the seat ... the very actuality of the phenomenon of expression .... the visual and auditory experiences .... are pregnant one with the other, and their expressive value is the ground of the antipredicative unity of the perceived world, and, through it, verbal expression and intellectual significance. ${ }^{129}$

Merleau-Ponty, together with thinkers such as Mark Johnson, George Lakoff, José Gil and Judith Butler, understands the body as the foundation of experience and reception of that experience. ${ }^{130}$ However, in the intersection with performance

126 Maurice Merleau-Ponty, Phenomenology of Perception, trans. Colin Smith (Oxford: Routledge, 2002), vii-x.

127 Maurice Merleau-Ponty, Phenomenology of Perception, vii-x.

128 Judith Butler,"Performative Acts and Gender Constitution", The Twentieth Century Performance Reader, $2^{\text {nd }}$ Ed., eds. Michael Huxley and Noel Witts (Oxford, Routledge, 2002, 120-134),122.

129 Merleau-Ponty, Phenomenology of Perception, 273.

130 Mark Johnson, The Meaning of the Body (Chicago: University of Chicago Press, 2007) and The Body in the Mind (Chicago: University of Chicago Press, 1987); George Lakoff and Mark Johnson, Philosophy in the Flesh (New York: Basic Books 1999) and Metaphors We Live By (Chicago: University of Chicago Press, 2003); José Gil, Metamorphoses of the Body (Minnesota: University of Minnesota Press 1998); Judith Butler, Gender Trouble: Feminism and the Subversion of Identity (New York: Routledge 1990) and Bodies That Matter: On the Discursive Limits of Sex (Oxford: Routledge, 1993). 
the lack of a specific critical discourse on the body - really, the lack of engagement of the performers who engage the body with the development of critical methodologies - has created a disconnect between theoretical understanding and both the actuality of performance, and the impact of performative knowledge in relation to critical readings, whether of texts or of performance itself. Although a number of scholars have addressed the idea of embodiment, generally they address either the body or the voice, not both together. Yet both aspects need to be brought together, in order to be able to understand the role of the body in the construction of operatic voice.

Scholars have often used the word "embodiment" to imply a visual and vocal assumption of an operatic role. A fashionable descriptor, embodiment has been much used over the last decades in many disciplines. In the realm of theatre and film it applies to the physical appearance and actions of the actor. Crucially, a number of scholars across the last two decades have pointed towards the importance of the body as a site in the construction of meaning, specifically in singing. Most scholars who have an intense interest in the voice recognise that a performer's body has different layers of interaction with the mind and with coperformers, and that they combine these bodily presences with his or her own inner life as an opera singer. Susan Rutherford in her article "La cantante delle passioni" points out that "vocality is not an innate, given quality but the specific product of body and of mind's direction of body." ${ }^{131}$ A singer needs the voice but also the discipline to train the mind and body to be an effective and communicative singer. In a similar way, musicologist Marco Beghelli in "Erotismo Canoro" refers back to Barthes, reminding us that the body is paramount, and that

the emission of song is, in and of itself, the acoustic exhibition of embodiment. It is not a sound that comes from a mechanical instrument; rather it is produced by the very body of the singer, the corporal flux that emerges from the most hidden cavities, and which determines its particular "grain" ...; not a generic timbre, codified in advance by technical instruments, but rather a peculiar

131 Susan Rutherford, “'La cantante delle passioni': Giuditta Pasta and the idea of operatic performance", Cambridge Opera Journal 19, 2 (2007), 107 -138),118. 
elusive highly individualised, acoustic image of a specific embodiment. ${ }^{132}$

Beghelli notes that the sound of the voice is as individual as the body is individual; it is the unique quality of voice that is compelling and crucial for the communication of the composer and librettist's work.

However interesting these perspectives are, they remain theoretical and are not concerned with the physicality of the actual work of singing. For this, virtually all aspects of the body are important. Writing specifically from the context of Western classical art music and musicians, Raymond Macdonald, David Hargreaves and Dorothy Miell in Musical Identities refer to embodiment as "the biological and physical presence of our bodies, which are a necessary precondition for subjectivity, emotion, language, thought and social interaction."133 In relation to musicians, acknowledging the importance of the body in the creation of meaning in performance is vital. While some scholars underline the importance of the body, it is the meaning of the vocal utterance that must be conceptually linked to the production of vocal sound through a person's body. ${ }^{134}$ One can of course embody music: the movement of our bodies is a reaction to a musical impulse and as such is embodied. However, Suzanne Cusick recognises what it is that makes singing so different from the performance of other instruments, saying that, "Musical performances, then, are often the accompaniment of ideas performed through bodies by the performance of bodies." 135

132 Marco Beghelli, "Erotismo Canoro", Il Saggiatore Musicale (Anno VII 2000) 123-136; 124. L'emissione canora è di per sé esibizione acustica di corporeità: non suono uscito da uno strumento meccanico, ma prodotto dal fisico stesso del cantante, flusso corporeo scaturito dalle cavità più riposte, che ne determinano la peculiare "grana"... non timbro generico, precodificato dalla tecnica costruittiva degli strumenti, ma peculiare ed esclusivo, altamente individualizzato, immagine acustica di una specifica carnalità.

133 Raymond R., Macdonald, David Hargreaves, and Dorothy Miell. Musical Identities (Oxford and New York: Oxford University Press, 2002), 2.

${ }^{134}$ A good example of the wide range of applications is Leslie Dunn and Nancy Jones, Embodied Voices: representing female vocality in Western Culture, eds. Leslie C. Dunn and Nancy A. Jones (London: Cambridge University Press, 1994), 1-3.

135 Suzanne G. Cusick, "Of Musical Performances of Gender and Sex." Published as "Feminist Theory, Music Theory, and the Mind/Body Problem, Perspectives of New Music 
My research focuses on two composers of the nineteenth century and on a change in vocal technique that may have in some way influenced the composition of their vocal music. Prior to the nineteenth century singers of course had to have bodily engagement to sing their very demanding roles. However, I take the fundamental shift in the physicality of the voice as it was enacted from 1830 as key to my research. James Q. Davies book Romantic Anatomies of Performance shows that the physical usage of the body in this period was drastically different to previous concepts. ${ }^{136}$ By explaining the nature of the body in singing and the nature and interaction of the mind and body in performance, informed by the changes in vocal technique, I will clarify the embodiment required to portray the roles of Verdi and Wagner with a heightened emotional engagement. In addition, I will lay out the critical aspects of how these processes work: music of the nineteenth century is recreated in the moment through twenty-first century bodies and therefore the performances must be different and created anew.

While Carolyn Abbate's article "Music-Drastic or Gnostic?" has prompted a welcome critical interest in the materiality and significance of the "drastic" aspects of performance, nevertheless, from a performer's point of view, the vital interconnection between drastic and gnostic during performance is much more complicated than supposed. Here, in Abbate's argument, "drastic" in Vladimir Jankélevitch's definition, connotes physicality and also desperation and peril, and "gnostic", a knowledge based on information secret to the very few. ${ }^{137}$ While she acknowledges that symbiosis is very important, Abbate never articulates in detail how that synthesis might take place. Building on Abbate's work, but putting the performer's experience front and centre, Michele Binnie breaks down the process of performance and emphasises the importance of the mind/body

32 (1994) 8-27.; See also Elisabeth Le Guin, Boccherini's Body: An Essay in Carnal Musicology (California: University of California Press, 2006) and The Tonadilla in Performance (California: University of California Press, 2013).

136 James Q. Davies, Romantic Anatomies of Performance, Berkeley, University of California Press, 2014

137 Carolyn Abbate, "Music -Drastic or Gnostic?" Critical Enquiry (30/3, 2004, 505-536), 509-510. 
relationship and how it is controlled, suggesting it is essential that the gnostic is embedded in the implicit memory to be able to cross over into the drastic in order to complete the ultimate symbiosis of score and performance. She uses the term "meta-drastic" to articulate this more complex level of interrelationship where elements of the gnostic interact with each other and have an important role to play in performance. ${ }^{138}$ The interaction of mind and body in the dedicated period of practice for any performance involves embodied intelligence: a sensual and bodily intelligence, that arises from an embodied unconscious mind.139

While Binnie's research is of course from a pianist's point of view, many of her insights are applicable to opera singers. Moving beyond theoretical conceptions, and by combining features of Binnie's research and that of theatre practitioner Rhonda Blair from her book The Actor, Imagination and ActionActing and Cognitive Neuroscience, I have found that it is possible to apply theatrical and pianistic values to the operatic voice. ${ }^{140}$ But there are a number of extra challenges a singer faces.

How do we talk about the use of the singer's body and the quest for the vocal sound that moves us? My experience of singing professionally, and of listening to and teaching many singers, provides a crucial lens for discussing the process of embodying voice; for not only does the vital engagement of the body with the voice contribute to the empowerment of the character, but the way a voice is embodied is, I suggest, also a major factor in making the vocal sound attractive to the listener. This has the important result of serving the composer and librettist; but the process of engaging with an embodied interpretation of musical texts again requires the combining of drastic and gnostic. The drastic itself contains the many layers of engagement in performance. At a basic level, Clemens Risi perceptively notes how, in performance, there is "a fluctuation

\footnotetext{
138 Michele Binnie, "Finding the Drastic: Exploring Forms of Attention in Piano Performance", MMA Exegesis, Victoria University of Wellington, 2014, 14-15.

139 Michele Binnie, "Finding the Drastic", 21.

140 Rhonda Blair, The Actor, Imagination and Action - Acting and Cognitive Neuroscience (New York: Routledge, 2008).
} 
between the embodiment of a fictional role, and the real bodily presence of a singing actor." 141 With this observation of the dual personality of the singing actor, the real and the imagined, he articulates the greatest challenge to the operatic singer, to combine these two facets to provide the magnetic attraction of the singer. ${ }^{142}$ This process then, the engagement of embodiment, with its difficulties and challenges in performance, is always tested in the public eye. No matter how much you practise, you cannot be sure of the efficacy of the process until you can carry it out under stress, in the spotlight. It is for the mind to control the body in those stressful circumstances, and to set up a continuum between conscious and unconscious modes of control; the result of this process is an integrated performance.

The conscious management of the areas needed in embodiment require an awareness of the intersections and boundaries between the areas of focus. Boundaries are always areas of tension and of interest, and the intersection of body and mind especially so. It is the management and manipulation of these intersections that leads, I believe, to the development of extraordinary performers. A human body's inherent instability for singing requires that there are three areas of focus in singing: the internal, the external and the "in between" or liminal, as in the diagram below. The mind's job is to control the working relationship, the intersections between these elements. Learning how to put the cognitive processes in place, training the attentional processes of the brain, takes time and concentration. ${ }^{143}$

\footnotetext{
141 Clemens Risi, "Opera in Performance-In Search of New Analytical Approaches" The Opera Quarterly (Vol 27 No 2-3, 283-295), 293.

142 Risi goes on to say that Walter Felsenstein, influential opera director of the Komische Opera in Berlin, 1947 to 1975, tried to make singers' acting credible, and in his opinion, this magnetic attraction was an aspect of performance that most needed to be controlled.
}

143 Michele Binnie, "Finding the Drastic", 18. 


\begin{tabular}{|l|l|l|l|}
\hline & intrinsic/interior & liminal/in-between & extrinsic/exterior \\
\hline Engagement & vocal folds 144 & articulators ${ }^{145}$ & muscle flexion ${ }^{146}$ \\
\hline Awareness & kinaesthetic & musical & Acoustical \\
\hline Subjectivity & emotional connection & character & presence/charisma \\
\hline
\end{tabular}

The successful negotiation of these boundaries, I suggest, produces an embodied and communicative singer: if one of these elements is lacking then the listener often experiences something as missing.

To explain the complexity of the process of constructing a vocal performance, I have laid out the main steps by which a singer must engage bodily processes. While I have interrogated my own experience as the basis of my work, I have also consulted widely with colleagues. It is, of course, solely the embodiment of the twentieth and twenty-first century used for nineteenthcentury works that I focus on here. This model may provide a frame of reference for all operatic singing, but in particular it serves me as the crucial background and starting point for my more detailed discussion of the Verdi and Wagner roles in later chapters. I have itemised the disparate, equally important mental and physical elements that a singer must learn to balance in turn, more or less consciously, in order to provide an engaged vocal performance. While I list the steps in the process of sung operatic performance, some of these steps are engaged consciously in preparation; others are more at the forefront of conscious control during performance; and yet others are engaged almost unconsciously during performance. I lay out the complexity of conscious controls that underlie the professional performance, the embodied continuum that in turn sets up the complex dialogue between mind and body necessary for successful communication with both onstage colleagues, as well as the audience. Some of these aspects have been addressed in various approaches, but others are more or

\footnotetext{
144 Vocal Folds are the two parts of the vocalis muscle that vibrate to provide the vocal sound. Please refer to Diagram 2.1.

145 Articulators are the tongue lips and teeth.

146 Muscle flexion is the use of the muscles supporting the alignment of the body and hence the stability of the vocal resonator tract - the oro-pharynx. Refer to Diagram 2.1.
} 
less taken for granted by singers and not often talked about.

\section{Diagram 2.1: Model of Embodiment}

\begin{tabular}{|l|l|l|}
\hline 1 & $\begin{array}{l}\text { Engagement of extrinsic } \\
\text { muscles, and release of } \\
\text { intrinsic muscles }\end{array}$ & $\begin{array}{l}\text { The fundamental anchoring and engagement of making a } \\
\text { vocal sound. }\end{array}$ \\
\hline 2 & $\begin{array}{l}\text { Kinaesthetic awareness } \\
\text { of body in space }\end{array}$ & $\begin{array}{l}\text { Awareness of body in space on stage and use of gesture; } \\
\text { alignment on stage with others; use of scenery and } \\
\text { props; attention to stage hazards }\end{array}$ \\
\hline 3 & Musical awareness & $\begin{array}{l}\text { Subconscious involvement in the music: preparation has } \\
\text { ensured awareness of orchestral textures and harmony } \\
\text { and other formal elements; awareness of the conductor } \\
\text { and others when needed. }\end{array}$ \\
\hline 4 & Character and reactions & $\begin{array}{l}\text { Individual imagination is needed to create the character } \\
\text { and his/her reactions and subtext. Of necessity, "the } \\
\text { character" is created differently by each singer. }\end{array}$ \\
\hline 5 & Emotional connection & $\begin{array}{l}\text { Activation of remembered emotions: by manipulating } \\
\text { musculature and engaging intrinsic and extrinsic } \\
\text { muscles, and changing the effort involved from role to } \\
\text { role, sound is coloured by minute changes in the vocal } \\
\text { resonator tract, and laryngeal tilt as required.147 }\end{array}$ \\
\hline 6 & $\begin{array}{l}\text { Acoustical awareness } \\
\text { and response }\end{array}$ & $\begin{array}{l}\text { Singer's formant: by minutely adjusting resonance, } \\
\text { projection, diaphragmatic and muscular energy and } \\
\text { intent, singers capitalise on the acoustic possibilities of } \\
\text { space.148 }\end{array}$ \\
\hline 7 & $\begin{array}{l}\text { Singers are expected to have the ephemeral quality of } \\
\text { presence or charisma. Exercising that mental projection } \\
\text { of character is a requirement of someone who is a } \\
\text { performer -some have that quality naturally, others } \\
\text { have to work at it, and the quality of presence develops } \\
\text { with experience. }\end{array}$ \\
\hline 9 & $\begin{array}{l}\text { Activation of the } \\
\text { articulators }\end{array}$ & $\begin{array}{l}\text { Vocal fold activation } \\
\text { preate the text. }\end{array}$ \\
\hline 1. & Eo create the sound. \\
\hline Engagisma & &
\end{tabular}

\section{Engagement of extrinsic muscles, and release of intrinsic muscles.}

As an instrument the human voice is the most difficult to control. Nothing is stable: apart from the skeleton there are no fixed structures. Therefore to create a balanced acoustic sound, the singer must provide that stability by

147 Cicely Berry, Voice and the Actor (London: Harrap and Co,1973), 45.

148 Indeed most singers unconsciously tune their voices to the acoustic as actors are trained to do, by listening to the ambient acoustic and the feedback they get in the venue from the sound they produce. See Michael McCallion, The Voice Book (London: Faber and Faber, 1988), 130. Most actors and singers will test the acoustics of the space before the performance, if possible. 
engaging extrinsic muscles to anchor and stabilise certain key bodily structures: the cervical spine, the ribs, the pelvic structure and legs. In stabilising and anchoring the body in this way nothing must ever be stiff and unmoving, but always remain flexible. The work the body does stabilises the vocal resonator tract (the small section of the pharynx from vocal fold level to the start of the oropharynx, the mouth proper).

\section{Diagram 2.2: The Vocal Tract}

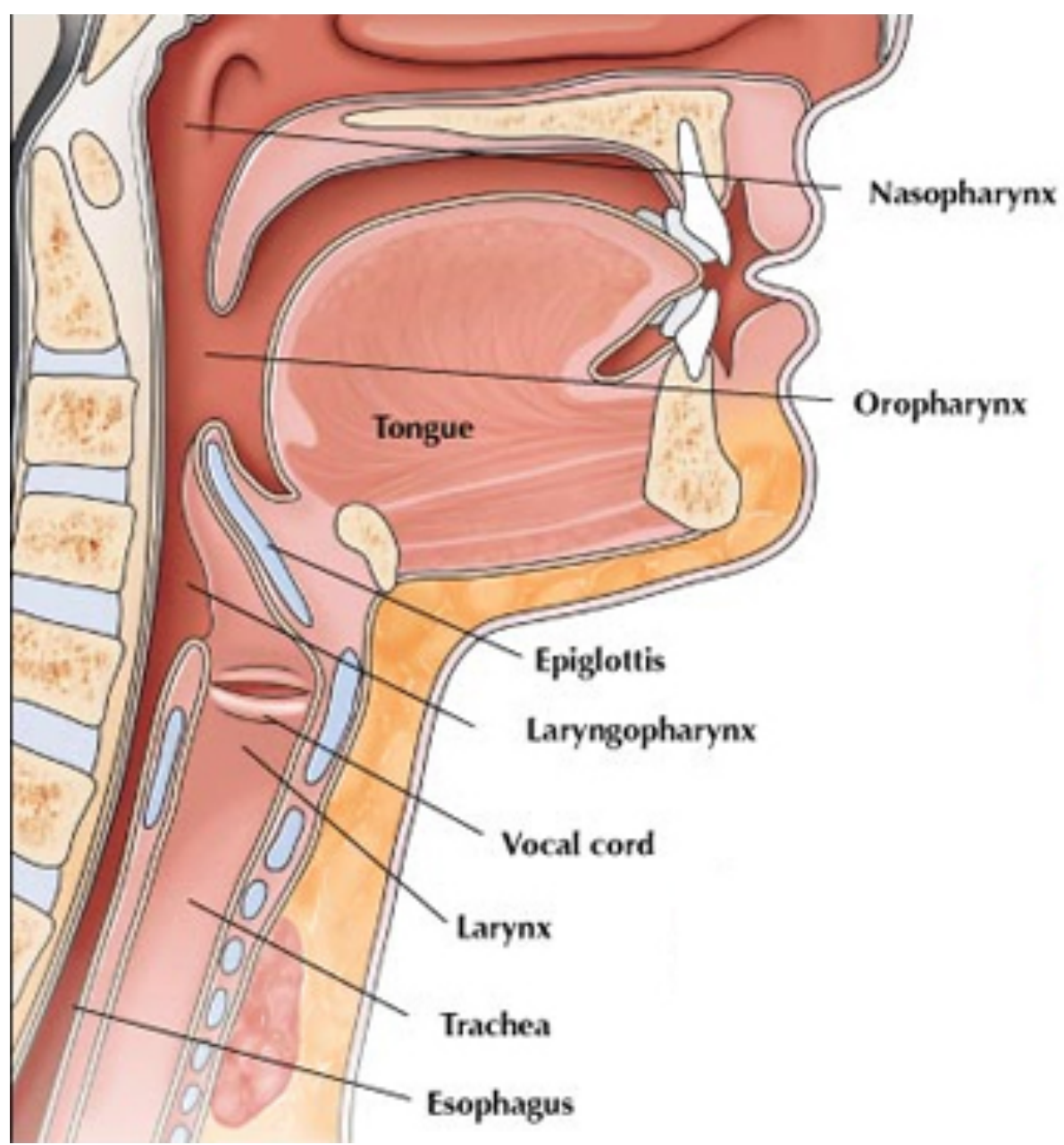

This remarkably small area enhances the sound made by the vocal folds. The tissues must be firm, reflective and amplify as much as possible the basic sound the vocal folds create for all the available harmonic structure to be heard in each individual voice. ${ }^{149}$ When singers first start learning it initially

149 Further amplification is achieved by placing the stream of sound in the mouth to pick up maximum resonance. The sound made by the vocal folds is of course made up of a number of harmonics. Those harmonics move through the pharynx picking up 
feels like a huge physical effort to keep the vocal resonator tract open, but the body soon gets used to the work involved. By engaging the extrinsic muscles, the intrinsic muscles are released from the unnecessary, tension-making work of support for the voice, and so the focus can move to shaping the vocal resonator tract and the text. These aspects of the European operatic tradition are learned consciously over many years and become automatic in performance with repetition and maturity. However, part of the creativity in performance is the ability for these elements to continue to be evoked and altered consciously in performance when needed.

\section{Kinaesthetic awareness of body in space.}

As singers move on stage they of course need to situate their bodies in the space available, be in the light, and be aware of stage hazards (stairs, furniture, fire etc). Of particular importance is the alignment on stage with others: this can enhance the dramatic impact on stage, heightening emotional affects. In some theatres the placement on the stage can be vital in the projection of the vocal sound into the theatre. An experienced actor-singer knows instinctively what their bodies can do on stage, where their arms and legs are, what shape gestures they are making, and where they should situate themselves for maximum effect. Physical gesture is one of the main markers of acting style. ${ }^{150}$ Some singers have an entirely instinctive reaction to space (they are often called "stage animals"); conversely other singers have difficulty being aware of what their bodies are doing when their attention is focussed on singing-these are the singers who do not notice, for example, that their arms are "windmilling" and who have trouble interacting with props.

\section{Musical awareness}

The accepted requirement for opera singers today is to arrive at the first rehearsal of the opera with their role already learnt, coached and memorised.

resonance which is individual to that singer. The shaping of the mouth brings that harmonic structure into one blended sound.

${ }^{150}$ For a further interesting discussion, see Mary Ann Smart's Mimomania (California: University of California Press, 2006). 
The first rehearsals are usually music rehearsals with the conductor, who will put his version of the music to the singers. Unfortunately gone are the days when conductors used to coach their own singers, or have their own trusted coaches prepare the singers they want to use. Carlo Maria Giulini, for instance, required Rosalind Plowright to work with Roberto Benaglio in Milan before she recorded and performed Leonora in Il trovatore with him. ${ }^{151}$ However, in current practice, the singer's interpretation and the vocality of a role is usually shaped by the coach they work with before the rehearsal period. In this way the vocal coach has much more influence on opera singers' preparation than is often recognised. Much depends on the differences in the temperament or indeed abilities of singers and sadly some singers only know their own parts. Others are able to delve into the music more deeply by themselves; though in relation to a vocal coach, a singer is not fully in charge of her own interpretation. Part of a singer's musical preparation is to "embed" the minute and detailed muscle control required for the vocal production of that particular part in the body and brain: the music should be so much part of the singer that the unconscious mind and body will sing for you when something unexpected happens on stage (as it always does in live performance). An awareness of the conductor is symbolic of the interaction between the musical decisions that have been learnt and embedded in the body, and the ongoing musical choices in the present that can shape the various musical aspects of a particular performance.

\section{Character and reactions.}

Imagination is needed to create the character and the character's reactions to both music and text as well as the dramatic subtext (the background and character analysis behind the story created by the actor or director). Singers have a reputation for being notoriously bad actors, with concern for their voices overwhelming dramatic considerations. However, directors are generally looking for singers to bring something to the production, some ideas they have imagined about the character, as there is no time to

151 Rosalind Plowright in Helena Matheopoulos, Diva: The New Generation (London: Little, Brown and Co., 1998), 133-44, 142. 
workshop ideas in the contemporary operatic system as there still is in theatre. Therefore as well as learning the notes of the score, the singer must be imagining a subtext, a back story,to the libretto. All libretti whether based on true characters and events or fictional ones, are set in a particular time and place. After researching the background of the historical period of both the work's conception and its setting, and the sources of the story, the singer then needs to make up her mind as to her character's perception of and reactions to the events: some things are already dictated by the score and libretto, but others are not. In light of the previous explanations, it can be seen that learning a role correctly and thoroughly is of vital importance.

Ideally I like to learn an opera role one year to eighteen months before I need to start rehearsing for the production. Doing the preparation, which includes background reading and situating the plot historically and sociologically, learning the notes and allowing the music to remain, as it were, fallow in your brain, allows for an alchemical maturation of the music and the voice which all singers I have spoken to experience, but none truly understand. Of course, one can learn a role in a hurry, but somehow it is never the same, never has the same depth of experience - in part, because it remains more intellectual, less fully embodied knowledge.

When learning a role the initial task is to read the text, making sure that I understand the libretto (sometimes not an easy task), and every word that is sung. If it is in a language I don't speak I will write a word-for-word translation over the top of the stave. Then I learn the notes, repeating each phrase so that the sound is right, solving all technical problems on the way, adding the text in last. This takes a long time and is very vocally demanding, so the learning of a role must be scheduled when there is not a lot of other singing in the calendar. Completing that part of my learning schedule, I take the music to a coach and sing it through to make sure that all the notes and rhythms are correct. Continuing with my own practice, I practise the emotional subtext and think about the emotional progression of the score. I usually then seek out a coach who is experienced stylistically with the particular composer who is able to give me coaching in a completely modern 
conception of "correct" Verdi and Wagner style. They may or not be able to comment on the diction and other linguistic concerns. If not, I find a language coach to check everything. Finally I memorise the piece, which is often relatively easy: with that amount of work the music and text are very well into the body, and virtually memorised already.

\section{Emotional connection.}

By manipulating musculature through the engagement of intrinsic and extrinsic muscles for each character, the sound is coloured by the singer's emotional reaction to the role. ${ }^{152}$ Though separate, engaging in an emotional connection and colouring a voice are intimately interconnected and the imagination of the singer provides the connection. Working through, and in some cases devising, the emotional subtext of a role is started when the text and music is in the learning stage. In the previous section I talked about the dramatic subtext, but I consider the emotional subtext as its own distinct aspect of a role: I often request students to write an emotional map of their character's journey. There are various methods for enhancing an emotional connection and all rely on the activation of the singer's imagination: the singer's relationship to the role, the connection to other characters, the connection to the audience. Some coaches suggest that the singers use a series of active verbs for each phrase, and insist on finding vocal colouring to suit. It seems that some singers are able to activate remembered emotions: we all have an emotional library of stored recollections. At times it is challenging to trigger those emotional connections and use them when you sing as they arouse emotions that may be difficult to control when singing or that make it difficult to control the singing itself. In my experience, though, artists develop those associations and use them to evoke a listener's response. ${ }^{153}$ The question of how much emotion is appropriate and in what

152 Cicely Berry, Voice and the Actor (London: Harrap and Co.,1973), 45.

153 See, for instance, the work of Antonio Damasio and others. The exploration of emotion in music is now a large area of research. See, for instance, Patrik N. Juslin and John A Sloboda, eds., Handbook of Music and Emotion (Oxford: Oxford University Press, 2010); Tom Cochrane, Bernadino Fantini and Klaus Scherer, The Emotional Power of 
way it should be shown in performance and on stage has been the number of recent studies, most particularly by Klaus Scherer; in his article, "The singer's paradox: on authenticity in emotional expression on the opera stage" he comments that,

... one should abandon the idea that actors should live through 'real emotions' on stage .... emotions are almost always regulated due to many different constraints .... the notion of 'natural' or uncontrolled emotion expression is practically unattainable .... for singers there is the constraint that the technical control of the voice required for their vocal performance could suffer. ${ }^{154}$

There is always the fine line between too much and not enough: the emotional authenticity needed on stage is hard to realise with conscious and deliberate control. Konstantin Stanislavski pointed out that the emotion must be worked through the body, so that people working with his "method" used conscious means to get unconscious results. ${ }^{155}$ Something similar is required with singers in the matter of technique; to be courageous and to sing on the edge of important emotions is engaging and gripping for the audience. But to overstep the boundary means a loss of technical control, which will immediately impact the vocal sound.

Music: Multidisciplinary perspectives on musical arousal, expression and social control (Oxford: Oxford University Press, 2013).

154 Klaus Scherer, “The singer's paradox: on authenticity in emotional expression on the opera stage", The Emotional Power of Music: Multidisciplinary perspectives on musical arousal, expression and social control, eds Tom Cochrane, Bernadino Fantini and Klaus R. Scherer (Oxford: Oxford University Press, 2013), 69-70.

155 Konstantin Stanislavki, An Actor Prepares (London: Methuen, 1988), 172. See also Mary Ann Smart, "Resisting Rossini, or Marlon Brando Plays Figaro, The Opera Quarterly (Vol. 27, No 2-3, pp 153-178), 156-158. 


\section{Acoustical awareness and response.}

Each acoustic space, particularly in a theatre, varies hugely. The major issue for singers to negotiate is the sound-changing and dampening qualities of the proscenium arch (the structure that frames the stage). Behind the arch, in the large space of the stage itself, it is very difficult to hear the sound from the orchestral pit. Increasingly most theatres now use an electronic system of foldback speakers, relaying the orchestral sound from the auditorium. Some theatres refuse to use foldback and then the singer cannot hear the orchestra very well. In these situations it is easy to push the voice through fear of not being heard, or to lose confidence as you are singing with no orchestral support. With foldback the singer needs to take care to follow the conductor, and sing slightly ahead of the heard accompaniment so that they are in time with the orchestra in the auditorium. The singer, using the Singer's Formant (a certain spectrum of harmonic frequencies around $3000 \mathrm{~Hz}$ unused by an orchestra,) also minutely adjusts resonance, projection, diaphragmatic energy, muscular energy and intent, capitalising on the acoustic possibilities of space. Indeed most singers unconsciously tune their voices to the acoustic as actors are trained to do, by listening to the ambient acoustic and the feedback they get in the venue from the sound they produce. ${ }^{156}$ The vocal production, the basic harmonic structure of the sound, should always be the same, and ingrained into the musculature. In addition all the aspects of vocal production that arise in the context of a particular role and are being negotiated in performance are individual to the role and the emotions played. If there is a reflective balcony for the circle level in a theatre, the singers will get an idea of the received sound they are making. Some theatres are so poor acoustically that they have had acoustical balancing systems installed, and have a technician to assist in that acoustical balancing. 157

\footnotetext{
156 See Michael McCallion, The Voice Book (London: Faber and Faber,1988),130. Most actors and singers will test the acoustics of the space before the performance, if possible.

157 For example LARES (Lexicon Acoustic Reinforcement and Enhancement) an acoustical enhancement system. This is not amplifying, but makes sure that there are no acoustically poor areas in the auditorium; it also gives the singers onstage a feedback from the auditorium.
} 


\section{Quality of presence/charisma.}

Singers are expected to have an ephemeral quality of presence or charisma. Exercising a mental projection of character is a requirement of someone who is a performer: some have that quality naturally, others have to work at developing it. The quality of presence develops with experience, and is, I believe, a form of vital energy. Stage performers often have a high personal energy, a force of character, a strong personal appeal, and emit magnetism. The psychologist Daniel Stern in Forms of Vitality, suggests that presence is more than just embodiment; he feels that it needs vitality intertwined with embodiment to enhance the presence, the "extra" happen in performance, that is, the force and temporal shape. ${ }^{158}$ As he says: "the difference between a technically adequate performance, and a transporting interpretation lies in the unique vitality dynamics that a great artist can bring to a work and transmit to an audience."159

\section{Activation of the articulators.}

To create the immediacy of the text, the articulators (the lips, teeth and tongue) must be set up on the "in" breath in the shape of the first vowel and consonant that will be sung as the breath turns around. Most singers will do basic exercises in early training which will educate their brain, lips, teeth and tongue in the minute and delicately controlled sequences needed for streams of words. Even so, there are languages or fast passages of text which require greater care and effort. Singing the faster sections of Salome required me to chant the text so I could get the words out fast enough, and then superimpose that on the pitches. The language of the text itself affects the production of voice, the word setting and emphases giving the music an individual character. The Czech language is notorious for the number of consonants and scarcity of vowels - once conquered though it is a very rewarding language to sing. The basic voice production is the same - the vocal resonator tract, supported by the extrinsic muscles ensures the stable vocal production - but

158 Daniel N. Stern, Forms of Vitality (Oxford: Oxford University Pres, 2010), 25-7.

159 Daniel N. Stern, Forms of Vitality, 27. 
the detailed movement of the articulators, reacting to the sound of the language, gives a particular resonance to each.

\section{Vocal fold activation}

To create the vocal sound, the last element in my Model of Embodiment is to close the folds, having carried out, or set up, the other elements to influence the sound. The body is trained to protect the vocal folds. Even in a grown man they are only the size of a small coin and they must be able to work cleanly without undue pressure and force, to provide a sound that has the full harmonics available. If the vocal folds become pressed and are adducted too hard, the sound becomes compressed and the voice tires too easily. To a listener the sound of the vocal folds pressed together produces a characteristic compression of the sound, and the harmonic structure is diminished. Teaching students it is imperative to ensure that the vocal folds, while supported and anchored within the vocal resonator tract, are able to move freely: the body is doing the work, not the vocal folds. If a voice is pressed for a long time it tires easily and eventually loses elasticity, and ages more quickly.

Opera singers have traditionally hidden behind the use of opaque language in describing their voices and what they do, using the excuse that they might lose the "magic" if they explain what they have learnt through tuition, intuition and experience. The balance is so difficult to achieve, and is such a complex combination of conscious control and entrained/unconscious processes that the feeling of many is that too much discussion endanger the "magic"-in a sense, this is a way in which many singers might well agree with Abbate's "drastic" view of performance. However, voice science is now proving what singers have learnt by instinct. Building on the turn to a more "scientific" approach of the midnineteenth century (such as Manuel García's discoveries), recent developments in the area and in neuroscience suggest a vocabulary that provides clearer explanations for the processes of both singing and listening to voice. ${ }^{160} \mathrm{~A}$

160 Manuel García, A Complete Treatise on the Art of Singing, ed. and trans. Donald V. Paschke (New York: Da Capo Press, 1975). For examples of the new approach see Johan Sundberg, The Science of the Singing Voice (DeKalb, Illinois: Northern Illinois University 
scientific vocabulary allows a singer and teacher to correlate metaphor, science and hearing to develop the foundation that provides the best possible vocal sound for that singer.

Without question, to have had a good training, singers must have excellent phrasing, legato, staccato, portamento, messa di voce, coloratura, ornamentation, accent and emphasis, and, most importantly for the communicative qualities of the voice, register, chiaroscuro and timbre. Chiaroscuro (light/dark) is used to refer to the balance of harmonic qualities in the voice; register refers to the different areas of the voice that are a result of changing vocal fold function as the voice moves in pitch. Elucidating these elements, Robert Toft in his book Bel Canto: A Performer's Guide, remarks that the practice of declamation was central to a bel canto singer's art (that is, the immediate antecedents of the prima donna assoluta in Verdi and Wagner), and much time was devoted to perfecting the blending of the tonal characteristics achieved. ${ }^{161}$ In addition to the essential technical exercises to achieve this technical facility, there was a need to cultivate a dramatic sense of the text. Declamation of the text at pitch allows for a quick and easy placement of the voice. In addition, there is a specific technical aspect of the spoken declamation: the increasing bodily involvement needed to project a spoken text leads to the use of a thicker mass in the vocal folds and optimal vocal tract resonance.

The connection between the spoken and sung word is vital for any singer. In my experience making that connection is essential to communication of the role. The practice of declaiming the text of the music (orating at pitch) enables a singer to access the quality of tone, inflection, emphasis and emotional content of the words without having to worry about the act of singing. In addition, the voice must "speak", it must contain a quality that should be present in the spoken voice of a dramatic rendering of text, the quality that can then be transferred into the

Press, 1987), and Ingo R. Titze, The Principles of Voice Production (New Jersey: Prentice Hall 1994).

161 Robert Toft Bel Canto: A Performer's Guide, 7. 
sung voice. ${ }^{162}$ A singer who has the ability to use the connection between singing and speaking develops their sound by the use of a stable lowered laryngeal position. The larynx is connected to the body, not the head-if that connection between body, spoken and sung voice is missing, I suggest that the emotional bond that has been set up between the singer and the listener is broken. While the physical connection between the parts of the body is widely understood, few seem to have noted that it is precisely when the connection between mind and body is missing that the emotional bond with the listener is broken. For young singers, not only do technical problems ensue, but I have found that without that fundamental connection between body, spoken and sung voice, students often fail to thrive vocally: without the body the voice does not develop and stabilise. Moreover, in my own experience, the work towards that integration has been vital in the context of virtually every role I have prepared, in facilitating the move from singing the vocal part to actually inhabiting the role, musically, dramatically and emotionally. Declamation requires intense bodily engagement to create the true emotional connection with the body. These attributes contribute then to the sound of all operatic voices, especially of the spinto and dramatic soprano. ${ }^{163}$ While emotional connection is important for all operatic voices, the roles that spinto and dramatic voices sing are usually intensely expressive and require a wide range of extreme emotions.

It interesting that the development in singing technique in teaching in the nineteenth century parallels the interest in developing this particular type of vocal timbre of the voice. In 1854 Manuel García II developed the laryngoscope, and once it became possible to see the human vocal folds, García verified his

\footnotetext{
162 A number of vocal pedagogues talk about training the singer to speak well in initial lessons, developing dramatic, "orating" level speech. See for instance James Stark Bel Canto: A History of Vocal Pedagogy (Toronto: University of Toronto Press,1999), 176; and Rodolfo Celletti, A History of Bel Canto, trans. Frederik Fuller (Oxford: Clarendon Press,1983), 31.
}

163 Spinto from spingere, to push. In voice classification this is a heavier voice with a rich timbre, but without the "metal" of the dramatic soprano category. As I will suggest in later chapters, it is this type of voice that has also tended to create such uninhibited devotion in its listeners. 
technical theories that in turn enabled him to further evolve his technique of singing. 164 The development of the use of the lowered larynx, in particular, as mentioned above, introduced the possibility of optimising vocal tract resonance, and darkening the vocal colour. It is the thicker mass of the vocal folds creating a heavier darker timbre, in combination with generally larger (but not necessarily overweight) bodies, which makes the vocal sound that many commentators call "Verdian" or "Wagnerian". The historical development of this aspect of the voice, when it became more commonly deployed and in what context, will be covered in Chapter Three. ${ }^{165}$

It is only in the last fifty years that the efficacy of certain singing techniques, intuited by most teachers from the sixteenth-century, have been shown by voice science to create harmonic structures in the vocal sound, such as the singer's formant. It is these particular aspects of vocal sound that are technically crucial for the development of the modern operatic vocal sound. The Singer's Formant is a concentration of harmonics around $3000 \mathrm{~Hz}$ which is not duplicated by other instruments: as the harmonic structure of the voice is not replicated by any other instrument, when a voice is singing with an orchestra, the voice will cut through the orchestral texture. Singers are trained to develop particular higher resonances in the vocal resonator tract, resulting in an increase in energy in the frequencies around $3000 \mathrm{~Hz}$, allowing them to be heard over an orchestra which peaks at $500 \mathrm{~Hz}$.

Combining the voice, body and breath in performance relies on a focused and calm state of mind. This state enhances links between certain areas of the brain and breathing control, and these connections in turn release tensions in the body allowing emotional content to be expressed in the voice, helping singers to carry out the complex process of singing. Neuroscientists, psychologists and

164 Manuel García, A complete treatise on the art of singing: complete and unabridged by Manuel Garcia II.; the editions of 1847 and 1872 collated, edited, and translated by Donald V. Paschke (New York: Da Capo Press, 1975, 1984).

165 A full history of singing is of course beyond the purview of this dissertation; in Chapter Three though, I will discuss in more detail the development of certain types of voice, and how they reflected or enhanced the compositional development of Verdi and Wagner's roles. 
other researchers in the emotional expression of music are now suggesting that arousing emotional empathy in others, as singers and actors routinely do, is dependent on activating brain synchronicities. ${ }^{166}$ Presently there is still some discussion as to how these mirror neurons work in humans; however, neuroscience is a fast advancing field and while at the moment scientists can only propose the emotional connections, it seems that further research will continue to provoke our understanding of the types of connections that for many of us seem instinctive. What is clear is that the mental processes required for efficient vocal practice use both implicit and explicit memory. Implicit memory is a form of long-term memory not requiring conscious thought and expressed by means other than words; explicit memory is long-term memory that is formed consciously so that it can be expressed in words. ${ }^{167}$ The development and use of these different kinds of memory provide, for Binnie, a contemporaneous analogue for Abbate's more academic terms, drastic and gnostic. ${ }^{168}$ The different ways the brain organises structures for processing and memorising complex many-layered procedures, lead to ideal performance states of flow.

The psychologist Mihalyi Csikszentmihalyi in his book Flow, says that when people are in flow "they are so involved in an activity that nothing else seems to matter; the experience itself is so enjoyable that people will do it even

\footnotetext{
166 See my previous chapter. Some of this work centres on mirror neurons, although that research is widely questioned: Jarrett, C.B. (2012). "Mirror neurons: the most hyped concept in Neuroscience? Psychol. Today" [Blog] http://www.psychologytoday.com/blog/brain-myths/201212/mirror-neurons-themost-hyped-concept-in-neuroscience; Mirror neurons and the research by Rizzolati and others has suggested that these neurons are the major factor in emotional connectivity: Giacomo Rizzolati and Corrado Sinigaglia, Mirrors in the Brain, trans. Frances Anderson (Oxford: Oxford University Press, 2006). For a full range of research connections with performance, with more reliance on Affect theory rather than mirror neurons, connecting music and emotion, see Patrik N. Juslin and John A. Sloboda eds., Handbook of Music and Emotion (Oxford: Oxford University Press, 2010) and Linda Phyllis Austern, ed. Music, Sensation and Sensuality (New York: Routledge, 2002).
}

167 http://www.sciencedaily.com/releases/2013/08/130807134512.htm(8 September, 2013. Quoted in Michele Binnie, "Finding the Drastic", 16.

168 Michele Binnie, "Finding the Drastic", 16. 
at great cost, for the sheer sake of doing it."169 For the performer "flow" is an optimum state for performance, diminishing stage fright and enhancing creativity, providing calm to balance the complex physical and mental engagement to create the operatic voice. In addition, the effect that rhythmical sustained breathing has on live performance and how it enhances communicative abilities and control nerves has been noted and discussed by singers. ${ }^{170}$ They recognise that long periods of singing alter one's perceptions: the chemical changes in the brain caused by deep constant breathing seem to facilitate neural connections across the brain, and can sometimes alter the singers' perceptions of their performance, as well as allowing for a deep emotional connection. ${ }^{171}$ Indeed, it is the complex role of the breath that brings together a number of conscious and unconscious physical and mental processes, making it the central hinge through which a singer negotiates her way through the complex modalities of the embodiment model I have laid out.

\section{The Breath}

Friedrich Kittler neatly sums up the importance of breathing for the drama and the music in opera: "The materiality of musico-dramatic data streams is based on the intensity of life in the diaphragm. That is why singing is the last and most important metamorphosis of breathing." 172 We breathe to live, and it seems facile to say that we breathe to sing. However, the breathing for singing is far from simple and does much more for the performing body than merely aerating it. Only one phenomenon is necessary in text and score, in drama and music -

169 Mihalyi Csikszentmihalyi, Flow: The Psychology of Optimal Experience (New York: Harper and Row, 1990), 4.

170 In my interviews and discussions with singers this is always a topic of conversation. Rhythmic breathing has connections to Eastern breathing practises and mind states. For an excellent discussion of the varying effects of breathing patterns see Breath in Action, Jane Boston and Rena Cook, eds. (London: Jessica Kingsley Publishers, 2009).

171 This is of course the basic premise of all meditative techniques.

172 Kittler, "World-Breath", 219. Kittler refers to the live performance of music as data streams. 
breathing. ${ }^{173}$ To sing operatic works one must not only produce a wonderful sound, but also have heightened and acute proprioceptive and kinaesthetic abilities to hear, monitor and modify the vocal sound made. The mind/body relationship is essential for peak performance and the breath is crucial in meshing the two together, anchoring the performance for the performer, to the moment. Operatic singers are pulmonary athletes and artists, and the voice we acquire is shaped not only by repetitive practise, but also by how great the desire is to communicate. The breath is a powerful creative and restorative force and the voice is the singer's principal means of communication; the information contained in the quality of the sound should invoke a response or reaction from the listener, draw them into the world of the text and imagination of the performer.

Roland Barthes in "The Grain of the Voice" is dismissive of the emphasis placed on breathing by singing teachers, saying that they assert that the whole of vocal mastery relies on correct breathing. ${ }^{174}$ In many respects Barthes is correct, but he is also wrong, for without the concentration to gain a fluid, reflexive breath which picks up emotional resonances from the body (for reasons I will explain further) a singer cannot sing efficiently, and so communicate all that they and the text has to offer. Barthes professes to like the sound of the body in the voice. His objection, I suspect, is thus more about the mechanics of singing: what he wants to hear is the end result, a voice with no obvious technical work:

The breath is the pneuma, the soul swelling or breaking, and any exclusive art of breathing is likely to be a secretly mystical art .... The lung, a stupid organ (lights for cats!), swells but gets no erection; it is in the throat, place where the phonic metal hardens and is segmented, in the mask where signifiance explodes, brings not the soul but jouissance. ${ }^{175}$

173 Kittler, "World-Breath", 219.

174 Roland Barthes, "The Grain of the Voice", Image Music Text (Glasgow: William Collins and Sons, 1977), 183.

175 Barthes, "The Grain of the Voice", 181. Jouissance is a French word deriving from the word jouir, meaning to have pleasure in. It is most often used in the literary criticism genre to mean a deep or extreme pleasure, physical or intellectual pleasure, delight or ecstasy. Signifiance: a term from Ferdinand de Saussure where he theorised that a sign has two parts; the sign and the one to whom the meaning is signified or conveyed. 
And yet to sing in the way that Barthes desires, in the way that communicates and touches people, requires the singer to have a technique that is imperceptible. The breath, then, in that way, is the meeting ground between the conscious and the unconscious. Indeed the invisibility of technique is a fundamental premise of classical singing, where a huge amount of bodily work is invested in singing while the work remains unseen by the listener. Barthes alludes to a dizzying number of practitioners who concentrate on breathing well, not only for the health benefits but also for good acting and singing. However, he does not acknowledge the public face of singing that requires a sustained effort to produce vocal sound that is fully supported by the breath, vital and moving, and that brings satisfaction to the listener and to the singer.

On a metaphysical plane, philosopher José Gil reminds us that the breath is more primitive than the voice, and is the basic stratum and condition for language:

What is body? It is speaking respiration. Respiration, breath, pneûma - these carry the unity of continuity in time, but not yet the unified spatialisation of this continuity ... being a permanent mediation, a modulating pathway between the interior and exterior of the body. It contains in itself the very possibility of expression (meaning). ${ }^{176}$

Gil's expression of the primary importance of the breath accords with the opera singer's focus: to breathe well is to sing well. Many Eastern philosophies and breathing methods have built good health and are not unlike the breathing required for good singing. Lucy Irigaray, the French philosopher, goes further, writing,

The practice of respiration, the practice of diverse kinds of breathing certainly reduces the darkness or the shadows of Western consciousness. But above all it constitutes the mental in a different way. It grants more attention to the education of the body, of the senses. It reverses in a way the essential and the superfluous. We Westerners believe that the essential part of culture resides in words, in texts, or perhaps in works of art, and that physical exercise should help us dedicate ourselves to this essential. For the masters of the East, the body itself can become spirit through the cultivation of breathing. ${ }^{177}$

\footnotetext{
176 José Gil, Metamorphoses of the Body, trans. Stephen Muecke (Minnesota: University of Minnesota Press, 1998), 192-193.

177 Lucy Irigaray, Between East and West: from Singularity to Community (New York: Columbia University Press, 2002), 7.
} 
To a singer, Irigaray recognises how the pattern of breathing that Eastern disciplines practise can allow the human body a glimpse of the "ineffable", the unknown, and that this Eastern concept is also applicable to the kind of breathing needed for operatic singing leading to pleasure for the singer and for the listener. ${ }^{178}$ It is also, I suggest, the connection to the uncanny and wild. An important teacher, Kristin Linklater, a leader in voice training for actors, combines both Eastern and Western teachings by connecting the diaphragm and solar plexus to sensitivity and emotional connection; the pelvic floor and sacrum to instinct and power (centre of gravity - centring); and the intercostal stretch (the muscles that bind the ribs) for capacity. ${ }^{179}$ This combination of Western and Eastern concepts is directly applicable to the art of singing and demonstrates how much the way one engages in breathing connects with a variety of concepts of the body-concepts that specifically challenge more traditional Western perspectives.

Breathing seems simple - you breathe in, then you breathe out. Without that flow of air we would die. Generally our breathing is under our unconscious control: the autonomous system in the brainstem controls the rate and depth of breathing according to the body's activity at any given time. When carbon dioxide levels increase in the blood, it reacts with the water in the blood to produce carbonic acid. This lowers the blood's pH level, as does the lactic acid created in any activity, and a message is sent via the receptors to the medulla oblongata and pons in the brain that in turn send a message to the diaphragm. With an intake of oxygen the gaseous exchange takes place and the cycle starts

\footnotetext{
178 Gary Tomlinson in Metaphysical Song (New Jersey: Princeton University Press 1999), 84-5, talks about the inspired practise of singing - resulting in the experience of the "noumenal". Carolyn Abbate also talks about the "noumenal" or "ineffable", following Vladimir Jankélévitch, in singing.

179 Kristin Linklater, "The Alchemy of Breathing", Breath in Action: The Art of Breath in Vocal and Holistic Practise, eds. Jane Boston and Rena Cook (London: Jessica Kingsley Publishers, 2009), 101-112, 102.
} 
again. Thus breathing is an interface between two areas of need: the organs and the level of movement. 180

This process sounds relatively straightforward and it is hard to see where the need for varying "methods" of breathing has arisen. Linklater puts the ideal breath management process succinctly and sheds some light on the matter:

Breath is the key to restoring the deepest connections with impulse, with emotion, with imagination and thereby with language. The voice is not just a musical instrument to be played skilfully - it is a human instrument. Reconditioning the way the voice works means reconditioning breathing processes on deep levels of involuntary neuro-physiological, psychophysiological, brain-body functioning. Any serious practice of breath and voice must bring to the level of consciousness activities that normally belong in the unconscious sector of daily being. 181

Conscious breathing has a long history of connection to the many forms of meditation, such as yoga. However, the controlled breathing for singing also involves considerable muscular process needed to sustaining the breath, and vocal sound. While I do not wish to attempt a large exposition on breathing technique, a brief overview of the process of breathing for operatic singing provides an explanation that elucidates my model of embodiment and its importance for efficient singing. Moreover, by pointing to the complexity between conscious/unconscious, mental/body, I posit a kind of bodily consciousness that is crucial for my later arguments.

Breath management in singers is critical, basic and fundamental to good singing and if the particular approach is often hotly disputed, the goal is always optimal function. The breath must always have airflow energy and the dynamic balance of that airflow and the low base of physical support. Classical singers obviously have special respiratory requirements and breathing efficiently for operatic singing requires an understanding of the important way that the breath affects vocal sound. Johan Sundberg, a leading voice scientist, suggests:

180 Blandine Calais-Germain, The Anatomy of Breathing, trans. Regine MacKenzie (Seattle: Eastland Press, 2006), 13-20.

${ }^{181}$ Linklater, "The Alchemy of Breathing", 102-103. 
the way in which the subglottic pressure (the air pressure underneath the vocal folds) is controlled by the respiratory muscle system may generate reflexes that affect activity in the laryngeal musculature ... Air flow (which, of course, determines air consumption) is entirely determined by subglottic pressure. And glottal resistance, the latter of which, in turn, reflects the degree of adduction activity.182

Singers often overpressurise the vocal folds, mistakenly thinking they will make a more timbred or louder sound and this over pressurisation merely results in a diminution of quality of sound. As James Stark in his book Bel Canto: A History of Vocal Pedagogy has written,

The constant interplay between breath pressure, glottal resistance, and vocal tract adjustments (especially the vertical laryngeal position) gives the singers the tools to vary the intensity and voice quality, and to sing with a seamless legato and without apparent register transitions. ${ }^{183}$

The attributes that Stark mentions come from the extensive and detailed training that a singer in the bel canto era underwent. Prominent and most valued of these attributes was a beautiful legato - the product of the most efficient breath management possible. Along with García's technical developments, these bel canto attributes were developed in the late nineteenth and early twentieth century, into the sound associated with the more powerful singing required for the operas of Giuseppe Verdi and Richard Wagner. ${ }^{184}$ (I will enlarge on these developments in technique and style in the next chapter.)

In teaching a young singer one is ideally setting the basics. Setting a singer up to breathe correctly in a physical sense is reasonably simple, given a sensitive student with good kinaesthetic feedback. The mechanics of conscious breathing for singing can cause movement in any part of the trunk of the body, but it is important to remember that the air only goes into the lungs. There are two types

182 Johan Sundberg, The Science of the Singing Voice (DeKalb, Illinois: Northern Illinois University Press, 1987), 25, 41. The glottis is an alternative name for the vocal folds, the vocal cords, the vocal apparatus, the vocalis muscle. Adduction is the contact between the vocal folds. The adduction needs to be just right for the breath pressure: too little and the folds blow apart, too much and the breath pushes too hard.

183 James Stark, Bel Canto: A History of Vocal Pedagogy (Toronto: University of Toronto Press, 2003), 120.

184 Stark, Bel Canto, 119. 
of movement for breathing: costal breathing that moves the ribs in and out; and diaphragmatic breathing that moves the diaphragm up and down, and by extension the stomach which moves when the viscera are displaced. The diaphragm and the muscle transversus abdominus are the primary inspiratory muscles. As the muscle that separates thorax and abdomen, the diaphragm, expands downwards to breathe in, and contracts upwards as air is used in lungs, creating a vacuum and on release of the muscle engagement, setting up optimum conditions for a fast recoil breath, vitally important as music frequently demands a quick breath intake.

The inspiratory and expiratory reserve volumes of the lungs are controlled in a way that is suitable to the music, the length of the phrases and to some small extent the volume of the vocal sound. The thoracic cage and intercostal muscles, alignment and pelvic floor muscles are all needed to maintain this controlled and extended action. The breath in is usually quick and must be unimpeded, and the breath out is extended and very even in emission. The term for this technique is appoggio, the balance between the inspiratory and expiratory breathing muscles. Stark, a singer himself, describes it as a form of vocal coordination, as an "elastic cushion" of pressurised breath just below the glottis. He adds that "the effect of appoggio on voice quality goes beyond chiaroscuro by adding a finely wrought buoyancy and malleability of colour and intensity to the voice, and by giving the voice 'projection'”. 185

Breathing problems in singing generally arise from emotional problems and disconnects - the metaphysical aspects of singing and communication in which many are insufficiently trained. Singers often talk about "freeing the breath" - but what does that mean? Traumas that an individual experiences are stored in the body as tension, and the breath is an important agent for repressing

\footnotetext{
185 Stark, Bel Canto, 119. The Italian terms used are standard to voice: to make an interesting and compelling sound one uses chiaroscuro literally light/dark, the appoggio is the delicate balance between the inspiratory and expiratory muscles. In the simplest sense, as you breathe out you are engaging intercostal muscles so that the ribcage does not collapse and is delayed in its release.
} 
and releasing those tensions. ${ }^{186}$ Defensive neuromuscular programming develops habits of mind and muscle that cuts us off from the instinctual connection between emotion and breath. Yet the voice cannot work to its true potential if the breath is not free. As long as we are emotionally protective our breathing cannot be free. As long as breath is not free the voice will depend on compensating strength in the throat and mouth muscles. ${ }^{187}$

Because of the heightened demands on the voice in operatic singing, especially in the "big" operatic sound represented in Verdi and Wagner, breath management must be as optimal as possible. As explained in the previous chapter, this in itself explains the need for a long training period for this type of singing - not only to acquire the technique, but also to build up muscle memory so singers can maintain their ideal vocal sound for up to two hours of singing. There is no doubt that the bodies that house such voices are built and developed in a particular way: most singers have "barrel chests" due to the constant expansion of the ribs and use of the intercostal muscles, the appoggio or rib antagonism. ${ }^{188}$ Breath hygiene to minimise the work of the vocal folds is essential, comprising a constant flow of air, legato as much as possible, and most importantly, a quiet intake of the breath. This allows the vocal folds to be relaxed when the breath comes in and prevents dragging the air through the folds, tiring and dehydrating them more than is necessary. Having said that, there will be moments in the score where a gasp of breath heightens the dramatic tension of the music. For example, Wayne Koestenbaum, in his essay on Maria Callas in The Queen's Throat, reminds us that, "Callas took in breath, audibly, as if she were gasping. She turned the

\footnotetext{
186 We are all subject to greater or smaller traumatic events from childhood, that reflect on the development of our personalities and any problems we may have. See Judith Herman, Trauma and Recovery (New York: Basic Books, 1997) for the classic account of the ongoing effect of trauma. There are a number of therapeutic methods that use body work to uncover and release underlying trauma: Feldenkrais is one such method.

187 Linklater, Freeing the Natural Voice, 22-23. Actors have training in place to free the body and breath, but I have not yet seen a corresponding emphasis in singer's education.

188 The thorax development has nothing to do with the weight and size of opera singers, another topic altogether, and subject of much discussion.
} 
need to breathe into an expressive opportunity."189 However, in her earlier recordings Callas has exemplary breath management, which deteriorated only as her health failed her. ${ }^{190}$

The reward of singing, in my own experience, is found in the cathartic and hypnotic rhythmic breathing which releases and engages the body as needed, bringing with it the over-oxygenated highs and a heightened thrill of performance, the result of a body and voice working synergistically. David Carey in "Transformation and the Actor", comments that breathing in, while of course a response to the body calling for oxygen, is also a physical desire to give voice to the person's thoughts and the pyscho-physical impulse to express an emotion. The breathing itself acts as a kind of creative motivation. The out-breath is then both the release of excess carbon dioxide, and the expression of thoughts and feelings. ${ }^{191}$ In a trained operatic singer the muscular activity engaged is different to that used when speaking normally or singing in an untrained way. It is more akin to an orator, or actor used to projecting in large spaces, thus the pertinence of texts for actor training and practise.

The operatic singer's process of embodiment in performance, discussed in depth earlier in this chapter, is challenging, and the many aspects contained within it can quickly overload a singer's neural processes. To facilitate the linkage between varying mental and physical layers, I suggest that the connecting process is the breath. Indeed, I propose that we can think about the intake of breath as the synthesis of communication between mind and body, as the unifying element that releases thought into the sound.

189 Wayne Koestenbaum,The Queen's Throat (London: Penguin, 1993), 146.

190 Callas' decline has of course been much discussed and debated, but that debate lies outside of the scope of this dissertation.

191 David Carey, "Transformation and the Actor: The Responsive Breath," Breath in Action: The Art of Breath in Vocal and Holistic Practice, eds: Jane Boston and Rena Cook (London: Jessica Kingsley Publishers 2009), 185-186. 
As we have seen, the mind generally has breathing under its autonomous control. However, in operatic singing, the mind consciously controls and edits the pattern of breathing according other effort involved on stage. A simple example of the change and development in breathing for optimum vocal sounds comes when a singer moves from the studio to the rehearsal stage. There, naturally, movement is involved, more vigorous in some cases than others. If there is any energetic walking, stair climbing or other movement to be carried out, then the bodily effort is increased and the breathing adjusted accordingly. Further, the increased emotional involvement in the rehearsal process often requires change in breathing patterns. It is a testing ground - there are times when the actions required by the director have to be sacrificed to the vocal requirements of singer.

Therefore, I propose that thinking about the breath is a way to engage methodologically with the full spectrum of embodiment I have laid out. An analysis of breathing and of the singer's conscious integration of the various levels of embodiment provide a fascinating way in which the singer's perspective can add an important element for detailed understanding of negotiating certain musical texts. Understanding then not only the physical process of the controlled breathing for singing, but also the psychological hurdles of release and control combined with the bodily release into breath, we begin to understand how a singer can manage the disparate task of the bodily engagement and facilitate the act of communication with the listener. This use of the breath is crucial in meshing together the elements of bodily engagement, the embodiment, and, because of its emotional connection to the body and mind of the singer, reflects on the quality of the sound that has meaning for the listener.

\section{The Complexity of Embodiment}

What research is discovering about memory and imagination, and how emotion, reason and physicality are inseparable in our brain's structure and function, can 
have significant implications on our understanding of performance. ${ }^{192}$ Applying the bodily, breathing and mental concepts to the practice of operatic singing can provide new insights into the fundamental connections between my practice as a singer, the body, the mind and its perceptions of the performance. Bringing these elements together in an ordered way is also crucial for the successful and affecting production of vocal sound. In many roles, the conscious ways in which the body is managed is central to the understanding of the character's place in the story. Combining these elements in a predetermined sequence brings certain enhancements to the vocal sound that suggests that the listener's enjoyment is amplified. Rebalancing elements as required, to change character, effect musical transitions, and minutely change the harmonic structure of the voice, can evoke the elusive effect of jouissance.

If James Davies' suggestion in Romantic Anatomies of Performance, of those "who dared to imagine what might happen when voice obeyed raw function alone, ... voices were unleashed to go their own way", was juxtaposed alongside the voices developing from García's technical developments, it seems that a new kind of voice, needing the intricacies of the bodily engagement and breathing emerged as the century ran its course. ${ }^{193}$ The "raw function" of sound, is, I suggest, an amalgam of a particular method of embodied communication of body, mind and emotion. ${ }^{194}$

The singer's imagination, which is of primary importance when devising a character on stage, can only be perceived in performance when it is manifested by movement, expression and sound. In defining what is communicated by the vocal utterance apart from the text and the music it is important to note that the perception of some of these features is dependent on a live performance. To be performing in, or to be present at a performance where the singer has combined

\footnotetext{
192 See, for instance, Rhonda Blair, The Actor, Image and Action: Acting and Cognitive Neuroscience (London: Routledge, 2008), xii.

193 James Q. Davies, Romantic Anatomies of Performance (Berkeley: University of California Press, 2014),92.

194 Gilles De Van, Verdi's Theatre, trans. Gilda Roberts (Chicago: University of Chicago Press, 1998), 49.
} 
all the elements of my model of embodiment, where they are totally in the "flow", is an extraordinary experience. My model has been drawn not only from my own experience but also that of my colleagues. A number of interviews confirmed that in training as a singer the number of gnostic requirements are large, and take time to embed in the mind and body. This studied and deliberate accretion of knowledge creates a powerful meta-drastic state, or, as I prefer to call it, embodied continuum. Further, as I will argue in the case studies of Chapters Four and Five, particular aspects of that experience, if we are attuned to it, can contribute directly to our understanding of a particular opera, and interact with our interpretation of text, music, staging and voice in essential ways.

How to manifest the singer's imagination and engage the power needed to create and portray a meaningful character becomes a matter of empirical knowledge, gained by experience, and the emphases will necessarily change from role to role. The challenging roles I have chosen as my case studies differ in areas of focus. Leonora concentrates on the vocal spectacle with an emphasis on the synthesis of body and voice. Kundry calls for a particularly complex engagement with the various aspects of performance: more than most operatic roles, a successful performance here requires explicit enactment of various facets of the character, to do with the body in particular. However, before turning to the detailed considerations of particular operatic characters, it will be useful to offer a broader comparison of how the music of both Verdi and Wagner calls upon the body in different and challenging ways. This broader discussion is the subject of the next chapter. 


\section{Chapter Three:}

\section{Verdi, Wagner and the Lowered Larynx}

Giuseppe Verdi and Richard Wagner are widely known for their transformative impact on operatic composition. Much less widely discussed, and arguably more important, is their impact on the style of operatic vocality. A comparative study of the vocality of these two composers provides a stimulating juxtaposition and poses a number of interesting questions relevant to my embodiment model. There is a considerable amount of critical literature surrounding the history and aesthetics of the two composers: indeed, comparison of Verdi and Wagner seems to spawn its own mini-field of musicology. ${ }^{195}$ However, there is scant in-depth discussion of their compositional processes for the voice and descriptions of the vocality; if the differences in singing the music of each are taken for granted by many practitioners, a clear elucidation of these differences should nevertheless be illuminating to both the singer and scholar.

In this chapter, I put this discussion in the context of a broad overview of some of the developments in vocal technique in the middle of the nineteenth century, that, I suggest, may have influenced the vocal composition of both composers. While my subject is not a detailed consideration of historical performance practice, nevertheless, the influence of certain aspects of these practices in the creation of the vocal qualities of the modern opera singer, and the vocal development of contemporary singers is instructive. Enlarging and explaining these ideas, I will move beyond theoretical conceptions to apply those technical concepts to the general vocality of Verdi and then Wagner. In conclusion, I will contrast the two styles of vocality and note similarities and differences in approaches, demonstrating how those demands are met, and touch on the elusive concept of jouissance.

Within the oeuvres of Verdi and Wagner there are obvious differences and developments in style in the use of the voice, but there are also useful similarities

\footnotetext{
195 See for example, Mario Pizzi, Verdi contra Wagner: Storia d'un amicizia segreto (Pizzi: Amazon Digital Services, 2014); Peter Conrad, Verdi and/or Wagner: Two men, Two Worlds, Two Centuries (London: Thames and Hudson, 2014); Dirk Böttger, Verdi +Wagner (Berlin: Pro Business, 2013).
} 
and characteristics that invite comparison. The case studies I pursue in this dissertation are connected directly to my experience of singing the roles on stage, and my own clear sense of the differences in the experience of the complex negotiation of embodied singing, that the two composers' operatic writing invites, or even demands. The choice for the case studies of two roles from each composer was deliberately provocative. While each illustrates for me some distinctive aspects of physicality in creating operatic characters, the historical position of these roles in relation to each other is also interesting and highly suggestive of how these two composers helped to encourage singers to embody their performance in essentially new ways by the way in which they wrote certain operatic roles. In addition, these roles exemplify the increasingly vital need for a more overt emotional expression through the vocal sound of this period which illustrates a clear movement towards a fully embodied continuum.

I have sung both the mezzo and soprano roles in Il trovatore, (an unusual experience today), which gives me a rare opportunity to compare both roles from the singer's standpoint. ${ }^{196}$ I will suggest, that both Azucena and Leonora appear to occupy crucial points in the development of Verdi's vocal style, in his move away from vocal spectacle towards the development of more unified dramatic and vocal entities. By examining each in turn I will show not only how the character is developed in certain ways, but also how the use of the breath, particularly in Leonora's role, for example, is crucial to her sense of creative authority. In turning to Wagner, I find the role of Sieglinde a fascinating transition from the traditional soprano role of providing the vocal spectacle, to a text-based vocal exposition set to music. Kundry, on the other hand, completely transforms the model of the traditional prima donna role and leaves vocal spectacle behind to move through multiple characters within the opera, each of which requiring significantly different levels of bodily engagement.

\footnotetext{
196 As will be explained shortly in relation to a "falcon" voice, my voice has a mezzo quality and a lower extension: hence I sang Azucena until I gained the body strength and stamina to sing Leonora. In contrast, singers tend to sing Leonora first then move on to Azucena as they age.
} 
Like many professional singers, I have been called upon to sing roles from Verdi and Wagner throughout my professional life. In singing these roles there is usually a vocal and career progression, moving from smaller roles of both composers to larger roles for Verdi, then adding in the larger roles of Wagner. It is fair to say that once you start singing the largest Wagner roles of Brünnhilde and Isolde consistently, the vocal mechanism develops a strength and muscularity that makes it then difficult to sing most Verdi roles with the expected nuances. Naturally this versatility in physical capability varies from singer to singer, each with their unique voice and character.

The development of compositional style of these two composers in the context of the history of singing at the time when vocal technique adapted to both singer and composer, has a fascinating synchronicity. Whereas most midnineteenth-century composers wrote for singers within the capabilities of the singers with which they were familiar, Verdi and Wagner created a hothouse for technical development of the voice in opera by challenging their artists both vocally and dramatically. Wagner, very much influenced by the performances of Wilhemine Schröder-Devrient, wrote, it seems, for his ideal singer. ${ }^{197}$ That their compositions pushed the boundaries of musical and dramatic interaction in part explains why the music of both Verdi and Wagner was initially claimed to be voice wrecking: Verdi was called the "Attila of the Voice" and Wagner's singers complained bitterly about the length of his operas. ${ }^{198}$

The driver for changes to operatic vocal technique over the past one hundred and fifty years - in part in response to the vocal demands created by

197 Thomas S. Grey, "Wilhelmine Schröder-Devrient and Wagner's Dresden”, Richard Wagner and his World ed. Thomas Grey (Princeton: Princeton, 2009), 201-229.

198 Rodolfo Celletti, History of Bel Canto (Oxford: Clarendon Press, 1991, 1977); Verdi also remarked in a letter to Salvarore Cammarano (May 3 1844) that "I am accused of liking a lot of noise and neglecting the singers" (Verdi: The Man in his Letters, ed, Franz Werfel and Paul Stefan (1942)(New York: Vienna House, 1973), 109; Richard Wagner, Actors and Singers, trans. W. Ashton Ellis (London: University of Nebraska Press 1995) 209. Wagner was horribly upset by the early death of his favourite tenor, Ludwig Schnorr a few weeks after the premiere of Tristan und Isolde, and especially as many people attributed the cause of his death to the overwork of singing the extremely long and taxing role of Tristan. 
Verdi, Wagner, and Puccini - can be simply put: to sing better and louder for longer. Physiologically the voice of good quality is one that has vocal folds with symmetry, good vocal fold closure and a symmetrical muscular engagement. ${ }^{199} \mathrm{~A}$ good vocal technique is one that enables the singer to sing taxing repertoire for a considerable time, and exhibit stamina with no loss of vocal quality throughout their range. ${ }^{200} \mathrm{An}$ "international" quality voice, as judged today, is one that has an interesting timbral quality, can make good quality sounds throughout the pitch range, and at volume. That is the ideal, but naturally there are successful exceptions - singers who have unexceptional voices but use them in highly musical and communicative ways; or singers with exceptional voices that are uneven through the range or unstable at the top of the voice. ${ }^{201}$

The previous chapter sets out a number of criteria that, in my experience, are needed to successfully sing certain operatic roles. This chapter will place these criteria in the context of some of the major developments in vocal technique from the mid-nineteenth century. Modern vocal technique - and in particular, the kind of vocal technique broadly associated with the singing of Verdi and Wagner - relies on a very particular kind of interaction between mind and body. ${ }^{202}$ Indeed James Q. Davies in Romantic Anatomies of Performance implies that the Romantic movement of the nineteenth century is all about the body: "The 1820s were pivotal in the processes of physiology, to the physical organisation of the brain-mind and the materiality of consciousness and emotions. Important vocal changes were taking hold and alternate schooling

199 Professor Paul Farrington, private conversation.

${ }^{200}$ It also helps one to sing even when you are sick and makes for fewer cancellations of performances.

${ }^{201} \mathrm{~A}$ beautiful voice is not necessarily the voice that moves and communicates with people; in my experience people with beautiful voices can tend to rely on the beauty only and often neglect the communicative effort. Prime donne Maria Callas and Renata Tebaldi are good examples of voices that had technical imperfections by today's standards. Interestingly, it is much easier to record a beautifully modulated voice.

202 In addition it is important to understand that not only have the bodies of female singers changed - corsets are no longer obligatory, but also diets are better and medical treatment superior, resulting in healthier, stronger bodies. 
methods were being tested across Europe."203 It is, I suggest, the interaction of the mind and body and the development of the body's strength, called for by the developing vocal technique of Verdi and Wagner's vocal music, that led to the modern conception of sound in contemporary voices that specialise in Verdi and Wagner. This change, including the blending of various "voices"- chest, head, falsetto, feigned, etc - into one voice, and the scientific discoveries of the times, drew the focus on the voice from the mouth into the interior of the body, to the glottis, the vocal folds. ${ }^{204}$ In order to articulate these advances and place them in context with Verdi and Wagner, an overview of the teaching of singing technique will allow me to suggest how the technical advancements required for increased and sustained use of the body were successfully maintained.

Singing technique and the teaching of singing have been a hotbed of debate, alive, as Robert Stark says in Bel Canto: A History of Vocal Pedagogy, with inquiry and controversy. ${ }^{205}$ Although I am interested in the technical developments of the nineteenth century, any examination of vocal technique needs to recognise the foundation provided by those earlier vocal treatises written by the Italian teachers who were often performers, castrati themselves, or who had had castrati as their teachers. Castrati were often placed in singing schools with a very exacting routine consisting of years of vocal exercises, and other musical

\footnotetext{
203 James Q. Davies, Romantic Anatomies of Performance (Berkeley: University of California Press, 2014), 19.
}

204 James Q. Davies, Romantic Anatomies of Performance, 125, 129-132. In addition the scientific discoveries cleared up the notion that a human body had a different glottis for each different voice. Indeed as Davies says "there was a time when the best performers in Europe cultivated any number of voices; head voices, chest voices, feigned voices, flautino voices, white voices, falsetto voices, half voices, mixed voices, medium voices, nasal voices, inspirited voices, covered voices ..." 127. I have written elsewhere about the chest voice and the uniting of the vocal registers. Conference presentation, "If you've Got it, Flaunt it: Chest Voice revealed". (New Zealand School of Music, Music Forum, 14/8/2015).

205 James Stark, Bel Canto: A History of Vocal Pedagogy (Toronto: University of Toronto Press, 1999). Stark goes on to say "Authors on singing have ranged from geniuses to fools, and have included voice teachers, singers, critics, voice buffs and musicologists." (xii).This, I suggest, is a fair assessment of the worth and usefulness of much of the material. 
tuition, including a thorough grounding in other aspects of music. Their rigorous training was highly influential and continued to influence vocal development long after their decline despite the context of wildly shifting aims and contexts.

Generally, the vocal teaching prior to the nineteenth century promoted the vocal characteristics that are today largely attributed to the tonal concept of the "Italian style" of singing, for example: legato, sostenuto, facility in coloratura and unification of the vocal registers. ${ }^{206}$ This style was exported all around Europe and held up as a paradigm: even in Mozart's day, this form of Italianate opera singing was the model. James Stark comments that most of these earlier treatises stay firmly within the confines of technical exercises. ${ }^{207}$ These texts require specialist knowledge to interpret, and while there are many explanations of stylistic considerations, expectations of ornamentation and crucial issues about treatment of text and of rhythm, there is no explanation of how one makes the sound.

206 Vocal treatises from the period before Manuel García II include: Giulio Caccini Le nuove musiche, trans. H. Wiley Hitchcock, (translation from Caccini 1602) (Madison WI: A-R Editions, 1970); Giovanni Camillo Maffei, Delle lettere ... libre due, un discorso della voce e del modo, d'apparar di cantar Garganta senza maestro, 1562, trans. in Carol MacClintock, Readings in the History of Music in performance (Bloomington: Indiana University Press, 1979); Giambattista Mancini, Practical Reflection of Figured Singing: The Editions of 1774 and 1777, trans. and ed. Edward Foreman (Champaign, Il, Pro Music Press, 1967); Vincenzo Manfredini, Regole armoniche,o siano precetti ragionati apprendere i principi della music (Venezia, G. Zerlotti, 1775); Pier Francesco Tosi, Opinions of Singers ancient and modern, or, Observations on Figured Singing, trans. Edward Foreman, translation of Tosi 1723 (Minneapolis: Pro Music Press 1986); Johann Adam Hiller, Treatise on Vocal Performance and Ornamentation, trans. and ed. Suzanne J. Beicken, translation of Hiller 1780 (Cambridge: Cambridge University Press, 2001). Interestingly Mathilde Marchesi (1821-1913), renowned teacher and student of García II when asked if she felt that bel canto was a good "method" of singing, famously said that, in her opinion, there was only good or bad singing. Richard Miller in National Schools of Singing (Maryland: The Scarecrow Press, 1977) lays out the differences in techniques in different European countries, and notes that the focus of the teaching in each country, led to differences in the vocal sound.

207 Stark, Bel Canto: A History of Vocal Pedagogy, 93-95 presents an excellent overview of the early treatises, as does Berton Coffin's Historical Vocal Pedagogy Classics (Maryland: The Scarecrow Press, 2002); The messa di voce is where the singer crescendos and diminuendos on a single note, with a perfect tone balance; fiorature are the fast runs and figures, needing much practise. As they were not written in the score, the exercises were often added by the singer; hence the singer needing musical training for the creation as well as execution. 
Pier Francesco Tosi was the first vocal pedagogue to advocate register blending along with an extended training for singers, and his vocal methods outlined in Opinioni dé cantori antichi e moderni osieno osservazioni sopra il canto figurato (1723) were highly influential and often mentioned in subsequent treatises, as John Rosselli has reported. ${ }^{208}$ Manuel García II (García fils) in A complete treatise on the art of singing of 1854, specifically built on Tosi's work, especially in the blending of vocal registers. Around the same time as García's book a number of other well-known treatises were published: those of Lamperti (1864), Leone Giraldoni ( 1864), Panofka (1866) and Delle Sedie (1874), all of whom also built on Tosi's work. ${ }^{209}$

While the other pedagogies, treatises and approaches are interesting, it is the influence of the Garcías - Manuel García I (1775-1832) and Manuel García II (1805-1906) - that interests me here. Manuel García I was an eminent tenor and well-known voice teacher, particularly of his son, Manuel García II, daughters Maria Malibran and Pauline Viardot García (both famous singers), and well known tenor, Adolphe Nourrit. ${ }^{210}$ However, it was Manuel García II (García fils) who became famous by developing and improving upon his father's vocal exercises and investigating the physiology of the larynx and vocal tract in hospitals in his employment with the French Army. Teresa Radomski has suggested that, although Dr. Benjamin Guy Babington (1794-1866), along with physiologists Czermak and Türck, has recently been credited with inventing the laryngoscope, García contributed to the invention by developing the use of the mirrors to understand the physiology of the singing voice, especially his own. ${ }^{211}$

208 Pier Francesco Tosi, Opinioni dé cantori antichi e moderni osieno osservazioni sopra il canto figurato (Bologna: Lelio dalla Volpe, 1723),Observation on the Florid Song, trans. J.E. Galliard (London: Wilcox, 1743).

209 John Rosselli, Singers of Italian Opera: The History of a Profession, 107.

210 April Fitzlyon, The Price of Genius: Biography of Pauline Viardot García (New York: Appleton Century, 1964); Berton Coffin, Historical Vocal Pedagogy Classics (Maryland: The Scarecrow Press, 2002) 12-18.

211 Teresa Radomski, "Manuel García (1805-1906), A Bicentenary Reflection", Australian Voice (Dec 2005, Vol 11, pp 25-41). Radomski provides a full discussion of García's achievements and technical refinements. 
García published observations about his own larynx and vocal process as seen by the judicious positioning of two mirrors to see his vocal folds, thereby predicating the laryngoscope. ${ }^{212}$ In addition, he was a very successful and influential teacher: some of the operatic stars of the day were his students including Jenny Lind, Mathilde Marchesi, Julius Stockhausen and Sir Charles Santley. Many of the singers he trained went on to become successful teachers: Mathilde Marchesi, for example, was first a famous singer, then prominent teacher, and also the author of a famous and effective vocal method. ${ }^{213}$

García fils and his method of singing, along with a number of other approaches of the time, both contributed to and responded to some of the biggest shifts in operatic singing conventions, and, I suggest, fundamentally changed the ways in which body and voice worked together. As the era of the castrato declined, changing the concept of the operatic body, the concept of dividing operatic roles into soprano, mezzo, tenor, baritone and bass became the norm and there was a realigning of gender assignment to roles. This development encouraged composers to start evolving specific voice types, linking them to certain sorts of characters. Rossini, Bellini and Donizetti promoted vocal characterisation and while they are known for the coloratura demands of their roles, there was a gradual movement towards more sustained singing. Although it is unclear if the new type of voices developing were important in inspiring the composition of new roles, the new type of vocal production, particularly for high notes, required singers to rework their mind/ body balance to sustain the pitch with a full sound.

As an important example, the development of the role of the tenor and the reception to the changed tenorial sound allows us to see how some voices adapted to the demands. Gilbert Duprez, the tenor who is reputed for first

212 Berton Coffin, Historical Vocal Pedagogy Classics, 19-23; Manuel Garcia, wrote four books: Mémoire sur la voix humaine" compte-rendus des Séances de l'Académie des sciences (12/5/81) (Paris: Duverger, 1847); 1840 École de García: traité complet de l'art du chant (A Complete Treatise on the Art of Singing $(1847,1872)$ trans. Donald Paschke (New York; Da Capo Press, 1975); $18472^{\text {nd }}$ Edition, École de García: traité complet de l'art du chant (addition of Part Two); and to clarify some of his earlier points, Hints on Singing, London, Chappell, 1911).

213 Mathilde Marchesi Bel Canto: A Theoretical and Practical Vocal Method (New York: Dover, 1970). 
singing the do di petto (chest voice high C) in public, had first used his high $\mathrm{C}$ in 1831. The sound was so well received that it spurred others to develop their technique to copy him. ${ }^{214}$ Duprez's achievement is surrounded by controversy: John Rosselli in his book Singers of Italian Opera: The History of a Profession mentions that several tenors before Duprez were said to have sung high notes in "full voice" or "from the chest". 215 What was clear though was that Duprez was an excellent Italianate singer, with very good dramatic delivery, and he used a lowered laryngeal position to great effect, along with a firm phonation and an expanded pharynx. Explaining the technicalities and mechanics of this developed vocal production, Radomski says,

Today we know about formants and their contribution to vocal quality. García's observation of the timbres corresponds to formant energy. The sombre timbre, with its lowered larynx, results in lower formants and a "dark" vocal color. It also contributes to the "singer's formant", or resonance peak around $2800-3200 \mathrm{~Hz}$ - the "ring" in the voice. The sombre timbre, with its lowered larynx and expanded pharynx, extends the upper chest register by causing the thyroid cartilage to tilt backwards, a position that facilitates the contraction of the cricothyroid muscle. This reduces the length of the vocal folds, thereby delaying the register shift and permitting active longitudinal tension to function beyond its normal limits. The pitch can now be raised by an increase of the internal tensors of the vocalis muscles, thus reducing the effective mass while avoiding the maximal length and tension of the chest register. ${ }^{216}$

214 There a number of people who disliked Duprez' high C including Rossini. He had heard Duprez in a private performance and said it was "like the squawk of a capon having its throat cut", Henry Pleasants, The Great Singers: From the Dawn of Opera to Our Own Time (New York: Simon and Schuster, 1970), 167.)

215 John Rosselli, Singers of Italian Opera: The History of a Profession (Cambridge: Cambridge University Press, 1992) 175-6.

216 Teresa Radomski, “Manuel García (1805-1906), A Bicentenary Reflection”, 18. Quote from García, Complete Treatise on the Art of Singing: Part One, xxix-xxxii. Interestingly, García II's first work, Mémoire sur la voix humaine, was only presented to the Académie des Sciences in 1840, after Duprez's usage of the lowered larynx. The technique used by Duprez was described to the Académie des Sciences by the French biologists Diday and Pétrequin in 1840, seven months before García's "Mémoire sur la voix humaine" was submitted, and therefore they received credit for observations that García had already made. However, a letter that was later read to the Académie stated: "Mr. García established that the lowered and fixed position of the larynx has been known to him since 1832 , and that since that time he has not stopped propagating that fact by teaching it to all his students." 
Though Duprez, to some ears, had a very good integration of his registers through to the head voice, which would have facilitated a mixed (in contemporary terms) and full sound for a high $\mathrm{C}$, others felt that the balance between the registers was in favour of the lower timbres and compromised the nuance of the sound.217 This had the effect of the voice sounding pushed, in extremis if you like, and certainly Duprez felt that the sound he made somehow unleashed his primitive, masculine self, perhaps by utilizing his body in a different, more extreme, way. ${ }^{218}$

Other events may have had some influence on the development of Manuel García II's vocal methods. His father had pushed his natural baritone into singing tenor roles, thereby damaging and weakening his voice. His attempts to find Italian teachers ended in failure, and his diversion into learning vocal pedagogy and thence to teaching can be seen as a reaction and desire to know about his own voice.

Adolphe Nourrit, a former student of Manuel García I, was somewhat outshone by his colleague Duprez, and spent the rest of his life trying to take the colour of the chest voice (called voix sombre) unsuccessfully up to his high C. Nourrit, also sick with liver disease and depression, committed suicide in 1839 after weakening and damaging his voice pursuing his goal with lessons with Giovanni Battista Rubini and Gaetano Donizetti in Italy. ${ }^{219}$ While it is problematic to attempt any sort of diagnosis at this distance as to the reason why Nourrit's voice failed to stabilise a timbred high $\mathrm{C}$, it is known that he had a falsetto/voix mixte range through the male upper passaggio to above the high $\mathrm{C}$, in itself quite

217 For a full and extremely interesting examination of Duprez' voice see Gregory W. Bloch's article "The pathological voice of Gilbert-Louis Duprez" in the Cambridge Opera Journal, (Vol 19 Issue 1,11-31, 2007). Bloch maintains that Duprez' small stature did not give him the muscularity to sustain such a sound that partly explains the shortness of his career. James Q. Davies, in Romantic Anatomies of Performance (145), suggests that Duprez's registers were not as blended as they could be.

218 James Q. Davies, in Romantic Anatomies of Performance,180.

${ }^{219}$ Nourrit also had a number of other ailments including liver disease and depression that would have contributed more to the reason for his suicide. Sarah Hibberd and Evan Walker "Adolphe Nourrit" The New Grove Dictionary of Opera, ed. Stanley Sadie (Online version 2009, accessed 5/3/2015). 
rare. It seems possible from his inability to secure the colour of the voice that either he was not activating his muscles in a correct way, or his vocal folds were not heavy enough. In addition, the rapid termination of the career of one of his famous students, Marie-Cornélie Falcon (1814-1897), seems to suggest that he had an imperfect understanding of how the body protected and enhanced the colour of the voice.

Falcon's voice was an unusual one and she was, at 13, scarily young (by today's standards) to sing the roles she was offered. Falcon even at the age of 18 (at the time of her debut), had an unusually coloured voice: it was a full and resonant voice with an especially dark timbre and she was an excellent actress. ${ }^{220}$ Sadly her career was cut very short at the age of 23 with a dramatic loss of voice onstage during a performance of Niedermeyer's Stradella; Berlioz, attending the performance, reported her losing her voice suddenly and making ghastly croup-like, guttural and whistling noises. ${ }^{221}$ According to Professor Paul Farrington, this vocal injury is consistent with a vocal haemorrhage brought upon by overwork. Complete voice rest is needed for a number of months then a careful rehabilitation is required. It seems that Falcon did not follow these measures. ${ }^{222}$ In the centuries since, the term "falcon" has come to designate a hybrid voice of a mezzo and dramatic soprano: able to sustain long legato lines and execute large leaps and sustain high notes.

It seems therefore very possible that Manuel García II in his second book École de García: traité complet de l'art du chant (1847) had been influenced by these vocal events quite close to him. His vocal methods had also been challenged by two medical doctors as well as other singers and teachers;

220 Philip Robinson and Benjamin Walton The Grove Book of Opera Singers, ed. Laura Williams Macey (Oxford: Oxford University Press 2008), 150.

221 Quoted by Charles Bouvet in Cornélie Falcon (Paris: Alcon, 1927), and reproduced in Mary Ann Smart's "Roles, reputation, shadows: singers of the Opéra, 1828-1849, The Cambridge Companion to Grand Opera, ed. David Charlton (Cambridge: Cambridge University Press, 2003), 116.

222 Professor Paul Farrington, Clinical Voice Consultant for the NHS, UK for 17 years. Private email 11/01/15. 
specifically his terms coup de glotte, a firm glottal closure, and the "pinch of the glottis" concept, were subject to much misinterpretation and he wished to clear his name. ${ }^{223}$ Importantly for the female voice and essential for the sound required in Verdi and Wagner's vocal music, he states that the chest register is an essential part of the female voice as well as the male. ${ }^{224}$

While the chest register is the modal voice, the speaking register for a man, it was seldom used by women. Women's voices are naturally inclined to the head voice and the brilliance it gives, and to use the female chest voice consistently needs more strength in the body. Working out that there were three vocal registers (chest, middle and head), García also added the concept of two timbres, light and dark. He also talks about the importance of the shape of the pharynx, and the lowered position of the larynx to attain the lower harmonics in the sound - the position that would achieve the dark colour of the voix sombre..$^{225}$ He devotes a large section to the use of the sustained tone: canto spianato. The legato and sostenuto of the canto spianato requires extra bodily engagement. However the articulation of this extra effort is ignored; García does not detail how the body needs to protect and support the small muscles that carry out those tasks in the neck and throat. ${ }^{226}$ Part of the colouring that Verdi and Wagner seemed to prefer was most of all García's concept of the lowered larynx, and consequently enlarged pharynx. These had a substantial influence on the way the body was used and on the nature of the vocal colour.

223 Paul Diday and Joseph Petréquin published "Memoire sur une nouvelle espèce de voix chanté" in Gazette médicale de Paris (16 May 1840). Quoted in Gregory W. Bloch's "The pathological voice of Gilbert-Louis Duprez," 11.

224 Berton Coffin, Historical Vocal Pedagogy Classics, 20. It is now generally accepted that there are two registers, the chest and the head, with the middle a mix of registers: this can be called the middle voice, voce mista, or in the past, the falsetto. A major problem with historical vocal pedagogy is the mutability of classifications and descriptors, leading to a considerable amount of confusion and disagreement between voice professionals about the application of current terms to writings from the past.

225 Manuel García, A Complete Treatise on the Art of Singing Part 11, 151-162.

226 Manuel García, A Complete Treatise on the Art of Singing Part 11, 186-91. 
The literature concerned with the changes to the male voice and the gradual rise of a different type of voice across the nineteenth century is varied; what is interesting is exactly how these technical developments manifested themselves in women's voices. The small but important changes in vocal production were, it seems, already being attempted by singers Duprez and Nourrit, and may be relevant to such singers as Maria Malibran and Pauline Viardot Garcia. However, though we have no evidence of similar experiments with the female voice, there is some suggestion that in fact, in the context of the new dominance of female singers after the disappearance of the castrati and before the development of the dramatic tenor, some well-known female singers' vocality was indeed based on the function of their lower, chest register. ${ }^{227}$

The prevailing female voice type before the advent of Verdi was the coloratura, a voice with high notes and an ability to move at speed and with ease. Interestingly though, most prominent female singers of the time had dark coloured voices and are described as contraltos, or as having a substantial dark timbre with a brilliant top to the voice. Singers such as Wilhemine SchröderDevrient, Marie-Cornélie Falcon and Maria Malibran (García's sister, taught by their father and himself) were most often described as contraltos. ${ }^{228}$

The key technical attribute of these women singers was that their registers were mostly blended or that they could manoeuvre through the register changes with considerable dramatic import. When the register blending worked well they were able to sing both soprano and contralto roles. Wellschooled in technique, though wild as an artist, Malibran had, as James Davies writes, "a way of altering her tone timbrally, shifting between registers and shading them to suit her part."229 She reportedly had the ability to follow the

227 John Rosselli Singers of Italian Opera: The history of a profession (Cambridge: Cambridge University Press, 1992), 68.

228 Maria Malibran is described as an unrivalled contralto in Manuel García, A Complete Treatise on the Art of Singing Part 11, vi, and a mezzo soprano elsewhere. She sang both soprano and contralto roles, en travesti, and definitely male roles and had an extraordinary range. See Susan Rutherford The Prima Donna and Opera 1815-1930 (Cambridge: Cambridge University Press, 2006), 243, 215 -217.

229 James Q. Davies, Romantic Anatomies of Performance, 88. 
teachings of her father and to alternate between a sombre (or covered) tone where the larynx remained fixed, and a clear sonority where the larynx followed the voice on its ascent. ${ }^{230}$ Malibran was excellent at moving between registers and I suspect that it was the way she manoeuvred her voice around the higher areas that made her so well-known in coloratura roles. However when it came to the more dramatic roles, my experience leads me to suspect that she would have blended those registers as a matter of vocal survival: a large change in vocal colour is not necessarily a register change. Marie-Cornélie Falcon's voice appears to have been similar: with a strong lower register and a silvery voice with a brilliant timbre, the sound emitted with force never lost its charm or purity. ${ }^{231}$ Moreover, some singers exploited those powerful tones and made a feature of a difficult, unblended voice; when Stendhal tried to explain his fascination with Giuditta Pasta's voice, he ascribed it to the laws of nature - the power of the operatic voice as a scientific fact: "A heretofore unknown blend of physical effects, to take power over the souls of the listeners with the speed of a lightning flash."232 By "physical effects" he meant that, to him, she possessed two utterly different and contrasting voices: that she alternated between head notes and chest notes. ${ }^{233}$ Whether this is a description of poor technique or a very marked change in vocal colouring is unclear, and it may have depended on what she was singing; however I suspect the latter, as the lowered larynx can alter a voice's colour substantially. ${ }^{234}$ Of course, there are circumstances where a singer needs to make abrupt changes in register, and, depending on training and flexibility, may need to make a noticeable "gear change". The lower voice, the chest resonance is particularly susceptible to losing the blend through the registers.

\footnotetext{
230 James Q. Davies, Romantic Anatomies of Performance, 89.

${ }^{231}$ Quoted by Charles Bouvet in Cornélie Falcon (Paris: Alcon, 1927), and reproduced in Mary Ann Smart's “Roles, reputation, shadows: singers of the Opéra, 1828-1849, The Cambridge Companion to Grand Opera, ed. David Charlton (Cambridge: Cambridge University Press, 2003), 116.

232 David Charlton, ed., The Cambridge Companion to Grand Opera, 116.

233 Naomi Andre, Voicing Gender, 140-1.

234 James Q. Davies, Romantic Anatomies of Performance, 89.
} 
Johan Sundberg in The Science of the Singing Voice talks about the chest register as being characterised by lower pitches and more relaxed thicker folds than higher pitches. ${ }^{235}$ Alternatively called "heavy mechanism" or voce di petto, today voice scientists talk of a two-register concept of vocality, and prefer to talk about chest resonance: the lowered larynx for lower pitches has more muscular contact with the thoracic area, transmitting vibrations into the chest, hence the misunderstanding. The vocal folds are thicker, but the larynx is tilted to maintain vibrato and what is called voce di mista. This is the safest way to sing in the lower voice, and many female singers mix successfully but absolutely refuse to entertain the idea that they are using chest voice. ${ }^{236}$

Female singers in general were in a disadvantaged position at that time, and needed to earn as much money as they could to ensure they were financially secure; overwork was a problem and, indeed, was an inevitable consequence of the operatic industry of the day. ${ }^{237}$ In addition, women wore corsets, never very good for the body in general and particularly problematic when trying to sing; medical care was poor, with child bearing risky at the best of times. Moreover most of these women started their careers very young, singing major operatic roles in their late teens. With contemporary eyes it seems that these women had no opportunity to mature physically, let alone concentrate on building up bodily strength to protect their voices. Susan Rutherford points out the clear contradiction between the portrayal of femininity on one hand, and the quite unfeminine resources of physical strength and stamina needed for the portrayal of opera roles on the other. This seems to be corroborated by the fact that, as vocal technique was developing and advancing, so many divas had such short

\footnotetext{
235 Johan Sundberg The Science of the Singing Voice (Illinois: Northern Illinois University Press, 1989) 50-55.

236 Stefan Zucker's film Opera Fanatic contains interviews with Giulietta Simionato and Fedora Barbieri, both of whom vehemently deny that they use chest resonance. The use of open chest (with no laryngeal tilt) is discouraged in operatic singing as it sounds uncouth and tires the voice very easily. I suspect that this is the sound that people associate with chest voice and have an objection to. See Robert Stark Bel Canto: A History of Vocal Pedagogy (Toronto: University of Toronto Press,1999), 57-90.

237 John Rosselli in Singers of Italian Opera: The history of a profession (55-70, 170-173) comments that women were often in the hands of reckless managers, and suffered from overwork leaving them vulnerable to sickness.
} 
careers. $^{238}$ While the comments on these young singers suggest a developing type of vocal colour, the early vocal ruin of singers such as Marie-Cornélie Falcon would point to a particular moment in the development of vocal technique. Indicating a collision between new conceptions of voice and the lack of knowledge of the underlying physical processes, it took time and concentrated physical application for singers to safely acquire the new conception of voice, at least without ruining their voices in the process.

The advancement of a safer vocal technique that could sustain a longer career, seems to have happened haphazardly, as working singers had time to practise new elements into their voices. It seems sensible that those with lighter voices specialised in the higher coloratura roles, and those with heavier voices and stronger bodies concentrated on developing their voices for dramatic roles. Moreover, it took singers time to realise the extra effort involved in anchoring the larynx a little lower, engaging and widening the pharynx a little more, unifying the registers, and employing more canto spianato. However, the composers and audiences appreciated the colour of the voice that the lowered larynx, the use of chest register and dramatic delivery it gave; and these new vocal timbres certainly were needed to compete with the larger orchestras that were being developed at the same time. Nonetheless it is difficult to determine if the singers responded to the new vocal compositional styles with this technique, or the composers responded to the colour and attack available to them. What is clear though, is that it took time for singers to appreciate the amount of physical support and vocal maturity to sing the new kinds of roles with any surety of vocal longevity. ${ }^{239}$ I suggest that, despite varying comments about register changes and breaks (a fraught subject in itself) what people were hearing were large changes in colouring due to laryngeal position and pharyngeal expansion, not undisguised register breaks. To continually move through the register

238 Susan Rutherford, The Prima Donna and Opera 1815-1930, 217-218.

239 Vocal longevity seemed to increase in singers by the end of the nineteenth century and into the twentieth. Vocal longevity is an elusive quality. It is hard to pinpoint exactly when it began to extend, as individual singers vary considerably in their strength and technical expertise. Some voices are strong, others are fragile. The complexity of the subject suggests further research. 
changes unblended, with no laryngeal tilt or placement techniques, is physically and vocally exhausting, and would seem unsustainable considering the large dramatic roles these singers sang. In addition, with the access to more chest resonance and a darker timbre, it was considerably more physical work to keep the registers blended while truly realising the character of most of these roles (that is, while engaging both physical and mental resources on the full range of gesture, enactment, and emotion articulated in the previous chapter). In retrospect, the lowered larynx and the requisite extra physical engagement became the cornerstone of vocal technique for some operatic repertoire, and these elements became the accepted vocal soundscape that is, I believe, actually more central to our modern experience of "voice"- and especially the intense fandom often generated by it - than is commonly understood.

\section{Verdi's Vocalità}

Examining Verdi's expectations for the singers, we can glean a substantial amount of information from his confidence in their ability and his expectations of the dramatic intensity he wanted to convey in the voice. The need for a distinctive colour is what distinguishes Verdi's vocal music. He also expected a focus on dramatic content and acting that was unprecedented; despite his complaints and insistence that singers cast in his operas must act, it was not a standard requirement of singers in the employ of opera houses at the time. ${ }^{240}$ In addition, Verdi changed the way texts were set to music. He was always very specific about his texts, demanding of his librettists that they be written in certain ways, asking, for example, for more emphasis on one character than another to achieve the balance of the plot and action that he wished. ${ }^{241}$ In the

\footnotetext{
240 In a letter to Antonio Lanari (January 21 1847) Verdi says "Singers must be engaged to sing and to act ...", a common request and also a complaint of his. (Giuseppe Verdi Verdi: The Man in his Letters, ed, Franz Werfel and Paul Stefan (1942)(New York: Vienna House, 1973), 121.

${ }^{241}$ For example in a letter to Salvatore Cammarano (November 23 1848) discussing La Battaglia di Legnano, Verdi asks for another scene for the prima donna, an agitated recitative, and more words in the chorus to add a certain dramatic significance. Giuseppe Verdi, Verdi: The Man in his Letters, ed, Franz Werfel and Paul Stefan, 145.
} 
shift from his early operas to the middle period Verdi expressed a desire to move away from cavatina operas. ${ }^{242}$ In this formal structure the words have a deep effect on the musical and dramatic structure - an effect that has a great influence on the way the words have been set to music, and hence how one sings them. Verdi eventually developed his style of composition, moving on from the formalised structure of chorus, overture and the required cavatina to a focus on a closer attention to semantic rather than structural text-music relationship. ${ }^{243}$ He was particularly skilled in registration (the setting of syllables to notes); he knew when open or closed vowels were needed for a better sound for example, and changed verse around to suit the vocality of the singer. In addition, the focus on individual words tends to put more emphasis on the setting of syllables. The priority was always the best possible vocal and dramatic delivery for the meaning of the libretto. 244

The shift in the Verdian middle period placed a greater emphasis on "expressive" vocality - that is, a vocality that conveys the more immediate wordto-word affect rather than larger structural shapes - which in turn calls for a fundamentally different type of engagement with a singer's body. Verdi had laid out the training he expected a singer to have: in a letter to Giuseppe Piroli from Genoa (February 20 1871) he says that for a singer,

I should want a wide knowledge of music, exercises in voice production, long courses in solfège, as in the past, exercises for clear enunciation both in speaking and in singing....then sing with his own feelings as his own guide. The result will be not singing according to any specific school but according to inspiration. The artist will be an individuality; he will be himself; or better yet, he will be the character he has to portray in the opera. ${ }^{245}$

242 Martin Chusid, Introduction, in Martin Chusid, ed. Verdi's Middle Period: Source Studies, Analysis, and Performance Practice (Chicago: University of Chicago Press,1997), 2 .

243 Roger Parker, “On Reading Nineteenth-Century Opera: Verdi Through the Looking Glass", in Reading Opera, eds. Arthur Groos and Roger Parker (Princeton: Princeton University Press, 1988), 288-305, here 298-9.

${ }^{244}$ Verdi had a useful ability to rhyme open vowels and closed vowels to gain a better legato line and vocal sound for the singer.

245 Giuseppe Verdi, Verdi: The Man in his Letters, ed, Franz Werfel and Paul Stefan, 300. Verdi also was a great admirer of the technical facility of singers trained in the bel canto style. But similarly, just the singing was not enough: he wanted someone who could 
Famously, in direct contrast to the bel canto ideals, Verdi did not want beautiful singing for the sake of it. Pure vocalità was not his over-riding concern and singers with the kind of training that he outlined were more able to exemplify - or actually create - the aural conception of the character that he had in mind. Requiring a greater emotional involvement from the singer than previous composers, contemporary accounts suggest that Verdi was mostly concerned with a greater authenticity of the human drama in conjunction with the natural expression of the voice. For example, Marianna Barbieri-Nini, the first interpreter of Lady Macbeth, left an account of Verdi's rehearsals in 1847, including his thorough coaching of the sleepwalking scene: "for three months, morning and evening, I tried to imitate those people who talk in their sleep, who utter words (as Verdi assured me) almost without moving their lips, and keeping other parts of their face, eyes included, motionless." ${ }^{246}$ Barbieri-Nini's ability to sing this role repeatedly in rehearsal speaks of her excellent training in protecting her voice -she had excellent teachers in Nicolai Vaccai, whose work is still in common usage today, and singer, Giuditta Pasta. For the distinctive vocal style of early and middle Verdi (particularly relevant for my case study on Il trovatore) the use of extended techniques of a bel canto training as laid out by Geoffrey Riggs in his book The Assoluta Voice in Opera 1797-1847 were crucial: “To master any of the assoluta roles," Riggs says "a diva must have an instrument that projects with ease over an energetic orchestra." He goes on to say that she must have a technique that encompasses all bel canto ornamentation and the skill to combine this with her most heroic vocal quality; a messa di voce, a large range from a high $\mathrm{D}^{\prime \prime}$ flat to a low of $\mathrm{A}$ or $\mathrm{G}$ below middle $\mathrm{C}^{\prime}$ and the ability to sustain both the low tessitura if needed and also the high tessitura; and most of

convey the dramatic character of the role. In an interview with Gino Monaldi, Verdi said: "the human voice, apart from being the finest of all instruments, is not merely a sound; poetry is wedded to this sound, and poetry requires an ideal form of expression that is both lofty and always intelligible." Marcello Conati, Interviews and Encounters with Verdi, trans. Richard Stokes (London, Gollancz, 1984), 191. See also Roger Freitas, "Towards a Verdian Ideal of Singing: Emancipation from Modern Orthodoxy", Journal of the Royal Musical Association (Vol 127, No. 2 (2002), 226-257), 231.

246 Marcello Conati, Interviews and Encounters with Verdi, 26-27. 
all, vocal stamina that allows her to sing long sustained roles with ease..$^{247}$ Interestingly the large dramatic voices that were often classed as an assoluta prima donna were in themselves sometimes a conflation of a specific and unusual voice type that combines the attributes and range of a mezzo-soprano and a soprano. ${ }^{248}$ I will explain and explore this interesting vocal development in Chapter 4 in relation to my discussion of Il trovatore's female roles.

To sing the major roles of Verdi one needs to learn to project the voice, and to develop resonance. For any operatic singer, to project over an orchestra in a theatre is necessary: this requires optimum placement of the singing voice; this placement is often found by speaking at pitch (which can be an unnatural placement for English speakers, except for people with certain U.S. accents). ${ }^{249}$ To create optimum vocal resonator tract resonance the singer muscularly adjusts the frequencies of the tract, maximising the use of the Singer's Formant (as explained above, see p. 83). As the pitch gets higher the bodily work must increase, not only to maintain the colour, the chiaroscuro, the balanced light and dark harmonics, but also to keep the throat open, ensuring the unobstructed movement of the air into sound. This free, unconstricted emission of sound allows the placement and hence the resonance of the voice to be enhanced; with larger orchestras and larger halls the voice has a need for more resonance. ${ }^{250}$

As always, technical considerations are paramount for an elite singer. The ornamentation of the vocal line characteristic of the bel canto repertoire takes

247 Geoffrey S. Riggs, The Assoluta Voice in Opera 1797 - 1847 (London: McFarland, 2003) 10.

248 Geoffrey S. Riggs, The Assoluta Voice in Opera, 8.

${ }^{249}$ Generally singers from the north-eastern U.S. have forward placed voices, perfectly placed for singing. The demographic mix of immigrants has of course contributed to that, particularly the influx of Italians. My observations also point to the number of top singers who come from large families: evidently bargaining loudly in a large family contributes greatly to the development of well-supported and placed voices!

250 There are other challenges - the most obvious being the use of the breath in Verdi's slow arias - a subject I talked about in Chapter Two and will develop further in the next chapter on Il trovatore. 
many years of daily repetition of scales, figures and trills. In training a voice one concentrates on flexibility first, before developing the heavier timbre. These exercises give a heavier voice, such as Verdi often used, a much needed versatility, even though they are much more difficult to execute for a timbred voice with thicker vocal folds. Also vital is the ability to use different modes of attack: to be able to sing a perfect legato and to handle with equal ease staccati, detached notes, notes that are a little forced, and notes that are strongly accentuated and make the most of the many instructions such as rallentando, ritenuto, or accelerando to help to increase the music's emotional effect. This flexibility is essential, not only for the needs of the music, but also for vocal health, as it stops the muscles from fibrosing into one position and dynamic. ${ }^{251}$ The ability to control the messa di voce is a hallmark of Verdi's music: the complicated balance of air pressure flow and bodily engagement required to produce a perfect crescendo and decrescendo, without compromising the quality of the sound or its energy is of vital importance. As the variety of dynamics demanded by Verdi covers everything from pppp to fff, singers of his music must have a near-perfect breathing technique that allows them to modulate their voices as the music demands it over their entire range. In addition to the ability to change vocal colours, Verdi's instructions are rather detailed: Marilyn Feller Somville says that "Verdi urged his singers to realise vocally by means of the right breath impulse, the right accent, rhythm, colour and intonation, the substance and meaning of particular words and phrases," all of which are notated in the text. ${ }^{252}$

\footnotetext{
251 With repeated loudness or intensity, the muscles holding the larynx will build to such an extent that they lose their flexibility; this is called fibrosing.

252 Verdi in letter to Varesi: 7 January, c. 23-30 January and 4 February 1847: quoted in Marilyn Feller Somville, "Vocal gesture in Macbeth" Verdi's Macbeth: A Sourcebook, eds. David Rosen and Andrew Porter (Cambridge: Cambridge University Press,1984),239244,242 . Rather less detailed technically but still valuable in the way the authors describe the sound expected of a Verdian voice, is Giancarlo Landini and Marco Gilardone's Dal labbro il canto: il linguaggio vocale delle opere di Verdi (Milan, Omega Music, 2001).

Verdi was very particular about what he liked in singers. Adelina Patti was a singer of whom he approved: she had a voice of lyrical purity and an unmatched bel canto technique and he complimented her on the way she sang his music, holding her up as the way his music should be performed, saying that she had "perfect equilibrium
} 
In light of the information gathered here, the central issue is how we define the sense of transition from the early nineteenth-century vocal music to Verdi. As Verdi was so demanding of the type of singing he needed, it is worth questioning why, famously, Rodolfo Celletti in his article "On Verdi's Vocal Writing", accused him of leaving the art of bel canto (a term only invented in the 1880s) behind. ${ }^{253}$ In fact, if we look at the various types of vocal technique that Verdi requires, we can see that elements of the bel canto technique remain deeply embedded: legato, coloratura, messa di voce. In addition,Verdi's vocal writing tends to start low in pitch in a set piece and build to a climax of generally one high $\mathrm{C}$ for a soprano, even though it might sit around the passaggio for a short time a typical style for bel canto.

What is new is the attention to words and dramatic delivery and the development of the use of canto spianato using the colour obtained from a lowered larynx. Yet the basis actually lies in the bel canto technique. Thus we can see that rather than leaving the technique of bel canto behind, Verdi broadened the notion of what it entails. I suggest that Verdi's text setting built on the concept of abstract beauty of bel canto, and retained the need for a highly flexible delivery as well as subtle and varied phrasing which revealed the inner emotion of the character. Demanding a "harsh, stifled and dark" sound, Verdi also developed the idea of female vocality by incorporating, particularly in Macbeth, a different type of vocal colouring. ${ }^{254}$ These new departures in the expectations of vocal sound ran alongside the developing concept of the powerful female role, whose strength was manifest both in stage persona and in her voice. Stamina, both vocal and physical, was a requirement of these roles to deal with the length and weight of them. In addition, the mental and dramatic expectations

between singer and actress, a born artist in every sense of the word." Marcello Conati, Interviews and Encounters with Verdi, 50-51.

253 Rodolfo Celletti, “On Verdi's Vocal Writing”, trans. Harold Barnes, The Verdi Companion, eds. William Weaver and Martin Chusid (New York: Norton and Co., 1979), 216-238. Roger Freitas, " Towards a Verdian Ideal of Singing: Emancipation from Modern Orthodoxy", Journal of the Royal Musical Association (Vol 127, No. 2 2002), 226$257,231$. 
challenged singers, male and female, to colour their voices in ways to match the orchestration.

With the role of the orchestra changing drastically through Verdi's life; with the influence of French Grand Opera from the mid-nineteenth century; and the reform of the Italian opera orchestra, which Verdi himself had a hand in, the vocal music in his operas can differ quite substantially between roles. While most of the early and mid Verdi roles such as Il corsaro and Il trovatore have some vocal music that is exposed and lightly supported by orchestra, by the late Verdi

roles he had developed a fundamentally different relationship between orchestra and voice. Verdi kept the sense of vocal and orchestra ensemble relatively simple possibly to deal with the lack of conductors. Other reasons for keeping the orchestration light include the need for clarity of the diction, and consequently the voice has more dominance in the music as a whole. As a singer, I experience Verdi's music as voice-led: his operas revolve around the simple and often repetitive libretto, but also require a vocal sound that conveys more subtleties than the text.

\section{Wagner's Wörter}

Where Verdi requires singers to have all harmonics in the voice available as vocal colouring for his roles, Wagner's tessitura tends to concentrate in certain areas. The physical strength needed to project the voice at the top of the vocal range, (such as for the steely tone colour and cries of Brünnhilde), and the concentration and strength in the lower middle/middle voice (as is required for Kundry), makes for idiosyncratic vocal needs. Singers of Wagner must also have good stamina, as most of his operas are long, and singers often need to be physically strong in order to deal with costumes that can be heavy and unwieldy. Wagner as a composer was alert not only to operatic voice but also to characterisation by way of the differing use of inflection and speech pattern; because of this he was concerned with the accuracy of presentation of his texts. His aspiration was to present a form of vocal delivery that was flexible and 
communicated a conviction of delivery that simulated heightened speech. ${ }^{255}$ This required a commitment on the part of the singers, to refocus and retrain, after what Wagner termed the sloppy freedom and benign musicality of Italian music. He hoped that after mastering the notes and durations of his vocal lines, singers would "proceed with discretionary freedom, showing animation rather than reserve" in order to "produce the impression of an impassioned and poetical mode of delivery."256 In fact, Wagner disliked what he saw of both German and Italian singers: he said that Germans "do not articulate properly" and offer only "hazy outlines of their character," and thought that they only sang dramatically when they bellowed out their last notes seeking applause. For Italians, they sang by the rule book for dramatic effect: "billing and cooing on stage was always followed by an explosion that made an incomparable effect". ${ }^{257}$

Wagner commentators suggest that he tried French, Italian, and German operatic styles in his earlier work, then abandoned these in order to forge a new mode of delivery that followed after the symphonic tradition and superseded it. Wagner was self-consciously trying to create a new kind of music theatre, so it is not surprising that he fundamentally altered the kind of vocality required for singers in his music dramas. Wagner felt that music should be an expression of the fusion of the words and music, sublimated to the drama. ${ }^{258}$

As a young composer, Wagner was very much influenced by the dramatic art of the great singer Wilhelmine Schröder-Devrient (1804-1860), who was highly praised for the originality of her histrionic talents. Her ability to completely identify with the character she was singing, apparently sublimating her own self, influenced Wagner's conception of vocal writing. Where a story is told serially by many different characters, an artist who has a skill in the

\footnotetext{
255 David Breckbill, "Singing", The Wagner Compendium, ed. Barry Millington (Thames and Hudson: London, 1992), 356.

256 David Breckbill, “Singing”, The Wagner Compendium, 357.

${ }^{257}$ Robert L. Jacobs and Geoffrey Skelton eds. Wagner Writes from Paris (London: George Allen and Unwin Ltd., 1973), 58.

258 Roger Parker, “On Reading Nineteenth-Century Opera: Verdi Through the Looking Glass," Reading Opera, 292.
} 
dramatic arts has an advantage on the stage. ${ }^{259}$ Even though her voice's capabilities declined considerably through her career, Schröder-Devrient's talents were to represent the concept of dramatic truth over mere vocal agility and beauty of sound. 260

Although Wagner's operas before Der Ring des Nibelungen had a more traditional number structure with arias and choruses and the consequent concentration on a more lyrical, operatic vocal delivery, by Der Meistersinger he had started to move towards a more naturalistic inflection of setting speech. In Der Ring, as is well known, he developed his own Germanic "sagas" and made use of an archaic type of speech he imagined the protagonists might use. He developed a particular use of stabreim - the rhyming not only of consonants but also of sounds within the words to provide that archaic character. ${ }^{261}$ In some aspects the alliteration Wagner required gave some support to his formal structure; it also generally served to bind two contrasting sentiments together. ${ }^{262}$ Carolyn Abbate comments on the tension (rather than agreement) between the words and the music when sung this way, wondering if "this tension between the operatic and music and the poetry of stage drama perhaps raises certain operatic works above the ordinary."263 My experience in singing Wagner with the attention to detail, and energy needed to convey the text in detail bears that observation out.

According to David Breckbill in The Wagner Compendium, following the composer's death two opposing stylistic developments came about. Under the reign of Cosima Wagner, a text-centred style of delivery evolved - particularly the type of Sprechgesang that Shaw described as the "Bayreuth bark", which was

\footnotetext{
259 Richard Wagner, Actors and Singers (1896), trans. W. Ashton Ellis (London: University of Nebraska Press, 1995), 219.

260 Thomas S. Grey, "Wilhelmine Schröder-Devrient and Wagner's Dresden", Richard Wagner and his World ed. Thomas Grey (Princeton: Princeton, 2009), 201-229, 206.

261 Jeffrey L. Buller, “The Thematic Role of Stabreim in Richard Wagner's Der Ring des Nibelungen" Opera Quarterly, 11/4 (1995),59-93), 59.

262 Carolyn Abbate, "Wagner, 'On Modulation', and Tristan," 40.

263 Carolyn Abbate, "Wagner, 'On Modulation', and Tristan,", 42 (Footnote).
} 
so vocally damaging to many singers and gained Wagner a reputation for being dangerous to sing. ${ }^{264}$ In contrast, a lyrical style developed over the course of decades in London and New York expounded by singers such as Lilli Lehmann, Lillian Nordica, Frida Leider, Lotte Lehmann, Kirsten Flagstad, Jean de Reszke, Lauritz Melchior and Alexander Kipnis. The characteristic features of this style were tonal beauty and purity, undistorted vowels, vocalic harmonisation and the use of sung consonants. ${ }^{265}$ In addition, as Breckbill comments, "these singers were notable for both energy and stamina, but memorable because their singing was capable of achieving a range of expressive characterization through strictly vocal (which includes enunciatory) means."266 Today most singers of Wagner are more likely to be dramatic and lyrical singers: to sing safely and economically they embed the words in the sound and make word-music as it seems Wagner wanted. Though the bel canto tradition was not part of his background, the vocal traditions of other European styles had an influence on his development. Because of Wagner's extensive conducting employment he had considerable experience in working with the operatic works of Mozart, Beethoven, Bellini, Weber and Marschner. ${ }^{267}$ Wagner was an admirer of Bellini and paid tribute to his bel canto aesthetic and Lohengrin and Tannhäuser certainly have a somewhat Italian style to them. But while Wagner appreciated the technical facility of most singers, he objected to the lack of dramatic articulation of the language. Wagner singers have a distinctly Germanic dramatic delivery: their vocal sound is bound to the body, requiring enormous support and energy.

In addition, when he came to the writing of the text and the music for Der Ring des Nibelungen, Wagner was very much influenced by the research and investigations he had done on the Eddas and Norse sagas, particularly the

\footnotetext{
${ }^{264}$ David Breckbill, “Wagner in Performance”, The Wagner Compendium, 364.

265 Jürgen Kesting, “German Bel Canto”, 2, 2011.

http://www.deutschegrammophon.com/html/special/pape-wagner/album.html. Accessed 16/10/2014.
}

266 David Breckbill, "Wagner in Performance", The Wagner Compendium, 365. For a fuller summary of the changes in the style of Wagnerian singing, David Breckbill is excellent.

267 David Breckbill, “Wagner as Conductor”, The Wagner Compendium, 99-102, here 100. 
Nibelungenlied. Scholars now believe that although the sagas in their original form would have been orated out loud from memory to groups of people, they were subsequently written down as a conscious creation. ${ }^{268}$ Nonetheless, I suggest that the feats of memory, projection and reiteration had some influence on Wagner in the way he composed the drama. In orating to an illiterate audience, certain stylistic conventions apply: the story is reiterated often, the themes and descriptions often have alliterative elements to aid the short term memory of the listener, and the dramatic delivery of the text reinforces the excitement and anticipation of the story. I suggest that these oratorical conventions, combined with his earlier operatic influences, led Wagner to set his text to his music in certain ways that helped the listener remember the often convoluted story.

To sing the major roles of Wagner, as in Verdi, one needs to learn to project the voice, and to develop resonance. To create optimum vocal tract resonance the singer muscularly adjusts the frequencies of the tract, maximising the use of the Singer's Formant. For Wagner, there are areas of the voice that need enhancing: the lower middle of the voice must have a perfectly mixed harmonic structure as it moves through to the lower register, and never drop completely into the chest resonance, the sound must always be mixed with head resonance. This is a cultural preference: Germans say they don't use chest resonance, but in fact they have a lighter mix of chest and head resonance than the Italians do - a more blended movement through the registers. The sound must also remain forward and carry through the orchestral texture. In fact the vocal sound itself must carry a certain amount of epiglottally shaped twang (a concentration of certain harmonics) that projects. To make this sound requires not only mouth and pharyngeal shaping but also considerable muscular involvement in the neck and cervical spine. As the pitch gets higher the back and core work must increase, not only to maintain the colour, the chiaroscuro, the balanced light and dark harmonics, but also to keep the throat open, ensuring the unobstructed movement of the air into sound. This free, unconstricted emission

268 Elizabeth Magee, "In pursuit of the purely human: the "Ring "and its medieval sources", Wagner's Ring of the Nibelungen, eds. Stewart Spencer and Barry Millington (London: Thames and Hudson, 1993) 29-32. 
of sound allows the placement and hence the resonance and stamina of the voice to be enhanced. Diagram 3.1 below shows the epiglottis that can be shaped to concentrate certain harmonics, giving optimum projection.

\section{Diagram 3.1}

Entrance to the Larynx viewed from behind, showing the epiglottis, and the aryepiglottic fold. This tissue can be shaped to concentrate the harmonic structure coming from the vocal folds. ${ }^{269}$

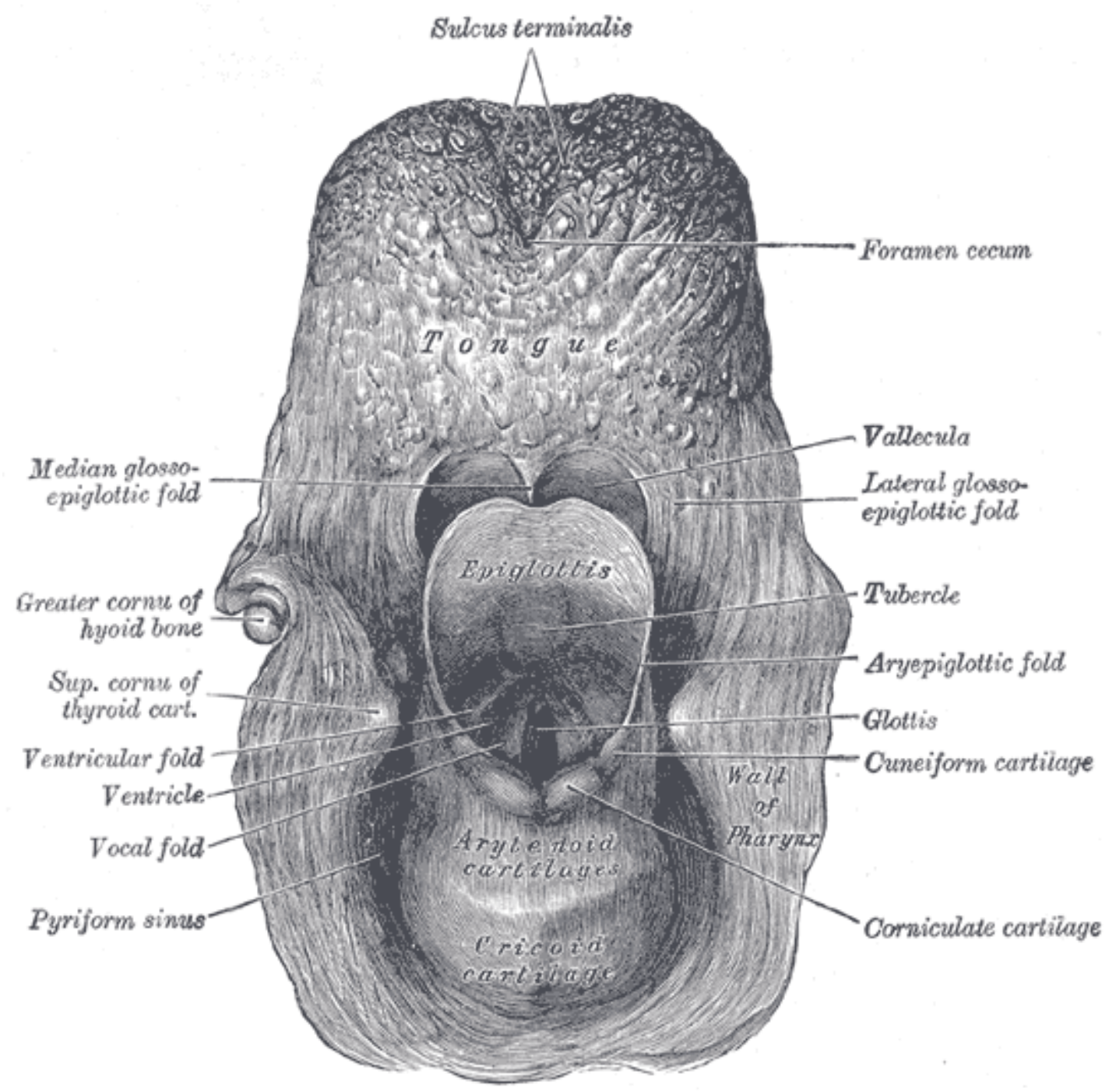

269 Image from Henry Vandyke Carter and Henry Gray Anatomy of the Human Body (1918). 
The use of a lowered larynx in these roles also adds an authority to the sound. The body strength and engagement required to keep that colour with the added lower harmonics, and yet project the sound, is considerable.

Crucially, as I will demonstrate in my detailed case studies, aspects of Wagner's vocal writing mean that as a singer you are forced to sing the text in the way that Wagner dictates: there is relatively little choice in the way of phrasing, and although presenting its difficulties of length and focus in certain parts of the voice, the text requires a certain sort of energy and projection connected with the lyric diction of German. In fact it requires a huge amount of breath and bodily energy to get the text carrying in a theatre and the implications for bodily engagement for the clear projection of text are quite different from the requirements of more lyrical music, requiring stabilisation and intent in the vocal sound. The combination of the setting of the German language and the pacing of the libretto, which Wagner of course wrote himself, sets up relatively little choice in the way of phrasing for the singer: there are very few places where the air is free to travel through a melismatic phrase, the major place being in some of Sieglinde's first act music in Die Walküre (a role that I will discuss in Chapter Five). The text is durch-komponiert (through composed), with few repetitions of words, a few lyrical areas, and generally is set one syllable to one note leaving precious few places for a lyrical phrase. ${ }^{270}$ To exemplify the aural conception of the characters that he created, Wagner found that the singers with a formal Italianate training had a better basic technique. Nonetheless, as Susan Rutherford writes, Lillian Nordica found that the task of reconstructing her Italianate voice into one that could sing Wagner took considerable effort and was not altogether successful. ${ }^{271}$ It is interesting to consider what extra a

${ }^{270}$ Particularly in much of Parsifal as I will discuss in Chapter Six.

271 Carolyn Abbate, and Roger Parker, A History of Opera; the last four hundred years (New York: Penguin Group, 2012) 298. Jürgen Kesting says that the prerequisite for the "German bel canto" of which Wagner dreamt was the symbiosis of Italian vocal mellifluousness and a delivery that conveyed the true sense of the drama. (Jürgen Kesting, 2, 2011). http://www.deutschegrammophon.com/html/special/papewagner/album.html Accessed 16/10/2014.) See also Susan Rutherford The Prima Donna and Opera 1815-1930, 221-222. Lillian Nordica's change of repertoire and vocal style was initially very successful but was later cited as responsible for her early decline in vocal control (Rupert Christiansen, Prima Donna, 176). 
conventionally trained singer of the late nineteenth century would have needed to do to ready herself to sing Wagner. Certainly as Nordica was originally a coloratura soprano and retrained as a dramatic soprano, she would have needed to lower her laryngeal placement and use more mass in her vocal folds, developing a more appropriate colour to sing Wagner. She would also have had to learn German thoroughly and to be trained in the lyric diction of the language. All of these extra elements need much more muscular engagement from the body, and perhaps she did not allow herself enough time to build up the musculature before she started to sing the larger roles. However, Nordica was successful for a time. Indeed, her very good vocal placement and excellent projection gained from singing Italian repertoire would have helped her find the energy needed to project German consonants, to project over the higher volume of the orchestra, and find the exactness of the text and rhythm Wagner's music requires. His music, as Abbate says, "actually projects poetry and stage action far beyond motivic signs", to concentrate on a distillation of style characterised by a focus on universal themes. This suggests to me that the focus on the diction, and the stabreim particularly, conveys just as much as the leimotiven from the orchestra, emphasising the importance of the singer and the text. ${ }^{272}$

Whereas Verdi developed the vocality and the orchestral support evenly, it seems that Wagner concentrated much more on the orchestral textures of his operas, leaving the text to perch on the top. This relationship makes it very taxing for the singer as the text must be energetic and meaningful, with a concentration of harmonics in certain areas. Wagner's vocal range, though not with the high Cs of Verdi, tends to sit on or just above the passaggio, requiring tremendous strength. In addition, after a sustained high passage he often requires the singer to sing a low one in the lower middle voice; this shift is extremely hard to manage after the forceful delivery higher in the range. The lowered larynx and consequent chest resonance heavy voice must be blended evenly in the lower middle voice. Always difficult to project, the voice must be securely supported and anchored within a strong musculature.

272 Carolyn Abbate, "Wagner, 'On Modulation', and Tristan," 42. 


\section{Verdi contra Wagner}

Both Verdi and Wagner pushed compositional boundaries and fundamentally shifted the nature of their singers' vocal development. It is unclear how many of these new requirements were a virtue of their compositional obsession, which forced vocal development in particular directions, or how many were a response to particular singers whose interesting and compelling voices, attracting both Verdi and Wagner, inspired them to write the roles they did. What is clear though, is that the vocal sound we expect to hear today in these roles certainly started to develop roughly at the same time these composers were writing. There does seem to be a natural progression for Wagner singers to move through Verdi roles and onto Wagnerian ones, even though a singer does not, or should not, change the way they emit the sound, and should not change the basic vocal production between the two composers. ${ }^{273}$ The reasons for this progression are various, as I have explained, and depend considerably on the individual singer's histrionic talents and interests. There is no doubt that Verdi roles demand a wider variety of technical demands than those of Wagner. It is essential for singers of Verdi to have a rich palette of dynamics and harmonic structure in the voice, but I suggest that the same nuance is not necessary for singing Wagner. Verdi demanded fidelity to his text, and he also demanded a bigger voice - bigger timbre and more sound and projection than used for singing Bellini, Rossini and Donizetti. However, the real difference is in the vocal sound. Verdi singers have a "rounded" quality, softer grained, if you like, and a dramatic delivery that can be distinctly Italian.

Moreover, there is another aspect to do with the vocal sound that is important but largely not articulated: it is to maintain all the possible harmonic structure in the vocal resonator tract - which is what enables the subtle interpretive nuances required in Verdi's music, and yet that also relies on the singers engaging considerably more bodily effort. Wagner's music also calls for a slightly different harmonic structure in the voice. While most pedagogues are quick to note the difference in the suitability of voices for either Verdi or Wagner,

273 Interview with John Fisher, Head of Music, 25/4/2013, Metropolitan Opera of New York. 
very few are able to articulate the exact differences in harmonic structure needed. The exception is Professor Paul Farrington, an internationally known voice teacher from London. He feels that Wagner's vocal music calls for a concentration of harmonics in certain areas of the voice, which vary between voice types. For a soprano the areas are the top of the voice F" to top C'", and the lower middle range $\mathrm{B}$ below middle $\mathrm{C}$ to $\mathrm{C}^{\prime}{ }^{274}$ The focus in harmonic structure allows for the weight in the lower middle of the voice and the brilliance at the top, common features in the largest Wagnerian roles. It is also true to say that if a singer can manage the vocal demands of singing Verdi roles, they have an ideal training for singing those of Wagner. Most important, though, is the increasing involvement of the body required in producing this sound, and I contend that a fundamentally new understanding of the relationship between body and voice was required to perform them. Finding ways to present these works in ways that enhanced the kinds of sound the singers were able to stabilise, was vital in preserving the longevity of singers' careers.

It is in this context then, that it becomes clear that the engagement of body and voice in performance that I laid out in Chapter Two has particular relevance for singing Verdi and Wagner. To sing Verdi and Wagner's music and to be able to sustain a career, not only do you need a very good technique, you also need physical and vocal maturity. In addition, to work a role into the voice and body not only does one need to be physically mature, but also ideally the role would be learnt over an extended time of several months, giving the musculature time to develop and build up the strength needed to sustain these roles. Often the singers creating the roles of Wagner and Verdi received their music shortly before the premières, and consequently there was hardly time to learn the music: there was certainly no time allowed to sing it into the body's musculature. In the repetition of roles, the mind directs the body to develop musculature to protect the voice; this protection also enhances volume, so there is no need to push: the sign of a successful singer is the ability to sing loudly and high in pitch with no loss of vocal colour. As roles were restaged after their premières singers began to have a possibility of repeating a role; only then might

274 Interview with Professor Paul Farrington, 26/1/2012. 
they have had the chance to work out strategies to maintain optimum vocal colour and stamina. Considering the amount of work needed, from a singer's perspective, it is not at all surprising that they began to develop towards and specialise in certain roles.

In contemporary singer training, careful consideration is given to the progression of roles added to the repertoire. Managements and agents are well aware, despite the intensity of focus on the visual appearance of a singer, that it behoves them to make sure that a singer is reliable and can carry out the engagement. This reliability not only enhances the agent's reputation but also that of the singer. Current vocal practice requires a proof of vocal fitness for the largest roles in varying sized opera houses. Christine Goerke, the American dramatic soprano now singing Elektra and Brünnhilde at the Metropolitan Opera and Covent Garden, spent a number of years at the start of her career singing Mozart, and moving through roles which developed her voice gradually and safely. ${ }^{275}$ She was able to spend time adjusting to the heavy musculature demands of a large voice, to learn to control the voice's naturally large timbre and keep it flexible by singing Mozart. As the musculature developed she was able to use more weight in the voice and adopt a more dramatic delivery when needed. It also gave her the time to learn and study the long roles of Wagner while singing larger Verdi roles such as Eboli in Don Carlos and Amelia Un ballo in maschera, to sustain the lyrical aspects of the vocality.

Ostensibly to help singers, agents and managements, there is a vocal categorising system in constant use, normally called the fach system. ${ }^{276}$ Most singers get typecast using this system: they get stuck in one category or another that can be frustrating and can limit their vocal development. In addition, most of my colleagues feel that it is vocally healthy to mix the singing of Verdi and Wagner, and would optimally like to do so professionally. Many feel that they

275 Interview with Christine Goerke, 26/7/2012.

276 The fach system is a method of classifying mainly opera singers by the weight, range and colour of their voices. Of more use to agents and managements than to singers, singer Jessye Norman famously refused to be categorised into dramatic soprano or mezzo, saying she wished to sing whatever suited her voice and temperament. 
have become pigeonholed by managements, particularly those who sing a lot of Wagner, and have been passed over in casting Verdi roles.

In my experience it initially seemed harder to sing Wagner after singing Verdi: the first time I attempted it I found it difficult to believe I needed so much more energy in the consonants and rhythm. My body and brain gradually got used to it, and when you do sing the music with the energy required, everything else (the placement and projection particularly), slots into place. One does not worry as much about the quality of the sound as it is the vitality and presence of the text combined with the orchestral sound that gives the unique timbre of Wagner. ${ }^{277}$ Returning to sing Verdi I realised that I was able to work much harder in my core strength to provide an extra stability for the "Verdian" sound needed from my vocal resonator tract. Furthermore, applying some of the "German" energy to the Italian text I achieved a greater focus and projection. Nevertheless, both styles of singing were still my own voice: I needed to adjust the harmonic structure of the vocal resonator tract to achieve the correct vocal quality for both, to prioritise the freedom of the breath for Verdi, and the textual vitality needed for Wagner.

The historical chronology of singing across this period and its relationship with compositional developments, and with particular composers' styles, is complex, and would benefit from further historical research. Nevertheless, from a singer's perspective the implications of these mid nineteenth-century developments for our technical expectations for vocal sound today can be

277 Premium operatic voices generally have a large vocal range: their reach of low A or G to high $D^{\prime \prime \prime}$ in a timbred voice needs a huge amount of bodily engagement to keep the tone even, and takes years to perfect. To sustain the tessitura of a role is a slightly different matter. Some voices lie naturally lower, others higher, and some voices will need to do a lot of balancing and projection work at the lower end of the range; others, especially those who do not have a natural high piano (like myself), will need to work very hard to attain this quality for Verdi particularly. Therefore it can be a relief to sing Wagner and not worry about ones' voice's natural tendencies. In my opinion these tendencies of the range arise from the development of the voice: if you were initially a mezzo then the bottom of the range will not be a problem, and vice versa. Well-known dramatic soprano Dame Gwyneth Jones commented that Verdi's music requires more body in the sound than Wagner's, meaning that the vocal folds needed to be thicker, that she was working harder in her body to maintain the canto spianato. Helena Matheopoulos, Dame Gwyneth Jones, Diva (London: Victor Gollancz,1991). 
defined in simple terms: lowering the larynx, engaging and widening the pharynx more, employing canto spianato and unifying the registers of the voice. In fact, through their compositions, I suggest that Verdi and Wagner participated in the development of different aspects of this new vocality. Moreover, predicating our contemporary taste for those voices, the greater emphasis on "expressive" vocality, as well as the attributes mentioned above, calls for a fundamentally different type of engagement with a singer's body.

In addition, the extra dramatic content (which both Wagner and Verdi demanded), always individual and dependent on the singer's unique gifts, was not written in the score, but necessitated the singer's bodily engagement, or embodiment, imagination and emotional engagement. Both Wagner and Verdi sought a greater authenticity of histrionic expression: Wagner was concerned with breaking with the stylized conventions of the past, and, as well as Verdi, privileged the dramatic concept within his vocality. ${ }^{278}$ These concepts, added to the important technical advances of the mid-nineteenth century, enhanced dramatic delivery, and enhanced the effect of the timbred voice.

In my case studies that follow it could seem that the requirements of the roles are similar; however, I will demonstrate that, in fact, they are quite different. I will lay out how the nature of the engagement with these texts is so individual; and, what is more, how the creative process of engagement with the vocality suggested in these scores is fundamentally different. It seems that Azucena and Leonora are crucial turning points in Verdi's compositional process, and Sieglinde is a transitional role for Wagner.

What is clear, though, is that Verdi approaches words from a melodic point of view-in many ways he moves from vocal spectacle to vocal meaning. Wagner on the other hand, I propose, approaches text as an oration, with the orator's attendant delivery. The ideas and concepts contained in his texts are more complicated and require auditory aids for the audience to remember them. I suggest that in Verdi's vocal music, because there are fewer words, more emotional information is carried in the vocal sound, and the singer's breath is a

278 Susan Rutherford The Prima Donna and Opera 1815-1930, 258-257. 
vital component in the formation of that sound; in Wagner, the information is in the text and the accompanying music. Both require the singer to be bodily engaged in different ways; both require the female chest register to be fully integrated and mixed into the vocal range. A singer developing facility with register blending, and the colour changes resulting from the ability to lower the larynx at will, developed a vocal longevity and stamina that served the roles of Verdi and Wagner.

\section{Jouissance from Verdi and Wagner}

I believe it is the sensual experience of a voice both for the listener - and, it must be said, for the singer themself, as I explain below - that can be hypnotic and addictive. It is, as Clemens Risi has written, the "particular ecstasy of the trained singing voice" that is my focus and interest in its potential for affecting the listener. ${ }^{279}$ Barthes and Poizat have famously introduced the concept of jouissance to explain this feeling of sensual magnetism of the voice.

Opera lovers have traditionally been passionate about singers. It is the pleasure, the jouissance that the voice gives them, that is so addictive: the emotional release a voice can give in itself, quite apart from the sense of the music and the text. Whether or not those moments transfer to audience's experience is matter for discussion: as a performer it is hard to gauge the effect on the audience in those moments, and it depends on other aspects of the performance experience including contingencies such as the size of the theatre. It is a place where the singer can enjoy the sensuality of singing and of her body, and that enjoyment is reflected in the voice. I have found in my own practice, working with my own voice particularly on Verdi and Wagner, and with those of others, that it is essential to train the singer's ear to desire the correct sound. Risi comments that the voice that induces jouissance in the listener and is like a drug

279 Clemens Risi, “The Diva's Fans: Opera and Bodily Participation”, Performance Research 16 (3, 2011), 49. 
to them. ${ }^{280}$ For the singer it is similar: you train your ear to desire a certain quality of sound that external feedback has told you is the most affecting sound you can make. By acknowledging that both singer and listener desire this extratextual information, we must ask what the singer must do to achieve this state, manifest in its highest concentration as jouissance. ${ }^{281}$ The answer, I suggest, lies in the technical advances I have outlined in this chapter, and also my explanation of embodiment in Chapter Two.

An emotional reaction to a voice is always subjective and unpredictable, but it remains a decisive aspect of a singer's effect in performance:

Everything seemed larger than life. The voices made it enormous, they filled me up. The musicality, the voices, the music; I was really emotionally moved. To me it was an emotion I felt every time I attended the opera. ${ }^{282}$

The fans' passion for the operatic voice has been well traversed in a variety of scholarly modes. Curiously though, one type of voice seems to recur as a favourite voice, at least in recent times, and to be the one that opera fans seem most often to identify with: it seems that not all voice types are created equal in their ears. Studies like Claudio Benzecry's confirm something that has long been taken as a given on the modern operatic stage: the voices that seem to invite the most passionate devotee, the ones the fans prefer above others, are the dramatic tenor, dramatic soprano and the spinto soprano. ${ }^{283}$ Voices and singers have always invited adulation: witness the literature about the castrati and coloratura sopranos. The preference for heavier voices is a relatively new phenomenon, as they themselves are.

${ }^{280}$ Risi, “The Diva's Fans, 51.

281 I use the descriptor "extra-textual" to denote that the voice carries a sound which in itself is communicative of an emotion. and not wholly reliant on the text to provide clarification. The singer of course does not properly hear her own sound, we are hearing received sound (if we are lucky enough to have any reflective surfaces) and a small amount of conducted sound, so the mind must be educated to trust the body with the task.

282 'Guillermo' in Claudio Benzecry, The Opera Fanatic: Ethnography of an Obsession (Chicago: University of Chicago Press, 2011), 86.

283 Claudio Benzecry, The Opera Fanatic, 86-87. 
In his book about the fans of the Teatro Colón, The Opera Fanatic, Benzecry interviews a number of opera fans and asks them to articulate what it is that moves them about certain voices. ${ }^{284}$ All of them comment on the dramatic deepness, the colour, the viscerality of the voices, the sound the voices make that connects to their own bodies, giving them the impression that they themselves are singing, are emoting. "Passionate fans," Benzecry says, "spoke as if the music had taken their body over, occupying the space where the core of the self used to be with such force as to make them forget who they are, or at least forget their daily problems."285

Although, in general, the attention has been on reception it may significantly enrich our understanding of jouissance to lay out that it is also potentially an important concept for the performer. ${ }^{286}$ Mezzo Christa Ludwig's words below reveal the physical pleasure experienced by the singer in the ideal performance. She says that

... pouring out the full voice and unleashing that torrent of sound over a full orchestra is a nice feeling, almost orgiastic, like making love. When on top of this, the part you are singing is full of emotion, it's quite, quite wonderful, in fact it's heaven. ${ }^{287}$

Singers enjoy their moments of vocal jouissance: the embodied work the singer does, specifically in relation to the breath can induce a singer's pleasure. This pleasure is rarely talked about. It is experienced where there is a bodily effort

284 Claudio Benzecry, The Opera Fanatic.

285 Claudio Benzecry, The Opera Fanatic, 88.

286 Carolyn Abbate, In Search of Opera (Princeton N.J.: Princeton, 2001); Suzanne Cusick, "On Musical Performances of Gender and Sex" in Perspectives of New Music $(32,1994,8-$ 27); Clemens Risi, "Opera in Performance-In Search of New Analytical Approaches" The Opera Quarterly (Vol 27, No 2-3, 283-295) ; “The Diva's Fans: Opera and Bodily Participation", Performance Research (16, 3, 2011); Michelle Duncan, "The Operatic Scandal of the singing body: Voice, presence, performativity" Cambridge Opera Journal (16, 3, 283-306); Wayne Koestenbaum, The Queen's Throat (London: Penguin 1993); Sam Abel, Sexuality in Opera Performance (Colorado: Westview Press, 1996); Michel Poizat, The Angel's Cry, trans. Arthur Denner (Ithaca: Cornell University Press, 1992); Roland Barthes, "The Grain of the Voice", Image, Music, Text, trans. Stephen Heath (London: Fontana 1977).

287 Christa Ludwig, Diva, Ed. Helen Matheopoulos (London: Gollancz 1991), 290. 
involved, producing a high from the release of endorphins in the bodily exertion, or just the sheer pleasure of the language and sound made. It is a moment where the singer can enjoy the sensuality of singing and of her body, and that enjoyment is reflected in the voice. It is a moment, moreover, that can be crafted into the score itself, as I will explain in my case studies, and explicitly used for dramatic effect by composers.

With a body and mind that is fully engaged, the dramatic expression of the voice, the fidelity to text and to the composers' intentions is fully executed by invoking the combination of the mind/body state of the embodied continuum. In this chapter I have discussed an idea of a particular aspect of bodily engagement and the technical developments that have demanded that engagement. While this idea is quite general, it lays the groundwork for what follows. It is only when talking about a particular body and voice in negotiation with a particular score, in actual performance, that one can start to unravel the details of the process of embodiment that a singer engages in.

To that end I will now turn to particular roles in Chapters Four and Five, which I have sung in performance. I will raise questions about the nature of that interaction discussing the ways in which the composer can control that interaction, and the space through which the singer negotiates her own creative contribution engendering the particular pleasure of jouissance. 


\section{Chapter Four:}

\section{Verdi Il trovatore: Prima la voce, or the Imperative of Passion}

Negotiating a balance between mind and body is the ultimate challenge for any singer. The training of an elite singer is a long process: not only is the training exhaustive, but the accumulative experience of live performance aids the singer's ability to sing in a communicative and imaginative way. Amalgamating the impulses of thought and body, consciousness and instinct to construct a platform where a performance can be creative and intuitive requires deep consistent training in the embodied process of implicit and explicit memory. It is that accumulated preparation and experience that allows singers to sing operatic roles successfully: indeed it is an embodied continuum that is necessary for a successful performance, where this term acknowledges the hours of preparation that are incorporated seamlessly into the mind/body nexus. ${ }^{288}$

In this chapter I will focus on the two pivotal female roles from II trovatore Azucena and Leonora, describing their roles and their vocality. Firstly, I outline what a singer does to learn a new role performed for the first time, including how the singer deals with the rehearsal process. I will then describe the vocality of each of the women, following each section with a reflection on the actuality of singing the role in performance. My reflection is a combination of the memory of the experience of a number of performances, and an analysis of the preparation for the role, and the pacing of my characterisation and singing.

\footnotetext{
288 My term "embodied continuum" denotes a state of flow where the mind and body are able to respond in an autonomous manner, due to the amount of preparation done before the performance. Comparable terms are found in Michele Binnie, "Finding the Drastic", 23. While Carolyn Abbate in her article "Drastic or Gnostic?" clearly understands that the drastic and gnostic (explained in Chapter One) should be active at the same time, in her own unsuccessful performance experiment to see if that is the case, she cannot achieve that state. Michele Binnie suggests that the two states need an overarching meta-drastic moniker that recognises the gnostic and small drastic work done prior to the performance, and special attention to the act of concentration, the drastic, to prevent overthinking and hence, distraction, in performance.
} 
Through these reflections I offer a first-hand account of a singer's experience backstage, and onstage, in negotiating a major role. ${ }^{289}$

Roles such as those in Il trovatore require a physical maturity to sing, much practice, and, as I explained in Chapter Two, a careful progression in the size of the roles undertaken through the developing performance career. Despite the level of competence of body and mind to make a stable and attractive sound, a singer must still invest a large amount of time and energy in the consciously intellectual aspects of learning a role, to sing a new role performed for the first time. Also, in any given day a singer must spend a certain amount of time "warming up" the voice and training specific muscular and breathing responses. Therefore, by the time a singer is mature enough to sing the specialised Verdi and Wagner roles, there is an assumption of muscular and brain fitness, excellent breath management and optimal vocal resonator tract harmonic structure, the result of many hours of detailed training of the body and mind. Of course, this preparation is expected for all operatic roles. However, as will become clear, the attention to detail that is required and the building upon empirical knowledge escalates when one is called upon to sing roles of Verdi and Wagner. The application of the embodied continuum is standard to all operatic roles (and can perhaps be applied in general to "classical" performance). What is different about singing Verdi heroines, and for most of the vocal music contemporaneous and following him, is that the modern expectation of the vocal sound builds on the mid-nineteenth century model, discussed in the previous chapter, which involves a lowered larynx, widened pharynx, thicker vocal folds, and increased use of chest resonance.

Every singer has their own routine in learning a role at the international level, but certain essentials are the same:

- Read and translate (if necessary) the libretto for complete comprehension (not just their own role but those of the other characters).

${ }^{289}$ Aided by my recordings and videos, I have excellent visual recall for performance, and can easily replay many visceral and musical aspects of the performances in my head. 
- Read any appropriate background material available and deemed necessary to understand the libretto.

- Learn the pitches of the role.

- Learn to sing the role: this requires an excellent vowel articulation providing good vocal sound, and solving each technical problem as it occurs. In some cases it may be necessary to adjust vocal warm ups to include exercises specific to the technical challenges of the role.

- Plot the emotional journey of the character and create a subtext and back story.

- Listen to the synthesis of music and words to connect musical impulses to the character's subtext.

- Declaim the words of the libretto. This kick-starts the involvement of the body and incidentally often solves technical problems. It also connects directly to the emotions needed without the act of singing getting in the way.

The emotional and physical journey of working on a role is one that constructs a workable personality of a character. All this is done before the singer works with a language coach and vocal coach for musical, linguistic and stylistic advice.

Finally the singer reaches the first rehearsal - usually a music rehearsal where the conductor is involved for the first time. The conductor may or may not have things to say about the music and vocality, all of which have to be put in place very quickly. Moving into the rehearsal studio to work with the director is the next step. Here the director works with the performer as a body in space, and as an emotional being. As the performer has already worked to create a character, they can offer much to the director to be enlarged upon or changed. While a performer must learn to sing the role in a way consistent with the director's concept of the role, there are often physical limitations demanded by the act of singing that ideally should be accommodated. Negotiation is often required so that the performer is free to concentrate on the technical challenges of singing the music. 
The extraordinary amount of work that goes into preparing a role is first tested when the singer is asked to put all aspects of performance together, in runs of sections of the music in the rehearsal studio. This process is continued when the rehearsal is moved into the theatre and onto the stage itself, where the singer is further challenged by costumes, makeup, lights and set, and the experience of singing with the orchestra. As the voice and body are living, everchanging entities there is always an element of risk in collating the large number of elements involved. Rehearsals are exactly that - a place to try out what works and what doesn't, what the singer can cope with in performance. As the singer progresses through the stage rehearsals there are opportunities to practise the performance in short runs: training the mind and body in these intricate processes. At those times, the singer, as information needs to be accessed or repositioned according to altered or unexpected demands and circumstances, calls upon the hours of accumulated preparation: the performative and formative are interwoven. The stage rehearsals are a time when an enormous amount of feedback is given to the singer: there are notes from the director and their assistant, the conductor and assistant, the director; the language coach, and wardrobe adjusting costumes. It is expected that this information is acted upon in the following rehearsals.

The experience of this continuum of performance is ideally one of creative freedom. Even if a singer is bound to follow the directions of the score, an interpretative artist can make many creative choices in building a character and colouring the vocal line to deliver a performance, a real-time experience of music making, where there is no room for reflective thought. As I have experienced regularly, a singer goes on stage to sing a role totally embodied in the character being sung: the vocal line is sung as if speaking, the movements are natural as if living, the music is the truth of the moment. ${ }^{290}$ The mind and body are so well trained that the implicit memory system takes over; the work that was done in advance is accessed in an unconscious way and does not impinge on the conscious state, where the focused attention of the singer is on expressing

290 Of course there are those directors who wish to have unnatural or stylised movement from the singers. 
emotion. ${ }^{291}$ This is truly the state of "flow", the state of the continuum, where temporal considerations are unimportant, and the performance seems to pass in a flash. However, this is an illusion: there is not just the entraining creative work engrained into the body, but a bodily/cognitive responsiveness to the present that is heavily engaged. After the performance, coming down from the "high" described in Chapter Two, the most noticeable effect of the performance is the exhaustion of the body.

The words used to describe the voices that sing Verdi are often descriptors of the body; sensuous, visceral, supple, arching and muscular. The technical requirements of the roles of Verdi are many and varied as I have explained; however it is the character of the sound that is the distinctive aspect and crucial to the dramatic character. Before talking about the specific technical areas which are central to the roles of Il trovatore, I need to point to a few characteristics of the nature of the bodily involvement in singing. As I have explained above, to carry out these changes the body needs a level of musculature and engagement suitable to carry the larger timbred voice that we have come to expect in these roles. The development of the "dramatic" voice came in parallel with the developing use of larger venues in the mid-nineteenth century. The dramatic and spinto soprano voices (the terms used today for such voices), like the dramatic tenor, had a somewhat similar development in their timbre and range. ${ }^{292}$ As the size of the performance venues was developed, it became important for singers to prioritise the vowel sound that carries the text to the listener. As we have seen in Chapter Two, to make these qualities carry in heavier roles needs much more bodily engagement than required for roles which

291 We have different types of memory: the ones that apply in the case of performing music are: implicit memory (unconscious and expressed by means other than words) the drastic, and explicit memory (conscious and can be described in words) the gnostic. http://www.sciencedaily.com/releases/2013/08/130807134512.htm accessed 25/08/2015. Quoted in Michele Binnie, 16.

292 I talked about the development of the tenore di forza in Chapter Three. The tenor voice was first to be developed although Gilbert Duprez's experiments in extending and mixing his middle voice up to a tenor high $\mathrm{C}$ was greeted by derision in some quarters composers and impresarios were quick to employ him, and to develop operatic roles for him to sing. The sound he made, the mix of the middle and head voice, had, by all accounts, a great deal of vocal timbre. 
are vocally lighter. In addition, the voice needs to "speak" - it must contain a quality that should be present in the spoken voice of a dramatic rendering of text, the quality of which can be transferred into the sung voice. The increased bodily involvement needed to project a spoken text at pitch in practising allows for a gradual development of the voice, leading to the use of thicker mass in the vocal folds and optimising vocal tract resonance. The connection between the spoken and sung word is vital for any singer; the practice of declaiming the text of the music (orating, if you like, at pitch) enables a singer to access the quality of tone, inflection, emphasis and emotional content of the words without having to worry about the act of singing. The practice of declamation also develops the singing voice, helping the placement and the support: if the connection between body, spoken and sung voice is missing, the bond, the emotional loop with the audience, is broken. This connection contributes to the effect of the operatic voice: these essential qualities for communicative singing then, are heightened for a timbred "dramatic" voice. For the vocality of Il trovatore the quality of the vocal sound is paramount: it possibly tells us even more about the character singing than the text does. In combination with generally larger (but not necessarily overweight) bodies, it is the lowered larynx, space in the pharynx and the slightly thicker mass of the vocal folds due to an integrated use of chest resonance, combined with increased muscular involvement that creates a heavier, darker timbre to make the vocal sound which many commentators call "Verdian".

However, what is critically different about singing Verdi is the use of the breath. As a performer I had long been aware that the way I managed my breath was of crucial importance in the creation of the vocal sound. Not only did it enhance the quality of the sound but it also had positive effects on my bodily preparation and engagement. In fact, breath has emerged from my research as one of the most important ways a singer, particularly a soprano, can manipulate and express her character creatively. Verdi wrote long sustained phrases, often with melismatic sections, dynamic fluctuations and repeated words. In some respects he sets up the use of the breath because of the way he has paced the phrasing - the way the melodic lines and melismatic phrases are placed - to 
force the singer to breath in a certain way and express them as Verdi intended. If the phrases are long and sustained, the breath equally has to be longer and more engaged in the body. However, the longer phrases allow the singer great creative freedom in the way she moves through them, how she places the breath and most of all, in the vocal colouring. Naturally, longer, melismatic phrases have fewer consonants, so while the breath is used less vigorously, the way it is used demands a certain response from the body to allow for a long, even emission. This bodily involvement impacts particularly on the thorax, involving the antagonistic use of the muscles to prevent the collapse of the diaphragm, the appoggio. Of vital importance, the appoggio, the lowering (the diaphragm lowers to breathe in and as it contracts it goes up) and sustaining of the position of the diaphragm, has an effect on the larynx which relaxes in a lowered position as the breath is taken, enhancing the lower timbres of the voice. ${ }^{293}$ The emission of air is controlled to maintain an even breath pressure, directly affecting the coordination of the vocal fold tension and closure. In other words, the control of the breath compression once the folds close balances breath flow and breath resistance. This in turn influences the placement of the larynx, and allows the singer the ability to set up the appropriate resonating spaces for the most economical use of the breath. The heightened bodily engagement enables the body to sustain a lowered laryngeal position, picking up chest resonance, a widened pharynx, giving the voice in addition to more timbre, enhanced power and authority. The appoggio also brings an overall improved support for the larynx so that both the lower and upper registers operate within the context of a supportive network which makes the shift from one to the other not just imperceptible but also functionally continuous. Vocal registers are perceptual elements of the human voice that reflect laryngeal physiology. ${ }^{294}$ The most well-

${ }^{293}$ While I do not want to take this thesis into the territory of a vocal treatise, some explanations are necessary, not only because of the abundance of confusing terms, but also because, being an inexact science, cultured singing is a minefield of opposing views. Appoggio is an another of the confusing terms in singing that is much misunderstood. Catherine Robbin in her talk "Appoggio Demystified"(York University, Ontario, Canada, http://journals.library.mun.ca/ojs/index.php/singing/article/viewFile/1035/889, accessed 25/08/15) has one of the clearest explanations I have found.

294 Indeed such was the interest in different "voices "in the nineteenth century and before, that there was a time, as James Davies lays out in Romantic Anatomies of 
described registers in singing are chest/modal register, and falsetto/head register and the more skilled singers with the colours that Verdi seemed to prefer in the mid-nineteenth century gradually developed a seamless transition throughout their vocal range. ${ }^{295}$

Although the developments in technique at this time were in every area of the voice, Verdi's music for women called for particular strengths, and he wrote roles that exploited those strengths. Thus, it is worth reiterating the technical areas that contribute to producing that particular type of sound. As I suggested in previous chapters, I suspect that the descriptions of singers having noticeable register changes in the mid-nineteenth century was in part an unrecognised colour change caused by the new technique of lowering of the larynx. Verdi's vocal music in some cases (Azucena and Lady Macbeth for example) certainly encouraged an extension of the register changeover, calling for an increased pressure on the vocal folds and the need for a heightened bodily protection of the vocal folds. ${ }^{296}$ The increased need for a speech like quality in the voice was the result of Verdi asking for vocal acting, used, as Marilyn Feller Somville puts it, as a vocal gesture..$^{297}$

Performance, when the best performers in Europe cultivated any number of voices:"head voices, chest voices, feigned voices, flautino voices, white voices, falsetto voices, half voices, mixed voices, medium voices, nasal voices, inspirited voices, covered voices." James Q. Davies, Romantic Anatomies of Performance, 127.

295 Voice science tells us that in addition to modal and head registers, there are two other registers; fry and whistle. Chest and head registers were originally named for the physical location in the body where the singers felt vibration when producing them. In terms of register production, there are many theories about how register is controlled but current theories suggest that singers shift from chest to head register by changing longitudinal tension of the thyroarytenoid muscle altering the vocal processes of the arytenoid cartilages, which in turn affects the vocal fold abduction and amplitude of vibration. Johan Sundberg The Science of the Singing Voice (Illinois: Northen Illinois University Press 1989); Ingo R.Titze, The Principles of Voice Production (New Jersey, Prentice Hall 1994).

296 Marilyn Feller Somville, "Vocal Gesture in Macbeth", Verdi's Macbeth: A Sourcebook, ed. David Rosen and Andrew Porter (Cambridge: Cambridge University Press, 1984), 240-1.

297 I disagree with Marilyn Feller Somville's interpretation of a number of technical matters. It is a physical impossibility to take "pure chest register" up above the stave. All 
In addition to register changes, the variety of rhythmic vitality in a Verdian role is a particular challenge. Most often that vitality is heard in the orchestra. However in the earlier and middle operas Verdi employs an energetic rhythmic movement in some areas of the vocal line that contrasts with the smooth legato lines of the melismatic phrases. I have already talked about the special work that must be put into sustaining the breath though a long line; in contrast, for a rhythmically energetic line with large intervals and staccato care must be taken for the diaphragm to remain flexible, along with the core muscles.

Although Verdi wrote considerately for the female voice, it has often been the case that the registration of the words (how the words are set to each note) can be changed to suit each voice. The worst example of this process is when all words are substituted by "ah" as the melodic line rises above the stave. ${ }^{298}$ Despite the initial panic of attempting words and good pronunciation at pitch, over time I have proved to my own satisfaction that if you follow Verdi's registration, a better vocal sound, and more importantly, a more economic airflow is achieved. The control of the breath is quite individual to a singer and is dependent on the singer's health on the day. Many vocal coaches and conductors have the ability to judge how long the air will last in a singer's breath once they have started the phrase: they 'hear' where you are in the breath, and move the phrase accordingly. As I have this ability myself, it is always disturbing to come across a conductor who does not have this empirical knowledge, and cannot

balanced sound in a dramatic role will include a certain amount of chest resonance, or "heavy mechanism", or thicker vocal folds. What I suspect she means is that she is hearing a sound that has very little or no laryngeal tilt - shouting or speaking at pitch, even with a certain amount of constriction. These sounds are able to be made in short amounts as colouring; but Lady Macbeth is technically very difficult and to sing and survive one has to find the way to colour in the way Verdi wanted, to act with the voice, and sing safely.

${ }^{298}$ A very good example of this practice is to listen to Leonora's Act IV aria D'amor sull'ali rosee on YouTube sung by a number of singers. The final section starting Ah, deh non dirgli has any number of variations of the use of 'ah', or other incomprehensibilities of text. 
accommodate you and your body in an individual way at each performance, thereby enhancing your creative component to the performance.299

Voices are individual, as is their ability to move and sustain vocal tone. Nonetheless there remains an expectation of vocal tone and technique for Verdi's roles that was formed in the mid-nineteenth century. Though the dramatic expression of the text was important to Verdi, it is the vocal quality that conveys to us much other information about the emotional landscape of the singer and their embodiment of the character they are singing. The increased bodily maturity and the development of the mind -body connection governing the voice allows for the engagement of vocal mechanisms that produce the required tonal effects, and the ability of the breath to extend into a beautiful melismatic phrase. All of these processes are ingrained into the mind and body by intense training and the embodied intelligence releases sound and drama into an intuitive and creative performance.

Il trovatore with its puzzling and seemingly absurd plot together with its overarching popularity, has been subject to much ridicule in the twentieth century. Largely ignored by English-speaking scholars in the face of criticism, the English translation of Gabriele Baldini's book The Story of Giuseppe Verdi: Oberto to Un ballo in maschera helped to usher in a new era of appreciation for Verdi's masterpiece: "In no other Verdi opera are there such prominent, energetic, eloquent, expressive and above all grandiose characters who resolutely retain their individuality in the musical framework....becoming personifications of passion and nature." 300 The criticism of its plot and "backwards" looking music, an easy target for those who do not understand its form and appeal, has been

\footnotetext{
299 It is always worrying to have a conductor who wants to fix you down on every musical point and nuance. In my opinion it shows a lack of technique in relation to conducting voices. The best conductors, once they assess your capabilities, allow a creative collaboration with the singer: we make music together. 300 Gabriele Baldini, The Story of Giuseppe Verdi: Oberto to Un Ballo in Maschera. trans. Roger Parker (Cambridge: Cambridge University Press. 1980), 210, 211, 218. Baldini asserted that the shape and substance of the libretto had a direct influence on its structure, and, rather than defending the music against the text, accorded the text extraordinary eloquence and stature.
} 
largely refuted in the last three decades by informed analysis and appreciation of the integrity of its structure. ${ }^{301}$ James Hepokoski, in "Ottocento Opera as Cultural Drama: Generic mixtures in Il trovatore", notes the seeming disparity between its blunt simplicity and enormous expressive power, and proposes that Verdi used the conventional musical forms to support dramatic and expressive choices. The binding to the musical form also made acceptable highly marginal (to society at the time) characters of the culture, allowing a highly charged emotional impact, as Baldini had suggested earlier. ${ }^{302}$

The five main characters in the opera are quite clearly defined and once Ferrando's opening scene is over, the four characters, as Baldini observes, fly from and pursue, unite with and confront each other, always in the presence of fire. ${ }^{303}$ Fire here is not the cleansing and transforming magic of Wagner's fire in The Ring. Rather it is the consuming and destroying fire of passion, of the stake and fire around it, burning flesh, the burning poison within Leonora and the amorous blaze within di Luna. ${ }^{304}$ Fire is here the metaphor for revenge, consuming everything in its path: revenge for a crime against a woman and

301 Always a popular success, often performed and much parodied, it was Julian Budden in The Operas of Verdi, Volume 2: From Il trovatore to La forza del destino who listed the opera's detractors back to nineteenth-century Italophobes, for whom it epitomised everything that was most vulgar in the Italian tradition. Julian Budden The Operas of Verdi, Volume 2: From Il trovatore to La forza del

destino (Oxford: Oxford University Press, 1991), 225. For an enlightening overview of the reception of Il trovatore see Elizabeth Hudson's "Narrative in Verdi: Perspectives on his musical dramaturgy" (Cornell University, ProQuest, UMI Dissertations Publishing, 1993. 9318824).

302 James A. Hepokoski, “Ottocento Opera as Cultural Drama: Generic mixtures in Il Trovatore", Verdi's Middle Period: Source, Studies, and Performance practise, ed. Martin Chusid (Chicago: University of Chicago Press 1997), 147-196, 147,193. Delving into musical analysis and dramatic structure, Pierluigi Petrobelli's "Towards an Explanation of the Dramatic Structure of Il trovatore", William Drabkin's "Characters, Key Relations and Tonal structure in Il trovatore" and Roger Parker's "The Dramatic Structure of Il trovatore", all helped to elucidate the appeal of this opera. It was Roger Parker who pointed out that it was partially the strength of Wagner's influence on our contemporary appreciation of opera, that mitigated against a critical appreciation of Il trovatore. (See Parker "Verdi through the looking glass").

${ }^{303}$ Gabriele Baldini, The Story of Giuseppe Verdi, 212.

304 Ibid, 211. 
another by a woman. ${ }^{305}$ Azucena's conscious and unconscious mind is consumed by the flames: they pervade her sleep and are a living nightmare for her. ${ }^{306}$ Leonora's passion consumes her, and the poison kills her. Interestingly Verdi and Cammarano present two versions of the truth: the official "male" one related by Ferrando at the start of the opera emphasising the inhumanity of the actions; and Azucena's "female" version of events, which conversely relates a very human story of the consequences of persecution and oppression. ${ }^{307}$

In spite of the controversy over the score's formal structures, or the moral hidden in the story, Il trovatore has always stood or fallen on the skill and virtuosity of its singers. ${ }^{308}$ Il trovatore is all about the vocality of its characters. Yet the difficulty in casting singers in these roles lies beyond the highly developed vocal skills each role requires. More than that, each role (except perhaps Ferrando), needs a highly developed theatrical sense of bravura, charisma, and presence to convince the audience of the veracity of the story. As I am laying out in this dissertation, these characteristics provide a particular technical, physical, intellectual, and creative challenge for singers that is little understood, and that goes to the heart of understanding the complex framework and functioning of vocality itself.

If you are singing a role professionally in Il trovatore today, by definition you are going to be relatively mature and experienced. Indeed, this seemed to be the case right from the premiere. Verdi, as we know, was famously fussy about the singers whom he preferred to sing in his premieres, always wanting singers who could convey the dramatic intensity of the situation, as mentioned in

18 Ibid, 211.

306 Susan Rutherford, Verdi, Opera, Women (Cambridge: Cambridge University Press, 2013), 166-167.

${ }^{307}$ Susan Rutherford, Verdi, Opera, Women, 167.

308 The tenor Enrico Caruso famously said that "all you need for a successful performance of Il trovatore is the four greatest singers in the world". Charles Osborne, The Complete Operas of Verdi (New York: Da Capo Press, 1977), quoted in Gina Monaldi, Verdi 1839-1898 (l. Ed. Torino: Bocca, 1926), 103. 
Chapter Three. ${ }^{309}$ It seems that in later performances his wish for singers with dramatic capabilities was generally adhered to. ${ }^{310}$ As well as the important aspect of matching the abilities of each singer so that there is no weak link in the casting, threatening the credibility of the dramatic performance, managements are not going to risk putting on an expensive production with untried singers. Il trovatore's detractors inevitably complained and still do, about the confusing story. I contend, though, that singers who are bodily engaged as per my embodiment model in Chapter Two, and who can use the breath to create and vary the vocal sound in the role, add an extra dimension to the story-telling, helping to humanise the isolated characters.

In the context of Il trovatore, an exploration of how the mind and body work synergistically with the voice allows a more nuanced perspective on how the creative embodiment of vocal sound influences our fundamental understanding of the two main female characters, Leonora and Azucena. Having performed both of these roles, I draw on my own embodied experiences in the interpretation that follows. My performance experience spread over a number of performances enabled me not only to go through a lengthy preparation in each role, but also afforded me the luxury to try things out in performance. I was able to act on any feedback I had from coaches, director and conductor and alter the accreted learned practice I had built up to facilitate a better performance. More importantly, I was able to analyse and act upon what it was that allowed me to access the continuum state. ${ }^{311}$ In the following case studies I have combined my personal recollections, using italics to differentiate between the personal and critical reflection.

${ }^{309}$ Martin Chusid, Verdi's Il trovatore: the quintessential Italian melodrama (Rochester NY: University of Rochester, 2012), 89-90.

310 Various books of letters talk about the casting of Verdi's operas: David Kimbell Verdi in the Age of Italian Romanticism (Cambridge: Cambridge University Press,1985); Marcello Conati, Interviews \& Encounters with Verdi. edited, introduced \& annotated by Marcello Conati, trans. Richard Stokes (London: Victor Gollancz Ltd,1984).

311 Il trovatore performances: I am drawing on and amalgamating information from a number of productions: I first performed Azucena in Melbourne in 1996 for the Victorian State Opera; Leonora for State Opera of South Australia in 1999; for Lyric Opera of Queensland in 2000 and for Opera Australia in Sydney in 2004. 
Anecdotally, we singers talk of Verdi's music needing the sound of the body in the voice. Hard for a non-singer to comprehend, it is a feeling of body weight in the voice, which no other composer demands as much. As a young singer, it took me time to be able to find an emotional courage, to involve my body in allowing the voice to colour properly; as an Italian coach showed me, the way through was by speaking the text, and sustaining it at pitch. Not only does one need vocal and mental confidence to use the voice in this way, but the body and the vocal instrument must be ready and physically able to sustain the quality of sound. It's as if the emotional courage grows with the body's maturity.

Did Verdi's well-known desire to have the strange and novel role of Azucena as the prima donna of Il trovatore, though seemingly thwarted by Cammarano's libretto, influence him into writing vocal material that seems to subvert the libretto's intention? ${ }^{312}$ It is clear what he wanted: in his first letter to Cammarano, he lays out his request:

"Io vorrei due donne: la principale, la Gitana carattere singolare, e di cui ne farei il titolo dell'opera: l'altra farei una comprimaria." (I would like two women: the principal, the gipsy, a singular character, and after whom I would name the opera; the other I would make a comprimaria). ${ }^{313}$

As the opera evolved Leonora was clearly laid out as the prima donna: she was given the set arias, the brilliant cabalettas, the duets with the tenor and baritone. And although she is set initially in a prima donna manner, as the solitary figure, it is not until Act IV, that Leonora presents in what Heather

\footnotetext{
312 Pierluigi Petrobelli, "Towards an Explanation of the Dramatic Structure of Il trovatore", Music in the Theater: Essays on Verdi and other composers, trans. Roger Parker (Princeton: Princeton University Press, 1994), 103, as quoted in Gina Monaldi Verdi 1838-1898 4th Ed (Milan: Fratelli Bocca,1951).

313 Gina Monaldi, Verdi 1838-1898, 10-11. A comprimaria is a female role of lesser importance in an opera.
} 
Hadlock describes as, "the usual defining gesture for a Verdi heroine - her 'primal scene' of self sacrifice" for her to become more connected with the action. ${ }^{314}$ And yet in performance, unless the singer is also a very good actor, the character doesn't quite convince. The vocality is brilliant, but as a character she still seems distanced from the action, almost as if the emotional connectivity to the story is lacking. She spends most of her time reacting to events until she decides to save Manrico by selling herself to di Luna. Leonora's character can be seen as one-dimensional compared to the all-too-human Azucena, whose vocal gymnastics dominate and stop the plot when they occur. Gabriele Baldini points out that Leonora is rooted in the traditional soprano character of Bellini and Donizetti, but with more Mozartian associations. ${ }^{315}$ Like Mozart, the arias and cabalettas are placed symmetrically in the overall structure and conventional regular strophic repetition is used. However, it is the full emotional expressivity, imbued with a sense of melancholy and regret that places this role apart from Mozart's roles. ${ }^{316}$

If the prima donna soprano had the vocal fireworks, why did Verdi initially feel that Azucena was the prima donna, but later change his mind? Is it important that the title should be given to the female character who drives the plot? Perhaps not. Verdi's intention in Il trovatore as in all his operas, was surely to make the operatic event a compelling, intense experience for the spectator, and its reception history shows that it has definitely done that. ${ }^{317}$ Baldare's intervention in the plot structure subtly changed the emphases on the women, forcing Verdi to ask for two arias in order to equalise Leonora's role - though without sacrificing the importance he had originally intended for Azucena. ${ }^{318}$ In

314 Heather Hadlock, "The firmness of a female hand' in The Corsair and Il Corsaro", Cambridge Opera Journal 14/1-2(2002), 47-50.

315 Gabriele Baldini, The Story of Giuseppe Verdi: Oberto to Un ballo in maschera (1970) trans. and ed. Roger Parker (Cambridge: Cambridge University Press, 1980), 221.

316 Baldini, The Story of Giuseppe Verdi, 221.

317 Susan Rutherford, Verdi, Opera, Women (Cambridge: Cambridge University Press, 2013), 1.

318 Budden, The Operas of Verdi, Volume 2, 65. 
Verdi's operas the female characters can be the emotional centre of the opera, and he focused his interest in seeking out characters who explore the outer limb of social restrictions, as is borne out in Il trovatore. Susan Rutherford comments that Verdi's shaping of the female protagonists made his heroines unsettling in their equivocal attitudes to the acknowledged codes of femininity. ${ }^{319}$ As a performer of both roles, it is clear to me that on stage the power and the audience empathy is always usurped by Azucena. She provides the immediate emotional connectivity for the listener; yet in all respects, the technical requirements for Leonora are far greater than for Azucena. Leonora's role requires that the singer develop the tonal qualities in her voice in an emotionally communicative way. Some singers are more skilled than others in this regard and I will expand on the way this is carried out shortly. Azucena's role on the other hand is driven more by a rhythmic and textual intensity, a direct reaction to the events that happen to her, or the recollection of them. A closer investigation of the two roles from the perspective of embodiment begins to reveal how Azucena's character, though less virtuosic than that of Leonora, is nevertheless able to draw the audience's attention and emotional empathy in a more compelling way.

\section{Azucena: La zingara}

Though a gypsy and beset by appalling circumstances, Verdi asks in a letter to Cammarano that

Non fare Azucena demente. Abbattuta dalla fatica, dal dolore, dal terrore, dalla beglia, non pùo fare un discorso seguito. I suoi sensi sono oppressi ma non pazza. ${ }^{320}$ (Do not make Azucena a mad woman. Broken down by fatigue, sorrow, terror and wakefulness, she is incapable of speaking coherently. Her emotions are in disarray but she is not crazy.)

\footnotetext{
${ }^{319}$ Susan Rutherford, Verdi, Opera, Women, 2.
}

320 Letter to Cammarano 9 April 1851, Gaetano Cesari and Allessandro Luzio, eds, I Copialettere di Giuseppe Verdi (Milan 1913) 118-121), 118, quoted in Pierluigi Petrobelli, "Towards an Explanation of the Dramatic Structure of Il trovatore", 103. 
Baldini felt that "her greatness derives from her feeling of being torn between emotion and destiny, birth and death (or rather flowering and decay) by a blind irrational game in an indistinct circle of madness". He goes on to comment that Azucena provides an opening to the spirit world within which we can cast a frightened glance at something lying at the roots of our origins. ${ }^{321}$ The comparison of Azucena to something primal with the implication of a malevolence is interesting. She is not wicked; rather it is the chain of events that has befallen her, as well as the influence of a life of a gypsy, that have made her who she is. She is without a doubt able to be cunning and sly, in the traditional stereotypical way of the gypsy. Nonetheless, it is her power, the power of her emotions, that is the moving force in the opera, catalysing the feelings of the other characters.

Originally conceived of as the prima donna role for a singer with the voice of the mezzo/contralto with an upper extension to the range, Azucena's vocality calls for a lot of energy at the bottom of the voice and an optional top $\mathrm{C}$ for the cadenza in the duet with Manrico - an unusually large range. ${ }^{322}$ Verdi was very particular about who sang his roles. For Il trovatore and the casting of Azucena, he wrote to Cammarano in 1851, proposing the premiere of Trovatore in either Venice or Rome:

"La Compagnia di Roma è più adattata per Trovatore, ma vi manca l'attrice per l'Azucena, per quell'Azucena a cui io tengo tanto! La Gabussi parmi farebbe benissimo quella parte, ma non so se sia scritturata o libera

\footnotetext{
${ }^{321}$ Baldini, The Story of Giuseppe Verdi, 223. To reference the primeval aspects of Azucena is interesting: she is similar to the pythia, who is important because she stands on the threshold of the pagan and the Christian worlds. She is meant to stand as the image of an inheritance from or throwback to the foul, forgotten, chthonic beginnings. She provides the vent or doorway through which the dark, demonic imperfectly superseded world of magic may creep back.
}

322 For the first Azucena, Verdi asked for Rita Gabussi or a voice like hers. Gabussi was always called a soprano even though comments on her performances often mentioned that the role she was singing at the time was too high for her. (See Budden, The Operas of Verdi, Volume 2, 68). Good voices usually have large ranges, though there are always exceptions. In some cases it is a matter of deciding what is the best part of the voice, and singing roles in that area. However you don't lose the notes that are not used regularly. 
a Napoli o altrove." 323 (The Roman company is more suitable for Il Trovatore, but they don't have an actress for Azucena whom I care about so much. It seems to me that Signora Gabussi would do this part very well, but I don't know whether she is under contract or free, either in Naples or anywhere else.)

Verdi needed an actress as well as a good singer to convincingly portray Azucena. In the case of the mezzo Signora Goggi, he asked his friend Prince Józef Poniatowski to detail the quality of each note in her voice: "I hope it won't be too much trouble to write again sending me a musical scale covering the whole range of her voice, and writing under each note, good, bad, weak, strong, etc." 324 By being so particular about the exact capabilities of a voice, Verdi was able to tailor the role to gain the best dramatic effect.

The range of Azucena is quite extraordinary - both the vocal range and the emotional. To portray her on stage it requires a singer/actor with a compelling focus, not only to be able to convey the idea of her internal world, but also to switch intensity and thought very quickly in an almost schizophrenic way. As Verdi says, however, Azucena is not mad; she is a survivor. In addition, to sing Azucena, you need to be a vocal survivor and very secure in your technique, as it is easy to let the emotional involvement in the role become the prime focus on stage. The voice is ideally suited to a dramatic mezzo-soprano with powerful lower and upper extensions to the voice; and again a certain physical maturity is needed to have the musculature to protect the voice. The role of Azucena is well known as a voice wrecker. It is not only the range of the role that can be vocally dangerous, but also the fact that the emotional involvement it calls for can tempt the singer to give her all and be completely realistic in the vocality. In addition, the sustained use of the thicker vocal fold mechanism and chest resonance can easily tire the voice, and cause irrevocable damage.

As a concept, chest resonance is a bit of a misnomer: air travels up and out

\footnotetext{
323 Verdi to Cammarano, 9 September 1851, cited in David Kimbell, Verdi in the Age of Italian Romanticism (Cambridge: Cambridge University Press. 1985), 286.

324 Verdi to Cammarano 3 July 1852, trans. David Kimbell, Verdi in the Age of Italian Romanticism, 289.
} 
and does not become sound until it meets the vocal folds, before continuing its journey out of the body. In simplified terms it is better to think about the mass of the folds, how thick the folds are (they get thicker as the pitch gets lower) and its effect on airflow. Chest resonance is about resistance to air pressure, and an increase in the thickness of the vocal folds in the lower range of the voice creates a certain resistance to the sub glottal pressure, the pressure under the vocal folds; this in turn creates a secondary resonance as it vibrates back down the trachea. This is why we feel "something" happening in the chest. As the singer goes higher in the range and the folds lengthen and thin, the closed phase of each cycle lessens and there is less "back pressure" down the trachea and more sense of vibration as the sound hits the soft and hard palates. This process gives the feeling of the sound going into "the head", which again is something of a misnomer, as any sensations of vibration a singer has in the head are secondary or tertiary responses to what is happening elsewhere. Resonance is a response to a stimulus, and in this case the vocal folds are that stimulus, and the manipulation of the vocal tract and resulting affect on formant behavior gives us the feeling that the voice is resonating in slightly different places in the thorax and head..$^{325}$

Johan Sundberg in The Science of the Singing Voice talks about the chest register as being characterised by lower pitches and more relaxed thicker folds than used for higher pitches. Alternatively called "heavy mechanism" or voce di petto, today voice scientists talk of a two-register concept of vocality, and prefer the expression "chest resonance" (rather than chest voice). The lowered larynx for lower pitches has more muscular contact with the thoracic area, transmitting vibrations into the chest, hence the misunderstanding. ${ }^{326}$ The vocal folds are thicker, but the larynx is tilted to maintain vibrato and what is called voce di mista. This is the safest way to sing in the lower voice, and many female singers

\footnotetext{
325 Professor Paul Farrington, private email, 6/6/15. Vocal technique books, especially the ones of Sundberg and Miller, can be quite confusing in their attention to detail in the explanation o chest resonance. Farrington's explanation, honed by explaining clearly to singing students, gives a clear and concise summary of the process.

326 Johan Sundberg in The Science of the Singing Voice (Illinois: Northern Illinois University Press, 1989) 50-55.
} 
mix successfully but absolutely refuse to entertain the idea that they are using chest resonance. ${ }^{327}$ The use of open chest (with no laryngeal tilt) is discouraged in operatic singing: it sounds uncouth and tires the voice very easily. In my opinion this is the sound that people associate with chest resonance and which is the subject of most objections. ${ }^{328}$ Most international singers however, mix easily through the chest and head register by using varying degrees of laryngeal tilt. This is the safest way to sing in the lower voice, and privilege the dramatic concept in vocality by using varying vocal qualities of speech, thicker folds, lowered larynx, and more or less laryngeal tilt to carry out the vocal acting that Verdi required.

Demonstrating the complexity of the embodiment of Azucena, the importance of the chest resonance, the attention to detail in the preparation and the release into creativity that is the continuum, I record below a recollection of a number of performances and combine them in a multi-faceted rendition of a single performance.

The gypsy, Azucena, does not make an appearance until the second act of $I l$ trovatore - often the placement of the first appearance of the main character in an opera. Her first aria, Stride la vampa, establishes her as a brooding, troubled character. She is placed on stage with the chorus of gypsies and sings an aria that seems both uncontrolled and lucid.

A stage animal, all my efforts since getting to the theatre for makeup at $5 \mathrm{pm}$ (for a 7.30pm show) have been about keeping myself focused on my body and what it is doing. I have read the score through, noted points that I have been given to improve upon or correct by the conductor and director, and warmed my voice up. My voice feels good, fluid and vital, ready to go.

\footnotetext{
327 See Stefan Zucker's film Opera Fanatic (Opera Road, Jan Schmidt-Garre, 1998) with interviews with Giulietta Simionato and Fedora Barbieri, both of whom vehemently deny that they use chest resonance.

328 Robert Stark Bel Canto: A History of Vocal Pedagogy (Toronto: University of Toronto Press, 1999), 57-90. Laryngeal tilt is what happens when the thyroid cartilage tilts to the front. This stretches and thins the vocal folds, giving a classical western music sound. It is often called sweetening the sound as it produces a natural vibrato.
} 
In makeup I concentrate on the way my face changes and the way I feel about that change, and remind myself of the feel of the gypsy's bodymy body warm ups and stretches earlier in the day keep me limber and fresh. My rising excitement and desire to get going on stage is a problem the role excites me and that excitement shows in an inability to keep still. I am restless, pacing. This role calls from me an intensity, abandon and recklessness; though the music counteracts the abandon and recklessness with a rhythmic formality and an obsessive use of repeating figures, I still have to keep a rein on my energy and excitement and remind myself of technical safety. Asking the conductor to keep me steady, I remind myself that the vocal challenges are more about using colour changes to indicate Azucena's specific internal processes.

Finally I am pre-set on stage. I am sitting and settle myself in an unladylike position to engage the vital pelvic floor muscles as well as others in the back and neck. I am still, but nothing about my physicality is passive the body feels, and hopefully looks, tortured, without the tenseness affecting the singing. Containing my movement and gesture, my focus and intensity goes out to the audience as I start to sing, capturing the audience and pulling them and the gypsies into my story. As I sing the first verse I become affected by the retelling of my story and I change my focus to see the visions again quite clearly in front of me. I am reliving the story and have no need to catch the conductor: the work in rehearsal has reinforced the musical aspects.

I remember a note the conductor gave me to give the dotted semiquavers more physical energy to be articulated properly, as in Ex. 4.1, to illustrate my emotional disturbance. 
Example 4.1

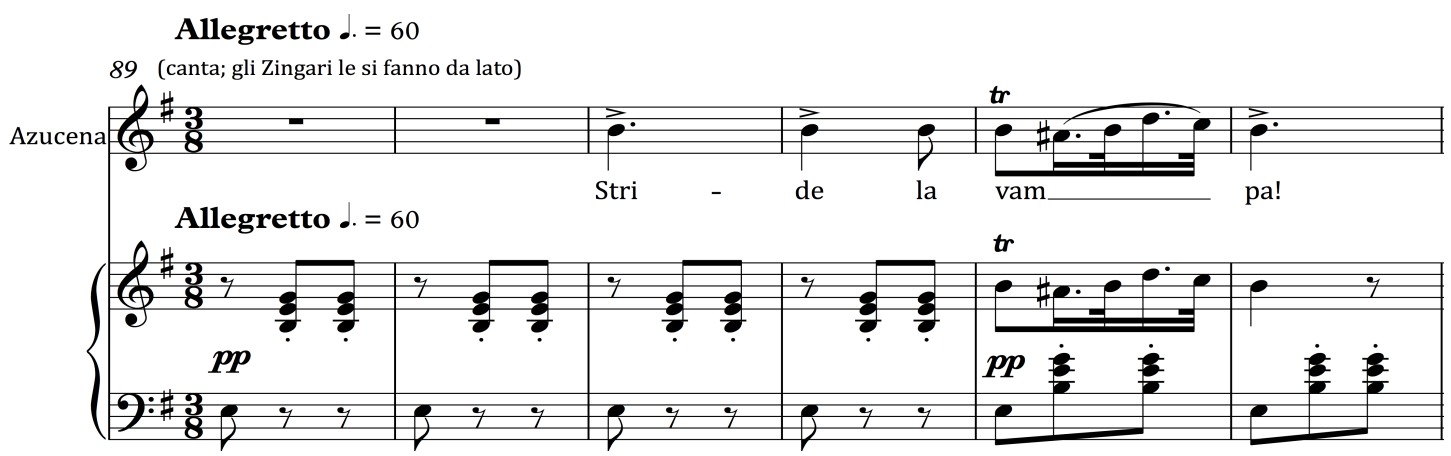

As the vocal line climbs to Urli di gioia, and la tetra fiamma, I get more excited and intense and in a split second remember to keep down inside to anchor and support: to keep the vocal resonator tract open, keep a dark timbre in the sound, keep the laryngeal tilt. The emotion brings me to my feet which is just as well as the trills at the end of both verses must be stable and engaged on the body, as though demonstrating inner conflict and fear; going up to the G at the top of the phrase can be a challenge as the aria needs a lot of tone, volume and projection in the middle of the voice, and can get stuck unless the laryngeal tilt is manoeuvred up through the passaggio successfully.

The second verse contains more inflammatory words, inciting me to more dramatic word painting; grido (cry) and orribili (horrible). Hearing the chorus comment on the story brings me sharply back from my visions, and I use that shock to drop the voice after Mi vendica! (I will be avenged) to the lower passaggio into the chest resonance. My process is to internalise here, pulling everything back inside, but still projecting out.

The chorus disperses and I hardly notice.... my mind is rerunning the scene of the burning and I feel myself becoming visionary again. Manrico asks me if I will tell him the story. This interruption from my intent focus on the imaginary allows me to stir surreptitiously to relieve the muscles a little as the racconto now needs heavy body support to protect the voice. I remind myself to keep low, as I get excited and emotional in Condotta ell'era in ceppi. It builds slowly, rhythmically and insistently. I gain colour from the bottom of the voice and move it up, the reiterated upward moving phrases 
here helping to set the voice up well for the following passages. I remind myself again to settle and not to hyperventilate, not to take too much air in; not only am I breathing in short phrases but the emotional involvement and horror of the story in the telling lends itself to gasps of breath, (Ex. 4.2). My hallucinations require such mental concentration and projection that the music sings itself: I am not aware of the music but only of telling the story.

As my body engagement mounts I remind myself not to bend over into the classic distress pose with arms clasping the stomach. It is tricky here when the psychical distress is so great. I remind myself to keep my face up and in the light so that the audience can the process of the emotion, can see my face and the eyes, can hear the voice projecting out over the pit; my alignment must be such that the movement of my body does not compromise the voice. ${ }^{329}$ I keep my mind stable and in the flow, allowing any emotional recollections or construction to come to the surface without disturbing the vocality. It is a satisfying feeling of "being" Azucena, being the wild and uncontained person she is.

Example 4.2
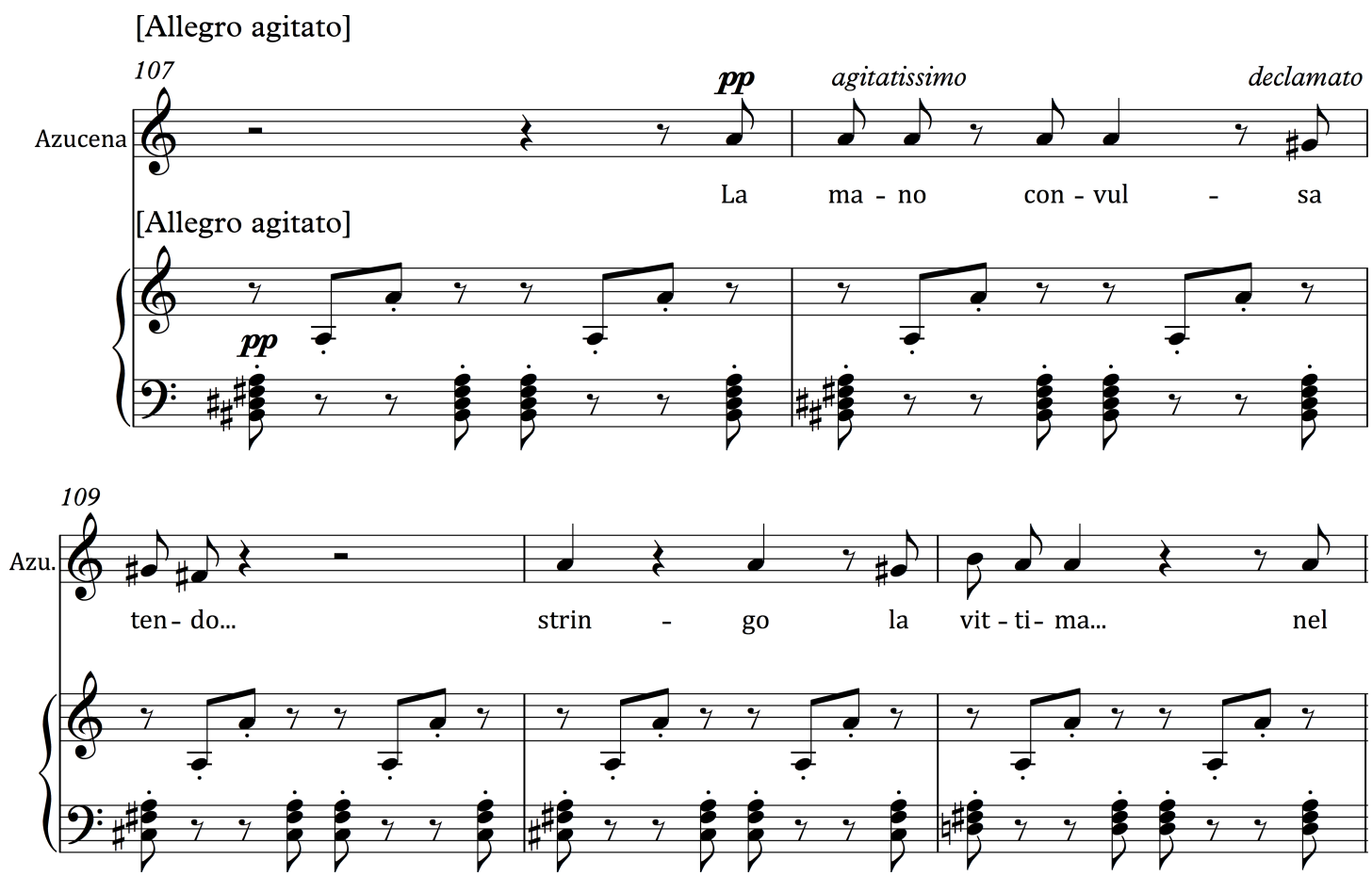

${ }^{329}$ Alignment: good singing relies on the correct alignment of neck and body, giving the back neck and back muscles the optimum working conditions. 
The natural inflections of fragmentary speech simulate a delirious nightmare accelerating towards a crisis, and my physical restlessness increases. As my tendency is to move too much, I rein in my energy and focus it. Driven by the quick changes of mood and memories of the racconto and driving rhythm, I hope the conductor will keep the tempo steady as I have asked him to, and won't go with me as I race towards the top A. I won't have time to prepare my body to sing the A in the properly timbred sound otherwise and I risk shrieking with consequent damage. Engaging the body and planning my approach I achieve the sound and mood I want and pull my full attention back to the vision of the body of the child burning in the fire. I am still and grounded, fully engaged as the top B flat leads in to desperate repetitions at the top of my voice, my imagination conjuring up the maximum laryngeal tilt to get the best possible affective vocal sound. After my cries of desperation I collapse, my heart racing from the effort in the embodiment, and the excitement. The end of the racconto is low and brooding, and I need to colour the voice appropriately, (Ex.4.3). I centre mentally and surreptitiously stretch my tongue out inside my mouth - the larynx is low here and I have used a lot of energy at the top of my voice on my folds so I engage the muscles of the retraction, back neck, and use a glottal stroke to thicken the folds and settle the pitch.

Example 4.3

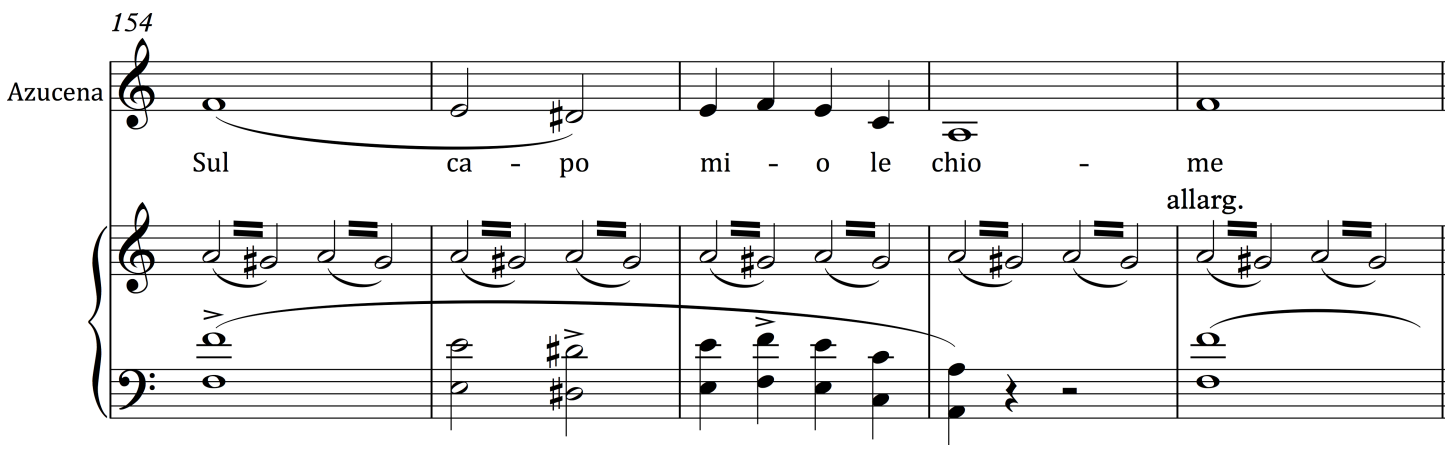


Using a gentler vocal timbre and a more intimate tone I soothe Manrico and allay his fears. The dialogue allows my body to calm down but my physicality remains alert. I quickly sidestep Manrico's question; though having something of a vocal rest here, my concentration, projection and focus on Manrico is unwavering. He sets off on his aria and I join in with dynamic lower notes that need a lot of diaphragmatic energy, remembering to contrast with phrases in the voce spianato style, again upward moving phrases with a strong vowel line. The duet is stirring and energetic and I remind myself to get my energy running on high, keeping the character vital and reactive to Manrico - almost masculine and warlike, but flipping back to the alternate world running in her head. I stay in the moment here, the rhythm driving the momentum and supporting the wonderful legato lines, culminating in the cadenza containing the top, (Ex.4.4). It is an easy approach to get this $C$ - I am swept up by the feeling and emotion; the $C$ is contained within a line and not sustained, and so sounds like the plea it is.

Example 4.4
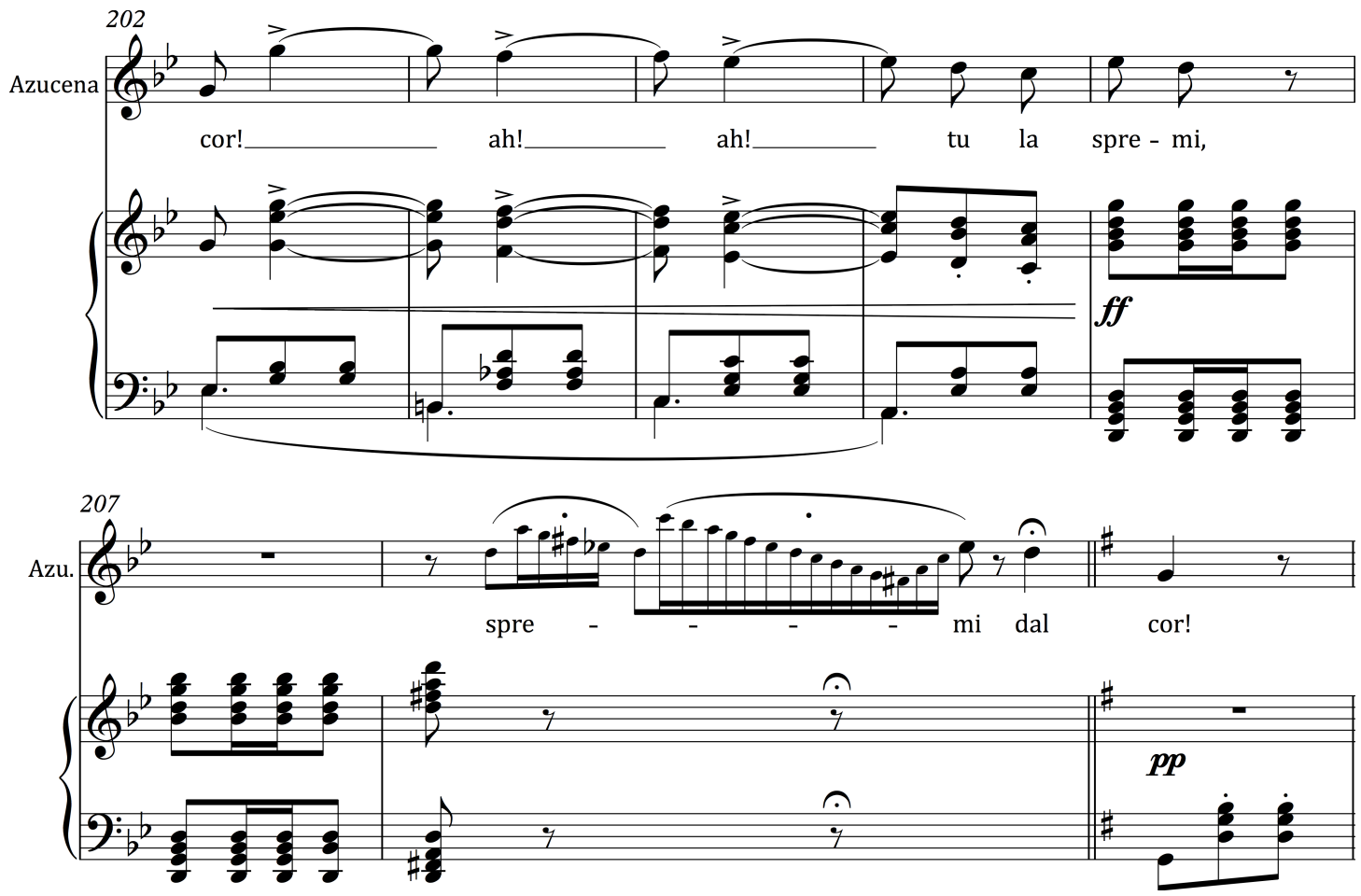
I sing this duet with bodily enjoyment, with jouissance: the feel of my voice, of singing with the tenor gives me pleasure and release and I come off stage quite high. In addition to the excitement of this passage, it contains much singing and I travel through the many breaths quickly, becoming overoxygenated.

Though pleased to be able to have a drink, I am impatient to get on with my story: I can't settle through the interval and pace until I am back onstage again. I concentrate to have a quick debrief of all I did - whether I felt it was good, whether it needs improvement, and what I could do to improve it.

The careful plotting of my interpretative process has paid dividends in this Act. I feel satisfied that I was able to keep in the role and emote what I needed to, yet calmly access all the procedures I have minutely practised. Settling into the meta-drastic or embodied continuum, my intensive work on the gnostic processes proved to be freeing and allowed me to work creatively with the text and music. The emotions got a little high but I was able to activate more anchoring on the body to keep them in check. Yet I was still able to stay in the flow, in the creative moment.

While standing on the side of the stage for Act III, I am hoping the men of the chorus have remembered my wish to be held firmly, so I can use them as a counterweight, but not so tight and roughly that I get bruised. As I move onto the stage I try not to use too much energy fighting the chorus however it does settle my body engagement for the singing. I try to wheedle my way out of being apprehended, invoking the wide open spaces of the mountains, invoking a "typical" gypsy persona. My words are simple but evocative and I want my persuasive articulation to reach my captors; I remember the many accenti here (another note from the conductor) and I try out different vocal weights and diaphragmatic energy and will ask afterwards what he thought of what I did. ${ }^{330}$ I enjoy the persuasive singing

\footnotetext{
330 Verdian accenti, staccati and marcato marks are quite different from those of other instruments. Each mark has its particular energy from the diaphragm: what is unstated though is that the accent is on the vowel not the consonant.
} 
of Giorni poveri vivea: the line and legato are pleasurable and a lovely melody I enjoy sharing (both as Azucena and as myself)(Ex 4.5). 
Example 4.5
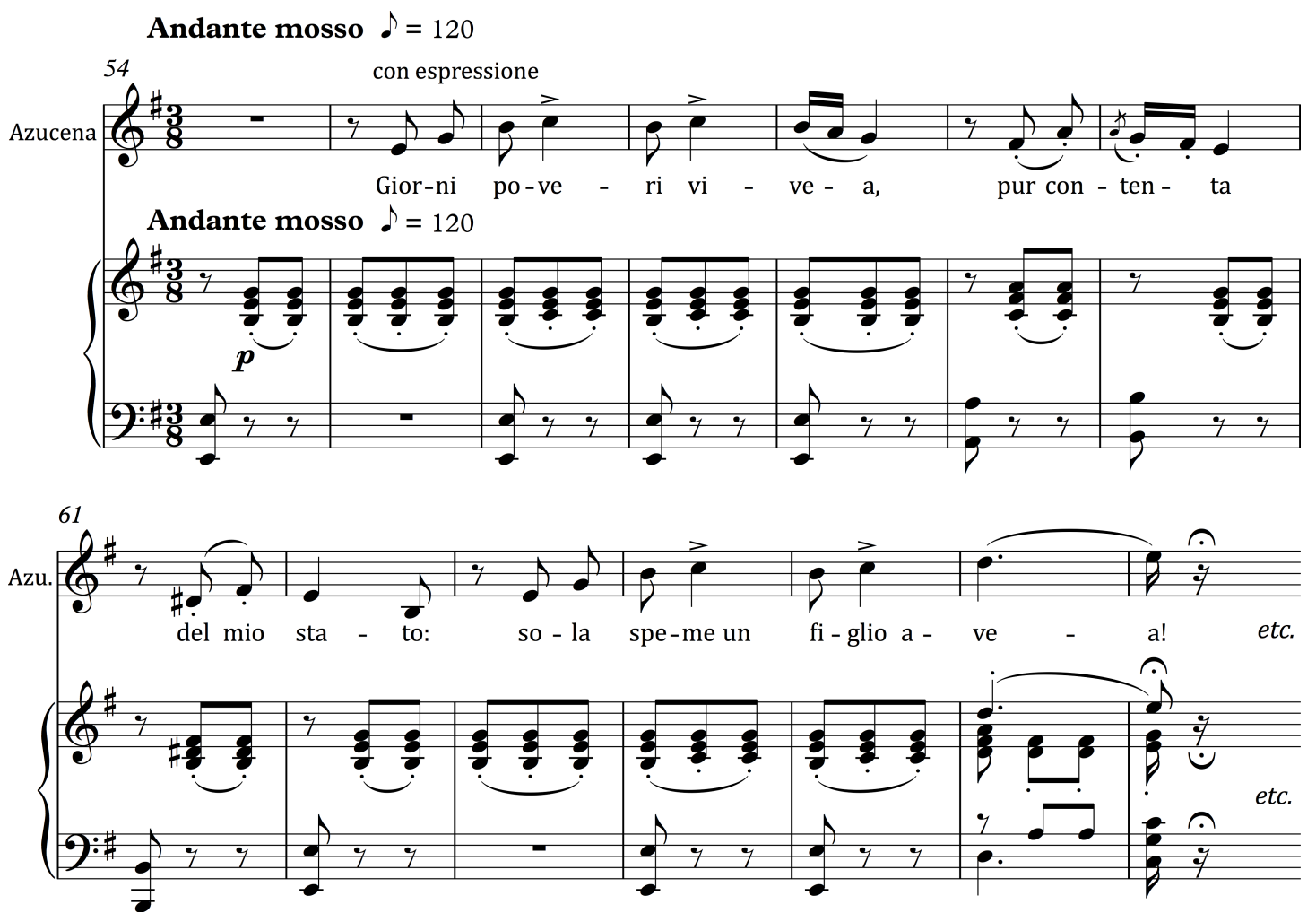

Concentrating on the quality of the vocal sound, I focus on the vowel stream and seek a persuasive and regretful tone, lowering and tilting the larynx. Once recognised by Ferrando and di Luna as the mother of Manrico, I snap back to my alert and dangerous physicality, letting go of the hackneyed gypsy pose. In the exciting ensemble that follows, my vocal line is supported by the male chorus sound and rhythmically driven forward by the energetic semiquavers. There are many accenti and the sound is well embedded on the body, almost declamato in places as per Verdi's markings. I employ a desperation in my vocal sound that seems to incite the men, and they drive the music forward, making it difficult to catch a breath - I keep calm enough to remember that a quick and strong release is needed to drop the larynx and also breathe effectively. Despite my physical struggles with the chorus I feel buoyant as I come off stage - but quickly remind myself that there is a long break until my next scene. I read my score, remembering notes given to me, setting myself creative tasks. It is difficult to create the slippery vague persona of Azucena when she is so distressed, and yet sing firmly with projection. 
Although I feel the scene has been successful, I felt a little out of control as the chorus men were an unknown entity, and I had to deal with whatever happened. I didn't mind that as I had to keep creative and adjust my acting and voice to deal with different interpretative, "ideal" routines I had worked on.

A pre-set on stage allows me to envision myself into Azucena's world before the music starts: traumatised by my capture and tortured by the claustrophobic cell, I start to slip back into my other world of the fire and the stake, reliving my experiences again. I find a way to sing this reiteration to make this memory different, more pathetic than before. I am aware of the powerful voice of Manrico and need to engage resonance to project my intentionally feebler one to match up. I project my disappearance into hallucinations, feeling the fire, il rogo, near me. I need to keep this real, to feel the horror: it is easy for this scene to descend into melodrama - to make it real makes it much more horrifying and gripping for the audience.

Though it has elements of melodrama in it, Il trovatore when it is played for real, when the elements of operatic excess are contained, is a much more effective piece of theatre. A much easier task for Azucena and di Luna than Leonora and Manrico, it has to be said.

Eventually calmed by Manrico, I sink into a sleep singing a simple song about our mountain home. Even though "going to sleep," I need to manipulate myself into a position that I can sing and project from, and see the conductor through my eyelashes. While I am "asleep" in the course of the scene between Leonora and Manrico, my physical restlessness fortunately prevents me from relaxing. Half-asleep, I join in their duet repeating my song about my home, then subside back into silence until I am abruptly woken by Manrico calling me as he is dragged away to be executed. The sudden awakening calls for careful planning and rehearsal - the voice needs to go straight up to the passaggio area and sustain the pitch and so needs a lot of engagement and colour in the sound. Here with shock, I am suddenly completely lucid - and can witness the fulfilling of my misguided revenge for my mother. I have declaimed at pitch to practise placement and projection 
for most of this section, so I am confident of the high B flat. It is difficult to make a decent sound at that pitch in these circumstances. I suspect Verdi did not mind that the sound was more like a scream as it suits the drama of the situation.

Though attempting to remain in the state of flow or embodied continuum during the performance, I still needed quick reminders to myself to achieve certain goals. And of course in an opera where there are intervals and times when one is not on stage it is possible to plan the scene coming in some detail. Then the challenge is not to waver from that plan. Mental rehearsal is vital in this regard, and after each performance I debrief myself to see what I achieved and what I can focus on next time. The role of Azucena is a rollercoaster of a ride, easy to over-act and over-sing as you let the emotion of the opera take you over. It is a role for a mature singer: the musculature as you get older has enough mass to work the body to keep the (relatively small) vocal resonator tract open; it needs an experienced singer, one who knows where to give and where to be careful. It is not a long role, but the range is wide and sits on the lower and upper passaggi that requires strength. Unless the role is well sung in and rehearsed, in addition to being mentally rehearsed, I run the risk of letting the stage animal take over, and blasting technique to the wind. My meta-drastic state contains a huge amount of preparation, the bodily accretion of knowledge. It contains inventive play, but I allow myself also to work creatively on stage. I am skilled enough to deal with most different elements my colleagues throw at me, and prefer to create anew each night to keep the performance in the moment, now. 


\section{La prima donna}

Leonora's vocality in Il trovatore is noticeably different from Azucena's. Verdi leaves the singer considerable freedom in some areas as to how she uses her breath to create her sound, and it is the manipulation of all the elements of bodily engagement that allows the singer to employ the breath creatively to enhance the dramatic possibilities of the role. As she appears to be passive in regards to the action, it is essential that her vocality has presence and can thus establish her personality. She is less active physically than Azucena, and her music is much more sustained in the arias, and much more vital in the coloratura cabalettas. She noticeably does not have the masculine forwardness or thrust that Azucena's vocality has, and her vocality requires a limpidity, in places reminiscent of Donizetti and Bellini, and a playful youthfulness in the earlier cabalettas. In the large ensembles, despite her unforthcoming personality, she must dominate the ensembles. In part that is relatively easy as she is singing the top line, but the sound of the voice must have authority. This is the way the voice of Leonora is trained: a declamatory practice builds up a certain harmonic structure in the voice, and that command is enhanced by the muscular involvement of the body. ${ }^{331}$

To balance the vocal spectacle of Leonora's music it is vital to find something within that is real and human: a quality in the sound that belies the assurance of the technical facility of the voice, and shows us how vulnerable and passionate she is. To be emotionally communicative her body must be heard in the sound. How it is involved in a slow aria - where there is time to think and prepare the sound, to respond to every core meaning of every word - is a matter

331 Geoffrey Riggs points out that evolving, as it has, from the prima donna assoluta, Leonora's entire role focuses most centrally on vocal spectacle and display. "To master any of the assoluta roles," Riggs says, "a diva must have an instrument that projects with ease over an energetic orchestra". He goes on to say that she must have a technique that encompasses all bel canto ornamentation and the skill to combine this with her most heroic vocal quality; messa di voce; a large range from a high $\mathrm{D}$ flat to a low of $\mathrm{A}$ or $\mathrm{G}$ below middle $\mathrm{C}$, and the ability to sustain that low tessitura if needed and also a high one, and most of all, a vocal stamina which allows her to sing long sustained roles with ease. This list contains everything that can challenge a large, dark coloured voice and yet clearly the music needs a voice of weight to command the stage and to align with the voices and music of the other characters. Geoffrey S. Riggs, The Assoluta Voice in Opera 1797 - 1847 (London: McFarland, 2003), 10. 
of the singer's individual creativity in articulating the internal voice of her character. The colour of the sound with the lowered and tilted larynx, creates a particularly affecting sound and is my technique to suggest the inner turmoil of Leonora: the frustrated woman, the woman imagining a more active life with a man whose voice she has fallen in love with. She eventually realises that her power is in the seductive use of her voice and uses it to try to save the man she loves, therefore silencing herself forever.

Leonora, as a representative of the Spanish aristocracy, is enclosed in her strata of society. The music and text invite a powerful expression of that sense of entrapment by wrapping her in the musical forms of that constraint. ${ }^{332}$ As a character, Leonora's choices are controlled by her role and standing in her society. She seems to be as passively enclosed in her music as she is in the society she lives in, bound to the rhythmic vitality and syllabic registration of her music: the way she interacts with Manrico and particularly di Luna, rhythmically entrain her. The trio in Act I with Manrico and di Luna, and her duet with di Luna in Act IV typify that movement. The music points towards these dramatic confrontations. Indeed as Roger Parker says, "the music is channelled into the key confrontations that mark its inexorable progress [of the drama]."333 Her marvellous arias indicate the level of virtuosity that was expected. In singing this fast-moving syllabic music one has no time for finessing the sound: one sets up the vocal resonator tract for the tessitura and sings, taking particular care to reset correctly every time one breathes. ${ }^{334}$ Rodolfo Celletti, in A History of Bel Canto, suggests that Verdi, "when he wishes to imbue Leonora with amorous sentiments, red-hot by their standards, and a capacity to react against adversity more powerful than that normally shown by vestal virgins, it is mainly through

\footnotetext{
332 See James A. Hepokoski, "Ottocento Opera as Cultural Drama: Generic mixtures in Il Trovatore", Verdi's Middle Period: Source, Studies, and Performance practise, ed. Martin Chusid (Chicago: University of Chicago Press 1997).

333 Roger Parker, "Il trovatore" in The New Grove Guide to Verdi and his Operas, Vol 4, ed. Stanley Sadie (London: Macmillan 1998), 827.

334 Baldini, The Story of Giuseppe Verdi, 218
} 
coloratura singing that he expresses the special temper of such a heroine." 335 Her love for Manrico makes her surrender to a long and sinuous line; but, as Baldini points out, she has moments of unexpected violence, particularly in the di Luna duet where she equals the baritone's enormous energy. ${ }^{336}$ Perhaps this unexpected vehemence in an indication that Leonora does have her escape routes from her society through both her voice and her mind. Her role is also about singing: Leonora's second double aria from Act IV D'amor sull'ali rosee is, as Roger Parker says, about singing, and listening to the same song. Interestingly the music was written before the words were, and they were, as Parker suggests, "loosely draped" around the music. ${ }^{337}$

To prepare for Leonora the singer must have facility in coloratura and for many singers that needs to be part of the daily vocal warm-up. Because of the variety of technical demands, Leonora is a feat of athleticism and the singer needs to keep in top form with daily vocal exercises that can be strenuous. Not only must the musculature be strong enough to hold available all harmonic possibilities of the vocal resonator tract open, to sing loudly and softly at height, but it must be flexible enough to allow staccati and runs of the cabalettas. In Act IV in the Miserere, Leonora must introduce a certain amount of chest resonance into her voice in a dramatic and forceful way. This requires additional bodily engagement to match the tone to the rest of the voice. The role is long and challenging and the singer is judged on the sound quality in a way that Azucena is not. On the other hand, there is less overt dramatic expression. However, it is the ability to spin a long, unbroken phrase with impeccable control that makes the greatest interpreters stand apart. The ability to get to the meta-drastic state is compromised in this role - the challenges are great, and the role's motivation relatively light, so that while the processes on the physical side are complex and exhaustive, it is hard to get to the state of continuum.

\footnotetext{
335 Rodolfo Celletti, History of Bel Canto (Oxford: Clarendon Press, 1991), 196.

336 Baldini, The Story of Giuseppe Verdi, 212, 221.

337 Roger Parker, “Leonora's Last Act: Il trovatore," Leonora's Last Act: Essays in Verdian Discourse (Princeton: Princeton University Press, 1997), 185-187.
} 
Rehearsing Leonora means that one is vocally fit and a warm up does not take too long. Most difficult to control are the nerves: I am not sure if I enjoy singing Leonora - there are bits that I like, and I admire her for breaking out of her sheltered upbringing, but I also wonder why she concerns herself with Manrico. However, she has been entranced and seduced by his voice, and is happy to be whisked off, to leave her home for some excitement. The first and most important challenge then is to control my mind: I must leave my twenty-first century feminist leanings behind, and put myself firmly back in the fifteenth century (or wherever the director sets the opera). ${ }^{338}$ Makeup time is spent thinking myself into the time of first love, becoming innocent and naïve again, and building gentle delicate energy.

Once on stage I am excited about having heard the troubador Manrico singing to me: I concentrate on bringing the full power and bloom of my voice from the start of the aria, anchoring low in the body, concentrating on the depth of sound that I feel gives me a feeling of physical release. In Tacea la notte the relaxed tempo of the aria allows me time to think creatively about the sound I am making. I concentrate on the voce spianato, even, sustained singing, and manipulate my sound in my best creative way to devise the compelling vocality I need: the climbing phrases at the end of each verse allow my own movement, my own intensity to move the phrase. The movement of the breath, the freedom of its flow and speed, assists my voice in climbing the phrases, optimising the phrasal structure, sending subtle messages about my character and motivations. I am aware of my ribs and the appoggio working hard to sustain the tone. Indeed the warming and more intense vocal quality, indicative of more physical engagement, indicates my rising physical excitement. Experimenting with different words, I have changed the registration of the words to the pitches to make the best possible sound I can. In the slow movement of the double

\footnotetext{
338 There is of course the question of whether you embody the world of the original setting, the composer, the setting of the production, or your own world? It would be hard to judge the difference, in terms of vocality, so the only way forward is to sing and embody that singing on your own terms.
} 
aria I am able to create a sound that is free from exacting rhythmic constraints and I relish that freedom.

Although the text is of course important, it is the sound quality that captures the essence of my feelings and delivers the "extra-textual" information to the listener. Mine is not an "action" role; I cultivate a certain stillness and projection as an actor here, and generally the concentration needed to make the sound required precludes rushing around the stage. Following Tacea la notte, Leonora's music becomes fast and rhythmically vital in the cabaletta Di tale amor. I focus my voice to be precise in the coloratura, and the physical experience of this cabaletta is of a kind of freedom with the ribs and diaphragm free and vital after the sustained previous work. There is a mental freedom as well: belying the exactitude needed, there is a recklessness and exhilaration in the rushing notes. It is true that the energy need in singing coloratura in cabaletti certainly engages the body more, and of course, in contrast to the aria, presents me as much more active and spirited; whether that can always be construed as more potent is another matter.

I take time to settle myself after the cabaletta. The following terzetto is hard; it is fast and sits high in the voice for me, Manrico and di Luna. Though there is a standoff between the two men, generally only some basic stage actions are carried out, as much bodily engagement is needed to sustain the sound. The pitch is unremittingly high, and the rhythmic setting of the text is very fast, and needs good ensemble singing. We have been reluctant to rehearse this terzetto as it is exhausting to sing, so we rely on learnt musical skills and empathetic connection to make the piece work.

After this challenging but invigorating trio, I compose myself offstage and think through my acting process as Leonora prepares to be admitted to the convent. After the physical excitement it is hard to become calm and yet still physically engaged enough to sing the canto spianato required for this scene. However, when Manrico appears I sing a recitative. The music is a joy to sing: the emotions are so bodily based I need to keep focused on my body 
and the vocal resonator tract as what follows is a strange frozen moment in time where a wonderful rhythmically entraining chorus happens, but no action. This is a tricky singing task for me, especially with my dramatic voice: I sing mainly above the passaggio, the top line, in a light spun sound with coloratura, riding the full chorus, other roles and the orchestra. It requires a tremendous amount of concentration and engagement to be in tune and to pinpoint each note accurately, and for a voice of weight, is a considerable challenge (Ex.4.6).

Example 4.6

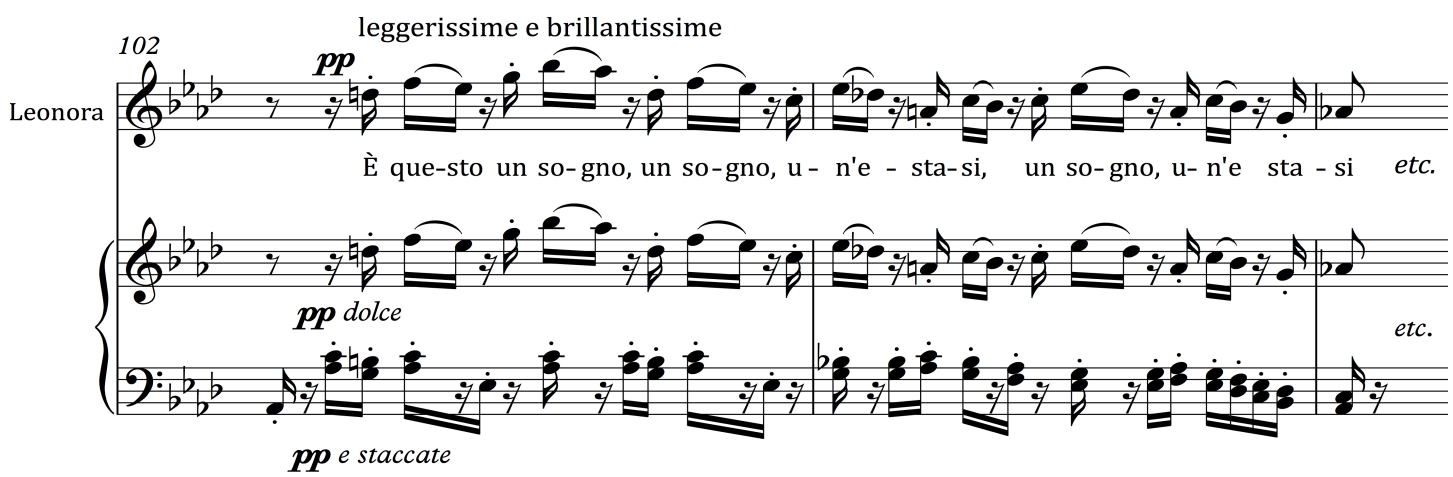

The interval comes as a welcome relief: to have a drink, to review how I am singing and whether or not I feel convinced with what I have achieved, and what more I need to do. I review my music and notes and set out for Acts II and IV. I feel trepidation as there is a lot of challenging singing coming up and I need to keep in the character and make her convincing. My vocal exercises and detailing have been exhaustive, but still so much relies on how I prepare in the moment, how my body feels in the moment, and I find that worrying, but try not to let it distract. The flow is not as embodied as I would prefer and allows anxiety to creep in.

Standing on the side of the stage for Act III, I practise some positive psychology and project the joy I will soon have: I finally see Manrico and am about to be married. Supported only by an off-stage organ, I sing of our life together. These lines require a light joyful, almost child-like tone with an innocent quality, almost disembodied, and I cut back the weight from the voice. When we are interrupted by Ruiz informing Manrico that Azucena has 
been captured, I interject powerfully; for the first time I feel I am showing some backbone, and I take this point as a turning point in my journey as Leonora. This is a scene where it is hard to build any sense of the character, and the music is insubstantial and unsatisfying from a physical point of view. I work hard at being collegial and stand embraced by Manrico while he sings one of the hardest tenor arias in the repertoire; it is a thrill to listen to such passionate singing at close quarters. This almost makes up for being left yet again, but it is the shock of my desertion that stiffens my resolve, and I feel energised and look forward to singing with some purpose and forward movement. I enter for Act IV feeling determined, loving and full of energy, ready to make the most beautiful, meaningful sound in D'amor sull'ali rosee.

An aria as slow and sustained as D'amor sull'ali rosee requires the body of the singer to be muscularly engaged in a way that stabilises the sound and maximises harmonic structure, enhancing the chiaroscuro and allowing the singer to fully engage the laryngeal tilt, necessary to create an affect. To achieve that affect I engage several different elements in my embodiment matrix: of course I work the extrinsic muscles hard to maintain the harmonic structure in the vocal resonator tract, but as I am by myself on stage for the first time, I work at a projection of presence and emotional connection. Once these embodiment requirements are met in their individual way in my mind and body, it then becomes a matter of choice how I move the air through the phrase, which word I emphasise. I focus on my breath control, concentrating on the appoggio; that work provides the focus for the most basic interpretative choices, choosing dynamic contrasts and minute changes of pressure on the vocal folds which enhance and shift the colour. Here, where there is little insistent rhythmic drive, I need impeccable breath control - a hard balance between keeping the sound flowing and yet not undernourishing (that is, undersinging) or running out of breath - one of the reasons it takes years to train for this repertoire. Again it is the movement through the phrases, the flow of the air into sound that gives us a subtext, individual to myself. 
Example 4.7

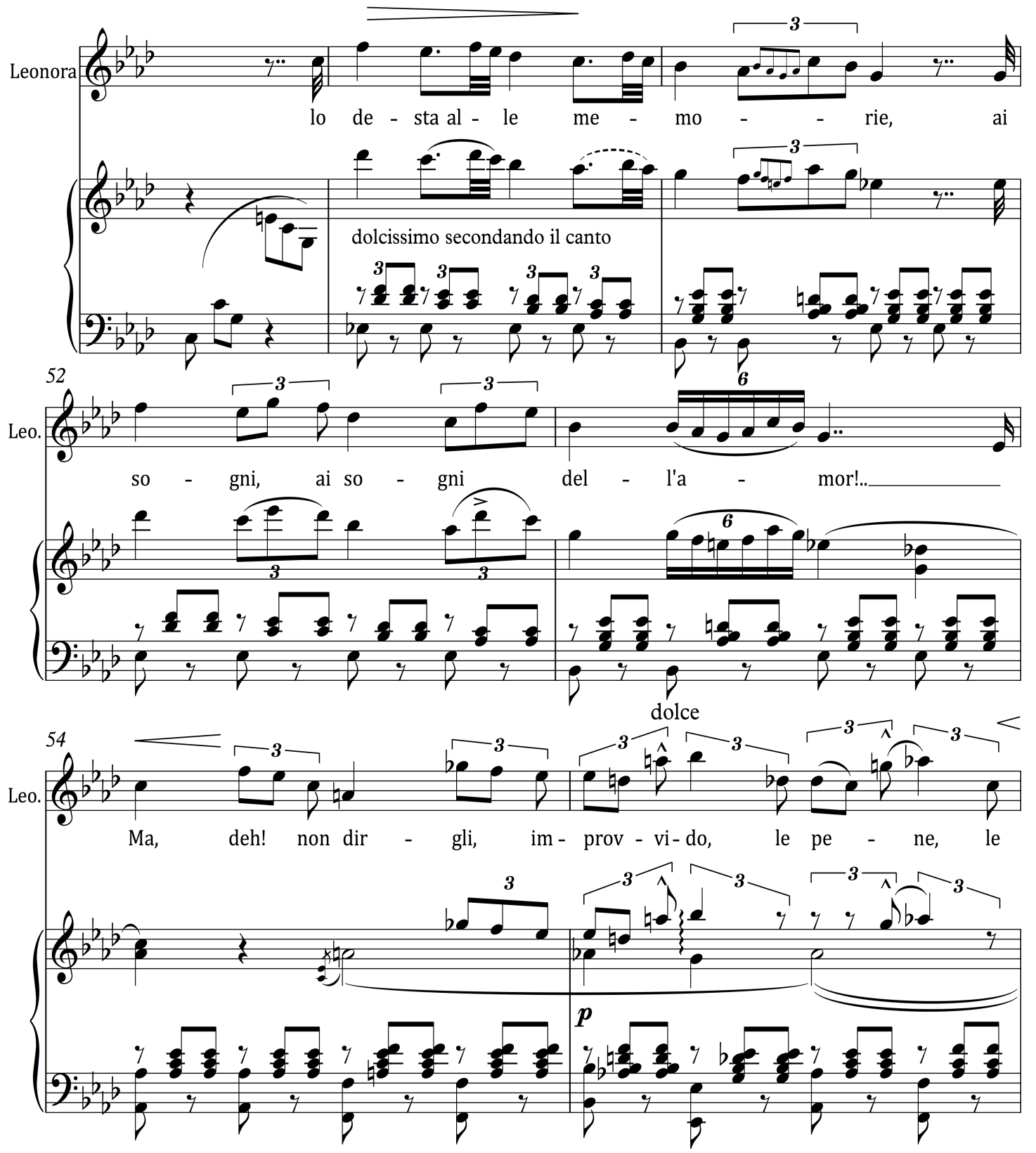

Towards the climax, D'amor sull'ali rosee climbs in tessitura, heightening the emotional intensity with textual repetition, (Ex. 4.7). There are differences in the way singers move through the phrase according to the subtext they have worked out for themselves, their breath management skills and their use of registration changes. The differences mainly lie in where the words are placed and where the breaths are taken, with the consequent alteration of the relationship of word to note. It is an aria that depends very much on my vocal health. I try not to do much onstage in the way of actions as the sheer physical concentration of making this continuous 
stream of sound requires delicately balanced muscular support making energetic movement difficult. However hard the singing is, the music and my voice respond to heightened emotions and simultaneously releases accumulated tension, bringing with it a sense of relief. (Ex. 4.8)

Example 4.8

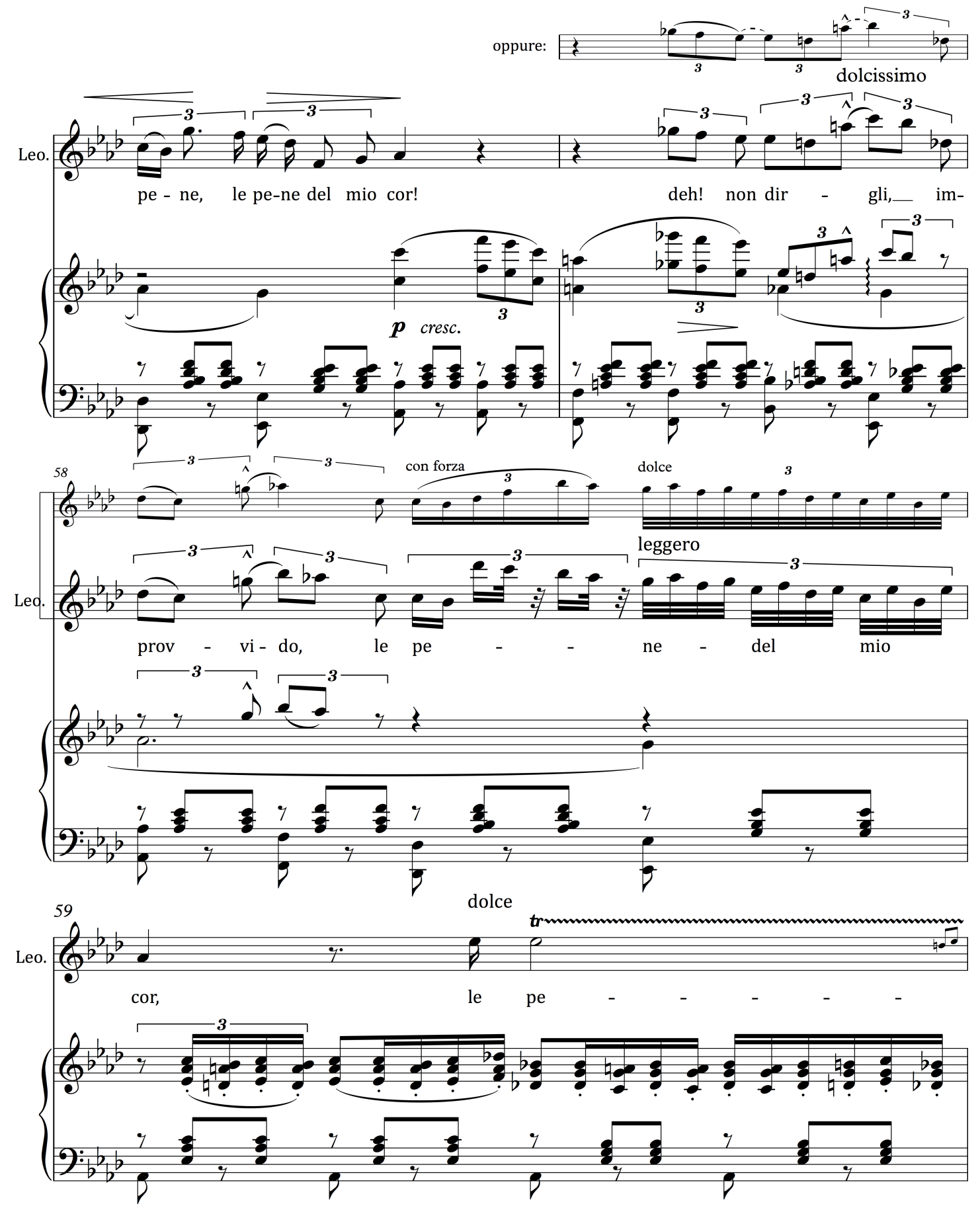



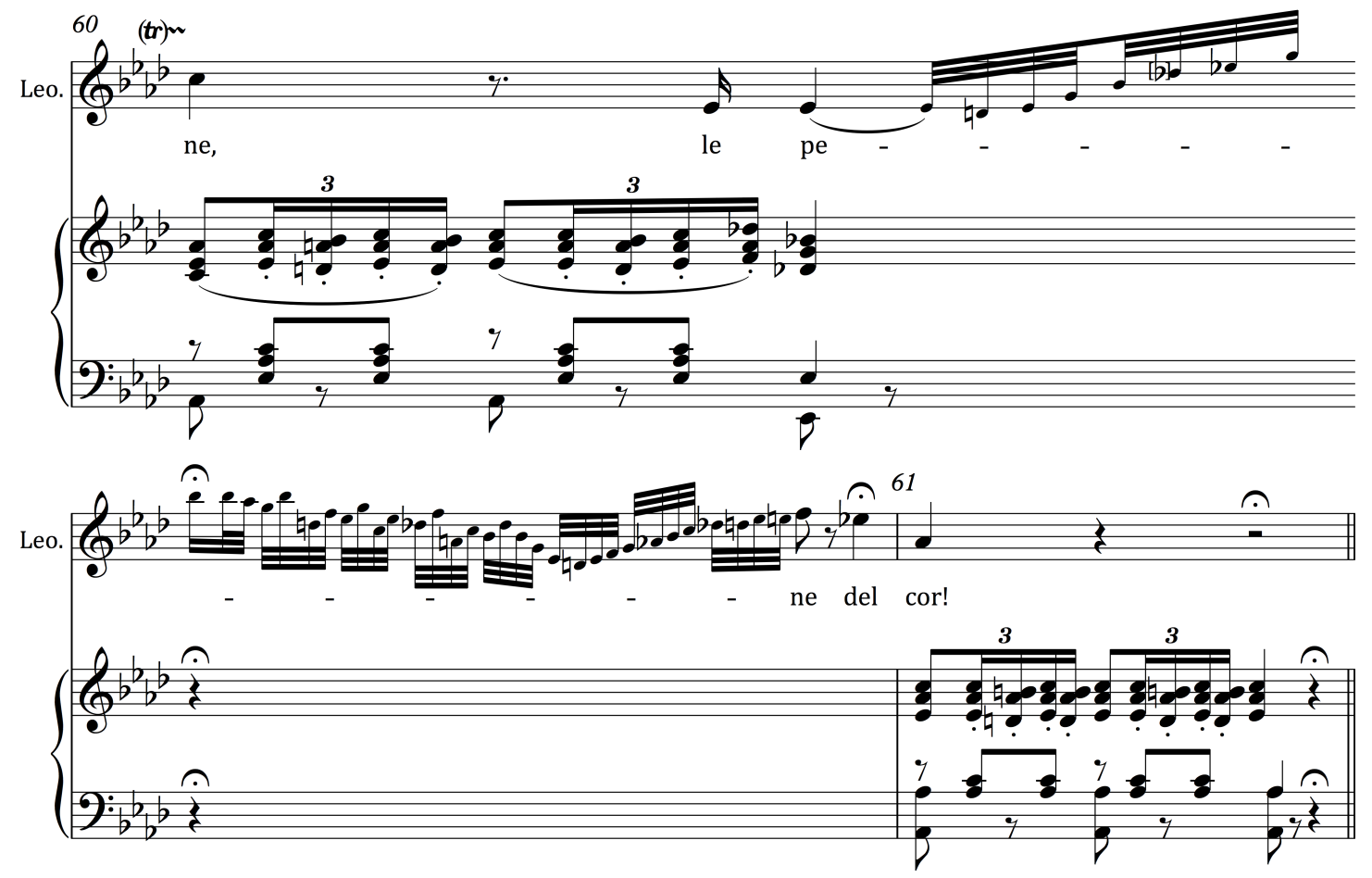

However, subtly and inexorably, it appears that Azucena's way of histrionic communication influences Leonora's and the prima donna role evolves in a way that paves the way for the dramatic development of Wagner's heroines.

After the aria, the dramatic setting of the Miserere is something I enjoy and is relatively easy to sing for me: the phrases are short and intense and require a more dramatic delivery than before, and a different use of the muscles supporting the voice from voce spianato to voce declamato. I remember on the words di te! di te! Scordarmi di te to gradate the colours of the voice, to show the emotional journey from despair and resignation to determination to find a solution and engineer Manrico's release from prison.

Example 4.9

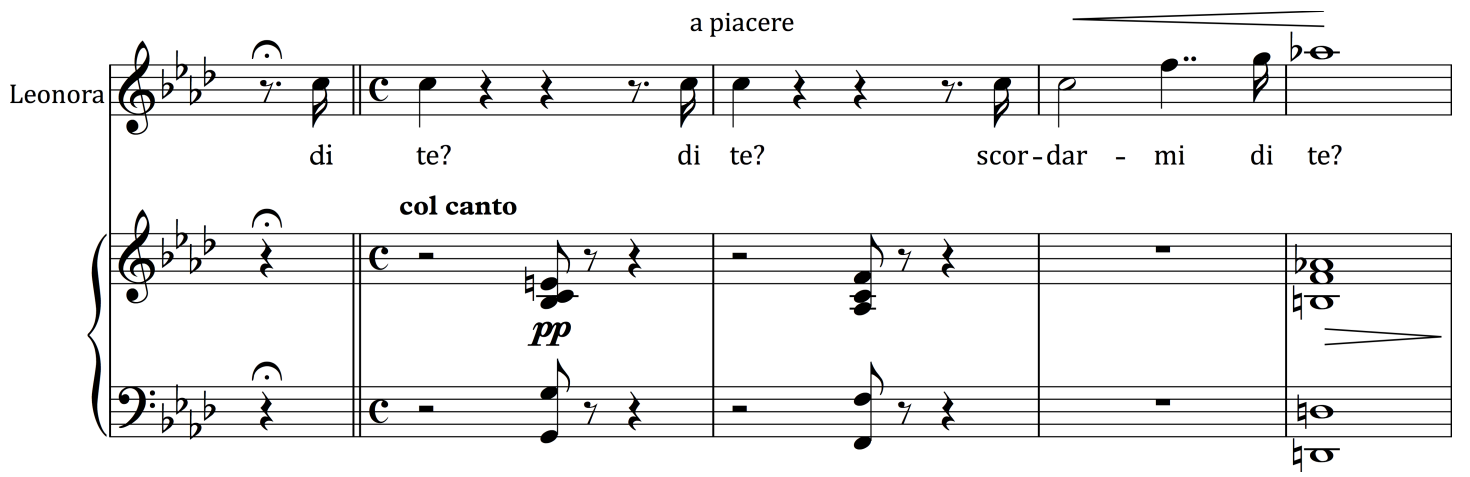


I concentrate on getting this phrase deep on my body, so that the voice is set up to sing the following challenging cabaletta, Tu vedrai che amore in terra. Starting at middle $C$ and ending on a sustained high $C$, this cabaletta is a test of register blending. ${ }^{339}$ It is a turning point for my character. Until now I have felt as if I was the "stand and sing" prima donna, all about vocal spectacle. Now I can combine the singing with dramatic intent and direction, and show the audience what I am capable of as a dramatic artist. In some ways this makes the role easier to sing; as a woman of action I now can move about the stage in a more purposeful way, and so release and engage muscular support as needed. The emotional connection, awareness of my character and presence/charisma are heightened and, as I have the whole stage to myself, I have to generate enough energy to fill and command the space. Even though this aria is testing, it is exhilarating to sing, but unless you are disciplined there is the risk you can rush. When this happens the body cannot release the muscles well enough on the breath in and the voice and body get tired too quickly. This then makes it impossible to set up well for the final triumphant high C. However, I have practised well and asked the conductor not to go with me, to hold me in check, and I finish with a high C I am pleased with.

As I finish the cabaletta, di Luna appears. I quickly hide (and have arranged with stage management to have some water available to me - my mucous membranes need some moisture as it's been a long sing), and I work through my process to give myself to di Luna in return for Manrico's freedom. I want the audience to see my process and reactions to what he is saying so I concentrate on being clear. Interpolated with very short bars of semi recitative this duet has a rhythmic insistence similar to much of Azucena's music, (Ex. 4.10)

\footnotetext{
339 The placement of it is interesting: Verdi was using the traditional form of the cabaletta in Il trovatore, when later he would break down and change the usage of it, but here it is, as Frits Noske puts it in" The Notorious Cabaletta", this cabaletta is "a milestone in the dramatic process", a necessary dramatic progression for Leonora. Frits Noske, "The Notorious Cabaletta", The Signifier and Signified (Den Haag, Martinus Nijhoff, 1977), 287.
} 
Example 4.10

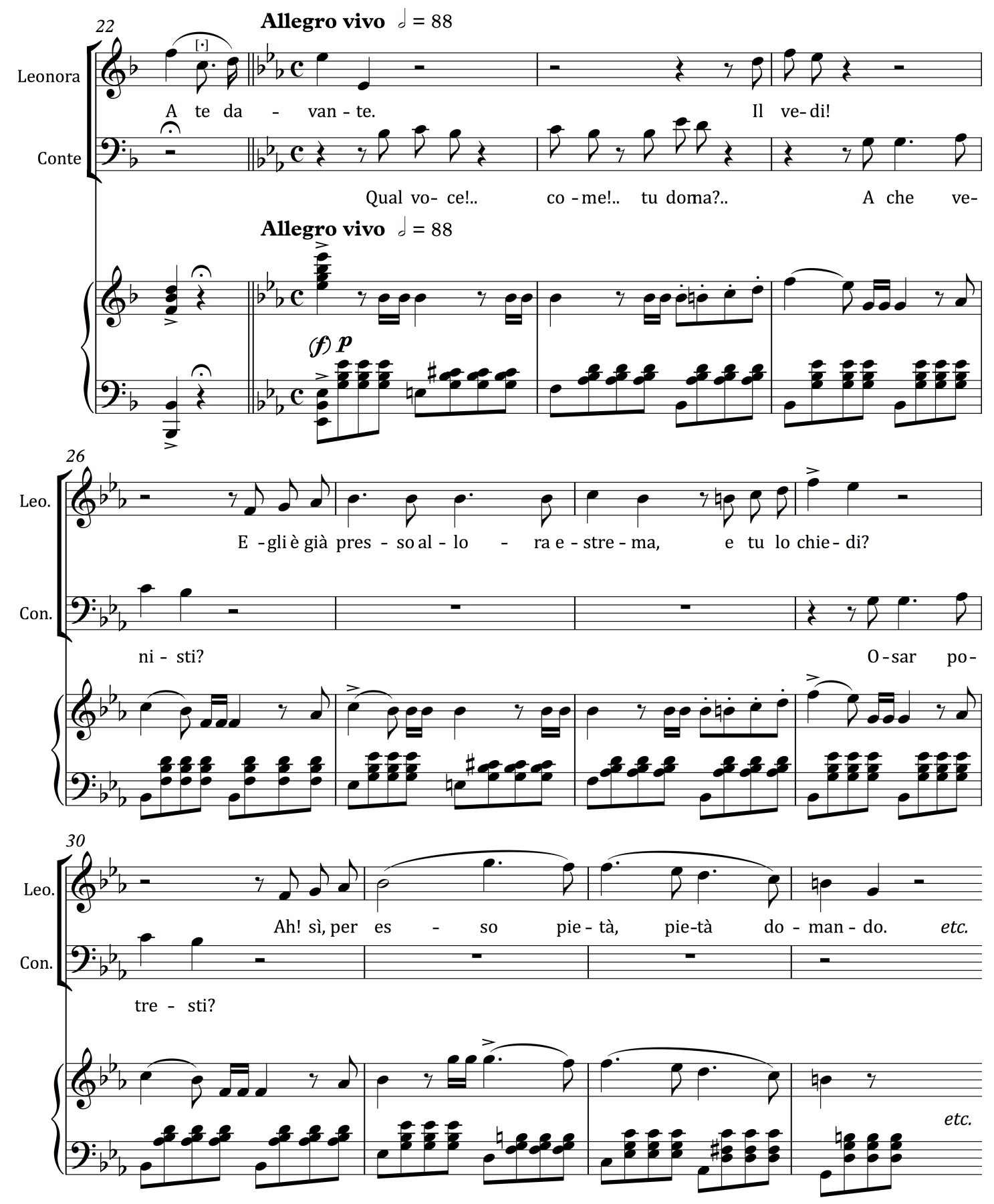

Its dramatic conception engages the singer, and gives energy to the singing: again the range is wide, but it is easier to deal with than the previous cabaletta, as the register changes are contained within the legato lines. 
When I take the poison, the best way to manage the transition is to go straight into chest resonance and stay in it (Ex. 4.11); I feel it provides an interesting brooding colour that contrasts well with the cabaletta that follows.

Example 4.11

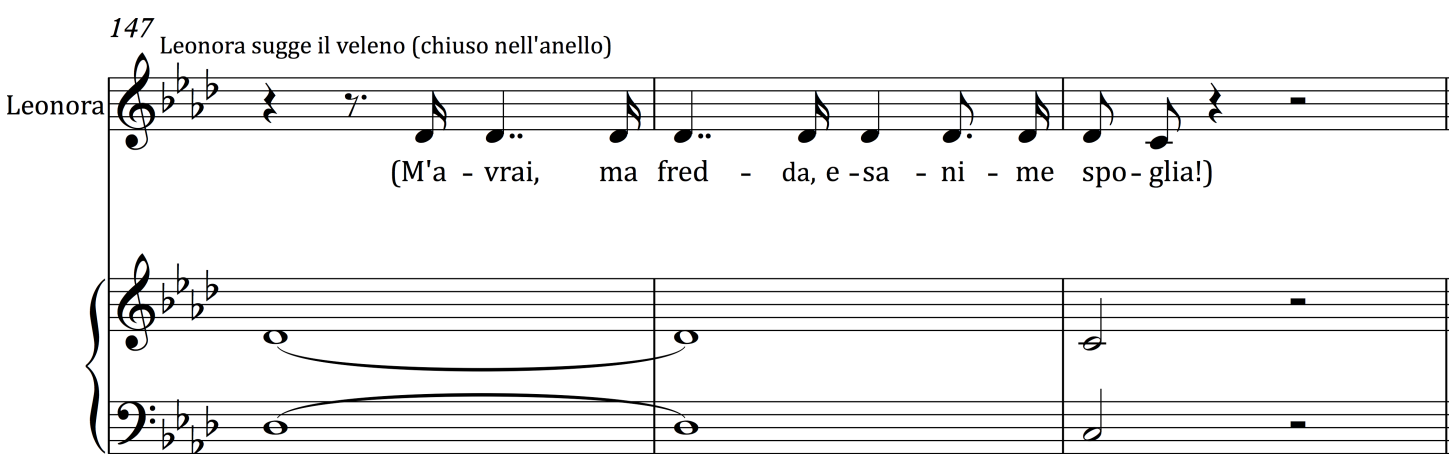

I enjoy the brilliant, fast singing in the cabaletta, with its articulated figures, cleverly written with short gasps of delight in the quaver rests contrasting with long legato lines. I leave the stage exhilarated and over oxygenated and quite "high" on the relief and satisfaction of finishing the long scene.

Reviewing my performance, I feel as if I have been over-thinking despite my best attempts not to. Over-thinking can limit one's performance by being too conscious of nuance and detail, preventing the activation of the creative consciousness. I have to trust that I have prepared well and need to let the voice and mind go and seek the embodied continuum I have worked so hard on.

The final scene is in the prison. There is not much of a break. I rest my back, stretch that out - it has been working hard on the appoggio. Manrico has just settled his distraught mother to sleep, and is surprised to be told to flee when I burst in on him. My energy is high and I need to project joy, triumph and fear. His immediate suspicion turns to anger at my betrayal; meanwhile my voice must show hysteria and become weaker as the poison takes hold. To sing this scene acting weaker and weaker but yet still projecting the voice is a challenge; as I collapse, I remember to get my body in a useful position, 
and then use laryngeal tilt, keeping the projection going, adding in more retraction and anchoring as I go through the scene; I need to look strong in my resolve to save Manrico, so this is a hard acting task, to act firm and yet physically weakening, at the same time showing that process in the voice, despite projecting into a large theatre.

As always in an operatic death scene, the actual dying is rather drawn out, and the singer must pace herself both emotionally and vocally. Often you are scrabbling around on the floor or prone on a bed, and these physically challenging poses require management, and often physical support from the tenor, all of which is worked out in rehearsal. Similarly, the sound of the voice must be managed: laryngeal tilt needs to be at its maximum effectiveness just before I die, and working back from that point I have planned what levels of distress I convey without crying myself. Needless to say this taxes the engagement of the muscles and the alignment, so crucial for optimum vocal sound (Ex. 4.12). My sound must convey the breathlessness of the pain and fear, written into the score, without hyperventilating, and yet still have enough strength to sing the ascending line in a superb legato at the end as I die. 
Example 4.12

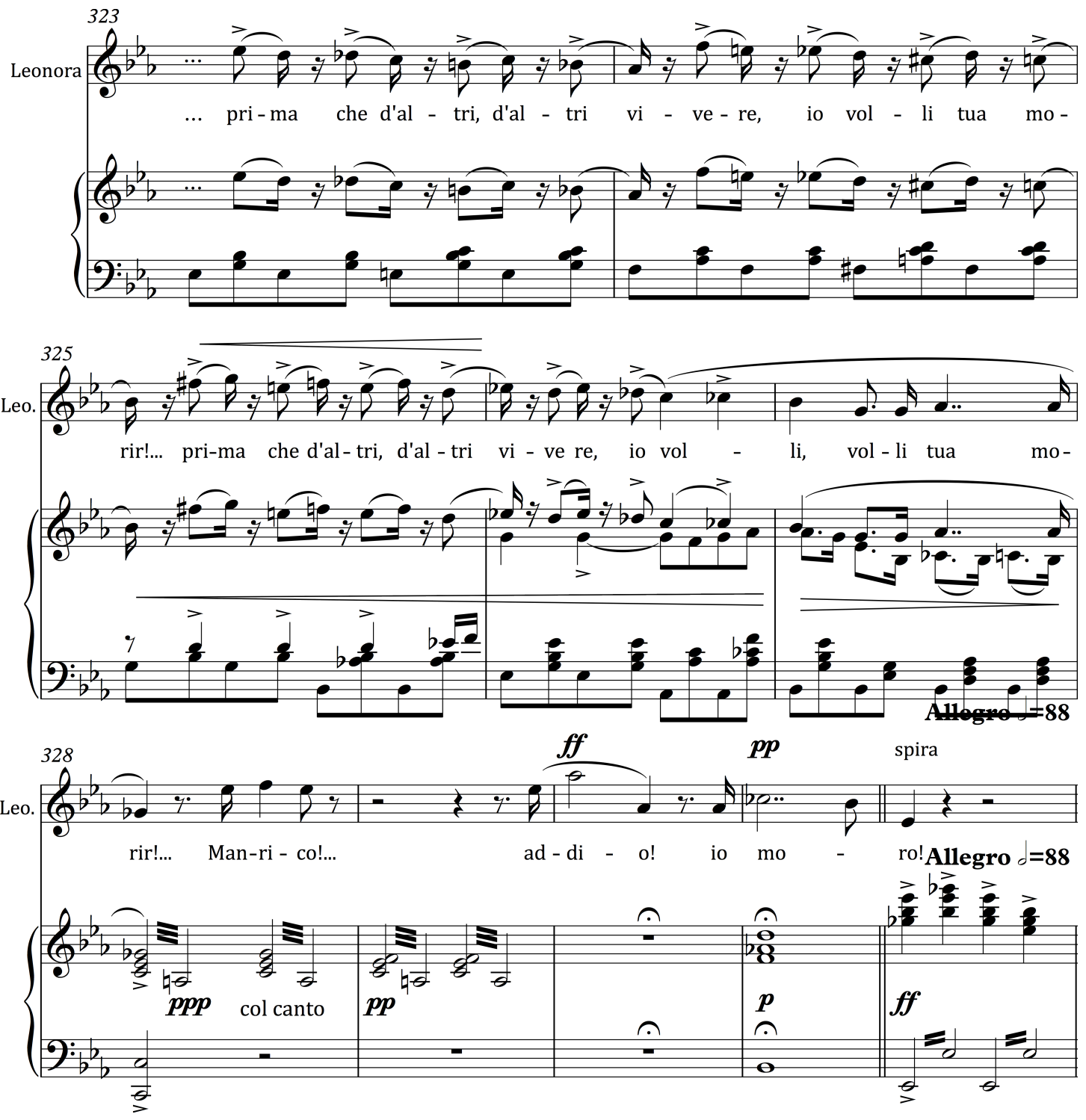

At the end of the opera, Leonora, with her societal context broken down and her unexpected repudiation of the mores of her upbringing, has become a personification of passion and power - as indeed all of the characters in $\mathrm{Il}$ trovatore are. I suggest that standing as she does between the world of the vocal spectacle and the dramatic characterisation that Verdi was developing at the time, in watching the singer's progression through the opera we see Leonora take the dramatic focus from Azucena as she gains in energy and power. For the singer of Leonora, it is a delicate balancing act. The hours of training cannot just be about the voice - if the singer performs as voice only the character becomes a 
cipher; she must step into the state of continuum in the performance to release and use the creative opportunities that Verdi has set up for her: the affective use of the breath in the long phrases and changes in harmonic colouring positively affect the development of the dramatic character. ${ }^{340}$ I suggest that by making her arias musically deceptively simple, Verdi enabled the singer to raise the emotional heat, and incidentally flesh her character out, by emphasising and creating the quality of her sound. ${ }^{341}$ It is as if voice and body become one.

Not only are the characters of Leonora and Azucena different, but each singer brings something unique to the role. Each is distinctive and has her own interpretation and subtext to communicate; as a result of the empirical knowledge of the text, creative embodiment and manipulation of body, she has many creative options. Having done the preparatory work, and made the choices needed in the preparation of a role, most singers create instinctively -from a position of empirical knowledge, not of control but from freedom.

Each role requires the minute and different use of the embodiment matrix I have devised. The engagement needed for Azucena creates a vocal sound that conveys the energy of her psyche: when I embody her I sing and act as if I am a force of nature. To do this I must be thoroughly grounded in my body, connecting the body and the earth, overlaying that connection with my musical awareness, emotional connection and awareness of the character. To be completely

340 Leontyne Price, a famous and recorded Leonora, was the consummate vocalist. However, watching her, while in awe of the vocality, I am very much aware that she is only about voice. Acting in any detail was either beyond her, or she was not interested in conveying anything extra to the sound. In contrast the contemporary singer, Sondra Radvonovsky, another well-known American Leonora, also has a compelling vocality and a wonderful voice, but manages to project a dramatic character.

${ }^{341}$ James Hepokoski points out that by grounding the dramatic illusion in the physical performance-reality, Verdi also gives the singer a chance to rest from the more taxing coloratura/heroic styles of singing. James A. Hepokoski, "Genre and Content in MidCentury Verdi: 'Addio del passato', (La Traviata Act III)", Cambridge Opera Journal (Vol 1, No 3, Nov. 1989, 249-276), 275. 
embodied in such a way, I can project the true drama and charisma of the character of Azucena and of myself, the singer.

In a different way in Leonora's music, Verdi leaves the singer considerable creative freedom in how she can use her voice and breath, and sets up certain ways for the requirement for an intensive physical engagement of voice and breath. As the singer of Leonora I feel as if I have less physical freedom; the vocal spectacle requires exactitude, and the mental and physical concentration to reach that perfection is high. As the role travels through from vocal spectacle to the fleshed out and uncovered dramatic personae, the physical demands seemingly relax and become more organic with the body and the emotions, and the states of flow and continuum activate.

The embodied cognition and an unwritten creative collaboration between the singer and Verdi, enhanced by a sensitive conductor, allows the singer to call on her extensive training and to inhabit the character she is portraying on the stage. Her listeners and admirers recognise her creativity by acknowledging vociferously that her intrinsic bodily sound helps create the character, and through responding to the extra information that the visceral, primal vocal sound transmits. The listener, having gone to watch a story, a fiction, is drawn into a world of un-nameable wild turmoil of sensation. I suggest that it is this notion of creating a particular type of vocal experience that is central to our understanding of operatic voice, and is so crucial to the success of Il trovatore.

It is an interesting exercise to articulate the demands of Verdi's women in Il trovatore. The opera is held up as a kind of "Mount Everest" of vocality, and you need very good singers to sing the roles. In addition, the attention to the detailed preparation of the embodied cognition requires a special sort of singer, well versed in optimizing the harmonic structure of their voice. Good singing alone is not enough though, and does not totally convey all elements of Verdi's dramatic conception. On a superficial level the roles of Azucena and Leonora seem very different, and they are two different voice types. Though the accessibility and nuance of the harmonic structure of the voice remains the same, it is in the use of the breath that the two roles differ, and hence the way in which the embodied 
cognition is set up. Being one of the few singers to have sung both roles I have found it interesting to analyse the difference in singing them. Subtly and inexorably, during Il trovatore, it appears that Azucena's way of histrionic communication influences Leonora's and eventually the prima donna role combines both in a way that paves the way for the dramatic development of Verdi's later heroines. I suspect that Verdi understood the jouissance that Azucena's role gives, and realised that to be fully satisfying for the singer, the role of Leonora had to be developed to give the singer the same sense of bodily pleasure from embodied cognition. 


\section{Chapter Five:}

\section{Wagner's Body: Wagner, the Singer and Sieglinde}

\section{Wagner's Body}

The importance of the singer's role in realising the operatic text through performance has been acknowledged by numerous composers. Opera is merely text on a page until it is brought to life by the singer - the conduit for both the music and drama. Intensely interested in the music and drama, Wagner, by all accounts, sought a bodily manifestation of his music and drama. ${ }^{342}$ Coaching his singers, he preferred the better actors over others; he was disappointed in what the mis-en-scene of the time could achieve and he exhorted his colleagues to be always trying something new in his productions. ${ }^{343}$ Further, though committed to the veracity of the sung drama, Wagner was a sensualist, loving beautiful silk fabrics and perfumes, greatly appreciating the pleasures of the body. ${ }^{344}$ That sensuality and concern for the body is realised in the case studies of Wagner roles I have chosen.

The body is, of course, vital to the performance of Wagner's works: a huge vocal effort is carried by the voice and the body throughout the large temporal scale of Wagner's operas. In addition, the theatrical illusion created by bodies onstage in Wagner's theatre tends to point not only to the embodiment itself but also to the metaphysical qualities of the Gesamtkunstwerk and the Bühnenweihfestspiel, and has been addressed accordingly in the literature. ${ }^{345}$ The

\footnotetext{
342 Barry Millington's The Sorcerer of Bayreuth (London: Thames and Hudson, 2012) has several discussions on Wagner's sensuality and his attitudes to the body, his women, and his fixation on fabrics and perfumes. See for example Thomas Grey, "Wilhemine Schröder-Devrient and Wagner's Dresden" in Richard Wagner and his World (Princeton: Princeton University Press 2009), 205.
}

${ }^{343}$ See Arthur Seidl in “Cosima Wagner's Bayreuth” from Thomas Grey, Ibid., 435.

${ }^{344}$ Barry Millington, "In the Pink: The Role of Silks and Satins in Wagner's Life" from Richard Wagner: The Sorcerer of Bayreuth (London: Thames and Hudson, 2012),148.

345 For a more detailed discussion of the concepts of the Gesamtkunstwerk and Bühnenweihfestspiel, particularly in relation to Parsifal, see Matthew Wilson Smith, "Laughing at the Redeemer: Kundry and the Paradox of Parsifal," Modernist Cultures, 
illusion of the stage is, of course, complex, and intersects with influences from many fields. In opera though, very little attention has been paid to the illusion of the body that the singer's embodiment creates. This illusion is intangible and unreal and is at odds with the physical reality of the singer's embodied vocality. Yet there is a meeting ground to be found, where illusion and reality meet in the singer's body and mind on stage. It is the deep corporeal understanding and heightened emotions combined with a total immersion in the sound, especially of the voice, that engages both the singer and the listener in the act of performance.

Despite the metaphysical interest, both his own and that of others, Wagner seems to have been above all a composer concerned with the tangible body - his body and the bodies of women. And overall, his concern is with a musical representation of human states of being, and the result of all-too-human actions. Laurence Dreyfus has investigated the eroticism inherent in Wagner's works, and found that "Wagner was the first to develop a detailed musical language that succeeded in extended representations of erotic stimulation, passionate ecstasy and the torment of love." 346 Dreyfus takes care to point out that "Wagner's is an aesthetic drenched in rich human experiences of every kind, especially erotic sensibilities and desires, and thus immune to the charge that it seeks to avoid culture, the body or material reality."347 Indeed, Wagner seemingly revelled in the tangibility of the body and his portrayal of it, and sought to control the body's movements. Mary Ann Smart in “Mimomania: Allegory and Embodiment in Wagner's Music Dramas", comments that Wagner was concerned with the minute control of the body and points to the detailed stage directions in the earliest published score of Die Walküre. ${ }^{348}$ The interest in Die Walküre lies in the two female heroines whose operatic bodies are vital:

Issue 5, 2007, 21; Patrick Carnegy, Wagner and the Art of the Theatre (London: Yale University Press, 2006)107-133.

${ }^{346}$ Laurence Dreyfus, Wagner and the Erotic Impulse (Cambridge, Mass.: Harvard University Press, 2010), 2.

${ }^{347}$ Laurence Dreyfus, Wagner and the Erotic Impulse, 222.

348 Mary Ann Smart, “Mimomania: Allegory and Embodiment in Wagner's Music Dramas", Mimomania (California: University of California Press, 2006). 
Sieglinde is concerned with love and the sensual aspects of the human condition, and Brünnhilde's love both for her father Wotan and for Siegfried is transformed into care and love in a more inclusive humanistic sense. In many respects Brünnhilde takes over from Sieglinde as the motivator of the drama. However, as my research is based on my actual performance of the chosen roles, and I have not sung Brünnhilde, I will not discuss her in this context.

In choosing to discuss Sieglinde, I will describe the vital qualities of the body - not only in the matter of the singing body - but also of the emotional, violated and loved body of Sieglinde herself. My experience of singing her is cathartic and joyful, and brings the reality of her embodied cognition to the foreground guiding her past the theoretical themes and ideas of the scholars. However, there is a concrete way of engaging with these themes to find explicit embodiment in performance, as will become clear.

Wagner's tetralogy Der Ring des Nibelungen, has been noted from multiple perspectives as a departure from any standard operatic approach, whether in the Germanic tradition or more broadly. One is the reversal of many of the common heroic archetypes: unusually, it is the women, specifically Brünnhilde and Sieglinde, who drive the Ring's action, and in the end seem to be the ones to save the world. ${ }^{349}$ And as a number of critics have pointed out, Wagner's female characters are given the opportunity to regain power specifically through the strength of their voices. Carolyn Abbate sets up that premise more generally in "Opera: or, the Envoicing of Women”, pointing out that “Composers' dependence on women is unique to opera ...Women are thus critical in authoring the operatic work as an audible reality." 350 Responding in part to the way in which Catherine Clement's analysis in Opera and the Undoing of Women focuses only on the treatment of women within the dramatic scenario, Abbate reveals how the

\footnotetext{
349 There is a considerable amount of fascinating literature about Brünnhilde, particularly Carolyn Abbate's articles. See "Brünnhilde Walks By Night”, Unsung VoicesOpera and Musical Narrative in the Nineteenth Century (Princeton N.J.: Princeton, c 1991).

350 Carolyn Abbate, "Opera; or, the Envoicing of Women", Musicology and Difference, ed. Ruth.A. Solie (California: University of California Press, 1995), 225-258, 255.
} 
women are actually empowered by the authority of the voice itself. 351 Clément neglects the locus of women's operatic triumph, not addressing the overwhelming sound of female operatic voices and the musical gestures that enfold those voices as a whole. As Abbate remarks, "This is a realm beyond narrative plot, in which women exist as a sonority and sheer physical volume, asserting themselves outside spectacle and escaping murderous fates." ${ }^{\prime 352} \mathrm{~A}$ broadly accepted feminist response to the disempowerment of women in these plots has rested on the ways in which a singer may regain control by sheer vocal presence, and Abbate's concentration on the vocal authority hints at its complexity:

But listening to the female singing voice is a more complicated phenomenon. Visually, the character singing is the passive object of our gaze. But, aurally, she is resonant; her musical speech drowns out everything in range, and we sit as passive objects, battered by that voice. As a voice she slips into the "male/active/subject" position in other ways as well, since a singer, more than any other musical performer, enters into that Jacobin uprising inherent in the phenomenology of live performance and stands before us having wrested the composing voice away from the librettist and composer who wrote the score. ${ }^{353}$

Abbate's focus is on liveness of the performance and the complexity of the embodiment and this is the area I intend to engage with in more depth in this chapter. Wagner promoted the Romantic idea of a fusion of words and music: his writings on the subject are well known, verbose and in many ways self justifying and self serving. ${ }^{354}$ However, as Roger Parker has written in Reading Opera, late twentieth century critical thought on Wagner's music has taken a rather different direction, pointing out that "such a naïve system of identifying words with music can create interesting ambiguities when applied to the verbal, musical and dramatic surface as complex and multilayered. Wagner, as we know, wrote

351 Catherine Clément, Opera and the Undoing of Women, trans. Betty Wing (Minneapolis: University of Minnesota Press, 1988).

352 Catherine Clément, Opera and the Undoing of Women, trans. Betty Wing (Minneapolis: University of Minnesota Press, 1988); Carolyn Abbate, "Opera; or, the Envoicing of Women", 254.

353 Carolyn Abbate, "Opera; or, the Envoicing of Women”, 254.

354 Roger Parker, Reading Opera, 292. 
prolifically on performance, on his own music and that of others." 355 Most importantly, from my perspective, he wrote about singers and the dramatic expectations he had of them.

Geoffrey Skelton points out that Wagner habitually wrote instructions to the singer in the score as suggestions for them to build on, claiming that if they had the proper instincts they would know what he wanted them to express. ${ }^{356}$ Apart from being unhappy with what he termed the "lazy" singers whose habits he attributed to the singing of the French and Italian schools, his comments about the actual singing of his roles are relatively few. In her article "Wilhemine Schröder-Devrient: Wagner's Theatrical Muse”, Susan Rutherford suggests that “Wagner's ideas of histrionic display were formed in the 1830s and 1840s when both Italian and German operatic stages were victims of what he called 'affectation.'"357 In addition to this affected style of acting, it frustrated Wagner that the singers did not learn their music and text correctly, and then sang it sloppily. ${ }^{358}$ Importantly though, in his essay "On the Performing of Tannhäuser" ("Über die Aufführung des Tannhäuser"), he promoted the use of declamation: “There is no distinction in my opera between so-called 'declaimed' and 'sung' phrases"; he did not want the customary division between recitative and song. ${ }^{359}$ As I will explain later, Wagner set his text in a way that it could be declaimed, and this expectation binds and controls the singing. Wagner's music is fully written out: there is no freedom in the less lyrical passages (the kind of vocal freedom that abounds in Italian opera, for instance, where the voice is given time within the rhythmic framework to voice properly); however he contradicts his own words and requirements by saying that if the mode of delivery laid down by him

\footnotetext{
355 Roger Parker, Reading Opera, 292.

356 Geoffrey Skelton, Wagner in Thought and Practice (Oregon: Amadeus Press, 1991), 123.

357 Susan A. Rutherford, "Wilhemine Schröder-Devrient: Wagner's Theatrical Muse", Women, Theatre and Performance: New Histories, New Historiographies, eds Maggie B.B. Gale and Viv Gardner (Manchester: Manchester University Press, 2001), 65.

358 Geoffrey Skelton, Wagner in Thought and Practice, 124.
} 
had been correctly understood and absorbed, then he would urge the singers to a completely abandon the strict adherence to the beat. Wagner felt that once the singer understood the effect he was aiming for, they should then be able to give free rein to their own natural feelings and even to the physical necessities of their breathing in moments of emotional excitement. ${ }^{360}$

Singers, in being challenged by the length, detail and difficulty of Wagner's roles were part of the debate as to whether their highly trained operatic singing was a prerequisite to a better style of "dramatic" Wagnerian singing, or an obstacle to achieving it. ${ }^{361}$ It took certain singers to commit to the singing to show that these roles could be well performed. Wagner was impressed by tenor Ludwig Schnorr von Carolsfield (the first Tristan). Schnorr complained at first about the length and difficulty of the music; but after following Wagner's instructions, with the minute changes in tempi in particular, the detail of the score became clear, and despite the initial extra work in the clarification of the text, the singing became easier. Wagner said interestingly that "Great physical exertion ceased to be felt as onerous with the singer's awareness of the correct expression of the passage: intellectual understanding immediately provided the strength to overcome the material difficulty." ${ }^{362}$ Wagner discovered in Schnorr von Carolsfield a singer of a rare sensitivity and responsiveness and committed himself to fully coaching his interpretation of Tristan. ${ }^{363}$ An observer at these rehearsals, pedagogue Julius Hey, commented that “... in his role as the master of interpretation ... Wagner had extraordinary things to offer."364

359 Geoffrey Skelton, Wagner in Thought and Practice, 124.

360 Geoffrey Skelton, Wagner in Thought and Practice, 124-125.

361 Thomas. S. Grey, "Wilhemine Schröder-Devrient and Wagner's Dresden”, Wagner and his World, ed. Thomas Grey (Princeton: Princeton University Press, 2009), 205.

362 Geoffrey Skelton, Wagner in Thought and Practice, 135.

${ }^{363}$ Katherine Syer, "From Page to Stage: Wagner as Regisseur", Wagner and his World, ed. Thomas Grey (Princeton: Princeton University Press, 2009), 12-13.

364 Julius Hey quoted in Katherine Syer, "From Page to Stage: Wagner as Regisseur", Wagner and his World, ed. Thomas Grey (Princeton: Princeton University Press, 2009), 12-13. 
Interestingly, Wagner also concerned himself with the use of the breath in the emotional expression of the extremes of passionate suffering and the attendant extreme degree of violence. Shorter phrases moving quickly engender a type of gasp indicative of distress. Wagner also suggested that a single wellcontrolled breath could invest a row of notes with their proper melodic and logical sense, preserving their relationship with each other, thereby doing justice to the "small" notes and their important function as links in speech and melody. 365

In The Ring, composed as it was over fourteen years, it seems that Wagner was developing his skill in setting the words of the drama. Wagner often set his text in the style of heightened speech, perhaps reflecting his interest in the presentation of the sagas and the Eddas of Northern Europe and Scandinavia that fascinated him. The operas are long and thus have many words in them; and like an illiterate audience listening to sagas with many convolutions of plot and many differing points of view, the audience needs help in comprehending and remembering the whole. The use of leitmotif both helps and hinders the reader's understanding of the text; while it provides a broad signposting of the story, it also, I feel, limits the multiplicity of the meanings available in the vocal sound. In all respects, the length and permutations of the words need commitment from each singer: heightened articulatory commitment, and an acknowledgment that the repetition of auditory clues are essential to the story.

What is more, I suggest that Wagner's text setting for particular roles is one of the most striking ways in which the vocality of these roles is created, and in fact marks a clear distinction between characters that establish dramatic meaning in specifically musical ways. Sieglinde and Brünnhilde are substantially different in their vocality. Not only are the ranges and tessitura different, but also the phrases for Sieglinde tend to be generally shorter. Further, the ways in which the emotions are more extreme in the Ring than Wagner's previous operas, as for instance in Act II of Die Walküre, adds a particular additional complexity for singers of certain roles (though not so much for Sieglinde perhaps), as the 
concepts of the text are harder to convey through the vocal production and articulation of that text.

To illustrate some of the ways in which the embodiment of vocal production in a Wagnerian opera establishes key aspects of both musical and dramatic meanings, let me now look at one character from the point of view of the singer in greater detail. A focus on Sieglinde also provides interesting correlations and contrasts with my Verdi case studies, on the one hand (which draw on roles that were being written in the Italian tradition at roughly the same time period, and which thus respond to the same vocal developments laid out in Chapter Three), and the much later role of Kundry, on the other. Centrally, though, the focus on Sieglinde allows me to expand on a key disjunction: although the articulation of Wagner's detailed musical text seemingly disempowers the singer (because of Wagner's compositional control of the word setting), there are other physical challenges of bodily performance to take into account, and over which only the singer has control. Crucially, though he was intensely involved with the body, I suspect that Wagner did not completely understand the amount of physical work and the protection of the body required for the singing of his marathon-like roles. Despite Wagner's best attempts at control of the body, in the end my experience of performing Wagner sets up an interesting negotiation with clear restriction and control, and a very different space for creative engagement than laid out in the previous Verdi chapter.

\section{The Singer's Body}

Whereas Verdi is generally associated with melody and the quality of vocal sound (both certainly a priority for singers), Wagner is most often associated with text. His interest in the development of his own words/libretti for his operas meant he had far greater control over the word setting than other composers. In the previous chapter I discussed at length the technicalities of learning an operatic role for Verdi. The process for learning a role is similar for Wagner. Where the difference lies however, is in the tailoring of the sound to the text. As well as the process of learning a role, the musculature of the body must be trained to support the added work in energising the lyric diction. There are 
many more words in Wagner's operas than in Verdi's, and the German language requires more aspiration and energy in projection than Italian. In addition, at times the orchestral forces are larger in Wagner, though there are many places where the orchestral accompaniment is kept to a minimum and the text setting is almost recitative-like.

In taking on any Wagner role today, the singer has to contend with a certain number of preconceptions as to what constitutes a "Wagner" vocal sound. With his conducting experience and contact with singers, Wagner must have been aware of the vocal technical developments happening in his lifetime, and he preferred singers with certain dark colours in their voices and good dramatic expression. His admiration for Schröder-Devrient was based in part on the way she imbued each word with meaning and dramatic intent. By contemporary accounts it was not a wonderful voice, but, as Susan Rutherford writes, " for Wagner, Schröder-Devrient's vocalising was merely part of her performance as a whole, and he viewed her concentration on the total effect of her operatic representation as something towards which every singer should strive."366 Though the quality of her voice aroused some controversy, it seems that the strong warm middle register and brilliant top provided a model for Wagner's development of the hochdramatischer Sopran of his later operas. John Potter, in Vocal Authority: Singing Style and Ideology, makes the point that,

Until the 1840s, the bel canto ideal had been exemplified by the coloratura soprano, whose high clear tones and decorative embellishments conveniently provided a kind of musical depiction of nineteenth-century notions of femininity. By the end of the century the pre-eminent voice was that of the dramatic soprano ... which offered a richer, more incisive and vigorous aural delineation of womanhood. 367

The dramatic soprano voice as a phenomenon, that was developing historically precisely across this period, has to a large extent governed our modern concept

\footnotetext{
366 Susan A. Rutherford, “Wilhemine Schröder-Devrient: Wagner's Theatrical Muse”, 64.

367 John Potter, Vocal Authority: Singing Style and Ideology (Cambridge: Cambridge University Press, 1998), 47-66; quoted in Susan A. Rutherford, "Wilhemine SchröderDevrient: Wagner's Theatrical Muse", 72.
} 
of Wagnerian female sound, and has played a central role in developing the style and breadth of the female operatic voice.

The qualities associated with Wagnerian voices are similar to Verdian ones: the lowering of the larynx and widening of the pharynx and more mass in the vocal folds to provide the requisite authoritative colour. As the vocal range of Wagner's female roles are concentrated in two main areas, the harmonic structure of the vocal resonator tract in Wagner's vocal music requires a concentration of harmonics in certain areas of the voice, which varies between voice types. For a soprano the areas are the top of the voice F" to top C'”, and the lower middle range $\mathrm{B}$ below middle $\mathrm{C}$ to $\mathrm{C}^{\prime}{ }^{368}$ This allows for the weight in the lower middle of the voice and the brilliance at the top, common features in the largest Wagnerian roles. In a vocal sense, it is also true to say that if a singer can manage the vocal demands of singing Verdi roles with the lowered larynx, they have an ideal training for singing Wagner roles. Indeed, most Wagnerian singers have moved to that repertoire from a grounding in Verdi and other Italian composers. To focus attention in these two areas of the voice and to develop their power, specific development of projection, resonance and muscularity must be engaged. In the lower part of the voice it is essential when adding in chest resonance to have a seamless register change, and to make sure that the chest mix is not overweighted with lower harmonics. The sound must be placed forward and if the singer sings the text with energy and the same focus as if orating, this placement is easily found. The musculature required here is discrete: an increased engagement of the muscles of the back neck and shoulder blades to keep the vocal resonator tract as open as possible to facilitate laryngeal tilt, which in turn facilitates a seamless register blending. In the top octave on the other hand, much more muscle engagement and strength is needed: in some respects the harmonic structure is compressed slightly for extra projection and

368 Interview with Professor Paul Farrington, 26/1/2012. 
to get the steely colour required in places. ${ }^{369}$ The colour of the voice is always commanding with a complement of lower harmonics, and energised text.

The tension between words and music is of course an essential one throughout operatic history. Some operas position the text as primary for the singer, and others, mainly bel canto operas, are experienced by the singer as being led by the voice. ${ }^{370}$ From a singer's perspective, both approaches have their challenges, but in either case, the way the text is set definitely dictates whether it is the artist or the composer who has control over the breathing. When practising a vocal work I often feel the influence of the composer making me work exceedingly hard on the articulation of the text because of the way it has been set in relation to how the breath must be controlled. ${ }^{371}$ Wagner's way of setting text forces it to be sung in his way: his use of alliteration, in particular, means that the onomatopoeic elements enhance the clarity, and so the singer's effort as dictated by the composer becomes, as described by Carolyn Abbate, part of the musical structure. ${ }^{372}$ In my experience, Wagner's operas work best vocally

\footnotetext{
369 It is fascinating to listen to live recordings and performances of Wagnerian sopranos. The most experienced never compete with the large orchestra at climaxes: as the orchestra diminishes, the singer powers through and increases her volume very quickly, never wasting her voice. Most keep their voices slender (in other words the harmonic structure is contained within the sound, but there are no bulges of particularly low harmonics). Exemplars are Birgit Nilsson and Nina Stemme.
}

370 By bel canto I mean nineteenth-century opera from the first half of the century: Bellini, Donizetti, Rossini.

371 The German composers of the nineteenth and twentieth centuries, particularly Wagner, are very demanding in this regard. Generally the music is durchkomponiert with a large amount of text with a libretto that has no repetition; in addition the German language requires a great deal of consonantal energy and clarity.

The law of temporal summation (one of the precepts of acoustics) states that: "If an acoustic event is shorter than 250 milliseconds, it must be higher in amplitude to reach the threshold of hearing." (I. Zwislocki Theory of Temporal Auditory Summation Acoustic Society, America Vol 32,1960). Normally consonants are shorter than this time span, and the vowels of course are longer. In order to lift the consonants to the threshold of hearing $(+250 \mathrm{~m})$, we either have to make them louder or longer.

372 Carolyn Abbate and Roger Parker, Analysing Opera: Verdi and Wagner (New York: Ithaca, 1984). 
and dramatically if his intentions are followed. ${ }^{373}$

In singing Sieglinde, the different aspects of the use of the body - the technical changes that require more engagement, the physicality of being on stage, the combination of gesture and melody, Wagner's sensuality and finally the bodycentric story of Sieglinde and Siegfried - lend themselves to a totality of involvement on the part of the singer. The heightened use of the body in this way allows the singer the creative freedom she needs to complete the embodiment of the role. Rutherford remarks on Schröder-Devrient's written articulation of her histrionic process, saying she "describes a fusion between imagination, memory, character biography and autobiography amidst the emerging psychology of the unconscious". ${ }^{374}$ In the increased involvement of the body required in producing this sound, I contend that a fundamentally new understanding of the relationship between body and voice in singers was developed. Not only was there a need for an engagement of the body in the physical act of singing, but also an awareness of the body in physical space on stage, and what meaning it could convey. This in itself is an important aspect of singing that has been overlooked by scholars, and even by a number of singers. If the singer's body is working well and in a communicative way, Wagner's vocal music becomes instinctive and cathartic as I shall demonstrate below with the focus on the role of Sieglinde.

If we are focused on the performing body as a vital agent in the realisation of music, Sieglinde can be understood as a transitional role, in a shift between the concept of vocality of Verdi based on the centrality of melody, and Wagner's where the text is paramount, and between the traditional soprano role of providing vocal spectacle, to a text-based vocal exposition set to music. Although in the case of Sieglinde, the orchestration also offers significant information about the musical state of the protagonist, the embodied emotions are primarily

\footnotetext{
373 For an recent interesting discussion on Wagner's setting of text, see John Deathridge's article "Waiting for Wagner: Reluctant Musicology, Radical Philosophy, and the Rescue of a Fraught Legacy", Opera Quarterly: Wagner and the Left (Spring-Summer 2014, 30,2-3), 267-285, doi:10.1093/oq/kbu017. Accessed online 11/02/2015.
}

374 Susan A. Rutherford, “Wilhemine Schröder-Devrient: Wagner's Theatrical Muse”, 68. 
dictated by the text, in part by Wagner's stage instructions, and by the preparatory process developed and practised by the singer. Hence the differences that each singer brings to a role can allow a wider interpretation of the significance of the singer's body in performance. Each singer develops their own subtext in working on the role, and this combines with their own bodily story and the character of Sieglinde, to provide distinctive portrayals.

The role of Sieglinde is the most "bodycentric" of my case studies: the role has an embodied, empathic connection to life experience. Thus for me as a singer, the character is more straightforward than other Wagnerian heroines; she is a woman of a sexualised body, built from a fairly common human experience, both of singers and most audience members.

The singer of Sieglinde can have a great deal of pleasure dramatically and physically, that in many respects enhances the control over her vocality, as dictated by the text setting. The role, I suggest, is a transition from the traditional soprano role of providing the vocal spectacle, to a text-based vocal exposition set to music. Sieglinde's humanity (as a half human/half god character), the character's musical and textual expression focus on emotions expressed both in the voice and on the body, that are easy for the audience to relate to.

Given the dramatic context of the character of Sieglinde, and the potential dynamic between the singer's/character's emotional experience and the eliciting of empathy and understanding in the audience, it is particularly important for me to lay out the ways that singing Sieglinde provides opportunities for bodily pleasure jouissance, for the singer. In the embodied continuum of performance, Act I with its constant escalation of sensually exciting music provides the singer with a dreamland of intoxicated senses, giving distinct bodily pleasures. The jouissance that a singer can receive in performance obviously varies from role to role according to a number of factors: the amount of physical work that is carried out, the difficulty of the music, the fitness of the singer, and the health of the voice. In Wagner's roles, the cultivation of the feminine and the tacit acknowledgment that the woman will provide the impetus in the drama gives the singer more personal power than has otherwise been realised. At the same time, 
however, it is as if Wagner disempowers the singer's choice and possibility of creative input into the performance by demanding a strict adherence to the text. In Sieglinde's case though there are many short and controlled phrases, Wagner also gives her long lines at the end of Act I, an emotional involved scene with many rests, and a lyrical end to her involvement in Act III. There is no doubt that the soprano singing Wagner is in a strong position vocally; she generally has a powerful voice, and the cachet of being suitable for these Wagner roles presupposes a vocal superiority in many eyes. How this contradiction can be resolved in the process of performance itself is the primary subject of this chapter.

Though Sieglinde is a short role, there are long stretches of lyrical phrases, and the involvement in the drama is in itself arousing; as I will explain, it is the combination of the physical involvement in producing the sound, together with the larger dramatic context, that contributes to creating a particularly striking potential for a singer's bodily jouissance. Again my reflections are the recalled kinaesthetic experience of the preparation and experience of a number of performances. ${ }^{375}$

\section{Sieglinde's Body}

If you have the requisite vocal weight, stamina and projection, Sieglinde is a straightforward role to sing and is set in a comfortable range. ${ }^{376}$ Wagner's setting of the text in the first act with its short vocal lines, helps to establish the character's insecurity: the setting itself incidentally feeds on the singer's thwarted desire to sing a sustained line. Bigger voices need space and time to

\footnotetext{
375 I performed Sieglinde in the 1998 Ring in Adelaide, Australia, both as understudy and on the main stage, and with the Sydney Symphony Orchestra in 2002.

376 The range for a dramatic soprano can be a below middle $\mathrm{C}$ up to $\mathrm{C}^{\prime \prime}$. However in this role the range is A below middle $\mathrm{C}$ and $\mathrm{A}$ " -very comfortable, with a lot of the writing below the upper passaggio, where the weight of a dramatic soprano's voice lies.
} 
initiate the sound, and smaller phrases need a disproportionally large amount of energy, so it is hard to reconcile the acting needs with the vocal ones. ${ }^{377}$

In preparation for my performance I ready my mind to project a sense of disembodiment at the start of the opera. This is tricky as I don't want to undermine myself on stage, but I need to show a growth of character, and of bodily engagement. The acting task is subtle: I project myself as being meek and humble as the opera starts, the repressed and subservient wife of Hunding, doing what is necessary to stay alive. Therefore to see a strange man collapsed in my house gives me a shock and I am immediately alert to the danger of Hunding finding me with that strange man. Hence I need to establish a sense of controlled panic, of curiosity, of imminent danger. The short phrases I sing are conveyed as questions, and with some nervousness they are in the low middle range of my voice, but the orchestral accompaniment is light, so though I am of course bodily engaged it is a good way to warm the voice into the role. Despite my initial reluctance I show that I recognise the attraction of the man - I find him compelling and want to help him, even though maintaining my distance by telling him I am Hunding's woman. I sing this with a sense of sense of sorrow and misery, with all the laryngeal tilt I can muster. The need to show an immediate and irresistible connection between us is manifest in our demeanour and also in our music. I feel Sieglinde's natural state (to which she will eventually revert) is one of being uninhibited and so I have worked on a freedom of physicality for this role, contrasting it with a grovelling, cringing physicality when Hunding returns. However, I need to grow to that physical confidence, and I make this bodily confidence disjointed to start. In musical terms, my persona seems fractured and reflects my lack of confidence; I work hard at conveying her isolation and bewilderment. This requires great mental projection, and it is important to strike the right balance between the disempowered character of a woman with no hope of any future, which

377 "Big" in regards to voices is a much misused term. Strictly speaking it should refer only to the amount of timbre or colour that the voice has. However, many commentators take it wrongly to mean volume as well. Generally a Wagnerian voice needs timbre, volume and projection. Heavier voices need more strength to work - the vocal folds are thicker, and need both more anchoring/ support, and breath pressure. 
negates the real body, and the real life singer that I am on stage, who needs to project both the embodiment of the character and my voice into the theatre. The enactment of a growing erotic and sensual connection facilitates an engaged bodily focus, perfect for singing. Though I seem passive and disempowered, I am working very hard in my body to belie that passivity, and to project the voice. When that deceit no longer is needed I sing with full power and authority.

As the initial phrases are short, my breath does not settle into any rhythmic pattern, and a lot of energy is needed to project the text, as here in Ex 5.1

Example 5.1

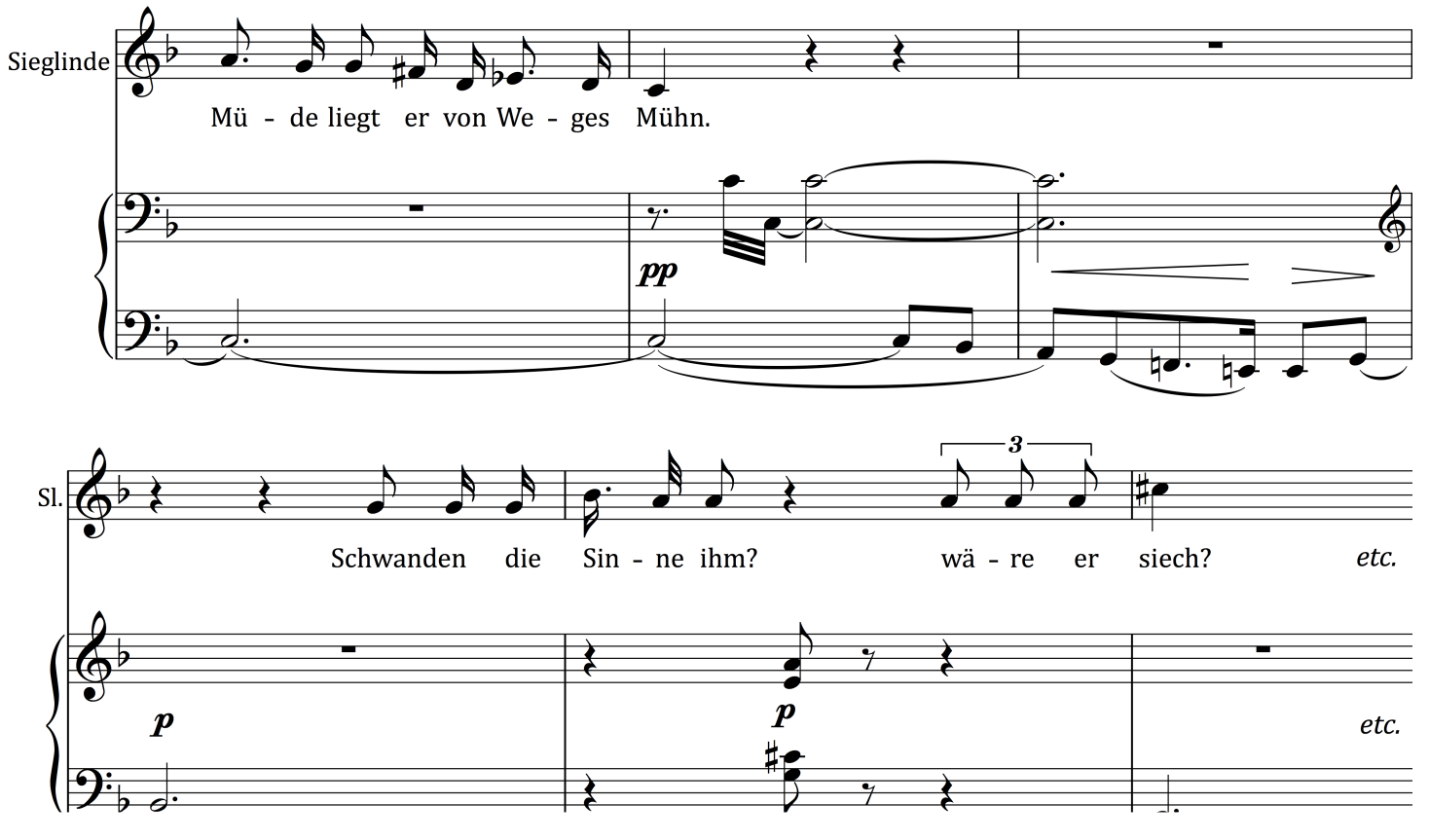

Many of the phrases are interjectory and become increasing forthright: my body is fully engaged waiting for the music cue ready to project through the orchestra texture into the conversation between Siegmund and Hunding. As I listen to Siegmund's story, I keep alert to his every movement and nuance, and when he returns, I am sensitive also to Hunding's reactions, wary of any menace. I balance and concentrate my body, in order to project a feeling of vitality and alertness, ready to move quickly out of harm's way when 
needed; I intend my physical wariness to project that Hunding has beaten and mistreated me in many ways.

In all respects this is a challenging start to the role; it is a difficult acting task and the singing never "gets going". The phrases are very short, and here, are never sustained so it is tricky to get the voice sounding well. In fact it is more like heightened speech. The singer needs to concentrate on acting techniques to measure up against Siegmund who has much more vocal presence. His vocal lines are more dynamic, sustained and higher in the voice, so they project sound and personality well. I have worked on my projection of personality in addition to the vocality in order to take up mental space on stage. As Siegmund is a more active role, Sieglinde can fade into the background when she is reacting to his statements. So it is imperative to take up stage space, to have gestures and movements that are larger than normal (without upstaging the Siegmund).

On my return to Siegmund after drugging Hunding, I launch into a long narration; my music becomes much more substantial, requiring more engagement physically. It is a mental relief to get stuck into the role to start to change and grow, to gain authority. The vocal lines are longer, but the first part of the narration is very low in the voice and needs care and energy to project. Telling the story of my life and the events that befell me, I become more confident and empowered in my mind and voice as I realise that Siegmund is the key to my liberation.

Gaining in vocal power adds to the empowerment of the character. Ex 5.2 is a case of starting lower in the voice with shorter phrases, of sustaining the projection and meaning, by adding as much colour as possible without digging into the voice. 
Example 5.2

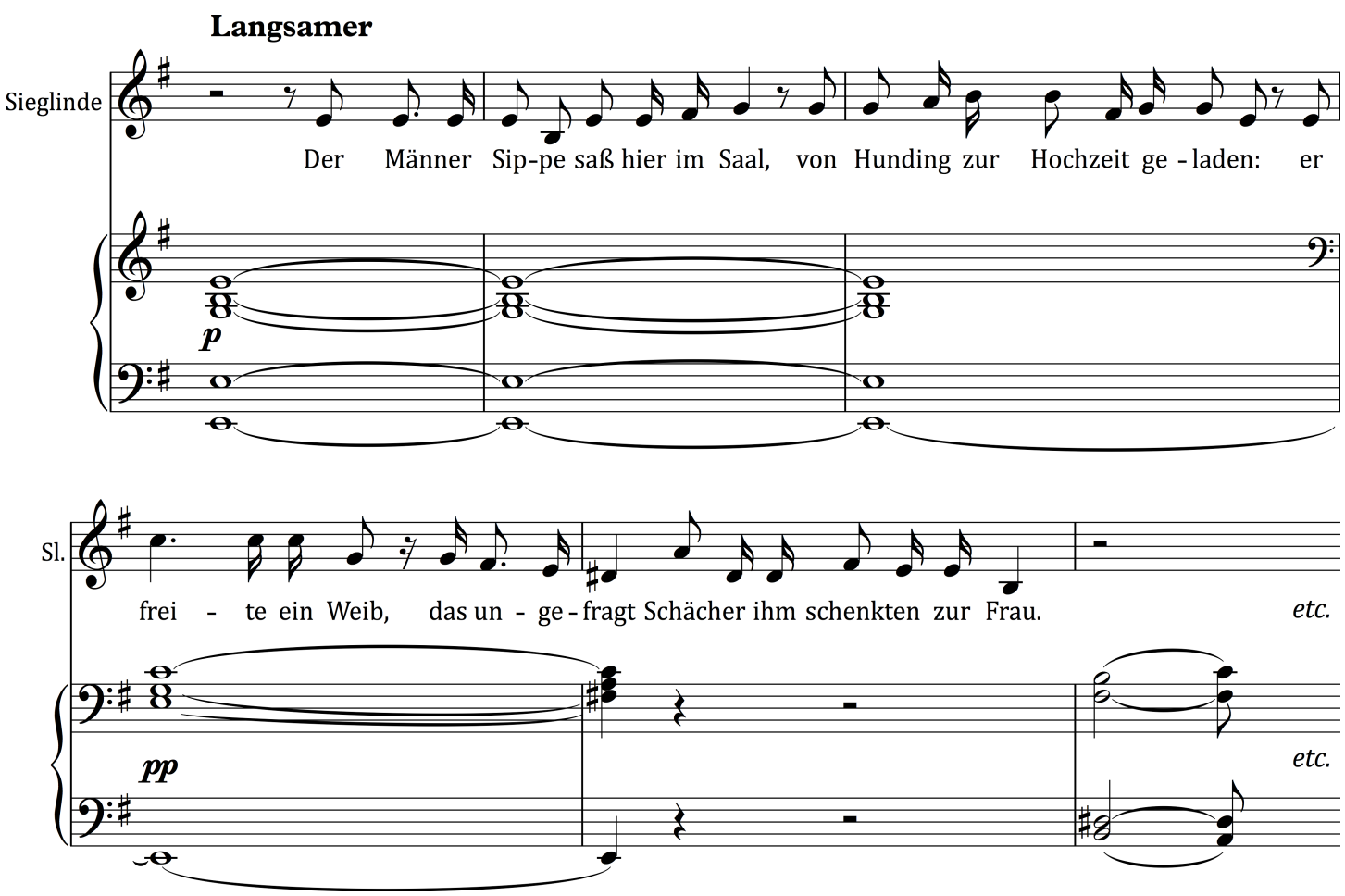

As I warm to telling my story the lines get longer and a bit higher, allowing the voice to speak a little more, allowing more legato tone to be heard. I become more physically confident here and need an assertive stance to engage more muscular strength. In Ex 5.3 the vocal lines start to have a leap up to the area beyond the passaggio - a typical phrasal movement for Sieglinde. This movement up of a fourth or a fifth, as in this case, makes the approach to the high note much easier than any other, and enables a better sound to be found, and the body to be engaged more easily. 
Example 5.3

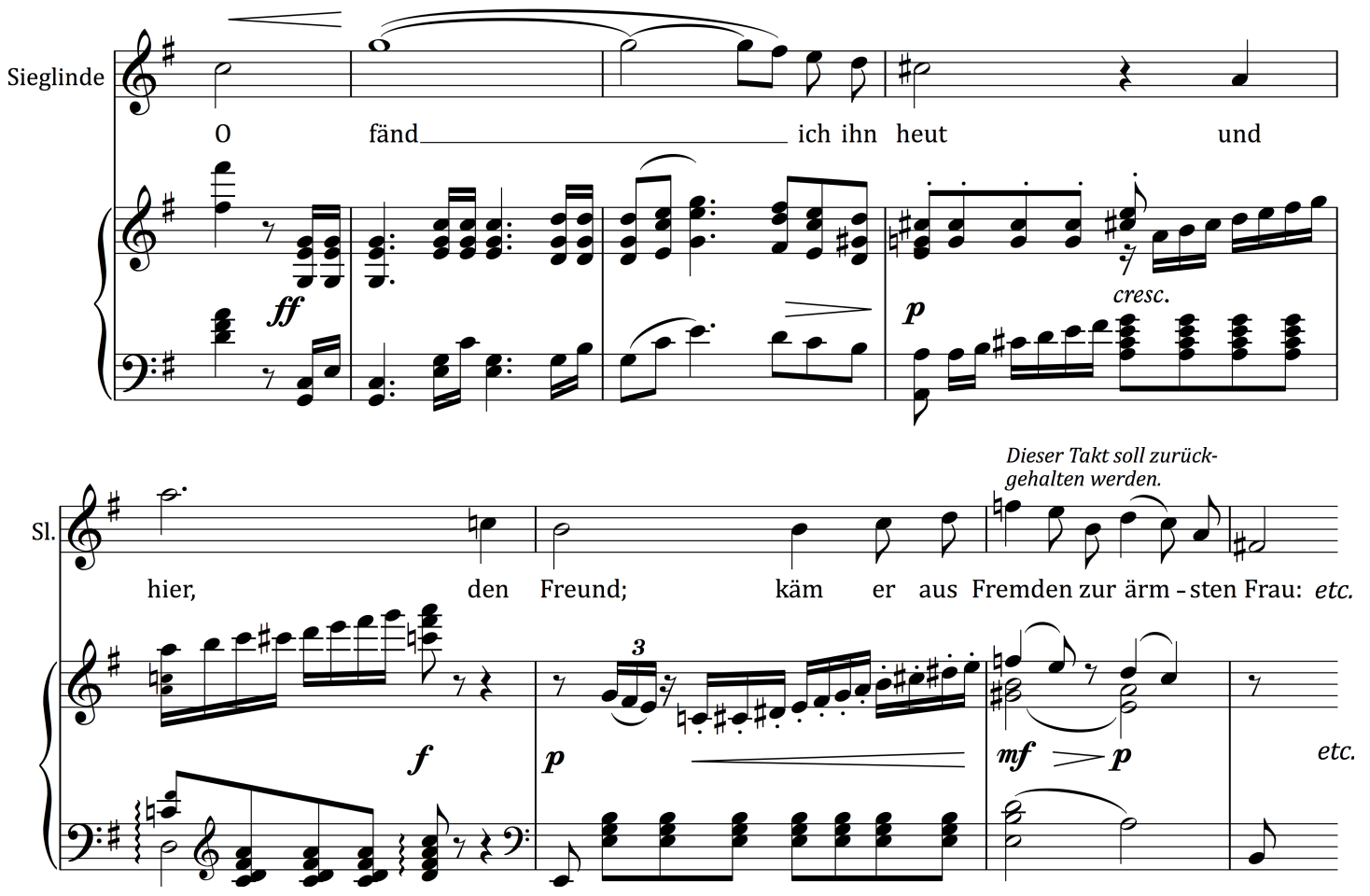

As I finally start sustaining loud high passages, I feel fully embodied and authoritative. Although these longer lines and climbing phrases require increasing engagement of the extrinsic muscles (the muscles of the neck, back and pelvic floor, and more mass in the vocal folds for harmonic colour in the voice), the release involved in the characterisation of the role makes it easier to sing. The long vocal lines with rhythmic breathing become hypnotic and the breath settles into a less conscious control; the sound is as legato as possible, optimising the vocalic harmonisation, so as to carry the text to the ear of the listener.

In Act I we see Sieglinde being set up with the equivalent vocal authority as Siegmund. Neither of them lives very long within the structure of the Ring Cycle, but their contribution to the plot is considerable. Therefore Sieglinde must quickly become empowered vocally, and as a character she must make the human events believable to listener. Also, I suggest that these lyrical passages stand the listener and Wagner in good stead, by seducing the listener into the 
complicated story of the Ring, keeping the emotional content and sensuality very much at the forefront of mind and ears.

By the end of Act One, as Sieglinde, I am fully engaged physically, fully embodied as a character, vocally requiring all my physical resources and concentration to be an equal partner to Siegmund. We have worked on the portrayal of the physical attraction so that is believable, and because of the intensity of the emotional content (and it has to be said the usual tactility and physical easiness of singers helps here) with a collegial partner, I have convinced myself, as the stage character, that I am in love. At this stage the feeling of exhilaration, the result of over-oxygenation of the brain caused by deep constant breathing, and chemical reactions within the body leading to the release of endorphins, produce "highs" and euphoric changes in mental states. Sustaining the controlled release of the breath for operatic singing is a complex interaction between the lungs (the appoggio discussed before), and the engagement of the muscles of the abdomen, back, legs and hips. The short example of 5.4 shows again how the vocal lines continually move upwards. Vocal quality is paramount here, with the lyrical support from the orchestra giving the singer the aural cushion they need for the voice, which you can hear here. 
Example 5.4
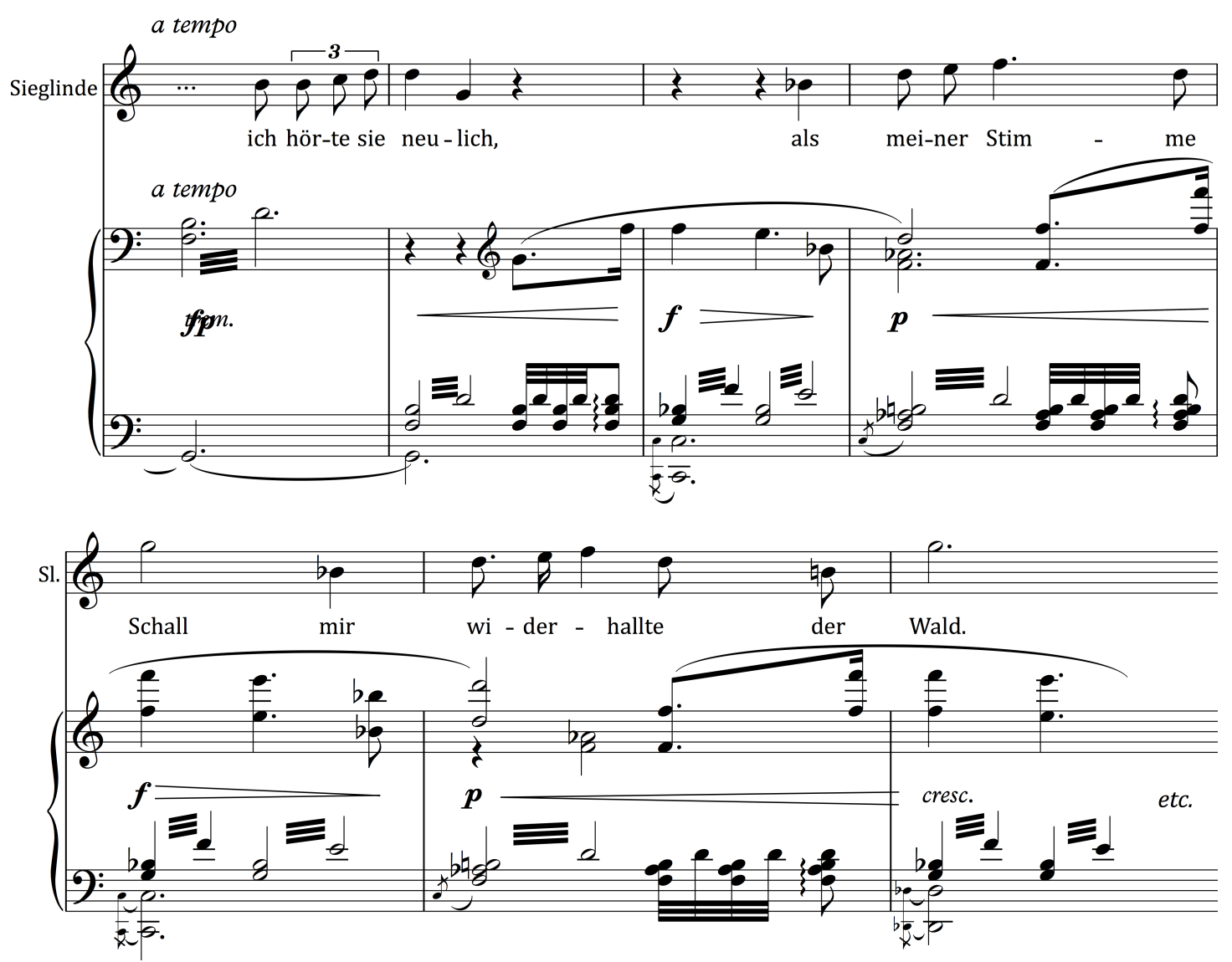

The emotional context of love and lust is one to which most singers connect to powerfully. It is relatively easy to remember and channel emotions, albeit heightened, that have been experienced in real life. Using my own emotional experiences, reliving the moment, my body releases tensions, but also engages in a way that circumvents the act of "singing" and therefore becomes more real. As laid out in Chapter Two, the actorly practice of orating engages the body with its emotions in a natural way. This has a similar effect to the use of declamation in my own preparatory practice. Earlier in Act I, I feel as if Wagner is controlling the vocality through the detailed way in which the text was felt, but here, engaging my body in the long and higher vocal lines, I win the reward of a cathartic release, heightening the emotional intensity, leading on to more textual intensity. While it is good to have a drink of water in the interval I am impatient to continue the story, to involve myself in the emotional turmoil to come.

In Act Two, Scene III Sieglinde enters exhausted and delusional, on the run from Hunding. I work hard here to maintain equilibrium: I am overcome 
with guilt at my action, my love for Siegfried and fearful of retribution from Hunding, and also, in my irrational perspective, from the god(s). The music, with its dissonances and unconvincing resolutions, is difficult to make sense of, and it is here that the time in the studio on the musical aspects of this difficult and fast moving section of the score is appreciated. The long vocal lines have been replaced here with short intense phrases where it is easy to take too much air in and become hyperventilated. In requiring this involvement of mind and voice, Sieglinde is at full stretch, creating different colours for her voice, prompting her to risk some aspects of the vocality to engage fully in the breakdown of her mind.

The pleasure of singing at this level, inventing colours, drawing on past emotional experience, engenders a danger, a wildness in performance. I am in control but allow myself to think of emotions that take me to the edge of crying by employing the maximum laryngeal tilt.

In Ex 5.5, mark how the vocal line sits on a $G$ at the top of the stave. Sustaining and reiterating a note at this pitch is challenging; the throat must be kept open and the larynx down to maintain a good sound. 
Example 5.5
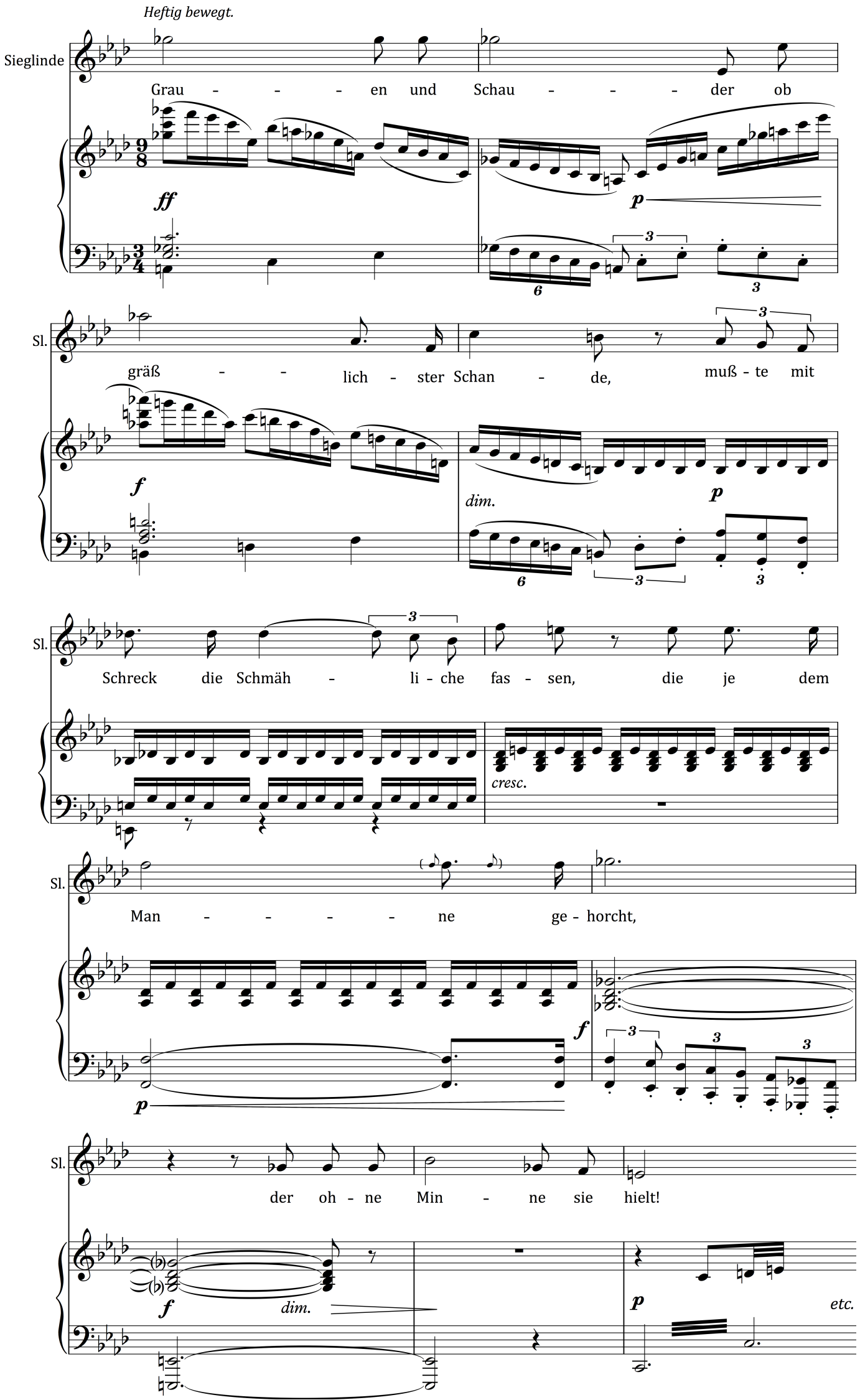
It is difficult to sing, act and keep control of the vocal sound and expression and yet involve the audience in your distress. Over-breathing to sing the shortened phrases in the desire realistically to create the distressed mood and to sing the shortened phrases, must be balanced by the need to keep the voice engaged on the body, and not let it disengage with the short breaths, and resultant lack of a deep release (recoil) as one breathes. I need to keep grounded and engage my body so that the emotions do not run away with me, and I forget to be careful with the low engagement in the pelvic area as I have a habit of doing. As my physicality becomes more desperate my alignment becomes more important: whatever I do physically, I need to protect the integrity of the structure for the instrument. It is a given that in such distress much laryngeal tilt will be used; I have practised to the point of crying in rehearsal and know exactly how far I can go before the sound becomes compromised. I do this deliberately as I know what sort of unsettling effect this amount of distress has on the listener-all the more to involve them.

Text is paramount in Act II, as is the ability to colour the voice thecolour which contains the manifestation of her distress. ${ }^{378}$ Sieglinde must concentrate to elicit sympathy from the listener, or to set up what has been described as the synchronicity of emotions. ${ }^{379}$ Most singers work hard at conveying the text, but it is the sound, and specifically the vowel sound that carries the text to the listener's ear. Although I am concentrating on the text, the vocal line keeps on climbing higher, and I work on the colour of the vowel sound to carry the primal sound of distress. The dramatic scene of Act Two Scene III invokes an impression of bodily distress that equally provides the body with a release; the short scene after the Todesverkündigung between Siegmund and Brünnhilde raises the emotional heat again.

\footnotetext{
378 Singers manipulate the plane of the thyroid and cricoid cartilages in the larynx to produce what is "cry". This sound is extremely empathetic and the effect on listeners can be remarkable in its ability to make them also cry.

379 Antonio Damasio, Descartes' Error: Emotion, Reason and the Human Brain (U.S.: G.F. Putnam's Sons, 1994), 155.
} 
Siegmund's death is the culmination of my fears. I was "asleep" when the action has been decided upon and I know nothing of the greater aims of the drama. ${ }^{380}$ At the top of my voice, in panic, and at full strength, I call for Siegmund and Hunding, and hearing the fighting, knowing I will be left unprotected, I ask them to kill me first. The high-pitched vocal sound here needs to sound panicked, and needs muscular protection: the laryngeal tilt is at its maximum and the orchestral texture is dense. Muscular engagement to provide resonance and projection is important, as is caution, to protect the vocal folds.

After the distress and excitement of Act II it takes a little while to debrief and gather myself for Act III. I need to focus on the way forward from the despair of Act II from an actor's point of view (there needs to be a variation of level of distress or else the listener turns off). Act Three's short scene with Brünnhilde and the Valkyries is not only uplifting for the singer after the emotional distress of Siegmund's death but also provides a finish to the role that leaves the singer on a physical high. I need to concentrate on my entry with Brünnhilde (who usually enters with a great deal of energy, and I need to keep up), and on maintaining an attitude of hopelessness and despair, despite her energy. It is difficult here to preserve my inward focus with so much going on around me - I centre my energy and focus on Siegmund and my sorrow, and allow my voice to start from that despair, from the deepest place inside that I can imagine. (Ex 5.6) I set up the maximum laryngeal tilt I can muster and lower my larynx: I am on the verge of tears myself as I describe my despair at Siegmund's death and ask to be left to die. Although only a thought, I need to take care that the emotion is still projecting outwards along with the text into the theatre.

380 Being "asleep" on stage is not the easiest task. The fear is always that one might actually lose concentration or even fall asleep properly, and then not awake at the appropriate time to sing or carry out an action. One needs to position oneself carefully: often being "asleep" means you will need to sing as one "wakes" up. This needs a studied positioning of the body with careful alignment and sight of the conductor. 
Example 5.6

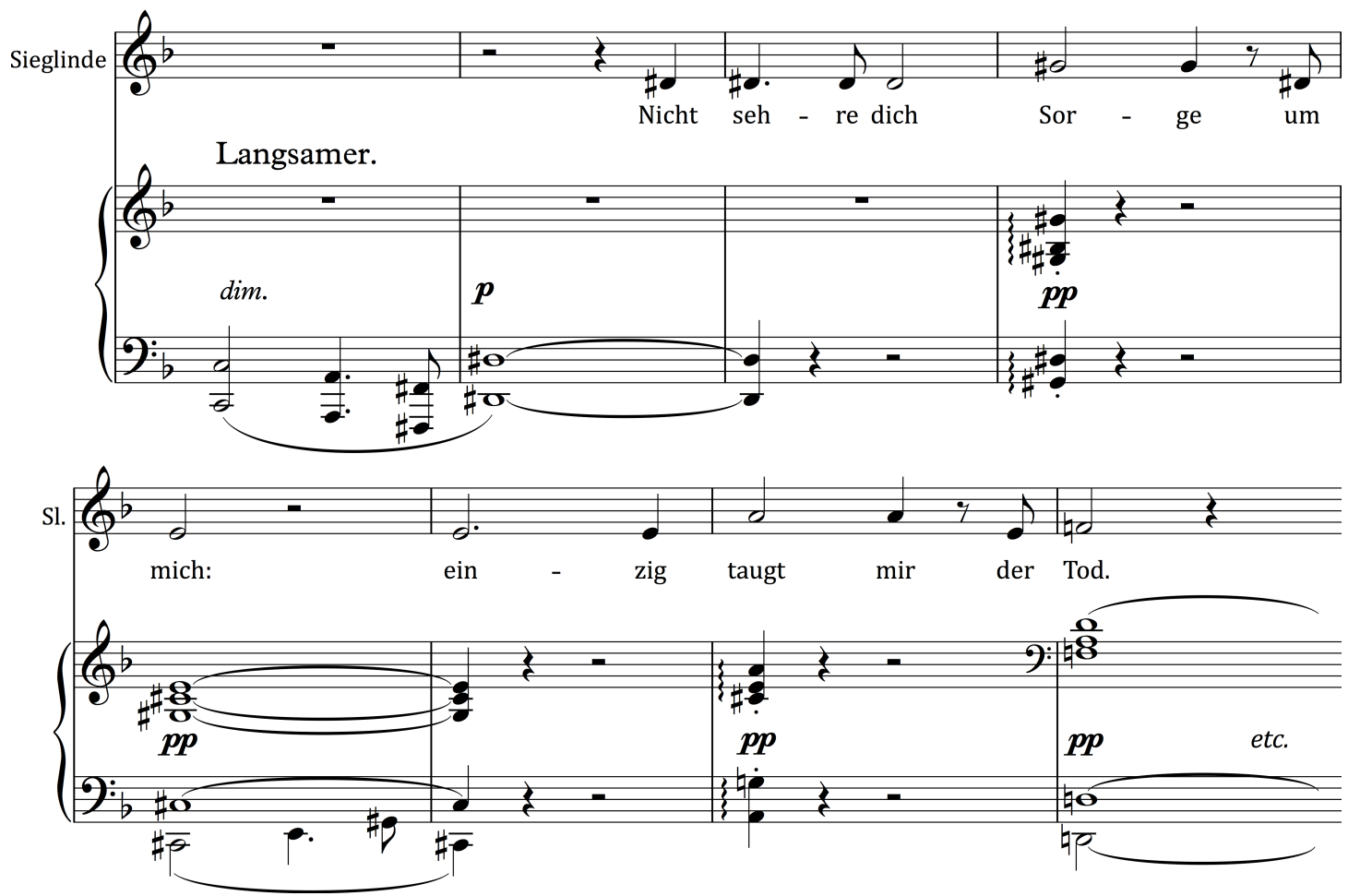

Starting low in the voice enables me to anchor the colouring in the voice, but requires all my strength to take up above the stave. The panic engendered at being told I carry Siegmund's child, awakens me to the danger I am in. Engaging pelvic floor muscles, back and inner leg as the pitch climbs to B flat, I keep the vocal resonator tract open with a full compelling sound. Once directions have been given to me, I am relieved and free to let my transmuted love soar in the ecstatic theme of the celebration of my life and the continuation of it. I sing 0 hehrstes Wunder, Ex 5.7, with rapturous vocal sound culminating in the outpouring of emotion at the top of my range, engaging my whole being. ${ }^{381}$

Because of the physical effort involved in sustaining this line, I receive a lot of pleasure, a physical high, a singer's jouissance. Not only has the character received the best of news and the relief and joy is manifest in her physicality, but it is the last line the singer sings at the end of her role, and it is a positive,

381 This place in the score is always a site of some negotiation with the conductor - some like it drawn out, others zoom through. Whatever they want you have to negotiate their needs with the length of your breath, not always easy! 
affirming ending rather than a form of death. However, there is also pain involved: the jouissance is of such intensity that it is hurtful.

Example 5.7
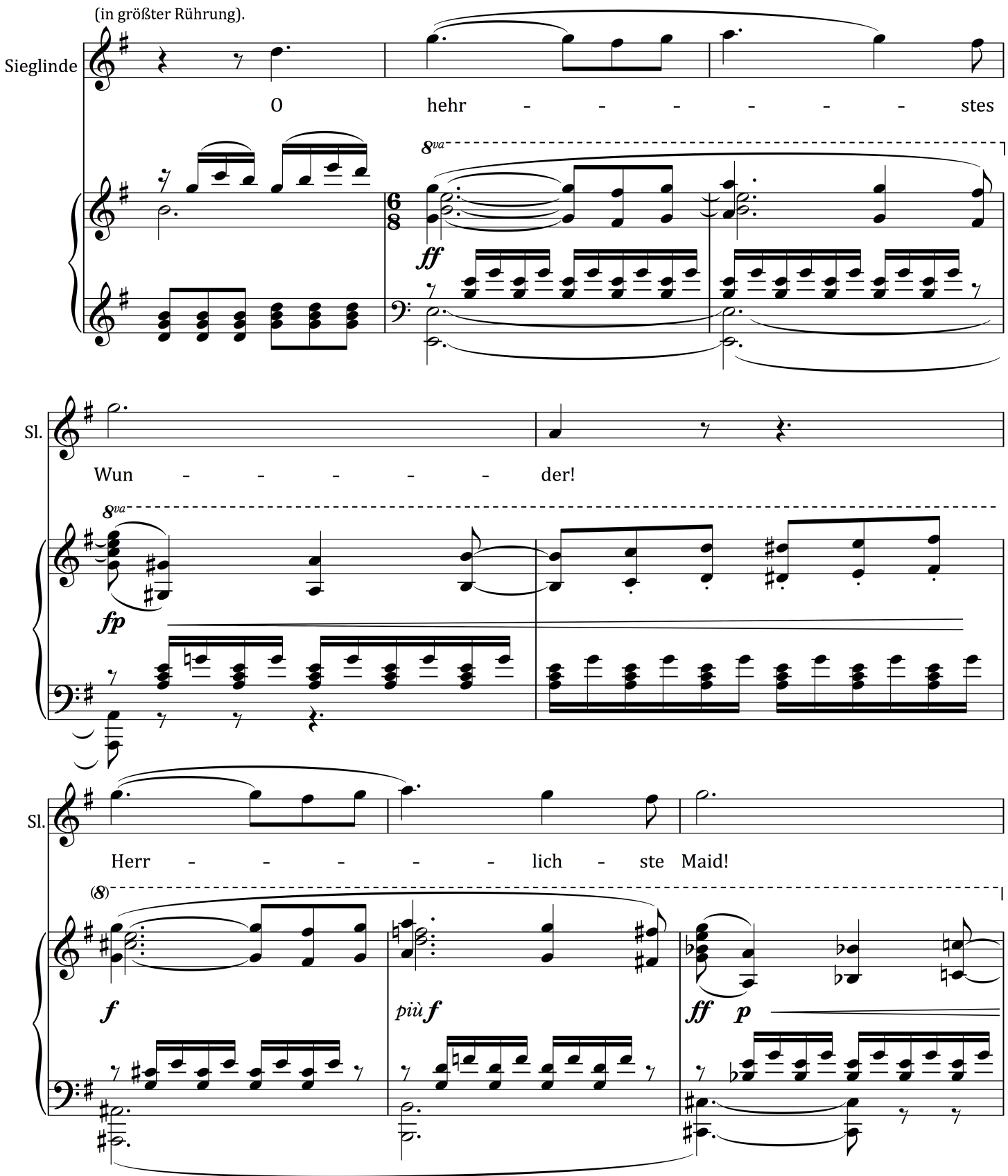


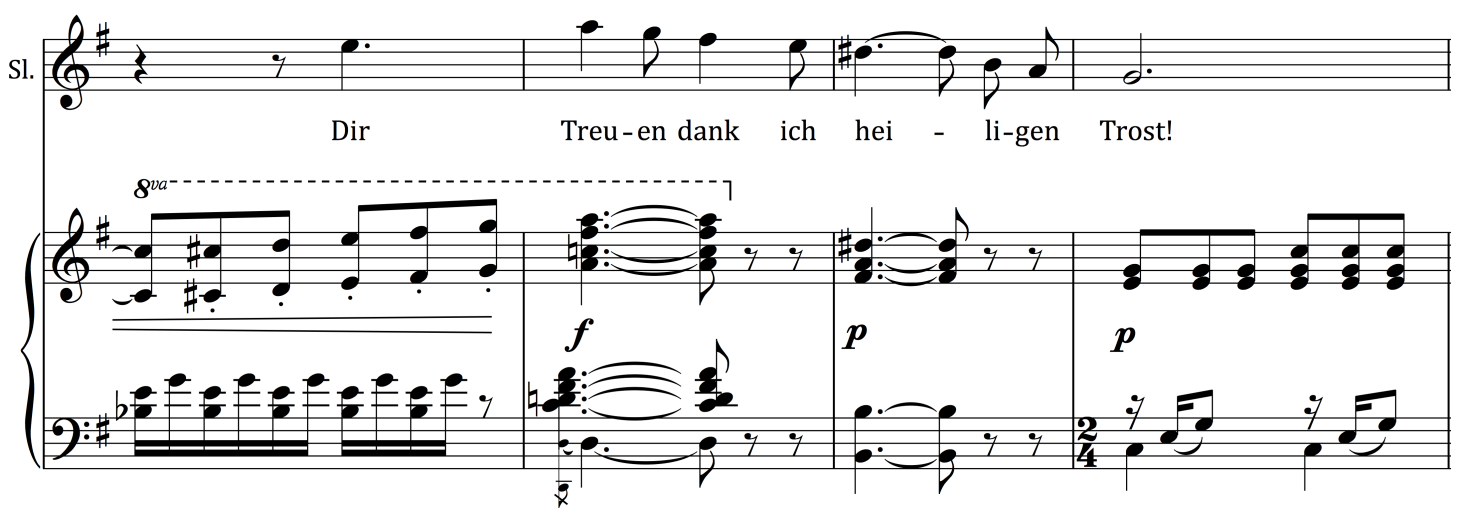

This vocal line is supported by, but can also be overwhelmed by, the full orchestra. Although it seems that a lot of breath should be needed here (as the vocal lines are long) care is needed to not to overblow the air pressure and flow: hence my ribs are working hard on the appoggio, and I compress the sound a little in certain areas to make sure that my sound cuts through the orchestral texture. The vocal folds are thinned out at pitch so although I need the sustained flow, the body is engaged to keep the remainder of the breath from putting undue pressure on the folds. In these lines Wagner has written long vowels: spread over longer periods of time over a loud and thick orchestral texture, demanding the extrinsic muscles to work continuously to stabilise the open tract. Here it is wise to choose sound over text, and indeed, Wagner's writing enhances that choice. ${ }^{382}$

These few bars are unusual. Wagner's concentration on the text and the story has been unremitting; yet here he allows the singer to indulge in pure voice. The voice the listener hears is an amalgam of the body and mind engagement, and I suggest that it is the harmonic structure of the voice, the call or cry of a voice, which engenders an ecstatic reaction in the listener. ${ }^{383}$ It is of

\footnotetext{
${ }^{382}$ Never forgetting that the vocal folds are about $1.5 \mathrm{~cm}$ in diameter, more air pushed at the folds means a diminution of the quality of sound. A good singer should be able to sing loudly (using the body resonance and projection as amplifiers) and at pitch with no loss of quality. Singing more loudly does not mean pushing more air through the vocal folds - it is a complex balance of more vocal fold mass, more retraction in the throat so that the vocal folds remain free, and more projection. Some manipulation of the harmonic structure of the sound maybe needed according to the acoustic, by adding more upper partials to cut through the orchestral sound.
}

383 Vittorio Gallese, "The Manifold Nature of Interpersonal Relations: The Quest for a Common Mechanism" from Philosophical Transactions: Biological Sciences (Vol. 358, No. 
course not coincidental that this is one of the very few moments when Wagner allows the singer to "indulge" in pure vocality: the times when pure love is vocalised (the duet with Siegfried in Act 1 Scene 1 of Götterdämmerung is another example). The brevity and lyrical ecstasy of this scene make it a very satisfying conclusion for the singer. This ecstasy through the nature of the bodily engagement manifests itself in the voice, not only unifying the whole of the singer's bodily system but also connecting it, through the vibration of the sound, I suggest, to the listener's body.

The call of ecstasy that I commit to at this moment moves me, gives me jouissance, and my intention is to involve the audience in my emotion, making the events of the opera mean something to all in a primal, elemental way. As singers, a bridge can be created between others and ourselves - the voice creates a neural and aural bridge to the listener, enhanced by our physical work, creating the mind/body fusion of the embodiment. ${ }^{384}$ My jouissance, my enjoyment and physical release of this moment, is a result of synthesizing expression, body and cognition on the in-breath, all practised before performance. Indeed, it is precisely these greatest moments of the singer's jouissance that drive the occasions of the listener's intense ecstasy.

Sieglinde is not the typical prima donna, not even the stereotypical seconda donna: she represents a change in the female operatic juvenile lead. Dynamic and motivated on stage, in touch with her body and feelings, she expresses them in a way that may have been seen as provocative in Wagner's time. Wagner's vocal writing, his combination of text setting and development of vocal line to create a vocal character, has a direct relationship to the dramatic and musical development, and also changes the way that the singer sings the role. As well as inherent vocal difficulties, (particularly the low tessitura that needs excellent projection and text which can vary on its impact from singer to singer), the vocal energy needs matching throughout the range. The high

1431), 571-528.

384 This is not yet proven scientifically: it will be fascinating to see if further developments of neuroscience will offer any proof of this type of experience. 
conclusions to many phrases where the text is difficult to enunciate clearly need much more bodily engagement to match colour needs of the lower area of the voice. To develop the ability to portray what I feel is Wagner's intention, and to experience how the vocality expands on the text, I believe you need to access your own creativity and unpredictability: if a range of feminist writers have talked about the vocal excess, the more that would seem to define the potential for female empowerment in operatic performance. It is the way the singer specifically works to manage this unknown and unmeasurable quantity in performance that establishes and defines that creative power. ${ }^{385}$ It does not just happen.

Though Sieglinde is used by the gods for their own purpose (to bear a child who will break their destructive cycle) her effect lies in her direct human actions and reactions on stage and her communication with the listener, conveying the "extra" in her articulation. Though this role could be seen as a degradation of the prima donna's typical form because of the lack of her centrality to the story and the breakdown and eclipsing of her position by Brünhilde, the character of Sieglinde, combined with the music and text of Wagner and the singer's unique voice and persona, mesh to provide a threesome of great empowerment and consequence. It seems therefore that not only does the singer embody the character in making the music, but in listening to music, our bodies subconsciously mirror the actions of the performing body; the listener too embodies the sound and the action. More research is to be done in this area, but it appears that an "affect" state is set up between the listener and the performer, setting up a cathartic state for the intense and heightened emotions experienced in opera. ${ }^{386}$

385 As we saw in Wilhemine Schröder-Devrient's account of her process, Wagner, though he may not have articulated the "extra" she brought to a role, certainly allowed for that creativity.

386 "Affect" theory has many cognitive applications in psychology. However, the one that is of interest in music is an instinctual reaction to stimulation that can be pre- or postcognitive. A reaction to music initiates emotional responses that produce thoughts, which produce affect. 
Building on the concepts and methods developed in this case study, I will now investigate what many audiences would assume to be Wagner's most disempowered female character, Kundry from Parsifal. I examine how her character develops the facility to build and change the nature of the character herself on stage with the brilliant engagement of body and mind, to wrest creative control from the composer. In this way she creates a persona that is not negated by her cessation of voice in Act III, in fact, as I will show she gains in power and importance in the plot. In addition, it offers the singer/actor a very particular kind of pleasure to be involved in the music yet not to be creating it. 


\section{Chapter Six:}

\section{Kundry: Embodiment as metaphor?}

There are many ways to examine Parsifal, and in particular the enigmatic Kundry: as the token female in a religious drama; as a problematic and troublesome woman who disturbs and unsettles the men in their serious business; as an hysteric; as the Outsider, the Wanderer, the Jewess - always as the Other. 387

However, on the page, in the score, she remains also a fiction: only on stage does she become manifest through the agency of a skilled singer. ${ }^{388}$ Just how the creative agency of an individual singer can augment the meaning of the performance, shifting our ideas of what the drama means, is particularly challenging in the context of Wagner's last opera, even if the ingenious and individual performances of singers, which surely contribute to the true meaning of a Gesamtkunstwerk, must be understood as an integral part of what Wagner hoped would produce the distinctive aspects of each particular performance. ${ }^{389}$

${ }^{387}$ As Michel Poizat and Slavoj Žižek have noted Parsifal lends itself to Lacanian analysis: the men desire the Imaginary, but are unable to reach that state because the materiality of the body (the Real, as its blood and desire) disgust them, particularly as the cause of the blood comes from the Other, Kundry.

388 A number of writers have written about the opera singer, and the effect of their voice on the listener: See Carolyn Abbate, In Search of Opera (Princeton N.J.: Princeton, 2001); Suzanne Cusick, "On Musical Performances of Gender and Sex" in Perspectives of New Music (32,1994), 8-27; Clemens Risi, "Opera in Performance-In Search of New Analytical Approaches", The Opera Quarterly (Vol 27 No 2-3), 283-295; Michelle Duncan, "The Operatic Scandal of the singing body: Voice, presence, performativity", Cambridge Opera Journal (16, 3),283-306; Wayne Koestenbaum, The Queen's Throat (London: Penguin, 1993); Sam Abel, Sexuality in Opera Performance (Colorado: Westview Press, 1996); Michel Poizat The Angel's Cry, trans. Arthur Denner (Paris: Métailié, 1986); Roland Barthes, "The Grain of the Voice", Image, Music, Text, trans. Stephen Heath (London: Fontana 1977).

389 Despite his best efforts, as Patrick Carnegy says in Wagner and the Art of the Theatre (New Haven: Yale University Press, 2006), 119, Wagner was disappointed in the technical deficiencies and the aesthetics of pictorial representation of his time. However, in the first performances of Parsifal the singers did seem to achieve what he wanted: an intense concentration on dramatic motivation. Their individual performances contributed to the essential elements of what Wagner called a Bühnenweihfestspiel. Of 
My own experience of Kundry from singing the role in performance stands a world away from the isolated and problematic woman who seems to feature in scholarly readings. Scholars have set her up in a particular way: she seems to be a cipher of the men, a servant with no power, or hystericalised, therefore losing her power, all quite different to my workings of her character in performance that I will demonstrate. For me, Kundry is an intriguing female character - not a silenced and powerless "token" woman, but rather someone who manipulates a series of embodiments caused, enabled or influenced by power: personal power, developed from the synthesis of the actor's craft and the character's development; and textual powerplays arising from the interaction between the characters in the opera.

In general, as I have demonstrated throughout this dissertation, to sing a role - literally to embody it - is to unite a community of internal voices in the process of embodiment, and also in the character's transformations during the length of the opera. Portraying the ambiguity of Kundry, Parsifal's only female character - embodying her and making sense of the mercurial and changeable quality of her body and voice for the listener - tests the singing actor's capabilities. Singing Kundry in a number of important productions has enabled me to base my analysis on my experiences; I have combined that information with concentrated study on this role with several of the world's leading Wagner specialists, all of whom have worked in Bayreuth. ${ }^{390}$

In this chapter I will illustrate the ways in which a singer's forms of bodily engagement realise the role of Kundry in live performance. The embodiment for

course, his term Gesamtkunstwerk (a total work of art or a synthesis of all the arts) is more widely associated with Wagner's aesthetic ideals, and is always an illuminating term to describe Parsifal. Also see Lucy Beckett, Richard Wagner: Parsifal (Cambridge: Cambridge University Press, 1981)87; Barry Emslie, 'Woman as image and narrative in Wagner's "Parsifal': A case study", Cambridge Opera Journal (Vol 3 No 2 1991), 100, 112.

390 Notably David Syrus, Lionel Friend, Antony Negus, Thomas Christoph, Jeffrey Tate. I understudied the role of Kundry at English National Opera in 1999 for the Nikolaus Lehnhoff production with Mark Elder conducting. I also sang the role in the State Opera of South Australia's 2001 production, conducted by Jeffrey Tate under Elke Neidhardt's direction; and in 2006 with I performed Kundry with Sir Donald MacIntyre and Simon O'Neill for the New Zealand Symphony Orchestra/ New Zealand Festival of the Arts (conductor, Antony Negus, director, Bernd Benthaak). 
the bodily production of sound, in and through the breath, shapes an interpretation of text and influences the very formulation of her dramatic character. This bodily involvement is crucial for vocal expression - the result of a finely tuned and highly expressive body and voice, combined with a communicative imagination. It is this synthesis, I believe, that creates intense operatic vocal experiences for singers and their listeners.

Here, after first offering a brief overview of critical perspectives on the role of Kundry, I will investigate why the body is important in this opera in particular, and how the action is built around the concepts the characters have of their own bodies and the bodies of others. Invoking, applying, and developing the concept of the three voices needed to sing Kundry, I will engage with a range of scholarly views before laying out my ethnographic case study of Kundry, employing my model of embodiment and explaining its implications for the physical experience of this role. I will explain how the bringing of the character to life in the hands of a skilled singer enhances creative agency, in turn augmenting the meaning of the text. In conclusion I will suggest that my work on singers' embodiment can transform our understanding of how Kundry is created in performance, in the process demonstrating how embodied performance can shape our notion of the interpretation and mutability of these operatic texts in specific ways.

\section{Body}

The story of Parsifal relies on illusion, the collapse of space and the interface between the real world and the enchanted. ${ }^{391}$ Suggesting that stage illusion is phantasmagoria, Theodor Adorno comments how Wagner managed in Parsifal, through the world of enchantment, to oppose the forces of life with sickness and desire. ${ }^{392}$ Adorno is here not talking about the tricks of scenery and light that are

\footnotetext{
${ }^{391}$ Abbate, In Search of Opera, 107.
}

392 Theodor Adorno, "Phantsmagoria" from In Search of Wagner (1 ${ }^{\text {st }}$ published by Suhrkamp Verlag 1952. trans. New Left Books, 1981, this edition London: Verso 1981), 
traditionally associated with phantasmagoria, but acknowledging the tricks and deceits of characterisation and the hiding of important emotional contexts behind others. To reinforce the illusion of the stage and actors and give the audience fewer distractions, for Parsifal Wagner rendered the orchestra invisible (the covered pit at Bayreuth). Phantasmagoria itself covers not only the mechanics of stage effects, but also, I suggest the illusions of the metempsychosis that Kundry undergoes. ${ }^{393}$ More importantly though, the conflict between the enchanted world and the sickness underneath left Wagner's singers in a difficult position. Anecdotally he wanted his singers to "embody" their roles, while at the same time subordinating that embodiment of life and desire to the work's larger dramatic aim - a sickness of body and soul - a difficult acting task at any time. ${ }^{394}$ As he professed a horror of costume and what he termed "makeup creatures", it seemed he briefly desired to deny the body of the singer as well: Cosima Wagner noted in her diaries that during discussions for staging Parsifal, Wagner had said "after I have invented the invisible orchestra, I would also like to invent the invisible theatre." 395 As we conceive of Wagner mainly as a composer of vocal music, it seems strange for him to deny the bodies of the singers for whom he wrote the music: from a singer's perspective, to deny the body is to deny the voice itself. For Wagner, in as much as a music drama finds its fulfilment on stage, bodies are implicated, whether acknowledged or not. ${ }^{396}$

\section{2.}

393 Metempsychosis is another word for reincarnation, or the transmigration of souls.

394 For an in-depth discussion of Wagner's philosophies on his dramaturgy, see David Levin, "Dramaturgy and Mis-en-scene", Unsettling Opera (Chicago: University of Chicago Press, 2007), 16.

395 Wagner to Cosima in 1878: Cosima Wagner, Tagebücher Vols 1\&2. ed. Martin GregorDellin and Dietrich Mack (Munich and Zurich, 1976, 1977). Wagner was not the first to conceive the idea of the invisible orchestra: Berlioz requested his orchestra be concealed by a curtain for Lélio; Lucy Beckett: Richard Wagner: Parsifal (Cambridge: Cambridge University Press, 1981), 90.

396 See Suzanne Stewart, "The Theft of the Operatic Voice: Masochistic Seduction in Wagner's Parsifal", The Musical Quarterly (Vol 80, No 4. 597-628), 605, 609. Wagner left quite detailed directions for staging works and clearly placed a lot of emphasis on the visual dimension. However people who work in the theatre tend to divide into those who like to see how the illusion works, and those who wish only to see the finished 
Does the obsession of Parsifal with the body reveal the depth of Wagner's own struggles to disallow the body in performance, even while he had to continue to rely on the singing body to bring his music dramas to life? ${ }^{397}$ There is no doubt that Parsifal's preoccupation is with the body - with its demands on the psyche, and the negation of those demands: in Parsifal, as Mary Ann Smart says, "the body is alternately suppressed (in the outer Acts) and highly eroticised, titillating, decadent ... (in Act 2)". ${ }^{398}$ Indeed, on the one hand, the tension between the characters in the opera revolves around those who are involved with their bodies - Kundry and Amfortas, and their corporeality and sexuality; and, on the other, those who believe in transcending its insistence, as Gurnemanz does. The plot hinges on an open wound that leaks blood - something that is all too confronting for those who live cerebrally. Parsifal purports to be about religion and salvation, but, as Barry Emslie has observed, it is also about paganism, incest and damnation - activities that require a corporeal presence. ${ }^{399}$ Most scholars emphasise the complex religious aspects of the opera and the difficulties of realising Wagner's conception, and accentuate the transcendence of the music, which somehow seems to overcome the unacceptable attitudes of the libretto. ${ }^{400}$ However, Parsifal's importance in the lexicon, and the reverence in which it is held, makes us forget at times the extent to which the story of religious transcendence paradoxically can only be engaged in through the context of a deep corporeal understanding.

result of all the human effort and work. It appeared that it was the sight of the business and trappings of the stage that most upset Wagner.

397 It seems as if Wagner was caught between two desires: the music was paramount to him, and yet to be brought to life on stage required bodies. For a further discussion see Matthew Wilson Smith, "Laughing at the Redeemer", 11.

398 Mary Ann Smart, Mimomania (Berkeley: University of California Press, 2004), 191.

${ }^{399}$ Barry Emslie, “Woman as image and narrative”, 112.

400 The distaste over the sense of racial purification implicit in the text is marked by a number of commentators. Emslie comments that they are disguised in part in the text and by the music; other merely point to the racial slurs: Lucy Beckett, Richard Wagner: Parsifal, 1981; Barry Millington, Richard Wagner: The Sorcerer of Bayreuth, 148; Slavoj Žižek, "The Wound is Healed Only by the Spear that Smote You: The Operatic Subject and its Vicissitudes" in. David Levin, ed. Opera Through Other Eyes (Stanford: Stanford University Press, 1994). 
Acknowledging that the body and desire are central themes, we can only be drawn into the larger themes and interpretations of the opera (as listener or as performer) through engaging with the materiality of the operatic performance. It is interesting to investigate how we experience Kundry as body and how that experience influences our larger interpretations of the body. A few scholars make the connection in Parsifal between voice and body, and the comments are generally to do with Kundry's presence. For example, Matthew Wilson Smith identifies the importance of Kundry's physicality, saying, "Kundry's Otherness is particularly centred on her embodied theatricality" acknowledging the physicalisation of her various guises and deeds. ${ }^{401}$ Smith recognises at least that she needs to assume varying guises to perform effectively. Emslie talks about the embodiment for Kundry, or what might be described as her corporeality, saying that she is "a character who must change her appearance often in order to fulfil her allotted task as the single embodiment of the male notion of The Female". But by referring to a "single embodiment" he means the single manifestation of the female rather than the complex creature Kundry is. ${ }^{402}$ Emslie suggests we think of The Female in very abstract and absolute terms, almost erasing the different bodies because they only serve to illustrate "femaleness". But by not acknowledging the processes involved in the singer's depiction of the facets of the role, we lose the chance to understand another aspect of the meaning of Kundry, and miss out on a crucial way of perceiving her significance in the story.

Before turning to explain in some detail how one changes physicality and voice in performance to embody this transmutating role, let us consider Kundry's role in the opera more generally.

\footnotetext{
401 Matthew Wilson Smith "Laughing at the Redeemer", 11. Other who reference both voice and body in Parsifal are: Poizat, The Angel's Cry; Žižek. "The Wound is Healed Only by the Spear that Smote You", 1994; Emslie, "Woman as image and narrative", 112; Bronfen, “Kundry's Laughter, 147-161.

402 Emslie, "Woman as image and narrative in Wagner's Parsifal", 116.
} 


\section{Kundry}

It can seem that the forward movement of Parsifal relies on what Kundry does with her body. Indeed, Kundry's body and its appearance is vital to the story. By hearsay from Gurnemanz and Klingsor we know that her body has been subject to metempsychosis (that is, reincarnation). ${ }^{403}$ How the reincarnation is carried out is unclear, except that we assume that she has some magical powers. On stage however, what we see are the metamorphoses of character, the transformations of a single character. Clearly to perform Kundry one must be able to balance a complex physical and mental role, with difficult concepts to communicate. Not only that, but the performer of Kundry needs to deal with a raft of preconceptions and misunderstandings of her role in the opera and her importance in the plot. It is an enormous challenge for the singer -how one might vary the configurations of the mental and physical elements involved in changing the character on the stage, and handle the knowledge that the lack of seemingly small elements in the matrix can cause our enjoyment and belief in the performer to diminish.

Working with Kundry from the inside and developing her for performance, it is hard to understand why she has been labelled a problem. Yet most definitely she remains a conundrum to many people. To some, her female body is a problem, her actions can be undecipherable and she has famously and often been called an hysteric. ${ }^{404}$ In real time in performance, we witness Kundry's body becoming transformed through metamorphosis, keeping the same character but changing and emphasizing different aspects of the whole for each manifestation of that character. The Kundry we see is bound by her corporeality, and Parsifal's plot hinges on her ability to change her bodily form. As a conflation of a number of historic and mythic figures, Kundry is damned for

${ }^{403}$ Carolyn Abbate, "Metempsychotic Wagner", 107.

${ }^{404}$ A number of texts describe Kundry as an hysteric, some in more detail than others: see Smith, "Laughing at the Redeemer", 11. Others who reference her hysteria are: Poizat, The Angel's Cry; Žižek, "The Wound is Healed Only by the Spear that Smote You"; Abbate, "Metempsychotic Wagner"; Emslie, "Woman as image and narrative", 112; Bronfen "Kundry's Laughter," 147-161. 
eternity to wander through time by way of magic and reincarnation because she laughed at Christ on the Cross. ${ }^{405}$ She is a woman damaged by tortuous psychological conflict and through her the futures of the three male protagonists are determined. ${ }^{406}$ Ranging far beyond traditional operatic manifestations of simple emotions, the character metamorphoses from an animal-like creature, to sorceress, to a maternal and then seductive woman, and finally to a penitent similar to Mary Magdalene. 407 She is an extraordinary character - an "anti-diva" unlike the image of woman and operatic leading lady prevalent at the time. ${ }^{408}$ Wagner details stage instructions that lay out how and what Kundry is to do with her body. What she does with her voice to interpret and colour those actions is left to the singer who works with voice, text and body in her individual way. 409 Moreover, because so many of Kundry's vocal utterances are indecipherable and/or enigmatic, the focus on voice and body as primary cipher for her character is even stronger than for the typical operatic role.

Despite the seeming incoherence of the role, it is nevertheless Kundry who is the catalyst for the narrative: without her, nothing would happen. Even though she appears to be a creature in thrall of the men in Parsifal, it is not the men who control the story, but her. As the male characters react to her actions, or are goaded to their own actions, we see that Kundry precipitates events.

405 Kundry is an amalgamation of a number of figures in the Grail myths, including the Loathly Damsel, Cundrie, Sigrune, Orgeluse, and Trevizant, not to mention her reincarnations Herodias and Gundryggia.

406 Lucy Beckett, Richard Wagner: Parsifal (Cambridge: Cambridge University Press, 1981) 4 , is one of a number of authors to suggest that Kundry is psychologically damaged.

407 Nila Parly and others see Kundry as progressing to redemption - as if that is the only and most important reason for her existence. Nila Parly, Vocal Victories: Wagner's Female Characters from Senta to Kundry trans. Gaye Kynoch (Copenhagen: Museum Tusculanum Press, 2011), 309-316.

${ }^{408}$ I take this term from Marc Begin's article, "L'Anti-Diva”, Musique en jeu (No 31, May 1978), 73-77.

${ }^{409}$ For example, at her first appearance, Kundry is asked to rush in, almost staggering (Sie stürzt hastig, fast taumelnd herein.); in Act III when Gurnemanz awakens her she is paler than in Act 1 and the wildness has disappeared from her looks and behaviour (....nur ist ihre Gesichtsfarbe bleicher; aus Miene und Haltung ist die Wildheit verschwunden). 
Perhaps the character of Kundry can be seen as a male construct to support the ideas and actions that are, as Kaja Silverman says, obscurely desired by men but unable to be voiced and come to fruition. $\mathbf{4 1 0}$ Or, as the men are unloved, uncared for, one wonders if, as Phyllis Chesler puts it, "male rage and anguish about not being loved and protected by other men" is again displaced onto the figure of Kundry, the female, subverting and balancing the male chauvinistic tendencies and stopping the inward and collapsing spiral of their situation. ${ }^{411}$

If various interpretations struggle with the nature of Kundry, a common theme in Wagnerian criticism is a presumption of her powerlessness. ${ }^{412}$ As Abbate points out, while in the power of Klingsor, Kundry has suffered multiple metempsychotic episodes as a result of her mocking of Christ. Although not stated in the text, the implication is that she has not had any choice in the matter of the timings of her transformations - indeed it is not clear whether she had any desire to undergo a metempsychotic episode at all. ${ }^{413}$

A range of scholars such Bronfen, Emslie and Smith have seen Kundry as depicting the quintessential female hysteric. I agree that many of her physical tics and mental states mimic the condition of hysteria. But the common inference - correct or not - that an hysteric is powerless (as I explain further shortly), that she does not know what she is doing, does not ring true to me in the case of Kundry. Interestingly though, engagement with hysteria implicitly recognises the importance of the material body in the story and, until Act II, Scene Two, her fractured personality in both text and music highlights her inability to keep even

${ }^{410}$ Kaja Silverman, The Acoustic Mirror: the female voice in psychoanalysis and cinema (Bloomington: Indiana University Press, 1988), 87.

411 Phyllis Chesler, Women and Madness (New York, Palgrave Macmillan, 2005), 41.

412 Many commentators see Kundry's death as a result as her powerlessness in the plot if she had any power or meaning to the men, she would live; Emslie, "Woman as image and narrative in Wagner's Parsifal', 120, 122.

${ }^{413}$ It is quite clear that these episodes are a form of punishment for her trangression. However, Slavoj Žižek suggests that her laughter, her mocking of Christ on the Cross could have been a reaction to seeing Him enjoying his pain, experiencing jouissance on the Cross. Slavoj Žižek, "I do not order my dreams" from Slavoj Žižek and Mladen Dolar, Opera's Second Death (Oxford, Routledge, 2002), 162. See also Abbate "Metempsychotic Wagner", 107. 
one personality going although her body remains constant. ${ }^{414}$ Her unmistakeable laugh is not only a manifestation of an involved body, but also an indication of her subversive irony. ${ }^{415}$

If casting Kundry as an hysteric implies a lack of volition, then it is an understandable way to explain her unpredictable behaviour and speech. What she says is often opaque and can be interpreted in a number of ways, and her excitability, her eagerness to offer her information and then withhold it, could be described as a manifestation of a truly disordered mind. The first time she appears, the stage instructions describe her as being of a "wild" appearance: she lies on and crawls around the floor, and the Pages describe her as an animal: Was liegst du dort wie ein wildes Tier? ${ }^{416}$ It is in Act 1 , when we first meet her, and in Act II Scene One, that Kundry's actions most imitate hysteria. Her physical actions are not as consistently "civilised" as the men's are; she communicates in short, sometimes incomprehensible bursts; and she moans, groans, screams and grunts for no discernable reason. It is only when she moves into Act II, Scene Two that her actions and speech become focused, fluent and powerful.

In fact the idea of Kundry as hysteric points to not only a sense of loss of control, but also deeper issues of trauma and the body. This has some interesting implications. As Elaine Showalter has laid out, hysteria has been the designation for a vast shifting set of behaviours and symptoms that have been difficult to diagnose. ${ }^{417}$ Indeed scholars have traced the use of the term back to Egyptian and Graeco-Roman thought, where the earliest sources of recorded medicine

\footnotetext{
414 Bronfen, "Kundry's Laughter", 147-161; Emslie, "Woman as image and narrative”, 109-124; Matthew Wilson Smith, "Laughing at the Redeemer", 11.

415 Žižek, “I do not order my dreams”, 162.

416 I use an Edition Peters Vocal Score: page number, system number and finally bar number. Edition Peters p 24, 5th system $2^{\text {nd }}$ bar. "Why do you lie there like a wild animal?"

417 Elaine Showalter, Hystories: Hysterical Epidemics and Modern Culture (New York: Columbia University Press 1997), 14.
} 
allies women with madness and with hysteria. ${ }^{418}$ According to Julia Borossa, the term itself, though originally used as a general term for ailments of the womb, came to refer to a vast array of complaints of both maladies and maladjustments. ${ }^{419}$ Within a patriarchal environment, as Showalter and Chesler point out, the hysteric came to embody femininity itself, as problem and enigma. Only hysteria, as Borossa says, "with its unique expressiveness and ability to symbolise conflict and distress in a kind of alternate language, with symptoms mostly exhibited by a victim (of oppressive social conditions) or a rebel (refusing those conditions) whose strange, disturbing behaviour expressed a sense of profound discomfort and/or protest towards the limitations of her or his situation, could symbolise the problematic, paradoxical relationship to patriarchal conformity". ${ }^{420}$ Hysteria was a functional disease with no pathology, and was therefore difficult to define, although it clearly has a strong connection with sexuality, particularly feminine repressed sexuality and sexual dissatisfaction. ${ }^{421}$

418 The word hysteria is derived from the Greek word hystera, meaning womb. See Phyllis Chesler, Women and Madness, 47-58; Elaine Showalter, Hystories, Chapter 1.

419 Julia Borossa, Ideas in Psychoanalysis: Hysteria (London: Icon, 2001), 3-5. Madness and hysteria were often vilified and mixed in peoples' minds. However, truly mad women, according to Phyllis Chesler, were always locked away, never on show, brutalized, feared and denied; on the other hand, hysteria as we know it is always visible, and as Thomas Szaz says, a function of social oppression in any form must therefore be regarded as prime determinants of direct communication of all kinds (e.g. hysteria) Chesler, Ibid, 86.

420 Latterly it has been suggested that hysteria adapted its symptoms to the ideas and mores current in the society it was prevalent in - generally speaking in Western Europe and North America. The frequency of it seemed to grow towards and peak at the end of each century when people were wary of possible imminent social changes. Incidences of hysteria have been recorded wherever there has been a written history. See Julia Borossa, Ideas in Psychoanalysis: Hysteria,12-14.

421 According to Julia Borossa, a sense of woman's sexuality as voracious has long been connected with hysteria, along with the other burdens of femininity: hormonal fluctuations, frigidity, a lack of or an excess of sexual responses, and thus has been connected with male appropriation of societal power. The rise of feminist activists in the last half of the nineteenth century, and the resulting rise of feminine power, contributed to the feeling of uncertainty for women. Julia Borossa, Ideas in Psychoanalysis: Hysteria, 42 .While some women were fighting for equality and independence, both men and some women were concerned with the dissolution of the family and lack of population growth, and wanted, if not needed, women to remain domestic and deferential. Included 
Of particular interest to the historical context of Parsifal is its correspondence with the heyday of hysteria's manifestation in late nineteenthcentury France, with Jean-Martin Charcot's well documented experiments and studies. He described hysteria as an illness with strange symptoms, involving the sufferer's changeable body and certain disturbing forms of behaviour. ${ }^{422}$ The sufferer's body seemed always at the mercy of the psyche - not only was that manifest in psychosomatic malfunctions, but also in strange psychoses. Charcot's work lent some form of scientific credibility to hysteria, and initiated a proper investigation. However, even in this context the forms of display continue to present female hysterics as powerless objects, pinned in the male gaze in disturbing ways, the subjects of distasteful experiments under the guise of gaining scientific information.

As Judith Herman has laid out in her now classic Trauma and Recovery, hysteria itself is the manifestation of trauma, clearly linked to sexual exploitation and violence. In Herman's account it was Sigmund Freud who linked these manifestations of hysteria to sexual predation. However, the shocking nature of his discovery - revealing the prevalence of violence against women even in upper and middle class society - caused him to turn against his own theory, refusing to acknowledge the exploitative nature of women's real experiences and choosing to believe instead that the women must be inventing their stories. ${ }^{423}$ For me, then, it is Hermann's positioning of hysteria as one of a number of both bodily and psychological reactions to severe trauma that offers deeper insight into Kundry's character. Interpreting Kundry in the context of trauma allows us

in the explosion of interest in biological and medical sciences was an attempt to prove that women had a baser instinct than men - one that was controlled by their sexuality that, if left unchecked, would lead to degeneration and social disruption. Women were controlled and subdued by violence or manipulated into subservience.

422 With Charcot's (Dr. Jean-Martin Charcot of the Sâlpetrière Hospital in Paris) patient hysterics of the Sâlpetrière in Paris, there was some doubt at the end of the 'performances' as to who was controlling whom. It seemed that Charcot had the upper hand, and yet others had their doubts about the women, and felt that they were acting for the benefits they gained from the performance. Asti Hustvedt, Medical Muses (London: Bloomsbury, 2011), 298.

423 Judith Herman, Trauma and Recovery (New York: Basic Books, 1997), 12-19. 
to understand the signs of hysteria not as some enigmatic and ultimately quixotic female display, but rather as the symptoms of the profound psychological trauma that her own history lays out for us - an explanation that makes great sense to me as a performer. Kundry is disorientated at times, she has flashbacks, her personality is fractured and she lives in fear of the memory of her deeds in her former lives. As Herman's research explains, it has become apparent that the dissociation from previous traumatic events creates a window into consciousness, memory enhancing the links between body and mind. ${ }^{424}$ This multivalent expression of consciousness goes some way, I believe, towards explaining Kundry's kaleidoscopic personality in the present, not only throughout her metamorphoses, but also within each personality she characterises. Her much discussed laugh, taken as emblem of hysteria, manifests itself at times when the personality she is portraying is uncomfortable and insecure - remembering her trauma or expressing an ironic reaction. ${ }^{425}$ Kundry is always thinking on her feet, as it were - although obviously the performer must always be in control - and what the audience sees is a manifestation of the split or multiple personality, traditionally thought to have been a symptom of hysteria, but re-categorised in the twentieth century as multiple personality disorder and other related conditions. In this sense, then, "hysteria" can become a tool for further interpretation, rather than a characterisation that dismisses women and places them in irrational female categories.

As a performer I perceive Kundry as a woman severely distressed traumatised if you will - but also actively thinking and manoeuvring her way out of her situation and into a position of power. In Act II Scene 1, for instance, after having discomfited Klingsor by her remarks, Kundry is quick to take advantage of that weakness by baulking at his orders. ${ }^{426}$ Her reactions to Parsifal's "enlightenment" after the Kiss in Act II Scene 2 suggest that she is thinking how she can turn the situation to her advantage. On stage I experience her as much

\footnotetext{
${ }^{424}$ Herman, Trauma and Recovery, 12-19.

${ }^{425}$ As discussed by Elisabeth Bronfen, Nila Parly, Slavoj Žižek, amongst others.

${ }^{426}$ Edition Peters, 112, System 3, Bar 1.
} 
more aware of her destiny and the way to achieve it than her supposed male masters are: her states of mind are generally well controlled, as are her ways of making the best of her opportunities. She is manifestly a vocal person, and I suggest that the places where her vocality is not singing (the screams, groans and laughter) are places where her transitions from one metamorphosis to another takes her over, or are in the process of happening: they are the tools of her transformational power, not a loss of ability to communicate. The control that Kundry displays, and her opportunism in appropriating power from the male characters, is not the behaviour of a weak and powerless woman.

Although a number of commentators see Kundry as allowing the men access to their feminine aspects, giving them the opportunity once again to be whole and free, I suggest that by manipulating her voice and body to gain control over the other characters, she in fact creates opportunities for herself to acquire power. That power is rarely acknowledged by the men on the stage nor has it been understood and explicated by scholars. However, in my experience as a performer, that power feeds her creative agency, and as the character evolves she is able to manipulate situations to her advantage, giving her the desired release from the incessant life she abhors. ${ }^{427}$ Often in opera there is a "dangerous" woman. In Parsifal, Kundry is "dangerous"; her voice is taken from her and it has been suggested by a number of commentators that by doing so, Wagner disempowers her. ${ }^{428}$ However, as I will lay out, Kundry's body and

\footnotetext{
427 Hans Jürgen Syberberg's film of Parsifal offers one perspective on this issue of Kundry as symptom of the reintegration of the feminine into male power. He sets up Woman/Kundry's erasure in Act III by re-making Parsifal female at the end of Act II, conflating the masculine and feminine in Parsifal from the moment of the kiss (famously bringing out a female actress to act the part of Parsifal from that point of the film to the end, lip-synching the role of Parsifal). However interesting and thought provoking the film is, Syberberg's medium separates the performers from their voices, so we lose touch again with the nitty -gritty performance aspect of Parsifal, the physicality. Ironically, it is exactly this split between voice and visual that he uses as the key to his interpretation, which further shows an unwillingness to acknowledge the part of the body in the operatic sound, and that generated so much backlash against the film as essentially unoperatic.
}

428 Most commentators say that once Kundry loses her voice, she loses her usefulness in the plot, that Parsifal has assumed her vocal power: Emslie, Bronfen, Smith, and Stewart, amongst them. Mary Ann Smart though, points out that Kundry still has her body, and the ability of gesture to mark her presence: Mary Ann Smart, Mimomania (Berkeley: University of California Press, 2004), 201-204. 
training enables her to build power which informs her vocality and ultimately her presence, allowing her to remain embodied and vital until the end of the opera. How personal power and body can inform vocality is the subject of the next section.

\section{Voice and Body in Parsifal}

However generally the centrality of embodied vocal experience may be understood in Parsifal's critical reception, or indeed most other operas, it is striking that at least from a singer's perspective, there is no detailed explanation of the specifics of the physical and vocal engagement for the singers, nor an acknowledgment of how an understanding of that engagement can in turn deepen our critical understanding. ${ }^{429}$ It is the actual embodiment of voice connecting with an interpretation of an operatic character, of operatic performance, and of the listener's experience, which is vital in all operatic singing, but is particularly important to portray the chameleon-like Kundry, to make sense of her multiple narratives. Only through embodied performance can we understand the manipulation of power that the skilled Kundry must enact to create a coherent character, and by extension, provide a coherent structure to the story of Parsifal.

In a staged performance Kundry is a challenging role both vocally and physically. It is relatively easy to stand and sing the role beautifully - but that is not what Wagner asked for. Just the physical directions in the score are tough on the singer, involving a lot of kneeling and grovelling around on the ground. If you have colleagues, particularly a Klingsor, who are physically fit, and the director realises it, certain productions can require all sorts of strenuous physical interactions. Add to this the possible difficulties of the costumes - which are

429 This sort of scholarship is rare in relation to any opera, but Parsifal provides a particularly compelling case study. 
often layered, long, and stiff - and it is easy to understand why most Kundrys are covered in bruises during rehearsals and performances. ${ }^{430}$

In roles such as Brünnhilde and Isolde, Wagner had demanded an increase in vocal stamina caused by the extreme length of the roles, and the singer needed to develop strength in the upper register to compete against a larger orchestra. The long tracts of non-repeating text require a formidable memory and the sheer stamina of being on stage for so long demands physical fitness. Although Kundry is on the stage for most of the opera, musically she is one of Wagner's shorter roles. Nevertheless, she poses technical and vocal demands that are quite different from Wagner's previous roles for women through the variety of tonal qualities, the periods of longer concentrations in certain registers, and the angular vocal lines and unvocal noises. ${ }^{431}$ I have already mentioned how Marc Begin comments on Kundry as an "anti-diva": she is a radically different conception of a leading lady to what has come before, and this is true not just in terms of the type of female character but also of the very nature of the vocal and physical role. He also pointed out the way in which the vocality of this role works towards twentieth-century extended techniques: "A range of procedures that would come into systematic use in the twentiethcentury: modifications of the timbre of the singing voice, ... transition from the sung laugh to the genuine laugh, ...from the cried out text to the true cry, and from the cry to the plain ... It is perhaps no surprise to find in the musical composition of Kundry's role a direct precursor of Sprechgesang." 432

Having performed the role, and other challenging ones that employ Sprechgesang, I agree with Begin: Kundry is a role with technical challenges that

\footnotetext{
430 In the Nicklaus Lehnhoff production premiered in 1999, the Kundry (Kathryn Harries) was encased (the only word for it) in a beetle-like carapace under which were two other costumes, stripped off in turn after the beetle wings were removed. The stage had a rough and abrasive surface and she had to wear thick flesh-coloured plasters on her hands and knees to protect them.
}

431 Eva Rieger, Richard Wagner's Women, trans. Chris Walton (Suffolk: Boydell Press 2011), 198.

432 Marc Begin “L'Anti-Diva”, 31, quoted by Michel Poizat in The Angel's Cry, 199. 
must be solved or you run the risk of damaging your voice. ${ }^{433}$ However, once those difficulties are conquered the technical facility gained is extremely valuable.

My own perspective on the character of Kundry which I have gained through my performances and which I articulate in part through my model of embodiment in performance as laid out in Chapter Two, has given me a substantially different conception of the role than the creature described in the critical literature, as noted before. As my process of preparation and my own experiences of her during performances illustrates, the disempowered female object that seems to feature in the critical literature is belied on two levels simultaneously: bodily, in that her very presence is affirmed by the end of the opera; and in her ability to gain power over the action and to gain redemption.

In order to understand how the detailed and different styles of embodiment come about, I will examine each character that Kundry assumes in depth, and lay out how the elements of that particular bodily enactment combine to inform the vocality. Concentrating specifically on the ways in which body and voice interact for the singer in producing the singing for the staging, I will also make explicit for the reader how the previous two sections about Kundry's relationship to the opera's narrative, and the interface between voice and body, connect, and provide an in-depth analysis of the complex task of her personification and the various metamorphoses of that personification. First though, let me discuss metamorphosis and why a singer's embodied presence, in Parsifal, enhances it.

\section{Metamorphosis}

We first see Kundry after her metempsychotic episodes. She is traumatised, mentally fractured, and having strong emotional reactions to previous events, all of which induce an altered state of consciousness. Her unpredictable hysterical

\footnotetext{
433 Roles I have sung include Marie in Wozzeck by Berg, Pierrot Lunaire by Schoenberg, Kostelnička in Jenufa by Janáček.
} 
states produce adverse reactions in the men, and perhaps in the listener: because of those reactions they tend to discredit her history and what she says. ${ }^{434}$

However, whatever interpretation is built around Kundry's role, the plot's positioning of her distinct function in each act, which in turn provides the key to redemption for the male world, requires her complex metamorphoses, her transformations of character. In real time, in performance, we witness her body become transformed through metamorphosis, keeping the same character but changing and emphasizing different aspects of the whole for each manifestation. What she does with her voice to interpret and colour those actions is left to the singer who works with voice, text and body to produce distinctly different, sometimes unrecognisable, representations.

It is in Kundry's metamorphoses that the vital need for embodiment is manifest. The singer's need for embodiment is clear, but it is also in the empowerment of the metamorphoses that the plot moves forward. In preparing the role of Kundry for performance myself, I came to understand that, just as there are four distinct characters and three metamorphoses, Wagner's writing demands the adoption of three different styles of singing: a declamatory, interjectory style; a lyrical, more intimate style; and a vituperative, demanding and forceful style of singing. ${ }^{435}$ In Act I and the first scene of Act II much of Kundry's singing is interjectory and gruff; there is no space for beautiful phrasing and the vocality and text needs power and projection with very little subtlety. Though there is relatively little to sing, there are wide dissonant intervals and she screams, laughs and cries. In contrast, in the second scene of the second act, Kundry is given a large vocal part with much more lyrical singing in the middle range, with a softer and more seductive vocal sound. Later on in this scene the vocality changes again: she sings in a much more forceful style, climbing in pitch,

434 In a somewhat similar vein to Freud's response to traumatised women. Bronfen, "Kundry's Laughter", 147-161; Emslie, "Woman as image and narrative", 109-124; Smith, "Laughing at the Redeemer", 5-25.

435 Even though Kundry appears as four different facets of herself, the two words Dienen, dienen which Kundry utters in Act 3, in her fourth metamorphosis, hardly constitute a different style of singing. 
with more aggressive rhythms and text. But a concentration on the production of these distinct styles is not in itself enough to prepare for performance; rather, it is the successful manipulation of the different levels of physical engagement and embodiment needed, in interaction with the complex and shifting vocal styles, that is the primary challenge of this role.

Kundry's three styles of singing during the opera reflect not only on her physicality, but also her frame of mind and her attempts to break the cycle of metempsychosis.The task is complex, but without a doubt the costuming and makeup help. However, it is the skill of the singer/actor in bringing the different elements together, subtly reordering some elements of their representation and emphasising others, which facilitate the alternative possibilities of portraying Kundry. In addition, it is the skill of the actor in concentrating the focus and gathering of mental and physical power that builds to the catharsis of metamorphosis, with the final transformation breaking the cycle of metempsychosis.

Like a shaman and shapeshifter, if sung by a charismatic singer/actor Kundry becomes a powerful character, capturing energy and putting that energy to good use by initiating events that heal both the men in the opera, and herself.436 By setting in motion the gradual questioning and eroding of Klingsor's power and control, she gathers energy to start the remarkable series of transformations - metamorphoses - that are launched in the second act. Without power, commitment and charisma on the part of the singer, the role loses substance and focus, and is in danger of being reduced to a fairly meaningless series of vignettes. The plot then becomes more difficult to understand, and the men assume a power that belies their lack of action.

Each metamorphosis is different: the first is from the "wild" woman of Act 1 and Act II, Scene I, to the beautiful motherly and seductive woman of Act II

\footnotetext{
${ }^{436} \mathrm{~A}$ shaman, male or female, is a powerful figure in tribal societies - different and unrivalled by any male religious counterpart. A shaman is a shape-shifter, a healer and communicator with an ability to catalyse energy in way that cannot be explained by science, even today: rather like a powerful performer. Kundry's character, is a conflation of the Wandering Jew and mythical figures such as Gundryggia, Herodias, and others.
} 
Scene 2. The change there is a fast off-stage one, with the music setting up the change of character. The second metamorphosis, however, occurs onstage, and takes much more skill. After the Kiss, Act II Scene 2, when Parsifal rejects her, Kundry must change her demeanour, and the style of singing is key to the progressive change of style and intent. Her anger and desperation builds until Klingsor appears at the end of the act. With Parsifal's capture of the spear, her world collapses around her. The third metamorphosis occurs because of that power exchange, and we see her next, after the interval, as an awakening penitent in Act III.

In a complex acting and singing role such as Kundry, one can see how a singer needs to balance and interweave a multitude of choices in order to gain the maximum amount of expressive content from the text. Indeed, it is in these shifting choices that what is - or is not - communicated about Kundry, is decided. At the end of Act II, Parsifal has started his transformation into a complete human being. Concurrently, Kundry metamorphoses for the final time, by way of the complicated process of the refusal of her request by Parsifal and the cathartic release of her magical powers.

In the next section I will lay out the most important aspects of what a singer must do to assume the role successfully. I will articulate the interaction for the singer between the bodily enactments pointed to above and the vocality through which the music is realised, and indicate how a skilled singer focuses all her power towards the moments of transmutation.

\section{The Shamaness/The Wanderer}

Before I enter in Act I, I assume an unruliness of figure and of movement, invoking a restless explosive energy. I enter in a rush and take my energy from the restless music. An animalistic energy, imagined distress and 
sleeplessness help my physicality. I keep my vocal delivery peremptory and matter of fact, with clear text projecting across the pit. 437

As Kundry is most often portrayed in these initial scenes as a woman who is unkempt and dishevelled, costuming and makeup is often challenging. Typically there is lots of hair from wigs, and fabric in large costumes to deal with. ${ }^{438}$

On stage for half of the act with intermittent phrases, I need fierce concentration as an actress. Singing in short bursts and crawling around in an animalistic way uses up a lot of energy and focus, and the voice can easily get cold during the long silences when one is lying on the ground. I remember to project and keep the voice focused. The tessitura is tricky middle to low, with a dense orchestral texture, that makes it difficult to project the text clearly. As in Ex 6.1 the vocal line is broken up and needs a lot of energy and clarity.

437 Singers must always be aware of the Law of Temporal Summation - the bigger the venue, the more energy is needed in the consonants to keep the text clear, without disturbing the legato line. In fact the energy of the consonants with the vowels should complete the legato line here- it is the sound of the vowel that carries the text to the ear of the listener. However, any given note should be $95 \%$ vowel sound whatever the length of the note, which means the consonants must be travelled through very quickly and with energy to make up the other $5 \%$.

438 The singer is always at the mercy of the designers, some of whom have knowledge of what costumes will work on stage, and others that don't. Ideally at the first costume fitting you will be asked, or make a point of trying out the actions you have so far been asked to do in the studio. There is often a conflict over the "look" of the opera, and the practicalities of moving, let alone singing, in some opera productions. 
Example 6.1
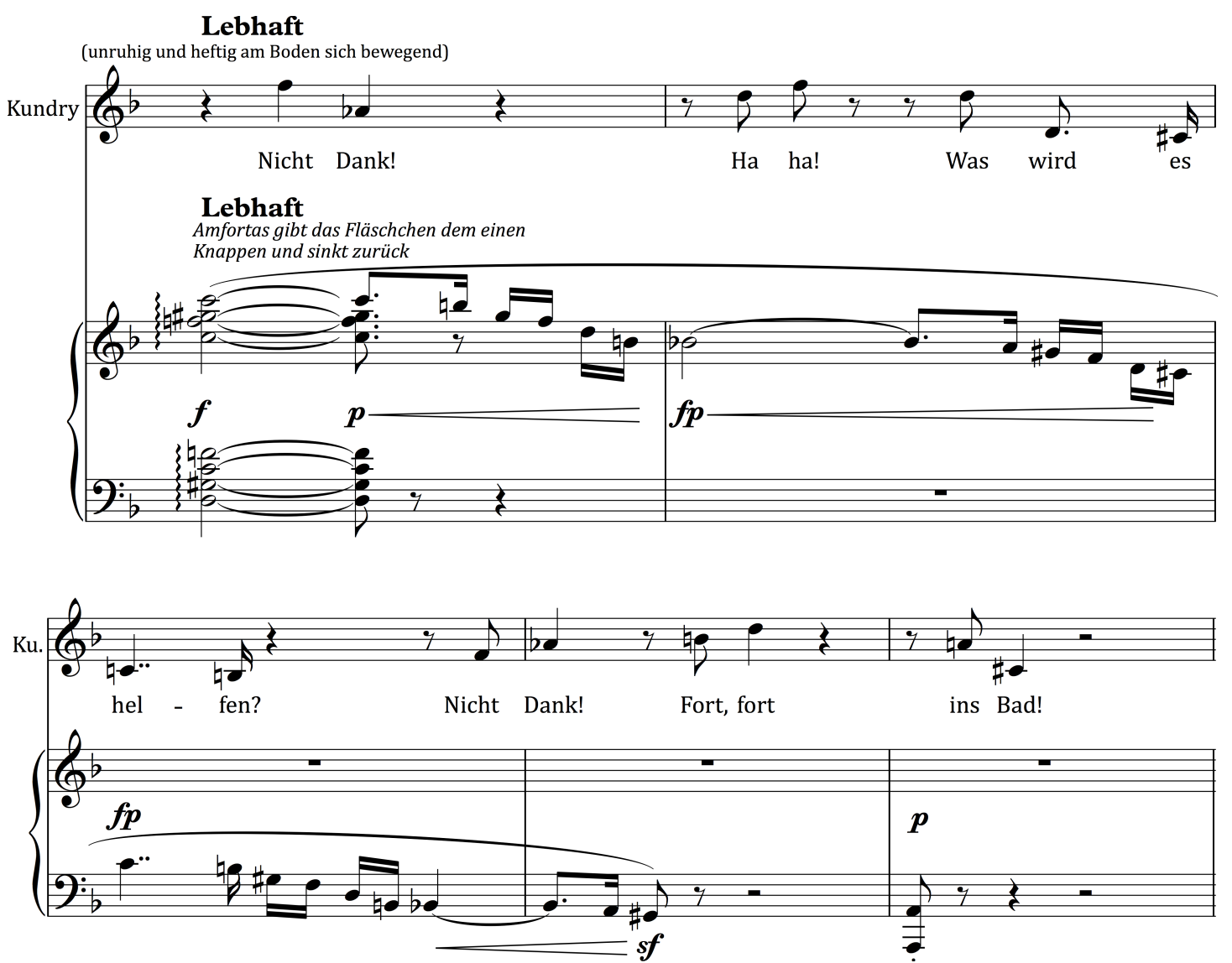

I am kinaesthetically alert to the others on the stage - particularly to the pages who start to torment me as an animal - and am ready to react physically to them. During Gurnemanz's narration I am ostensibly asleep throughout, but reacting bodily to the story he tells. ${ }^{439}$ Here, the need to react physically forces me to create for myself a relationship with what is being sung. I am heedful of the story (both music and text), physically engaged, and working to embody another character's music and text in a way that is visually perceptible to an audience. ${ }^{440}$ Recognising Parsifal's music, I am awake, ready to greet him. The angular vocal lines in Ex 6.2 interrupting his story require a lot of vitality in the pelvic floor and intensity in the text, using articulator muscles to project the text.

\footnotetext{
${ }^{439}$ Edition Peters, 36-45.
}

440 While it is unusual to physicalise another's story onstage, we often hear things in the music that are the internal, unverbalised thoughts of a singer (Example 6.3). 
Example 6.2
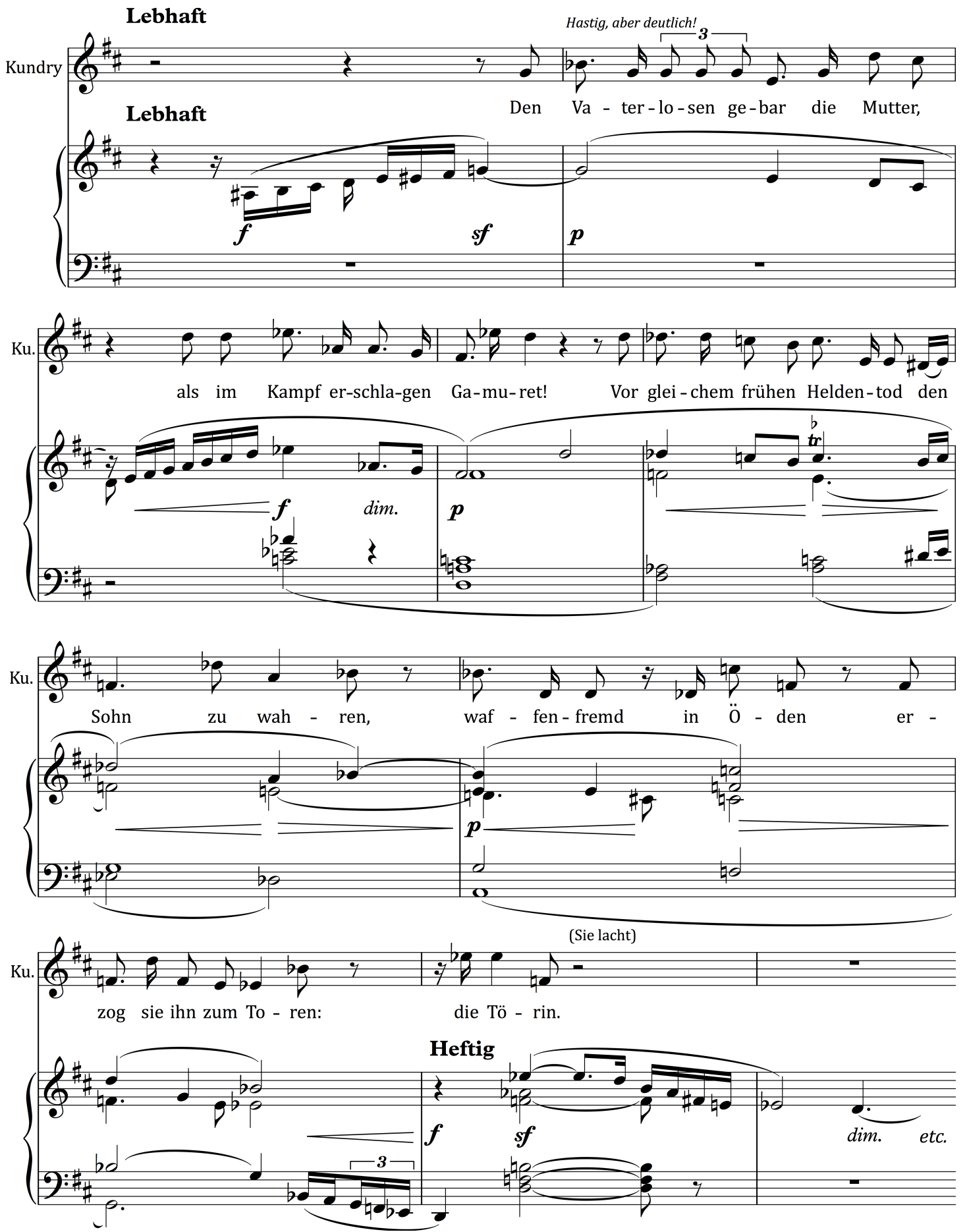

I work hard mentally and physically to wind him into my story musically,

thereby helping to create his identity. ${ }^{441}$ My concentration is on showing the

441 Pelvic floor muscles are part of the core muscles of the body, and if they are working properly, take the stress and strain of producing the voice away from the throat. We use the articulator muscles, ie the muscles around the mouth, without however over enunciating which tends to disturb the sound of the vocal resonator tract and results in 
emotion aroused by Parsifal's entrance, and the knowledge that I already have of him. Although the vocal line is low in the voice, the orchestral accompaniment is light and my text is easily projected. After my burst of manic energy I have another acting hurdle: I slip towards a cataleptic state, fighting sleep and Klingsor's control all the way. I imagine hearing Klingsor, even mouthing some text, pre-empting his words in the second act; I feel as if I am repeating a mantra from a restless mind: Nie tu' ich Gutes, Schlafen and Oh dass mich keiner wecke. ${ }^{442}$ (Ex 6.3)

Example 6.3
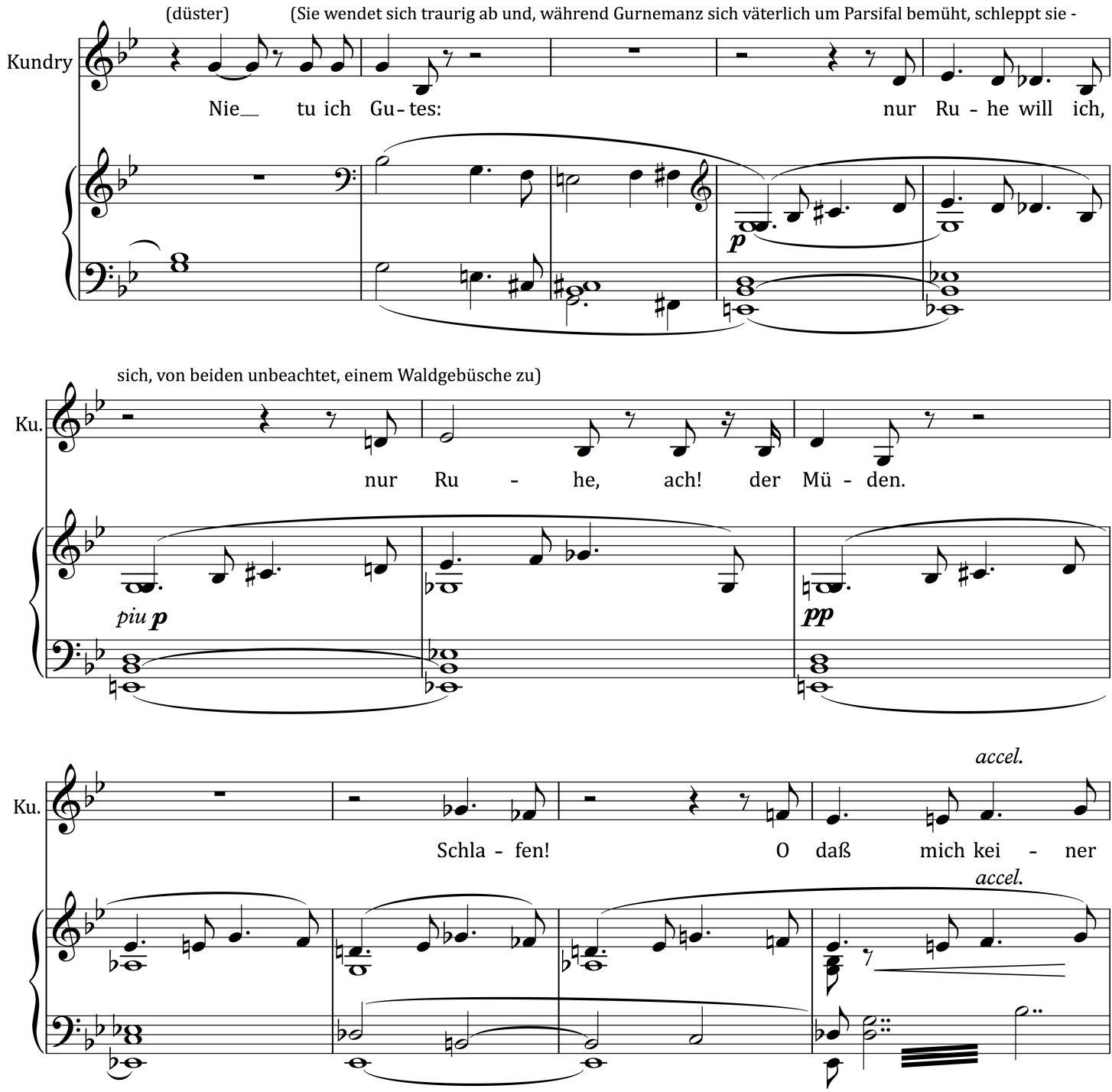

a loss of legato.

${ }^{442}$ Edition Peters, 63, systems 3-5 :"Never do I do good, To sleep, 0 that no one would wake me". 
My body must show the conflict between fighting Klingsor and the desire to go to sleep and never wake - a complicated task of sudden movements and reactions to imagined voices in my head, making the audience wonder what Kundry really is, animal, puppet or witch? The music winds downwards in pitch and loses energy, and I crawl off stage.

There is a long break here for the Transformation scene, followed by the dinner break. Having been in makeup since about $2 \mathrm{pm}$ for a $5 \mathrm{pm}$ performance, food and energy is a problem for me. I have a big lunch to keep me going, but by this stage I need more energy: I eat a snack while reviewing my Act II music, remembering notes I have been given. Knowing what is to come I keep quiet, keep my energy down and focused. The gnostic process here has concentrated on the physicality of the body, and a manifestation of animal-like energy.

After the challenges of Act 1, my physical approach must be quite different in Act II Scene 1. Even though the costuming is generally the same, my demeanour is subtly changed - I no longer feel completely at the mercy of Klingsor, and while starting the scene seemingly confused and longing for unconsciousness, I steadily gain in power and authority throughout the act, both in character and in voice. Starting with a musically stuttering confrontational scene with Klingsor, I come awake with interjections similar to those of Act 1. The screams and groans required here need intense body preparation so as not to harm the voice: the body needs to be prepared as if to sing a high note, and the throat must be open. 443 If you are thrashing around on stage as you might be if coming out of a coma, you need to make sure that your physical alignment is such that you can engage the correct muscles to protect your voice. Directors will ask for some impossible positions at times, but most singing actors will at least try the position, and modify slightly where they can in order also to sing well. In this vehement intermittent singing, I need to be highly musically aware, as the interjections

\footnotetext{
${ }^{443}$ It takes a bit of practice to scream well, and obviously singers don't want to do a lot of it. I am not a fan of the "singing" scream that a lot of singers do which I think takes from the reality of the drama. The real scream offers the character a chance to make a sound that is primal in character - giving set of harmonics that elicits a visceral reaction from the audience. The singing scream vibrates and sounds false.
} 
are placed within the musical fabric, and entries are sometimes difficult. Generally there is a lot of action and the musical cues are tricky, so a lot of time has been taken in the rehearsal room to make sure that no moves compromise the music, nor the quality of the singing.

As well as singing the disjointed lines about my struggle with Klingsor, the mental contest relies increasingly on bodily presence. Klingsor has the stronger and more lyrical music, whereas my fragmented music makes it hard to present a musical or textual case to the listener. Therefore much of my story and subtext must be displayed by my body when I am ostensibly listening to Klingsor's music. As I cannot join in the vocal spectacle, I must fight with mind and body for control over events. I have different powers than Klingsor and can see different futures. I feel as if I am the only figure with any real energy on stage - the men tend to stand around and sing, and even Parsifal's great deeds are carried out offstage and are only reported by him. I need many different physical styles of movement and these constant and sometimes abrupt changes in physicality are one of the major challenges of the role. In this scene I start by rolling about on the floor in a foetal position, singing low in the voice, assuming an animal-like demeanour; I end up complaining about my lot on my feet, singing high in my range, fully alert.

By asking awkward questions and discomfiting Klingsor, challenging his authority and the source of his power I make sure I gain leverage, questioning why I must go and seduce Parsifal if he is as weak as all men are. Again my speech is stuttering and as if struggling to get anything meaningful out, as in Ex 6.4. 
Example 6.4

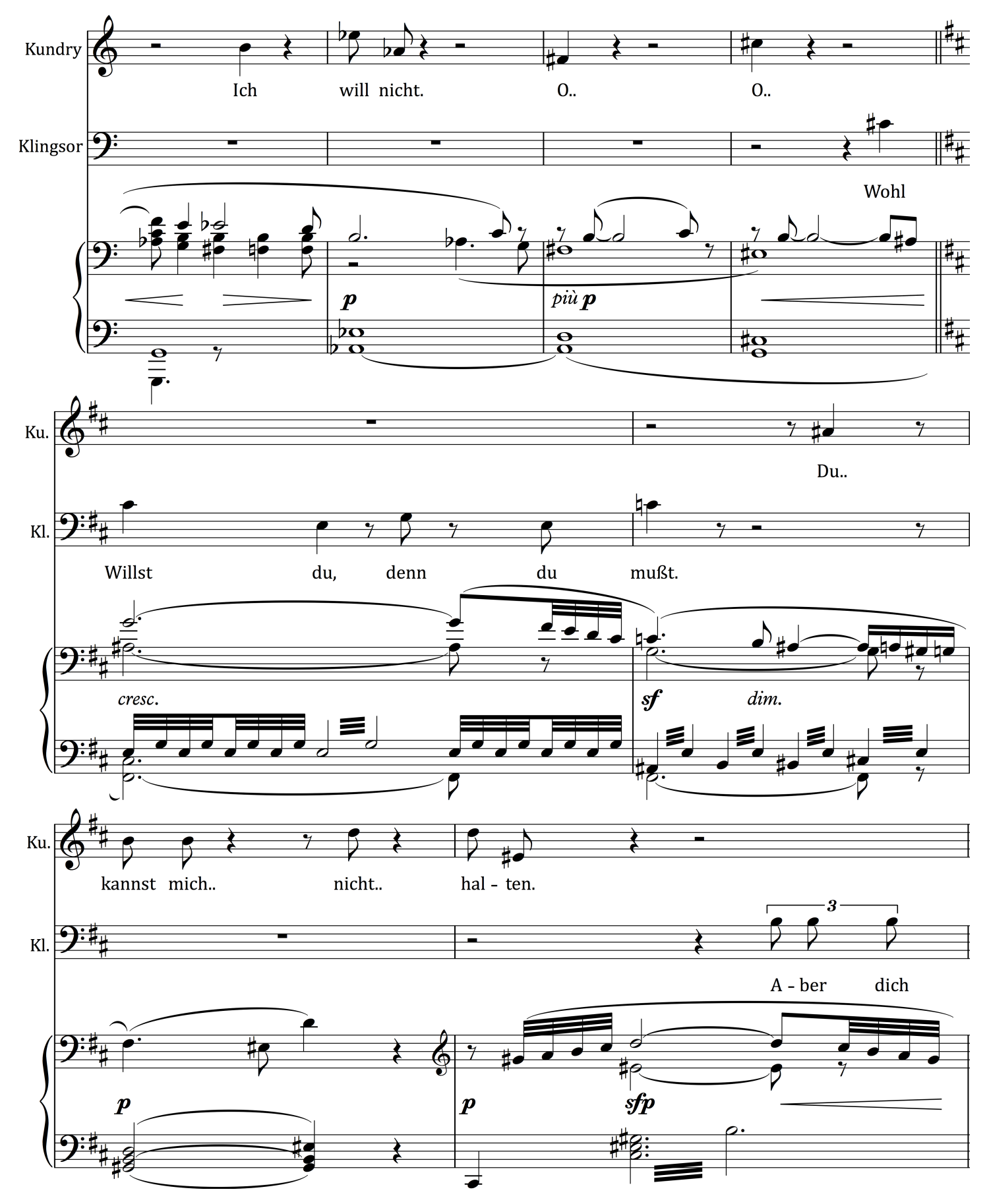



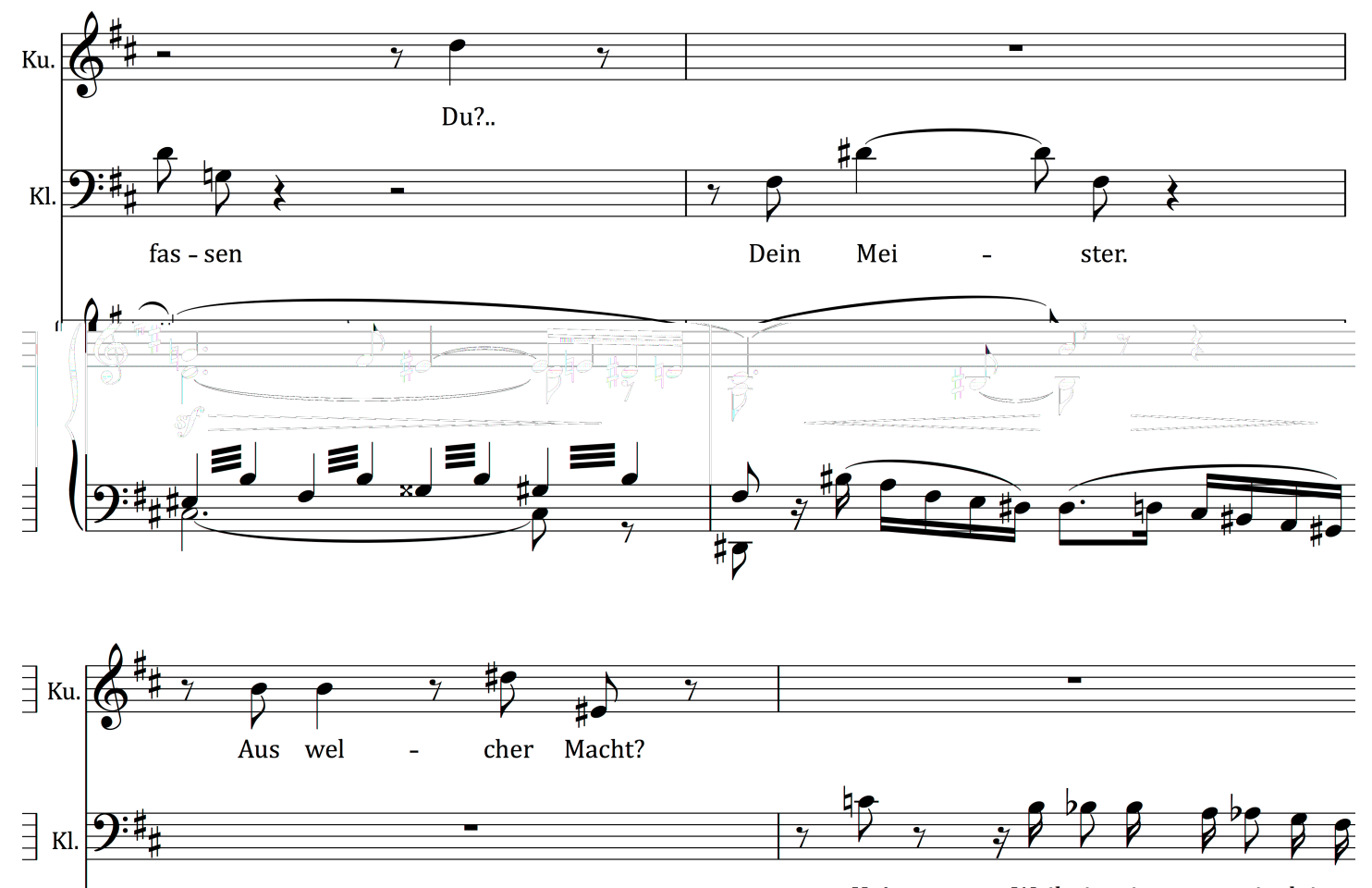
$\mathrm{Ha}$ Weil ein-zig an mir dei-ne
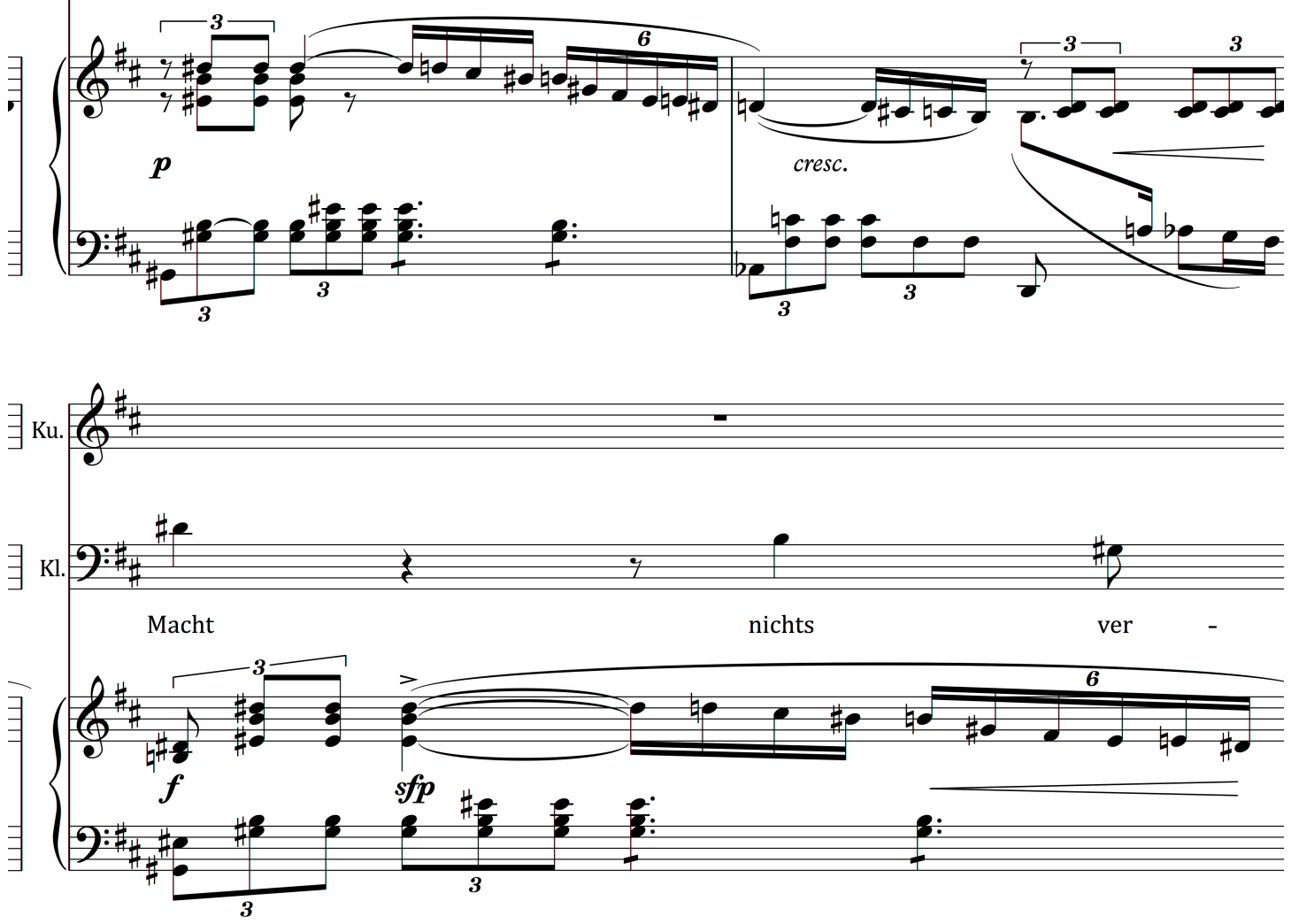


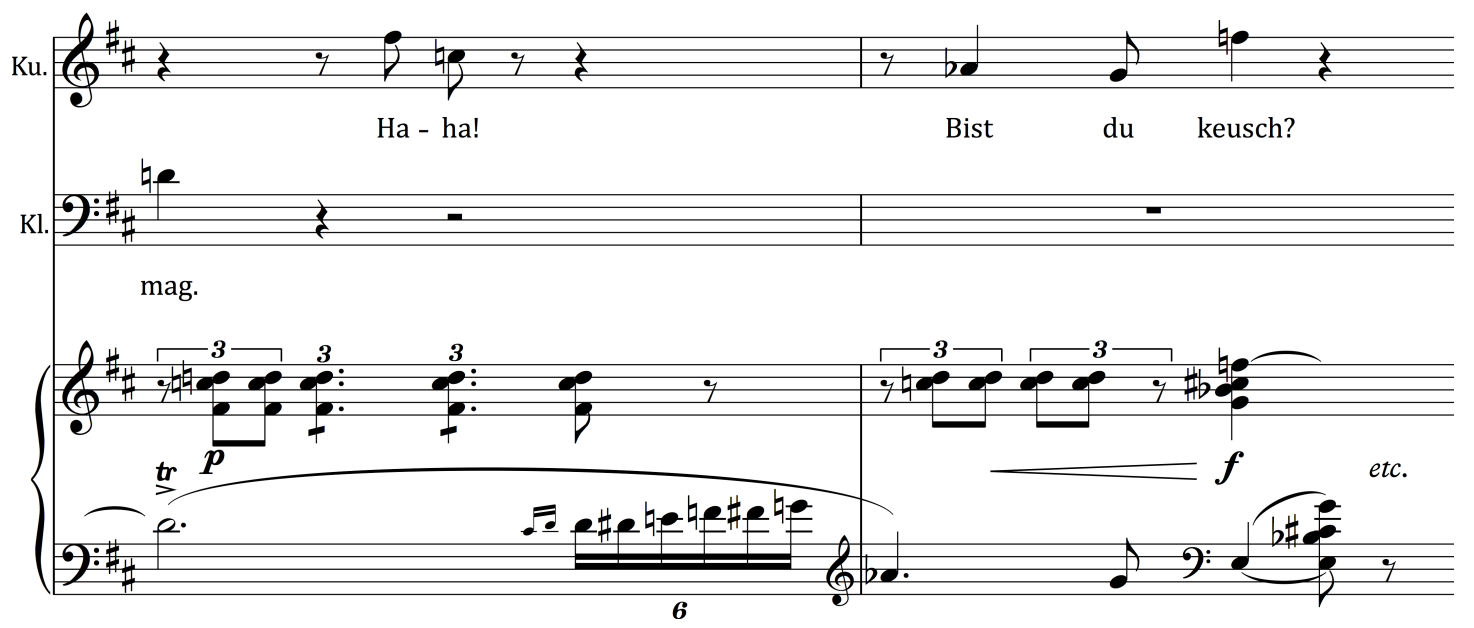

Physical enactment is necessary to make these vocal passages convincing; and if you have a good actor as Klingsor and the director and costuming permit it, the staging can be very challenging. I must react to Klingsor's comments, be disturbed and restless in my body, torn between the peace of my sleep and the possibility of seducing, or not, Parsifal, thus finding a saviour. Physical reciprocity and reaction between Klingsor and Kundry fuels the musical exchange - and can be dangerously exciting. In one production I was required to roll around the stage, on and off furniture, in reaction to Klingsor's movement of the spear. I feel the power of my stage presence here, starting to pull power and focus, gaining in strength from the challenging of Klingsor and preparing the audience for my domination of the stage in the second scene.

Leaving the stage in a tumble, I undergo radical costume and makeup makeover on the side of the stage in about nine minutes, focusing myself for my first striking physical and vocal metamorphosis. I gather my resources and keep calm, aiming the state of flow. There is a lot of gnostic information to access in the coming scene, and the need to keep my mind clear and in the moment will allow me to create the role anew. 


\section{The Mother/The Seductress}

My entrance in Scene 2 offers me a singular thrill as I enter singing Parsifal! Weile! As a beautiful and attractive woman, both mother and seducer, I prepare my voice and body for the extraordinary amount of sensuality and allure I must now portray vocally. Not only am I seducing Parsifal, I am seducing the audience, and that sensuality must carry in the voice through the theatre. Different vocal colours are used - those of persuasion and suggestion, nothing forceful. My sound is comforting, almost murmuring, although at all times the text must be clear. Now the emphasis is on a beautiful legato line, optimising the vocalic harmonisation, with a full sound that is engaged by the body so as to carry the complicated and convoluted piece of text to the ear of the listener. ${ }^{444}$ I also completely change the type of physicality: I reimagine myself to be graceful, languid even, imitating a beautiful loving mother/seductress, re-enacting the words of Parsifal's mother. The sound of the call of Parsifal! Weile! requires a physical anchoring of my body that allows the voice to pick up strong emotional overtones.

Example 6.5

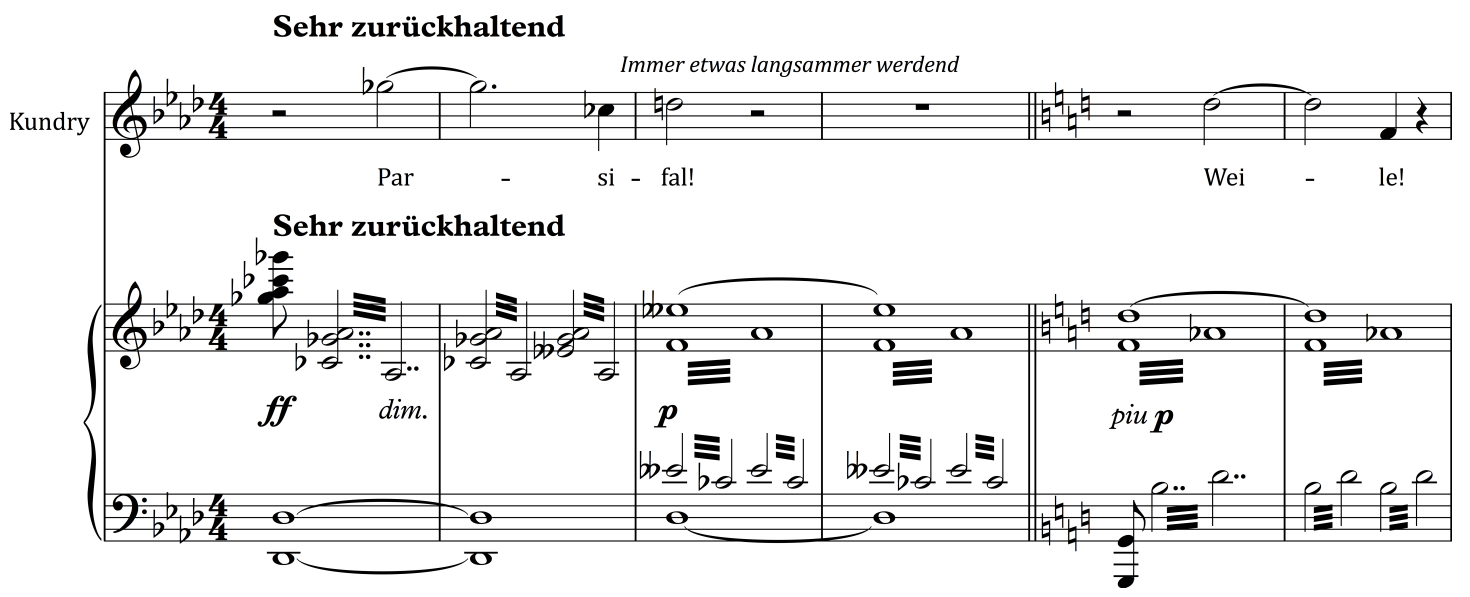

444 Vocalic harmonisation is the matching of the harmonic structure of the vocal sound in every vowel - matching placement and vocal tract length to produce a homogenous legato sound. 
I am seemingly sexualised as a character, and project as much of a seductive quality as possible. Interestingly, at this moment of dramatic physical metamorphosis, the music that Wagner has written further offers the first moment of vocal jouissance to the singer inhabiting the character. The effort involved in producing the sound for Parsifal! Weile! releases endorphins into the blood and I feel "high" and excited. The listener receives the sound, and hopefully experiences the excitement vicariously in their own body; indeed the singer's experience at this moment is crucial to set up well I must provoke Parsifal's crisis - although the audience's sympathy may well be with Parsifal, it is only through being completely manipulated by me that he moves on through his transformation to a whole person.

Playfully and gracefully dismissing the Flower Maidens, building on the power gathered in the previous scene with Klingsor, I create an intimate theatre of the senses, to ensnare not only Parsifal but also the audience. With a sensitive conductor you can sing very quietly with huge intensity and focus here, ensuring that the sound travels to the back of the theatre. Although this music requires increasing engagement of the extrinsic muscles in order to project the voice and enable it to carry through the increasingly dense texture, the release involved in the characterisation of the role with increasingly engaged physical effort (to effect louder singing) makes it more rewarding to sing than the interjectory style of singing. ${ }^{445}$ (Ex 6.6)

445 Edition Peters, 173-179. 
Example 6.6
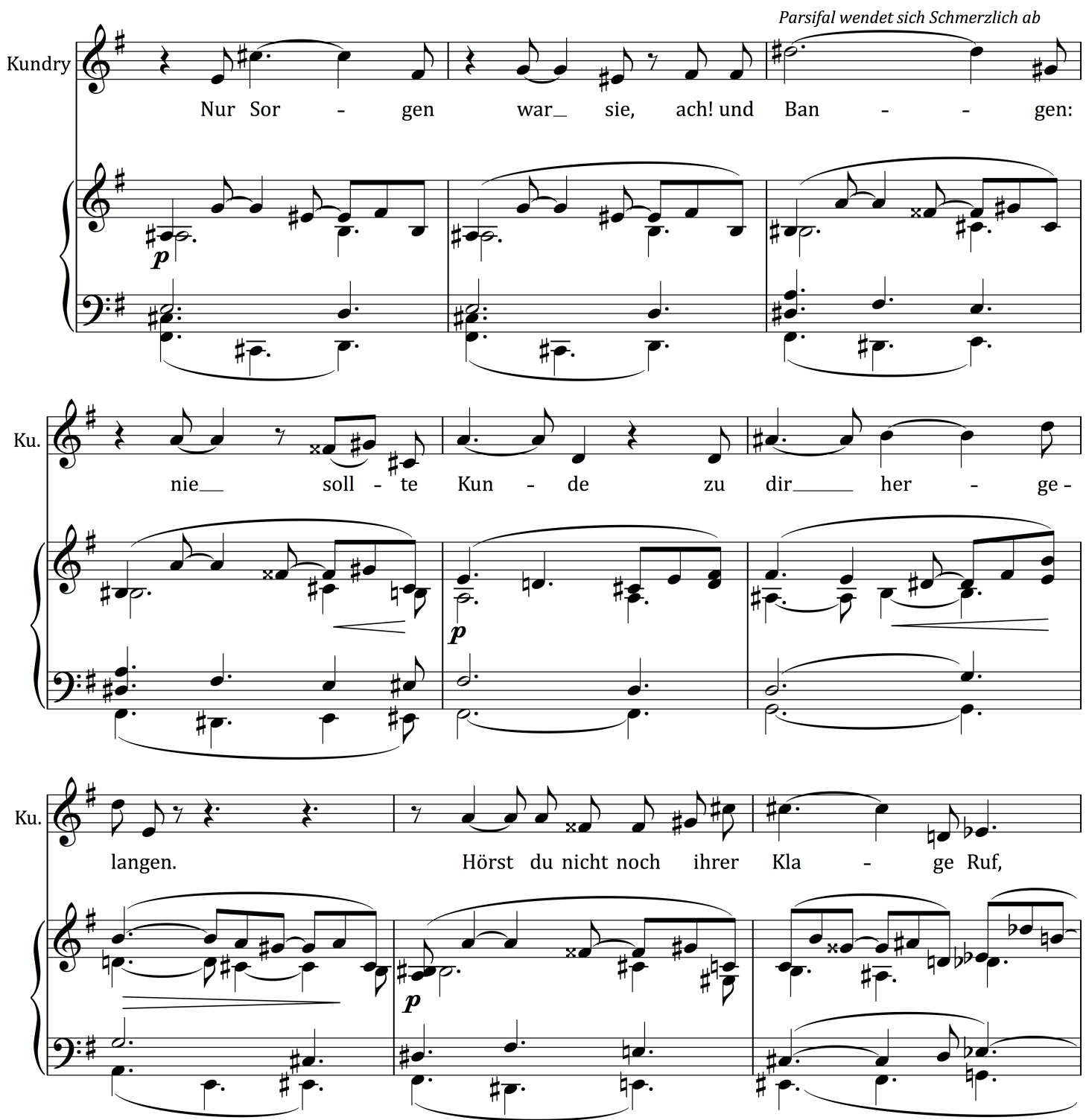

I play games with Parsifal - word games to reel him in; he has a vague idea of what is happening, but I am totally in control, doing very little physically (which is just as well considering the complexity of the text). The musical lines shimmer and interweave, slipping and sliding through different keys, deceiving all the time. As I start my narration, I begin to change my tone; though still beautiful, it contain hints of increasingly disturbing colours. I use more and more laryngeal tilt, manipulating the colouring of the voice, to set up an "affect" in Parsifal and the audience. 446

446 As discussed in Chapter 2 the degree of tilt can be controlled by the singer and at its most extreme will sound like crying. The effect of that sound is likely to affect the 
After comforting Parsifal, having lulled him into a state of enchantment with voice and slower, more sensuous body movements, I weave the picture of Herzeleide's distress at Parsifal's abandonment. The increasingly louder and more harmonically complicated sensual sound from the orchestra, supports my voice and I attempt to match the instruments' colours. By using the alliterative elements of the text, emphasizing the sensuality of the articulation, I heighten Parsifal's senses while never touching him, until I can give Parsifal the Kiss, that central moment of the entire work. ${ }^{447}$ In the switch from the concentration on the physical movement to seductive voice and text, I focus all the energy that was dissipated in some respect by the physical movements, and all elements of my personification come together powerfully to rivet my focus on Parsifal. I feel incredibly powerful: I am gathering energy from the audience and Parsifal. Moreover it is the place where I can enjoy the sensuality of singing and of my body, and that enjoyment is reflected in my voice.

Central to the whole work and significant to my thesis and the discussion of Kundry's embodiment is jouissance: the whole of Parsifal, its reception and its performance for Kundry is bound up with the sensation and pleasure the listener gets from the music. Most people find the music of Parsifal spell binding and cathartic, despite its seeming "misalignment of sound and what it accompanies"

listener by setting up a similar laryngeal posture in them, and creating what psychologists call an "affect".

447 The Kiss itself -how you get there, what angle, etc, - is always a subject for much discussion and experiment in rehearsal. Parsifal needs to get out of the clinch quickly, Kundry's costume needs to be taken into consideration, and sometimes Parsifal's girth needs negotiating! The length of the kiss, and how much writhing, how much Kundry is going to clutch Parsifal, requires forethought, as it can look very ungainly and becomes embarrassing very quickly. With the help of a good director who understands movement, the movements can be worked out quickly, leaving the artists, particularly Parsifal in this case, to concentrate on singing.

Not only is the sensuality of the stage picture important here, but Barthes' comments in "The Grain of the Voice" resonate profoundly with my recollections of the experience of singing here: my enjoyment of the feel of the text in my mouth, the feel of my voice on my body, all contribute to my jouissance.

Wagner exerts a forceful influence over the singer: his use of alliteration means that the onomatopoeic elements enhance the clarity of the meaning, and so the singer's effort as dictated by the composer becomes part of the musical structure. 
as Abbate says. ${ }^{448}$ But it is, as Risi has written, the "particular ecstasy of the trained singing voice" that interests me, and its potential for affecting the listener. ${ }^{449}$ We all know Barthes and Poizat talk about jouissance to explain this feeling of sensual magnetism of the voice. From a singer's perspective it may significantly enrich our understanding of jouissance to lay out that, although in general the attention has been on reception, it is also potentially an important concept for the performer. ${ }^{450}$

Singers enjoy their moments of vocal jouissance: it is experienced where there is a bodily effort involved in producing a high from the release of endorphins in the bodily exertion, or just the sheer pleasure of the language and sound one makes. ${ }^{451}$ Whether or not those vocal moments from a singer's standpoint map on to the audience's experience is matter for discussion: as a performer it is hard to gauge those moments, and it depends on not only the performance experience in live performance, but also on the size of the theatre.

\section{As I move through Act II, with the reality of sweat and bodily} jouissance, I prepare for another metamorphosis. Primed by the atmosphere I set up for the Kiss, Parsifal takes over musically and dramatically with his revelation about the effect of the Kiss, his awakening to the effects of lust and his empathetic experience of Amfortas' seduction. I concentrate on having a short vocal rest - but this does not mean that there can be any

\footnotetext{
448 Abbate, "Metempsychotic Wagner", 110.

${ }^{449}$ Risi, “The Diva's Fans", 49.

450 Only Clemens Risi has written about the singer's and the listener's jouissance in some detail.
}

${ }^{451}$ How the voice is trained to create and carry the extra-textual meaning of the body that the scholars above have noted, has been explained previously with the help of my model of embodiment. As I have demonstrated, the process is complex. I have found in my own practice, working with my own voice and with those of others, that it is essential to train the singer's ear to desire the correct sound - the sound that is compelling for a listener and will induce pleasure: it is the best way to get the listener listen to the text and the music, the duty, I believe, of any musician. Risi in "The Diva's Fans" realises that to the listener, the voice that induces jouissance in the listener is like a drug. For the singer it is similar: you train your ear to desire a certain quality of sound, that external feedback has told you is the most affecting sound you can make. Risi, "The Diva's Fans", 51. 
lapse in any concentration. Shedding my pretence of the seductress I turn into a woman who is desperate to break the metempsychotic cycle and be redeemed. I work through the emotions and reactions of what Parsifal is saying, enact his music bodily, and at the same time allow the audience to see my puzzled response to Parsifal's actions and musings. I need to make it clear to the audience that I am working out my next plan of attack; this is a difficult acting task, demanding a hypnotic intensity-one that contains anger, need for salvation, my love for the man, and focus my power on my goals. Inevitably he resists my honeyed tones, and I show the audience the tipping point has been reached: I embark on a dramatically different approach. 


\section{The Virago}

When I realise that I am not going to get what I want, at Grausamer, I change into a virago.

Example 6.7
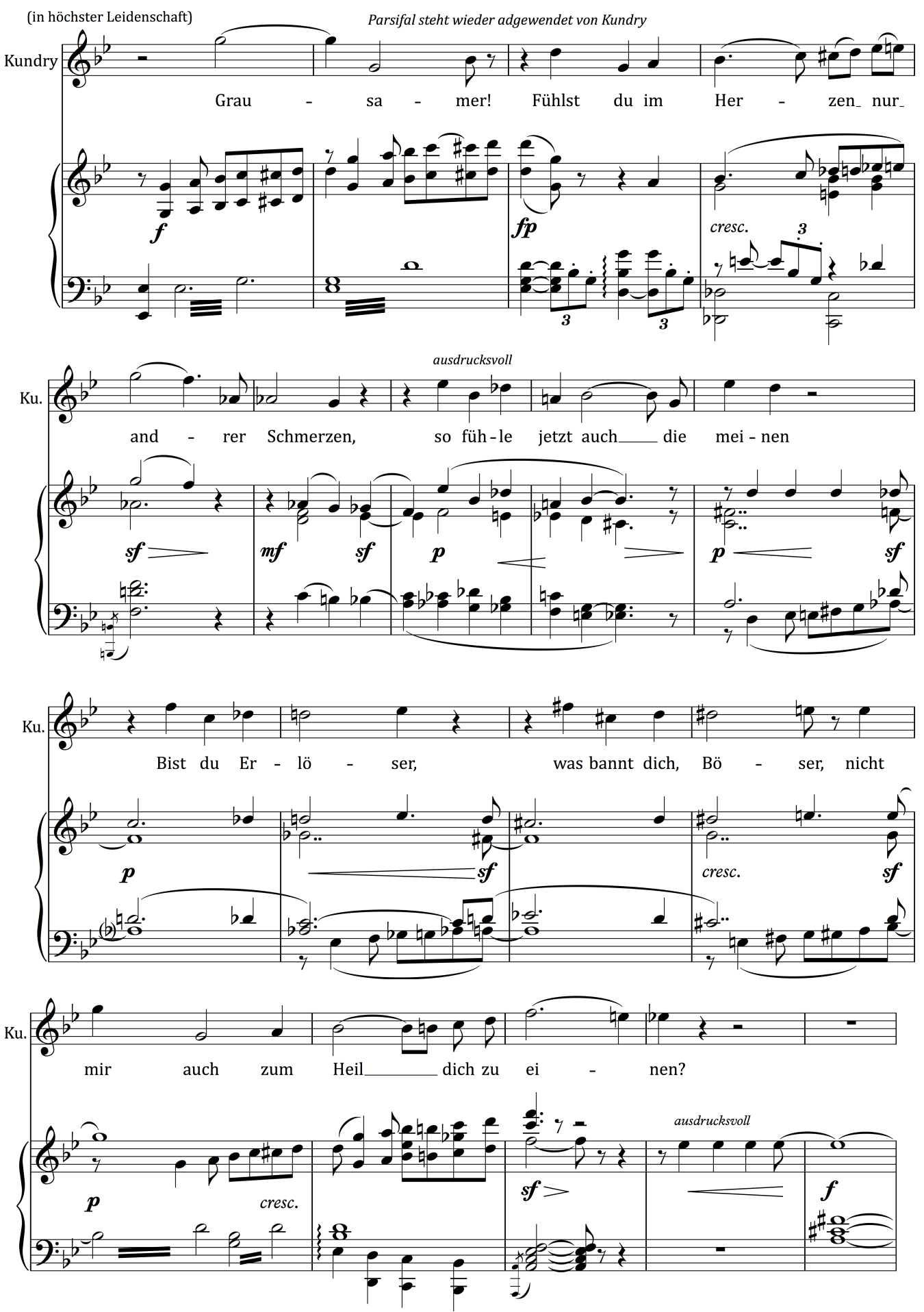
This is a difficult metamorphosis - it is within sight of the audience, and there is no costume change; I must change my demeanour, my vocal delivery and gesture. Changing vocal colour for such a forceful personality as I am here needs singing with considerably more effort: higher, more forceful lines with pointed almost "spat out" text makes me sound aggressive, as is needed in such passages. The energy of the singing, fed by the energy of the music, feeds into the energy needed to break me free from the cycle of metempsychosis; I put as much desperation in my voice as I dare as I reach that breaking point - Wagner writes in a range that keeps on getting higher, and the rhythms become more insistent.

However, I do not become vindictive immediately; I am firstly a graciously wronged woman, desperately in need of help, and by explaining why I am damned by laughing at Christ on the Cross, I hope to elicit some understanding from Parsifal. The range here is very wide - high $B$ to middle $C$ - and the tessitura is sustained with excursions down to the lower range. 452 As it becomes clear that Parsifal is not going to help me, I become more deliriously excited and exulting. The excitement of the possibility of release and the catharsis of my "confession" adds to my realisation that he might really be the one to release me from the metempsychotic nightmare of my everlasting reincarnations.

The range of the vocal line, the ever increasing height in tessitura, and the rhythmic vitality together with the general excitement takes all the singer's control to keep grounded, to engage the pelvic floor muscles strongly to keep the pressure away from the vocal folds. In passages like this it is easy to over-breathe in excitement, to "stack" the breath, and one must take particular care to release the engaged muscles on the in-breath. Singing German gives one a perfect opportunity to get rid of stale air on the final consonants, and so to breathe in a deep, connected way. The mental concentration is immense: as all know who have been on stage in whatever capacity, it takes audacity to stand in complete silence in front of a large gathering of people. In powerful performers it can be a question of bravura

452 See, for example, Edition Peters, 202 -203. 
and also a game to see how long the silence can be held. The intensity in the silences here in Parsifal can be powerful, amassing energy to be released into the following musical passages. In my experience it is an incredible feeling of gathering and holding the audience's electrical energy: much power is invested in those moments, if a singer has the courage to hold them. 453 The passage of Ich sah Ihn, ... Ihn ... und lachte ... da traf mich sein Blick. is quite extraordinary to sing because of those silences. ${ }^{454}$

Example 6.8
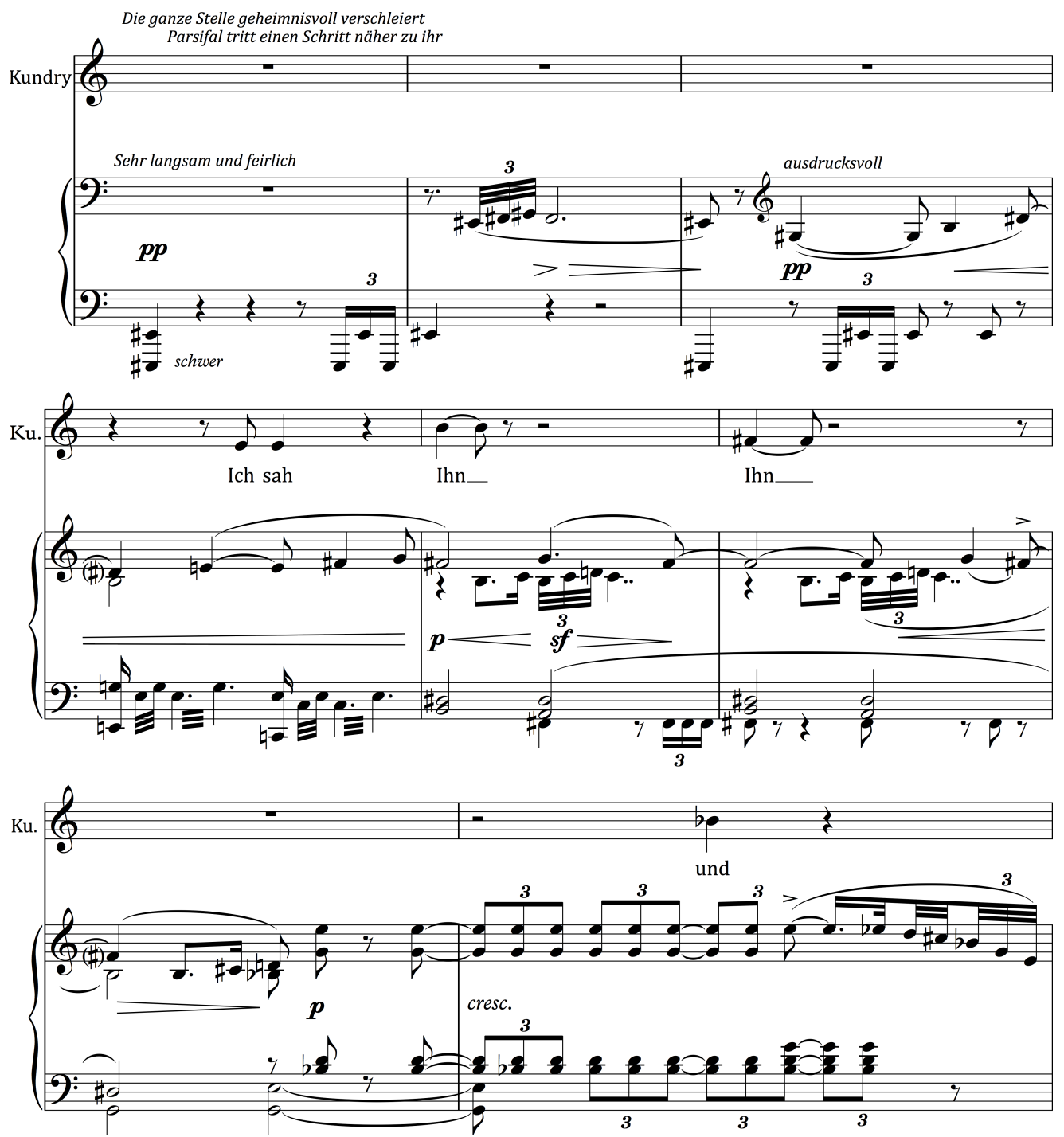

453 It is here that the human brain's capacity for reacting to distress can become very powerful and affecting.

${ }^{454}$ Edition Peters, 193: 3/4 on. I saw him, him, and laughed....there his look passed over me. 

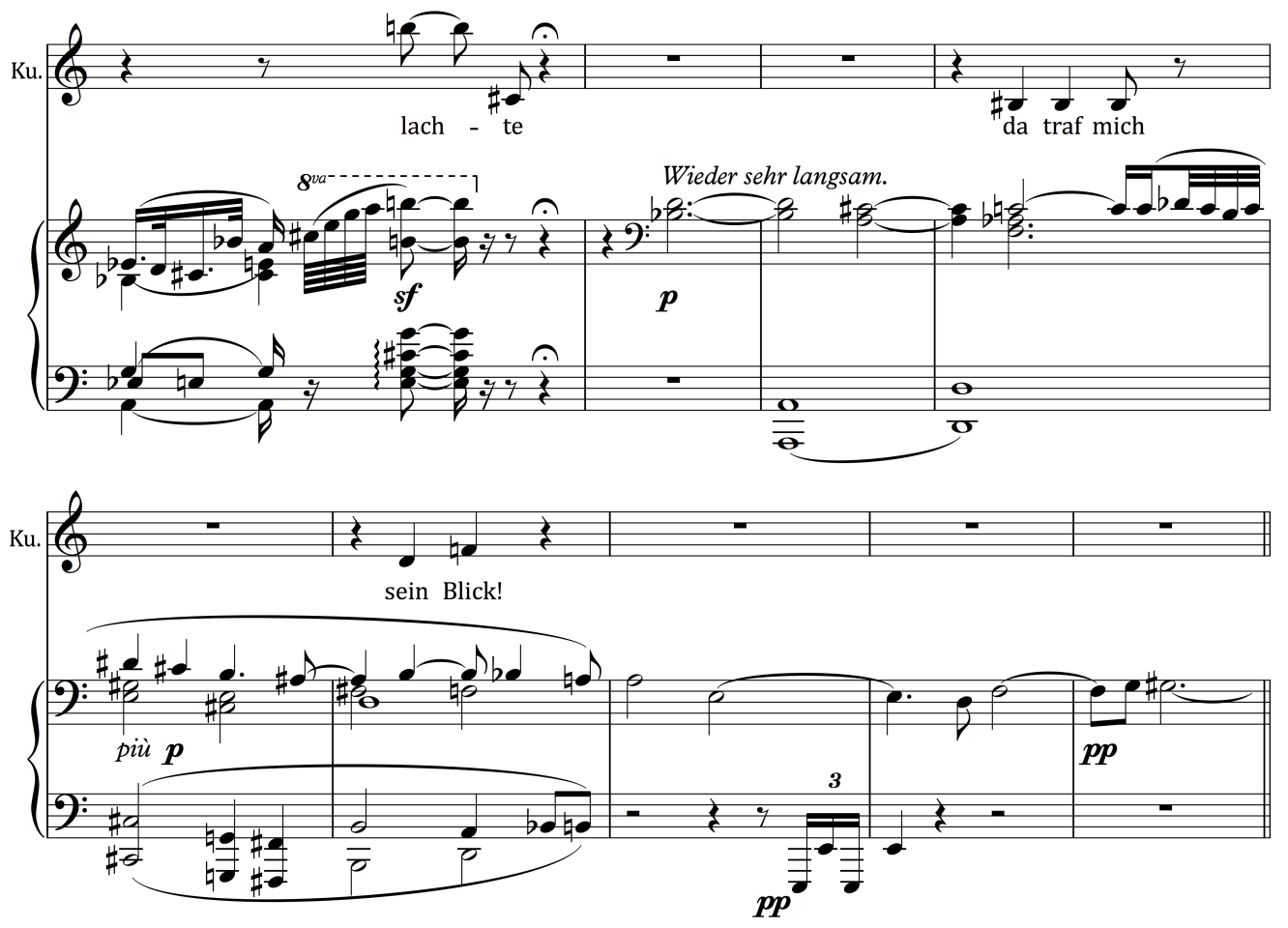

Although the conductor is in charge of the length of the pauses, with the build up of musical tension the atmosphere can be charged with such potent meaning as to make the high $B$ in the vocal line shoot out like a lash, and terrify. The temptation to give of your all in this role is large however the sensible singer trains to remain in control. However it is the power unleashed by the state of flow that allows to me access a feeling of wildness, and the "letting go" of inhibitions and of gnosis, allowing the embodied continuum to work freely, that engenders the creative spark.

The famous last ten pages of the act are where, if the singer is exhausted through giving too much voice too soon, she can get into trouble and risks beginning to scream - in other words to lose vocal control just at the moment when the singer needs most concentration in interpretative areas. ${ }^{455}$ Generally the reason a singer starts to lose control here is because she has not been involving her body enough and protecting her voice: the increased engagement of the body needed to sing the end of the act, the most emotional part of the role, requires all one's strength. If the voice has become tired through over singing or pushing

455 Dramatic sopranos find this passage easier as their voices lie more naturally on the A, A flats and B naturals. 
too much air through the vocal folds, it shows that the singer has not been protecting the voice, preparing for this moment in everything that comes before, and the sound will suffer. ${ }^{456}$

As I have laid out in earlier chapters, the way the text is set dictates whether the singer has control over the breathing, or if the composer dictates the way in which one must breathe. When practising a vocal work, I often feel the influence of particular composers making me work exceedingly hard on the articulation of the text because of the way it has been set. With Wagner, any emphasis on sound or voice over text is enacted through the way the singer engages the breath. In many areas through Parsifal we can see that the vowels are spread over longer periods of time over a loud and thick orchestral texture. ${ }^{457}$

456 This is where it becomes apparent that those to whom the stage calls above all else must work very hard to prepare technically to ensure the voice is safe.

${ }^{457}$ See, for example, the passage at Edition Peters, 201-202. 
Example 6.9

SS

Lebhaft
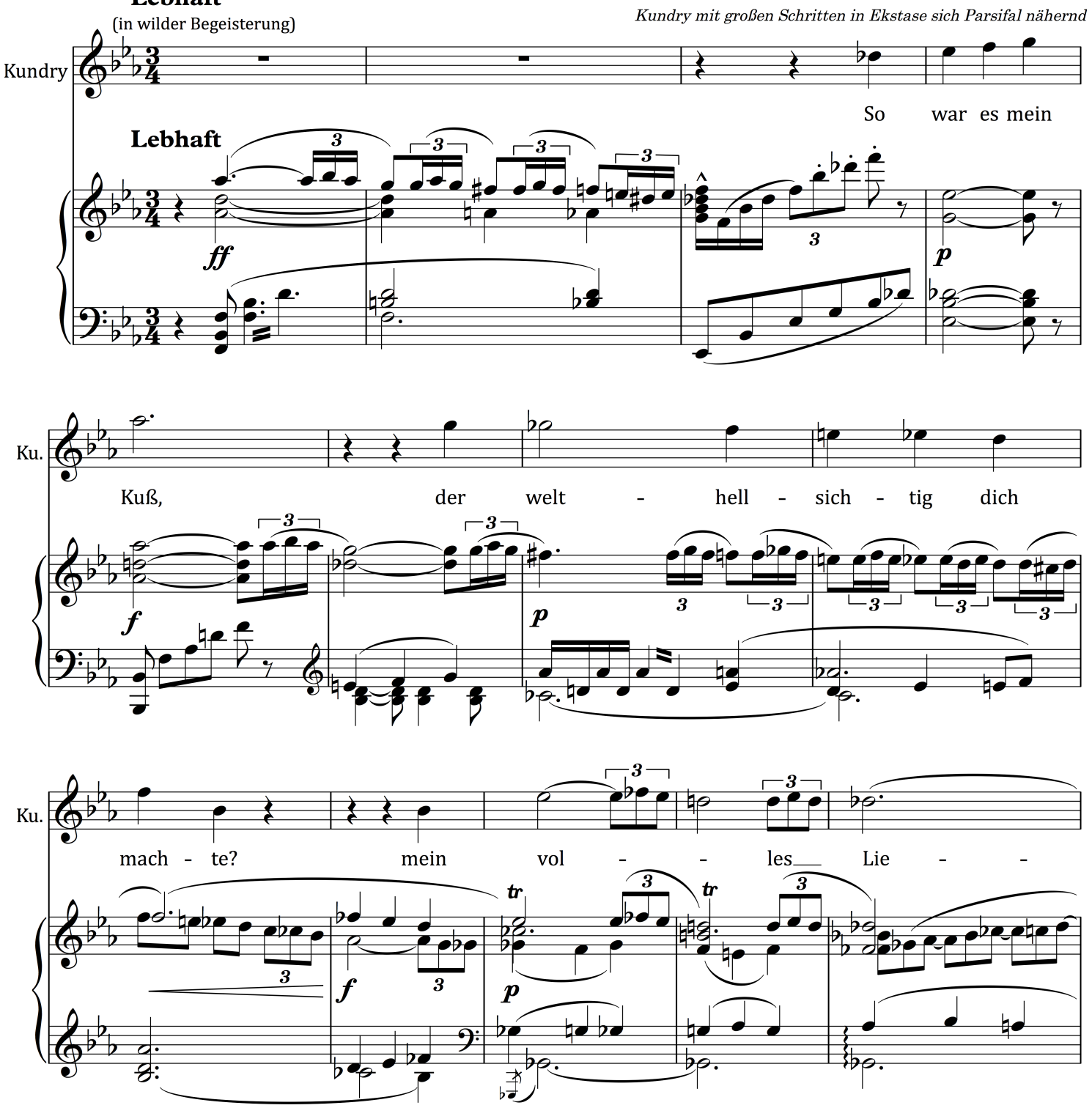

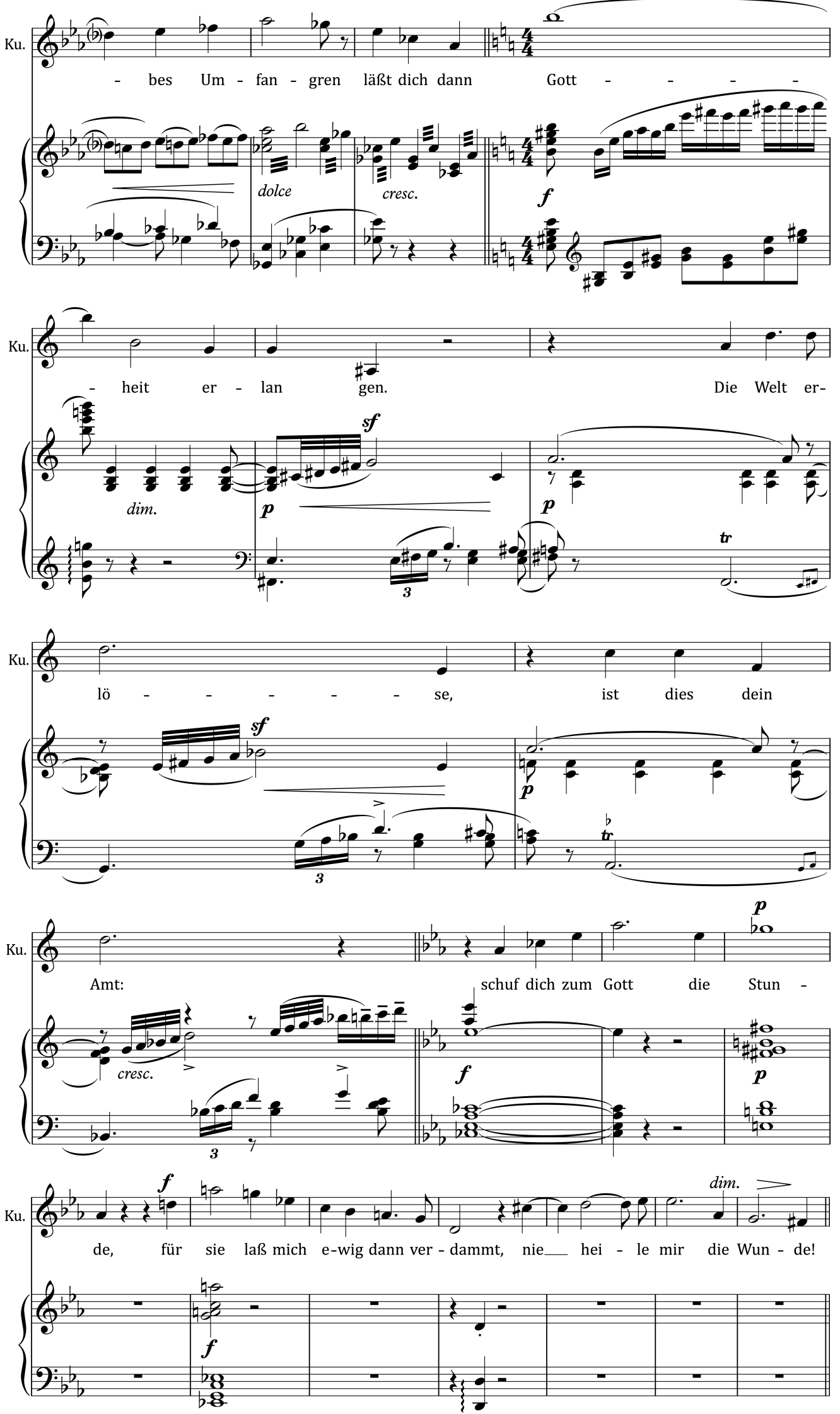
The vocal line is high and loud, demanding that the extrinsic muscles work continuously to stabilise the open vocal resonator tract.

Vocally challenged at the end of Act II (involving a difficult line of musical laughter), I still sustain the power of presence and charisma I have gained from my interactions on stage. As a singing athlete, with the endorphins in the blood, I come offstage feeling very high and in a state of released tension with the sheer physical enjoyment of the act of singing, truly in keeping with the idea of the Gesamtkunstwerk - which as Adorno comments, has ecstasy and intoxication as an inescapable principle of its style. 458

Though having a rest after Act II, I feel it is important to keep in character to work through what has happened to Kundry, to imagine her mental transformation. Though I don't have to worry about text, music or singing, Act III is a hard act of concentration and focus, and requires my utmost ingenuity and projection of character.

458 Adorno, In Search of Wagner, 93. 


\section{The Magdalen.}

I am preset on stage for Act III and though calm, composed and centered, I awake with a scream. I have worked out how to lie so I can engage the correct muscles to protect my voice. Here, famously, I am silenced: after my final two words Dienen, dienen, I sublimate my vocal character into pure embodiment of the music, even before I breathe my last on stage (or not, depending on the production). ${ }^{459}$

Example 6.10

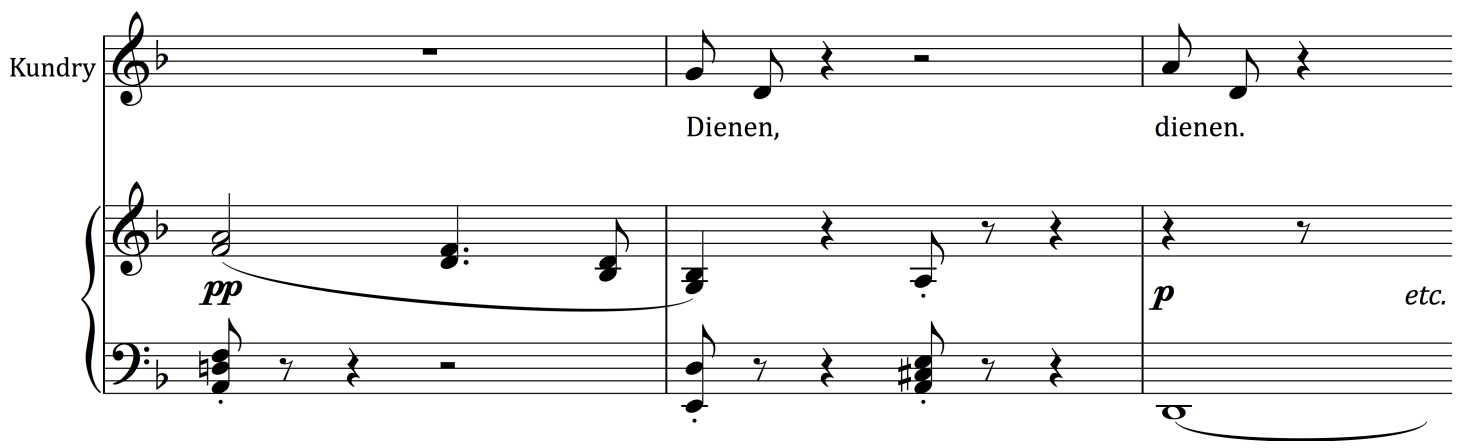

Physically I am calm, alert and serene, helped by a change of wig and costume.

Typically with the loss of the dangerous woman, opera gives up its narrative: the singing ends with her death. ${ }^{460}$ Here the dangerous woman loses her voice while she remains on stage, and it has been suggested that because of this, she becomes disempowered. ${ }^{461}$ In Act I, she sings albeit infrequently, and inhabits a complex half-human character; here in contrast she falls completely silent. While the silent presence, the inability for a singer to be allowed to sing has been taken as a sign of operatic disempowerment, I propose that in Act III of Parsifal, Kundry's silent presence actually affords her, even voiceless, to project a character on stage. This enables her to continue a full engagement of her

\footnotetext{
459 Edition Peters, 217. To serve, to serve.

460 Emslie, "Woman as image and narrative", 120.

461 Emslie, "Woman as image and narrative", 120; Bronfen, "Kundry's Laughter", 147161; Smith, "Laughing at the Redeemer", 5-25.
} 
narrative, which is inextricably tied up with the embodiment of the others' music.

From my perspective, the silent presence on stage actually affords a different kind of pleasure: although a huge amount of concentration is needed to communicate the emotions involved and to project my presence in the drama, because there is no need to sing I can be as one with the orchestral music on stage. ${ }^{462}$

I propose that Kundry, when performed by a charismatic singer/actress, does not become powerless in this third act: rather, apart from singing two words, I am at liberty to listen to the wonderful music. Further, in addition to the pleasure I receive in singing the music of Kundry, I also receive another in performance; when I am able to stand on stage, losing myself in the music - the singing of Parsifal and Gurnemanz and the orchestra- I can even become so involved in the music that I allow myself to be moved to tears. ${ }^{463}$ Not only have I had my moments of bodily jouissance as a singer, but here I can experience a different kind of jouissance - one as both a listener and as a performer, an in-between state in which I actually feel as if I can become the music in a way that neither singer nor a listener in the audience can. ${ }^{464}$ This final jouissance enhances my power and embodiment and contributes an essential aspect to the experience of my final metamorphosis.

It is this final depiction, when linked with the bodily metamorphoses across all three acts, which can in fact create an experience of Kundry for the

\footnotetext{
462 In many theatres, to hear the orchestra onstage, foldback is needed so that the orchestra can be heard on the stage side of the proscenium arch; the use of rear facing speakers on stage behind the proscenium arch in performance assists all on stage to hear the orchestra within the theatre proper.

463 When one is singing, of course, it is not sensible to cry - you must keep your wits about you, and although you might wish to move others to tears, it is how you do that with the quality your voice.

464 Interestingly my most affecting listening musical experiences have been when I have been very close to the musicians, either in a Sitzprobe (the rehearsal before one goes in the theatre), often in an orchestral space, or in an intimate environment. My body also vibrates with the music being played.
} 
listener that engages with the opera's resolution - with Parsifal's final triumph. Kundry's final jouissance enhances the connections of body and mind in a powerful performer, and her transitions through distinctly different embodiments and three styles of singing enable her to gather energy and power. Her metamorphoses, narrative thrust and vocal jouissance transform the role from a cipher to the catalyst for a Gesamtkunstwerk that truly synergises the work from oratorio to profound theatrical experience. ${ }^{465}$ Because of the stasis of the men, Kundry has been the character who has initiated all the movement of the plot: her actions have been the impetus for the resolution of the situation, and her reward, if you like, is not only to be redeemed (whatever that means in Wagner's world), but also to remain engaged and reacting to the music of Act III - a kind of musical 'redemption' that has peculiar significance for the singer of Kundry.

When the singer is fully involved in the creative process of productions, the effect of her role can be startlingly different from other productions for the listener. Personal charisma and power can change the dynamic of opera performances and also enhance our understanding of the plot.

\section{Conclusion}

Most commentators have pointed to Kundry as being somewhat of an enigma in the larger religious drama that many perceive Parsifal to be. The work has proved to be challenging for both directors and performers, and it is noteworthy that there are relatively few new productions of the opera that contribute new ideas to the existing critical perspectives. Seeming to dismiss what Wagner wanted on stage, a number of commentators have remarked that the music transcends the stage business, and that even the music is best listened to without reference to the stage, without bodies, at all. ${ }^{466}$ In the present musical climate it

\footnotetext{
465 Emslie, "Woman as image and narrative", 111.

466 Dismissing the stage business, Claude Debussy famously said that "Parsifal is one of the most beautiful edifices in sound ever raised to the eternal glory of music." Quoted in
} 
is important to remember that cultural modes are built on recordings, juxtaposing societal expectations of performances with expectations built up by recording paradigms. ${ }^{467}$ However, as Wagner was a composer of stage works and conceived of Parsifal as a Bühnenweihfestspiel and Gesamtkunstwerk, that is, as a work meant for the theatre, perhaps a return to aspects of the staged experience can alter our sense of what this opera is about - indeed, I can't but wonder how much of the critical literature about Kundry has been built from study of the score and recordings, rather than live performance.

I suggested at the beginning of this chapter that for the role of Kundry, the singer needs to engage a community of voices and narratives with an actor's ability to change and facilitate the metamorphoses through the several physicalities that the role requires: she needs to be a shapeshifter. The change is not just about altering costume and makeup, but about modulating physical movement and gesture, shaping a narrative which reflects both upon the embodiment of the sound and articulation of character. The gnostic requirements are thus heavy, but create a powerful meta-drastic state. In the context of my articulation of the layers of embodied vocal enactment a singer engages with, we can propose a new concept of what and who Kundry might be, when sung by an outstanding performer, which shifts our reading of Parsifal.

When an actor-singer maintains self-conscious control over the metamorphosis of the embodiment, the metamorphoses of Kundry provide an intriguing counterpoint to the process of Parsifal's own journey of transformation that has been the focus of so much commentary. I believe that the singer who has a commanding presence, who retains the power of the charismatic actress on the stage and accesses the embodied continuum, transforms the portrayal of Kundry from a mere kaleidoscope of emotions and transformations into a powerfully controlled series of embodiments that serve to demonstrate a complexity of character, offering an engagement with a Kundry

Abbate, 110 .

467 Philip Auslander, Liveness: Performance in a Mediatised Culture (Oxford: Routledge, $2^{\text {nd }}$ Ed, 2008), 183. 
whose very silences are part of her influence over the unfolding music drama. ${ }^{468}$ Even without voice, presence, form, enigma and contact with the other characters contribute to the never ending mystery of presence radiating from an actor profoundly connected in body and imagination. 469

Many productions suggest a conclusion, disturbing to feminists, that focuses on the erasure of woman, the transfer of the gathered power Kundry has amassed from Kundry to Parsifal at the moment of the Kiss. The clear implication is that female power has been conceded to the man, who takes the power partially through "cleansing" it of its female bodily corruption, which in turn is key to the new religious transcendence of the transformed male. There is no doubt that for a performer of Kundry, to die at the end of the opera is a disappointment - it is a much more satisfying conclusion to live and be joined with Parsifal as if to make humankind's existence a viable option in a future beyond Parsifal. In my reading, that shift in the story actually matches more closely the enacted musical drama I experience as Kundry. For a modern performer, to remain alive at the end suggests a greater respect for the work she has done on stage. For though silenced in the end, Kundry, in my experience, is not powerless. Through her embodied performance, and the bodily enactment of the music of others, she has enlightened us to the complexity of the character, the complexity of being human. She has reminded us that stage performance is all about the control of power, on stage between colleagues, and personally through the creative agency of her own presence. The jouissance she attains with the work of her body and voice makes some sense of the vocal spectacle that Parsifal is: as Suzanne Stewart says, "Wagners' Parsifal ... is an attempt at staging this fundamental operatic desire, this quest for the voice, ... an allegory of opera's desire: it is its embodiment". 470

\footnotetext{
468 The other vital elements she brings to a performance, charisma, concentration and stage presence, can only be experienced in live performance, and so the experience of a live performance can be quite different to a concert performance, or listening to a recording.

469 David Zinder, Body Voice, Imagination (New York: Routledge, 2002), xi.

470 Suzanne Stewart, "The Theft of the Operatic Voice”, 605.
} 


\section{Conclusion:}

\section{Voice Unleashed}

In engaging with the embodiment of operatic singers, I have sought to explain the elusive and compelling quality of voice that transfixes the listener. An embodiment that is fully centred on and encapsulates vocal performance is an enacted and sung set of meanings carried out in real time. The commitment to singing the roles of Verdi and Wagner in the way I have investigated here results in a powerfully original creative act. My dissertation challenges and expands current musicological tropes, which continue to locate the creative act primarily in the work of the composer rather than the performer.

While I have situated my case studies in relation to my own vocal techniques and performances, this is not intended solely for practitioners singers and teachers. My research presents an alternative concept of performance that expands on persisting musicological attitudes towards performance and performer, as outlined in Chapter One. My model of embodiment proposes that, in addition to the music and the text, there is a third agent in performance, carrying important extra information pertinent to the other two, that of the live sound and its performer's body.

There is a theory that music and words convey emotion and story in operatic singing. As surveys have shown, a low percentage of words are understood in performance, so one must deduce that the music must be the main conveyor of emotion. However, I contend that the voice itself conveys as much information and emotion about the character and their emotions as his or her text and music provides. Barthes and Poizat noted these attributes but did not elaborate. In building on their observations I am attempting to create a new paradigm of operatic vocal sound, one that can be understood as an engagement of mind and body.

In addition, in delving into the discourse of vocality and juxtaposing my experience in live performance, I have uncovered how important creative agency 
is in the performance of vocal music, and how some composers have left space for the singer to be a co-creator of the music. The quality of the performer's histrionic abilities can determine the relative level of success of an opera. My research proposes that it is the ability of individual performers to engage their creativity through their embodied continuum that can enhance their performance, and elucidate alternative ways of thinking about important works. This is nowhere more evident than in my study of Kundry.

Moreover, in laying out a new way of thinking about vocal performance I have elucidated a specific way of thinking about singer's operatic embodiment. I explain the nature of the body in singing; I lay out the nature and interaction of mind and body in performance. I explain and lay out the changes in vocal technique in the nineteenth century, and how that change in physicality clarifies the embodiment needed to portray the roles of Verdi and Wagner with heightened emotional engagement.

The critical aspects of examining my case studies, which summarise and articulate aspects of my own experiences in performing four operatic roles by Verdi and Wagner, are vital in suggesting how the singers recreate the music of the nineteenth century through twenty-first-century bodies. By articulating these conceptions of vocality and body with readings of opera, I propose that opera singers, in their quest to perfect the communicative qualities of their voices, employ complex processes that incorporate embodied cognition. Moreover, these layers, based on mental preparation that becomes thoroughly ingrained, in turn produce an engaged enactment that probes into various layers of consciousness during live performance. This embodied continuum in performance is the core of this entire dissertation; it is a summary of why a singer's embodied enactment is so vital; of how the function of voice, on which fans and scholars have focused so much attention on, is the nexus of a compelling collision between mind and body, conscious and unconscious, thinking and feeling.

The invisibility of the work of the voice and the body is problematic for any outside observer (it is a rare scholar who understands the intricacies and 
risk of performance) who is not helped by the fact that singers engaged in this work very rarely articulate what they do. And yet, by viewing singing from the inside, as this thesis has done, both performers and scholars can come to a much more nuanced understanding of both composers' works and how singers' voices and bodies assist the composer in ways that can transform the listening and performing experience.

Balanced as I am on the interdisciplinary border between the world of the performer and the world of the scholar, I have, in this dissertation, integrated my knowledge and experience of the realities of performance with both the relevant and provocative aspects of scholarship, and propose theories that may be challenging to the scholar. The gap between theory and practice is providing fruitful areas for research as an increasing number of scholars, engaging with increasing frequency with the contexts of performance, have found. I can only speak of my own reality in performance, of how my background and experience has developed my voice and body Nonetheless, that performance experience and teaching work gives me a detailed knowledge about the inner workings of performance that are wholly absent from - and deeply relevant to - the scholarly discourse on performance. In addition, as a working singer recording my reactions to the processes evolving and developing in my mind, I am in a unique position as a performer to propose and foster further investigations in the world of theatre and performance.

The issue of liveness lurks behind the case studies; I have reiterated that as a performer, my perceptions come from being part of live performance or listening to live performances. However, as Philip Auslander suggests, it was "the development of recording technologies that made it possible to perceive existing representations as live." 471 Countering the widely held belief that the "ubiquity of reproduction of performances is a depreciation of live presence and that live performance brings performers and spectators together in a community", he asserts that "this view misunderstands the dynamic of performance, which is

471 Philip Auslander, Liveness: Performance in a Mediatised Culture $2^{\text {nd }}$ Ed. (Oxford: Routledge, 2008), 56. 
predicated on the distinction between performers and spectators; while we are in the living presence of the performers there is still also a gap." 472

The power of the voice entrances, puzzles and transfixes and that effect happens very famously through recordings. However, the full effect of the embodiment that I am outlining is, for me, only ever realised in live performance. In a live performance, there is a sense of community, of working together to receive and experience emotional communication, conveying a fuller sense of what it is to be human. Performance art specialist Peggy Phelan comments that "only life is in the present, performance cannot be saved otherwise it becomes something other than performance." 473 Live performances are manifestly something other than recordings, as they carry a quality of presence and extratextual communication that depend crucially on the quality of the voice and the frisson unique to an irretractable present. Further, recordings increasingly tend to be of smaller, more containable voices. Large voices need a live, resonant space to properly form and communicate, and contain qualities that are difficult, if not impossible, for a recording engineer to capture. Many of the extra communicative aspects of embodiment are absent in a recording, even one that includes the visual representation of performance.

Despite the prevalence of recordings of voice, it is still the live interaction between student and teacher, and the actuality of performance that thrills. My critical readings show the range of ways that the body is vital in contributing to a harmonically balanced vocal sound, and how the engagement of the body - the elements of the mind/body synthesis - informs the vocal sound in a variety of ways. Every body, mind and voice is different: that is part of the fascination and frustration of voice. ${ }^{474}$ If the main point of the dissertation is to lay out the nature

\footnotetext{
472 Philip Auslander, Liveness, 40, 65, 66.

${ }^{473}$ Peggy Phelan quoted in Philip Auslander, Liveness. 44.
}

${ }^{474}$ We hear the result of the intervention and usage of the body in the voice in the sounds produced, and certain sorts of voices and bodies, those better muscled and with more mass, are able to create more colour and volume, but it is difficult to measure the exact levels of this enhancement. Note that I am not talking about weight or fat here. Singers generally need to maintain a certain body mass to provide the body and the voice with substance, with the engaged muscles a counter weight, providing stability 
of the creative negotiation that certain works of Verdi and Wagner invite from singers, the model of embodiment that I put forth here also has many implications for performers, more generally. Indeed, the complexity of this process that the training of an opera singer could be further systemised in some way, in order to better prepare singers not only for the (typical) focus on the preperformance preparation, but for performance itself. The ways in which singers, in the process of live performance, must systematically draw those elements back together again into a complete whole (in the manner laid out in Chapter Two), is rigorous. Singers have been trained in certain ways to use the implicit and explicit memory systems to their best advantage. The use of these systems corresponds to the focused use of particular types of preparation, where the vocal technique is consistently reiterated, language is perfected and vocal sound is developed to be maximally communicative. Without this detailed work on both mind and body before live performance, excursions to the kind of creative power I describe, even in rehearsal as a "test", cannot take place. These "tests" are attempts at putting all elements together for a short time, and observing whether or not the detailed accretion of knowledge can be fused into a focused "mini" performance in rehearsal. With time and practice these successful small tests give feedback and confidence to the singer who then can launch into a full-blown performance - into the state of embodied continuum. To be able to perform to the best of its ability the brain must be in a state of focused concentration, placing the full concentration where it is needed, an attentional placement, reinforcing neural pathways.

While the considerable discipline that this task requires might be widely recognised, the lack of articulation of the detailed process means that singers must learn these techniques virtually on their own, not only for vocalising but for being in the moment when singing a role (despite distractions and the everpresent temptation to be negatively self-critical). By not systemising the pedagogy for the processes laid out here, we risk misplacing our training of

and anchoring to the force of the voice going out. The process of analysing my technical procedures and bodily engagement has been rigorous; moreover, my conclusions have been tested in performance and duly discussed in the case studies. An important discovery was the amount of time it took to build up muscular strength to protect the voice, and also to enhance and add a certain quality. 
singers. The desire to foster singers who can move beyond the ongoing vocal training any serious operatic career requires, in both performance and on stage, the courage to release the attachment to all accreted knowledge and sing from a position of intuitive reaction to the emotions expressed in, and aroused by, the music.

I have placed an emphasis on the organising of the vocal resonator tract and associated muscles, which must be employed in a considered way on the inbreath. My term for this sequential engagement of selected elements is "set-up" and it is vital that this organisation is carried out on the in-breath, effectively linking all the elements together. Once the vocal resonator space is set and the breath changes from "in" to "out", to close the vocal folds, it is very difficult to vary the choice of tonal colour. These tonal possibilities create the potential for forging a creative, dramatic, and emotional interpretation of character that is both consciously created and yet that also builds on the authenticity of the singer's own personality and experience. And it is this process, in my experience, that the potential to embody the physiological practices of the performer/character arises, so that singing can become a pure sensual notion performed by the body, contributing to the singer's charisma and personal power.

Some singers are more talented at this than others. The elusive affect of charisma and vitality of opera singers tends to obscure the clinical and nonsubjective appraisal of the voice; often it is the powerful personality of the singer that somehow overrides and commands the music. In many cases the vocal authority of the singer obscures the authority of the composer. Fabrizio Della Seta describes this effect as the result of the voice itself being the true role - the voice is the centre of the drama and is merely clothed in the costumes of the character being played. ${ }^{475}$ The drama is of course important, but what remains, the impact of performance, is the vocal sound as a representative of the text. The vocal sound and emotional connection creates a strong reaction in the listener, most of whom are transfixed by singers who have a sense of mortal urgency in

475 Fabrizio Della Seta, Not Without Madness : Perspectives on Opera (Chicago, IL, USA: University of Chicago Press, 2012), ProQuest ebrary. Web. 20 January 2015. 
their sound and their performance, who sing as if it were a matter of life or death. However, it has to be said that most singers seem to play it safe and make an often homogenous sound that can be unidentifiable. The embodied readings I offer in this thesis demonstrate that there is a need for the development of a technique for singers that moves away from clinical vocal production to a wholly intellectual, embodied, musical training that can more particularly foster the kind of voices, the kinds of performances, that are so exciting, and that compel the entire field forward. These performances in turn would reignite the appreciation of those composers who actually did, or do, understand the singer, and who appreciate(d) the creative collaboration that the singer with an embodied continuum can bring to their works.

Many opera composers, but especially Verdi and Wagner, seemed to understand the effect a singer's creativity brings to their compositions. There were expectations at the time that that the singer would have this kind of involvement and add his/her own stamp to the role. In the recent past the role of the creative performer has been obscured by the overwhelming focus on fidelity to the work; however, as Lydia Goehr says, it is not a question of silencing the composer, but of reigniting the kind of creative synergy between composer and performer that seems to have been taken for granted. ${ }^{476}$ Verdi in particular talks about the vocal sound and its effect on dramatic expression, and leaves space in certain areas for the singer to use the sound and the breath in creative ways, to enhance meaning. He specifically leaves time in certain vocal lines that can be interpreted in a number of ways, not only rhythmically, but tonally and emotionally. In fact, Verdi uses the articulation of the melody to transcend the text.

Wagner would seem on the surface to be quite different: the method of text setting that Wagner engages and develops across his career sets up a fundamentally different kind of negotiating between the singer and composer's text than we observed in Verdi. Despite this wildly contrasting context, though, I

476 Lydia Goehr, The Imaginary Museum of Musical Works: An Essay in the Philosophy of Music (Oxford: Oxford University Press, 1992). 
have nevertheless identified a fascinating space that is left open for the singer's bodily creative engagement in Wagnerian opera. The formative influence of Wilhemine Schröder-Devrient on Wagner suggests that the involvement of the singer's imagination is what he valued above all else: although he confines the singer in regulated text, he leaves space for the singer as dramatic entity to create roles anew. The role of the singer's bodily engagement seems to have interacted with his own sensual obsessions, and which he seems to have known how to exploit at particular moments of his texts. In fact, in singing Wagner there is a peculiar synergy between the sensual bodily involvement in vocalising and in the sensual bodily involvement in the production of the text that gives a somatosensual continuum to the whole.

Thus, though both Verdi and Wagner require a creative engagement from the singer for the full expression of their text, each is substantially different from the other: Verdi uses the melody and the creative use of the breath to transcend the text; and Wagner is defined by the text, and in the dramatic use of it transcends the music. Understanding the nature of this creative role for singers, both as something defined by the composer's text and as something that lies essentially beyond the text, in negotiation with particular singer's own creative and performative energy, is key to defining the nature of performance. The role of vocality in these operas, and potentially, if defined in performative terms, in a wide variety of operatic texts is a vital interpretative tool. Hence the engagement of a singer's body and mind serves a number of purposes: to provide the stability to the vocal sound; to intensify and reinforce the colour of the voice; to "flesh out" and give weight to the physical enacted character; and most importantly to expand and fortify the vocal sound in such a way to give the singer maximum presence and charisma.

In addition to the definition of the singerly role invoked by each of these two composers, another aspect of these case studies is to point towards a new assessment of the well-known historic transformation of vocality across the nineteenth century, in synergy with the development of the vocal styles of these two particular composers. The question of historical and vocal development is a good one; but though my choice of characters seems to present a clear 
evolutionary line between the characters, the reality is more complex. The roles present an interesting progression from the diva as vocal spectacle to the diva as actor, and because of their increasing psychological complexity, they offer an interesting study in the developing intricacy of the character and need for embodiment. They show us how vocal technique was developing, driven by the demand of the composers. However, most importantly, the use of the body not only in the embodied cognition of the vocality, but also in the use of the body in an actorly way, changes throughout. Azucena's bodily energy in Il trovatore is a bridge to Leonora's development later in the opera, creating an über-character out of the opera itself. The psychological complexity of the role of Azucena is apparent, yet it is the juxtaposition of the vocality, the extra information carried in the vocal sound and the extraordinarily difficult physical engagement required for Leonora's music that fascinates. Nonetheless, Azucena seems to engage universal human emotions in a way that bears similarities to Wagner's Sieglinde. We see Sieglinde dealing with a vocal range and orchestration that is more challenging in many ways, and yet the embodiment of her simple emotions is, relatively speaking, less complex. All three have single assumptions of character of varying complexity, and a vocality that, though developing the role of the prima donna, is understandable within its context and relationship to earlier nineteenth-century models. In all three roles, there is a contradiction between wilful diva and passive woman; the development through these binaries, and the closure of that dichotomy is the part of the development of the role of the diva, and also of the degradation of the traditional role. The tension between the voice and the body becomes less overt as all three move through their roles. At the end of their roles they fully inhabit their human embodiment; in addition, the vocality reflects that change, and calls for the colouring obtained from the lowered laryngeal placement.

The role of Kundry, however, breaks this progression; her emotions and motives are beyond the scope of normal human experience, and in many respects a singer's assumption of the role needs to be an embodiment of pure imagination. Not only does her vocally challenging role defy accepted norms, but it also asks for her to forgo singing and emit sounds: groans and screams. I 
believe these noises define the embodiments through which Kundry moves. She requires an engagement and singerly responsibility different to previous roles: for Parsifal to work as a piece of drama the role cannot just be sung, it must be embodied as well. What is the impact of focussing on Kundry in this way? Partially created out of this new tension created by the reliance on female bodily vocality, she is a new operatic phenomenon, an actor who happens to sing.

In articulating my process for these four roles, it is interesting to note how dependent Verdi and Wagner's vocal conceptions seem to have been in relation to the newest advancements of vocal technique of their time. The emerging technique of the mid-nineteenth century, especially that of the lowered larynx, required a more extensive and consistent use of the engaged body. Those singers who managed to make the muscular changes and apply them consistently survived in the demanding world of elite singing. In reimagining the historical body of singers, one can see why people use the terms "Verdian" or "Wagnerian" when it comes to descriptions of voice. With persistent use of muscularity, dependable technique and excellent training, the technical advances have become the accepted sound for the vocality of those composers today. In addition, it would appear that Verdi and Wagner, in different ways, each set up portions of their scores that set up conditions that allows singers to unleash "wildness" and specifically exploit those kinds of vocal expression that lies beyond the text.

As I have mentioned previously, it is intriguing how much opera fans focus on precisely this new type of spinto and dramatic voices. The notion that there is a particular physical enactment on the part of the singer that in fact lies behind the production of these voices, and that may partially explain the nature of the connection itself, is quite a novel concept. That can in this context be only speculative, and by necessity needs to be explored in a separate research project; still, the appreciation of the nature of that voice, the concrete aspects of production I have laid out, suggests that there are ways of engaging in a more detailed way with what is being created here, and with how the vocality itself functions, both in terms of the composer's text and in relation to the singer's performance. 
While the listener's jouissance is widely discussed, very few scholars have discussed the singer's jouissance. Intimately connected with the singer's body, jouissance is a result of and yet also a part of their embodiment. It is a selfrenewing resource tightly connected to cognitive processes and emotional connections, dependent on vocal and bodily health and fitness. It is a quality entirely of embodied continuum of performance once the detailed work of practice and study is done. However, for the singer to experience jouissance the body must be functioning well. To have an opportunity to embody the music as Kundry does in Parsifal in Act III and yet remain silent, adds another layer to the idea of singer's jouissance, as the work becomes purely cognitive.

The perspectives of the singer and the scholar are of necessity quite different, with the scholar's concern being located primarily in the philosophical, poetic and metaphysical aspects of voice, rather than in a consideration of the realities of producing a voice. There are scholars who talk about the embodied thrill of the listener, and indeed, jouissance is a very physical concept. Yet there is a difference between the jouissance of singer and listener; singer's jouissance is embodied, physical, tangible. The listener's jouissance is metaphysical and intangible, and purely reactive.

Considering how ephemeral voice is, its materiality has a huge impact on the listener. In engaging in the articulation of vocal sound, the body can inform vocality. Vocal sound can be examined and analysed scientifically: readings from oscilloscopes can detail the individual harmonic structure of each voice. However, the human ear is more discrete and is able to pick up vocal colours induced by subtextual process, and vocal messages from the mode of delivery. In addition, we have a pre-existing understanding of most of the behaviours that opera singers sing about. Therefore, in most cases, we can identify with the emotions displayed and sung, especially those of love and loss. It is the use of differing colours related to the embodied state, and the undeniable risk and excitement of live performance that, I suggest, releases the singer into a state of continuum, of flow, a release, a letting-go into the area of the unknown - the creative. Perhaps then it is no wonder that scholars use the words "uncanny" and "wild" to describe the extra that they are hearing. They are listening to vocal 
music beyond the realm of the text, and with the variety and breadth of human experience the vocal inferences and psychological aspects of "affect" are unlimited. The reaction to opera is always a reaction to the vocality.

In live performance, the voice makes the connection of body to body, singer to listener. Vladimir Jankélevitch asks in Music and the Ineffable where indeed is music? ${ }^{477}$ I would elaborate and ask: Where is vocality? - Is it in the singer or in the listener? By embodying voice in the way I have described in this dissertation, as a singer, I create that body-to-body connection, that emotional connection that transcends words, and moreover, I establish a discourse in vocality. I facilitate the expressive power inherent in the human voice: voice brings words and music together, yet voice is greater than both.

477 Vladimir Jankélévitch, Music and the Ineffable, trans. Carolyn Abbate (Princeton: Princeton University Press, 2003) 91. 


\section{Bibliography}

Abbate, Carolyn, Unsung Voices: Opera and Musical Narrative in the Nineteenth Century, Princeton N.J.: Princeton, c 1991.

Abbate, Carolyn, In Search of Opera, Princeton N.J.: Princeton, 2001.

Abbate, Carolyn, "Music -Drastic or Gnostic?", Critical Enquiry, 30/3, 2004, 505536.

Abbate, Carolyn and Parker, Roger, Analyzing Opera: Verdi and Wagner, eds. Carolyn Abbate and Roger Parker, California: University of California Press, 1989.

Abbate, Carolyn and Parker, Roger, A History of Opera; the last four hundred years, New York, Penguin Group, 2012.

Abbate, Carolyn, "Opera, or the Envoicing of Women", Musicology and Difference: Gender and Sexuality in Music Scholarship, ed. Ruth Solie, Berkeley: University of California Press, 1993, 225-259.

Abbate , Carolyn, "Metempsychotic Wagner", In Search of Opera, New Jersey: Princeton University Press, 2001.

Abel, Sam, Opera In the Flesh: Sexuality in Opera Performance, Colorado: Westview Press, 1996.

Abitbol, Jean, Odyssey of the Voice, San Diego: Plural Publishing, 2006.

Adorno, Theodor, 'Phantsmagoria' from In Search of Wagner, $1^{\text {st }}$ published by Suhrkamp Verlag, 1952. trans. New Left books 1981, this edition, London: Verso 1981.

Adorno, Theodor, Quasi una fantasia, trans. Rodney Livingstone, London: Verso, 1992.

André, Naomi Adele, “Azucena, Eboli and Amneris: Verdi’s writing for women's lower voices"; Harvard, Proquest Dissertation and Theses, 1996.

André, Naomi Adele, Voicing gender: castrati, travesty, and the second woman in early nineteenth-century Opera, Bloomington, Indiana University Press, 2006.

Atkinson, Paul, "Opera and the Embodiment of Performance", Body/Embodiment; Symbolic Interaction and the Sociology of the Body, ed. Dennis Waskul and Phillip Vannini, Burlington: Ashgate, 2006.

Appia, Adolphe, Music and the Art of the Theatre, trans. Robert W. Corrigan and Mary Douglas Dirks, Miami: University of Miami Press, 1962.

Adorno, Theodor, In Search of Wagner, trans. Rodney Livingstone, London: Verso 1981.

Auslander, Philip, Liveness: Performance in a Mediatised Culture $2^{\text {nd }}$ Ed, Oxford: Routledge, 2008. 
Austern, Linda Phyllis, ed. Music, Sensation and Sensuality, New York: Routledge, 2002.

Badiou, Alain Five Lessons on Wagner, trans. Susan Spitzer, London: Verso, 2010.

Baldini, Gabriele, The Story of Giuseppe Verdi: Oberto to Un Ballo in Maschera. trans. Roger Parker, Cambridge, Cambridge University Press, 1980.

Balthazar Scott L., The Cambridge Companion to Verdi, Cambridge: Cambridge University Press, 2004.

Barba, Eugenio "Words or Presence", The Twentieth-Century Performance Reader, $2^{\text {nd }}$ Edition, eds .Michael Huxley and Noel Witts, Oxford: Routledge, 2012.

Barthes, Roland, "The Grain of the Voice", Image, Music, Text, Glasgow: William Collins and Sons, 1977.

Barthes, Roland, S/Z, trans. Richard Miller, New York, Hill and Wang, 1974.

Bartley, Jim, Breathing Matters: a New Zealand Guide, Auckland: Random House, 2006.

Bauer, Oswald Georg Richard Wagner Goes To the Theatre, trans. Spencer, Stewart, Germany: The Bayreuth Festival, 1996.

Beacham, Richard C., Adolphe Appia, Theatre Artist, Cambridge: Cambridge University Press, 1987.

Beacham, Richard C., Adolphe Appia: Texts on Theatre, London: Routledge, 1993.

Becker, Judith, Deep Listeners: Music, Emotion and Trancing, Bloomington: Indiana University Press, 2004.

Beckett, Lucy, Richard Wagner: Parsifal, Cambridge: Cambridge University Press, 1981.

Begin, Marc, 'L’Anti-Diva', Musique en jeu No 31, May 1978.

Beizer, Janet, Ventriloquized Bodies: Narratives of Hysteria in Nineteenth-Century France, New York, Cornell University Press, 1994.

Bekker, Paul Richard Wagner-His Life in his Work, trans. M. Bozman, New York, Norton 1931.

Benzecry, Claudio, The Opera Fanatic: Ethnography of an Obsession, Chicago, University of Chicago Press, 2011.

Berger, Harris M., Stance, Connecticut: Wesleyan University Press, 2009.

Bernhart, Walther and Lawrence Kramer, eds., On Voice, New York, Rodopi, 2014.

Berry, Cicely, Voice and the Actor, London: Harrap and Co, 1973.

Black, John, The Italian Romantic Libretto: A study of Salvatore Cammarano, Edinburgh, Edinburgh University Press, c 1984.

Blades-Zeller, Elizabeth, A Spectrum of Voices, Maryland: The Scarecrow Press, 2002. 
Blair, Rhonda, The Actor, Imagination and Actio: Acting and Cognitive Neuroscience, New York: Routledge, 2008.

Bicknell, Jeanette, Why Music Moves Us, Basingstoke: Palgrave Macmillan, 2009.

Binnie, Michele, "Finding the Drastic: Exploring Forms of Attention in Piano Performance", MMA Exegesis, Victoria University of Wellington, 2014.

Blackmer, Corinne E. and Patricia Juliana Smith, eds. En Travesti: Women, Gender Subversion, Opera, New York, Columbia University Press, 1995.

Bloch Gregory W., " The pathological voice of Gilbert-Louis Duprez”, Cambridge Opera Journal, Vol 19 Issue 1,11-31, 2007.

Borossa, Julia, Ideas in Psychoanalysis: Hysteria, London: Icon, 2001.

Boston, Jane and Cook, Rena, eds. Breath in Action, London: Jessica Kingsley Publishers, 2009.

Breckbill, David, "Wagner as a Conductor", The Wagner Compendium, ed. Barry Millington, Thames and Hudson, London, 1992.

Breckbill David, "Wagner in Performance", The Wagner Compendium, ed. Barry Millington, Thames and Hudson, London, 1992.

Bronfen, Elisabeth, "Kundry's Laughter", New German Critique, No 69, Autumn $1996,9,147-161$.

Brooks Peter, "Body and Voice in Melodrama and Opera", Siren Songs: ed. Mary Ann Smart, Princeton University Press, Princeton, c.2000 .

Brooks Peter, Body Work: Objects of Desire in Modern Narrative, Cambridge, Massachusetts: Harvard University Press, 1993.

Brooks Peter, The melodramatic Imagination; Balzac, Henry James. Melodrama and the mode of excess, New Haven, Yale University Press, 1976.

Budden, Julian Verdi, London: Dent, 1985.

Budden, Julian, The Operas of Verdi, Volume 2: From Il trovatore to La forza del Destino, Oxford, Oxford University Press, 1991.

Butler, Judith, "Performative Acts and Gender Constitution", The Twentieth Century Performance Reader, $2^{\text {nd }}$ Ed., Eds Michael Huxley and Noel Witts, Oxford, Routledge 2002.

Butler, Judith, Bodies That Matter, Oxford: Routledge, 1993.

Caccini, Giulio, Le nuove musiche, trans. H. Wiley Hitchcock, (translation from Caccini 1602), Madison WI,: A-R Editions, 1970.

Calais-Germain, Blandine,Anatomy of Breathing, trans. Regine Mackenzie, Paris: Editions Dés Iris, 2006.

Carnegy, Patrick Wagner and the Art of the Theatre, London: Yale University Press, 2006. 
Caruso, Enrico and Tetrazzini, Luisa On the Art of Singing, New York, Dover, 1975.

Castle, Terry, "Breath's End: Opera and Mortality", The Arts of the Prima Donna in the Long Nineteenth century, Oxford: Oxford University Press, 2009, 206213.

Cataldi, Sue L. Emotion, Depth and Flesh: A Study of Sensitive Space, New York: State University of New York Press, 1993.

Cavarero, Adriana For More than One Voice, Stanford, Stanford University Press, 2005.

Cavell, Stanley A Pitch of Philosophy: Autobiographical Exercises, Cambridge, Mass., Harvard University Press, 1994.

Celletti, Rodolfo, History of Bel Canto, Oxford, Clarendon Press, 1991.

Chesler, Phyllis, Women and Madness, New York, Palgrave Macmillan, 2005.

Christiansen, Rupert Prima Donna: A History London: Pimlico, 1995.

Chusid, Martin, Verdi's Middle Period: Source Studies, Analysis, and Performance Practice, Chicago: University of Chicago Press Ltd, 1997.

Chusid, Martin, Verdi's Il trovatore: the quintessential Italian melodrama, Rochester NY: University of Rochester, 2012.

Clément, Catherine Opera and the Undoing of Women, trans. Betty Wing,

Minneapolis: University of Minnesota Press, 1988.

Cochrane, Tom, Bernadino Fantini and Klaus Scherer, The Emotional Power of Music: Multidisciplinary perspectives on musical arousal, expression and social control, Oxford, Oxford University Press, 2013.

Coffin, Berton, Historical Vocal Pedagogy Classics, Maryland: The Scarecrow Press, 2002.

Connor, Steven, Dumbstruck: A Cultural History of Ventriloquism, Oxford; Oxford University Press, 2000.

Coghlan, Brian and Middenway Ralph, eds., The Enigma of Parsifal, Adelaide: Richard Wagner Society of Australia, 2001.

Conati, Marcello, Interviews and Encounters with Verdi, trans. Richard Stokes, London: Gollancz, 1984.

Conrad, Peter, A Song of Love and Death, New York: Poseidon, 1987.

Cowgil Rachel and Hilary Poriss, eds, The Arts of the Prima Donna in the Long Nineteenth Century, Oxford, Oxford University Press, 2012.

Crutchfield, Will, "Vocal ornamentation in Verdi: The Phonographic Evidence" Nineteenth Century Music, Vol 7, No.1 ( Summer, 1983), 3-54. 
Csikszentmihalyi, Mihaly, Flow: The Psychology of Optimal Experience, New York: Harper and Row, 1990.

Csikszentmihalyi, Mihaly, Creativity, New York: HarperCollins Publishers, 1996.

Cusick, Suzanne, G. "On Musical Performances of Gender and Sex”, Audible Traces: Gender, Identity and Music, eds Elaine Barking and Lydia Hamessley, Los Angeles: Carficioli, c.1999.

Cusick, Suzanne, G. "Feminist Theory, Music Theory, and the Mind/Body Problem", Perspectives of New Music, 32 ,1994, 8-27.

Damasio, Antonio, Descartes' Error: Emotion, Reason and the Human Brain, U.S.: G.F.Putnam's Sons, 1994.

Damasio, Antonio, The Feeling of What Happens: Body and Emotion in the Making of Consciousness, New York: Harcourt Inc, 1999.

Damasio, Antonio, Self Comes to Mind, London: Heinemann, 2010.

Danahar, Geoff, Tony Schirato and Jen Webb, Understanding Foucault, Crows Nest: Allen and Unwin, 2000.

Davies, James Q., Romantic Anatomies of Performance, Berkeley: University of California Press, 2014.

Davidson, Richard J., Jackson, Daren C., Kalin, Ned H., "Emotion, Plasticity, Context and Regulation: Perspectives from Affective Neuroscience" Psychological Bulletin 126, No 6, 2000, 890-909.

De Van, Gilles, Verdi's Theatre, trans. Gilda Roberts, Chicago: University of Chicago Press, 1998.

Dellamora, R. Fischlin, D., The Work of Opera: Gender, Nationhood and Sexual Difference, ed. D. Fischlin and R. Dellamora, New York: Columbia University Press 1997.

Deathridge, John, Wagner: Beyond Good and Evil, London: University of California Press, 2008.

Della Seta, Fabrizio, Not Without Madness,(2008) trans. Mark Weir, Chicago, University of Chicago Press, 2013.

Derrida, Jacques Writing and Difference, trans. Alan Bass, Chicago: University of Chicago Press, 1978.

Dreyfus, Laurence, Wagner and the Erotic Impulse, Cambridge, Mass.: Harvard University Press, 2010.

Dolar, Mladen and Slavoj Žižek, Opera's Second Death, London: Routledge, 2001.

Dolar, Mladen, A Voice and Nothing More, Cambridge, Mass.: MIT Press, 2006.

Donnington, Robert ,Wagner's Ring and its Symbols: the music and the myth, London: Faber, 1963. 
Duncan, Michelle, "The Operatic Scandal of the singing body: Voice, presence, performativity", Cambridge Opera Journal 16, 3, 283-306.

Dunn, Leslie C. and Jones, Nancy A. Embodied Voices, ed. Leslie C Dunn and Nancy A Jones, London: Cambridge University Press, 1994.

Emslie, Barry, Richard Wagner and the Centrality of Love, Suffolk: The Boydell Press, 2010.

Emslie, Barry, “Woman as image and narrative in Wagner's 'Parsifal': A case study", Cambridge Opera Journal, Vol 3 No 2 1991, p. 112

Eslinger, Paul J. " Neurological and Neuropsychological Bases of Empathy”, European Neurology, 39, 1998, 193-199.

Esse, Melina, Elizabeth, "Sospirare, tremare, piangere: conventions of the body in Italian opera" ProQuest Dissertations and Theses, 2003.

Esse, Melina, Elizabeth "Chi piange, qual forza m'arretra?": Verdi's interior voices, Cambridge Opera Journal, 14, 1\&2, 2002, 59-78.

Freitas, Roger ,"Towards a Verdian Ideal of Singing: Emancipation from Modern Orthodoxy", Journal of the Royal Musical Association, Vol 127, No. 2,2002,pp 226-257.

Friedheim, Philip, "Formal Patterns in Verdi's Il trovatore," Studies in Romanticism, Vol.1 No.2, Winter 1973, 406-425.

Foucault, Michel, The History of Sexuality Vol 1, trans. Robert Hurley, London: Allen Lane 1979.

Gale, Maggie B. and Gardner, Viv, Women ,Theatre and Performance, Manchester: Manchester University Press, 2000.

Gallese, Vittorio, "The manifold nature of interpersonal relations: the quest for a common mechanism.", The Royal Society, 2003, February 14th 2003.

Garcia, Manuel, A Complete Treatise on the Art of Singing Part II, trans. Donald Paschke, New York; Da Capo Press, 1975.

Garcia, Manuel Mémoire sur la voix humaine présenté à l'Académie des Sciences en 1840, Paris: Duverger, 1847.

Garcia, Manuel A Complete Treatise on the Art of Singing Part 11, $(1847,1872)$ trans. Donald Paschke, New York: Da Capo Press, 1975.

Garcia, Manuel, Hints on Singing, London: Chappell, 1911.

Giger Andreas, Verdi and the French Aesthetic: Verse, Stanza, and Melody in Nineteenth-Century Opera. Cambridge: Cambridge University Press. 2008.

Gil, José, Metamorphoses of the Body, trans. Stephen Muecke, Minneapolis: University of Minnesota Press, 1998.

Goehr, Lydia, The Quest for Voice: Music, Politics, and the Limits of Philosophy, Oxford: Oxford University Press, 1998. 
Goehr, Lydia, The Imaginary Museum of Musical Works: An Essay in the Philosophy of Music, Oxford: Oxford University Press, 1992.

Gollancz, Victor, The Ring at Bayreuth and some thoughts on operatic production, London: Gollancz , 1966.

Goodall, Jane, Stage Presence, Oxford, Routledge, 2008.

Goodman, Paul, Speaking and Language: In Defence of Poetry, New York: Random House, 1971.

Gossett ,Philip, ed., Works of Giuseppe Verdi. Critical commentary. Series I, Operas = Le opere di Giuseppe Verdi : Critical commentary / editorial board,.1901. 1983

Grey, Thomas, Richard Wagner and his World, ed. Thomas Grey, Princeton: Princeton, 2009.

Grossmann-Vendrey, Susanna, Bayreuth in der deutschen Presse. Dokumentband 1: Die Grundsteinlegung und die ersten Festspiele(1872-1876), Regensburg: Gustave Bosse Verlag, 1977.

Grosz, Elizabeth, Sexual Subversions: Three French Feminists, London: Allen and Unwin ,1989.

Grosz, Elizabeth, Volatile Bodies: Towards a Corporeal Feminism, Bloomington: Indiana University Press, 1994.

Grover-Friedlander, Michel, Vocal Apparitions, Princeton: Princeton University Press, c.2005.

Gruner, Walther, "Voice Production and Body Coordination", Tensions in the Performance of Music,ed. Carolyn Grindea, New York: Kahn and Averill, 1978.

Gumbrecht, Hans Ulrich, Production of Presence, Stanford: Stanford University Press, 2004.

Gura, Eugen, "Impressions of Bayreuth", Richard Wagner and His World, ed. Thomas Grey, Princeton: Princeton University Press, 2009.

Gutting, Gary Foucault: A Very Short Introduction, Oxford: Oxford University Press, 2005.

Hadlock, Heather, "The firmness of a female hand in The Corsair and Il Corsaro", Cambridge Opera Journal, 14(2002) 1-2.

Hahn, Reynaldo, On Singers and Singing, trans. Léopold Simoneau, Portland, Oregon: Amadeus Press, 1990.

Harrison, Peter, The Human Nature of the Singing Voice, Edinburgh: Dunedin Academic Press, 2006.

Harwood, Gregory, Giuseppe Verdi: A Guide to Research, New York: Garland Publishing, 1998. 
Hemsley, Thomas, Singing and Imagination, Oxford: Oxford University Press, 1998.

Hepokoski, James A., "Genre and Content in Mid-Century Verdi: 'Addio del passato"” (La Traviata Act III), Cambridge Opera Journal, Vol 1, No 3, Nov. 1989, 249-276.

Hepokoski, James A., "Ottocento Opera as Cultural Drama: Generic mixtures in Il Trovatore", Verdi's Middle Period: Source, Studies, and Performance practise, ed. Martin Chusid, Chicago: University of Chicago Press 1997, 147-196.

Herman, Judith, Trauma and Recovery, New York, Basic Books, 1997.

Hill, Leslie, The Cambridge Introduction to Derrida, Cambridge: Cambridge University Press, 2007.

Hiller, Johann Adam, Treatise on Vocal Performance and Ornamentation, trans. and ed. Suzanne J. Beicken, translation of Hiller 1780, Cambridge: Cambridge University Press, 2001.

Hilmes, Oliver, Cosima Wagner: The Lady of Bayreuth, trans. Stewart Spencer, New Haven: Yale University Press, 2010.

Hines, Jerome, Great Singers on Great Singing, New York: Limelight Editions, 1990.

Hollywood, Amy, Mysticism, Sexual Difference, and the Demands of History, Chicago: University of Chicago Press, 2002.

Holsinger, Bruce W., Music, Body and Desire in Medieval Culture: Hildegard of Bingen to Chaucer, Stanford: Stanford University Press, 2001.

Howard, John, Breathing Embodiment: A Study of Middendorf Breathwork, Germany: VDM Verlag, 2009.

Hudson, G Elizabeth, "Narrative in Verdi: Perspectives on his musical dramaturgy", Cornell University, ProQuest, UMI Dissertations Publishing, 1993.

Hustvedt, Asti, Medical Muses, London: Bloomsbury, 2011.

Hutcheon, Linda and Hutcheon, Michael, Bodily Charm: Living Opera, Lincoln: University of Nebraska, 2000.

Huxley, Michael and Noel Witts, eds. The Twentieth Century Performance Reader, $2^{\text {nd }}$ Ed., Oxford, Routledge 2001.

Ihde, Don, Listening and Voice: Phenomenologies of Sound, $2^{\text {nd }}$ Ed., New York: State University of New York Press, 2007.

Irigaray, Lucy, Between East and West: from Singularity to Community, New York: Columbia University Press, 2002.

Izdebski, Krysztof, Emotions in the Human Voice, Vol 1: Foundations, San Diego: Plural Publishing, 2008. 
Izdebski, Krysztof, Emotions in the Human Voice, Vol 2: Clinical Evidence, San Diego: Plural Publishing, 2008.

Izdebski, Krysztof, Emotions in the Human Voice, Vol 3: Culture and Perception, San Diego: Plural Publishing, 2008.

Jampol, Joshua, Living Opera, New York: Oxford University Press, 2010.

Jankélévitch, Vladimir, Music and the Ineffable, trans. Carolyn Abbate, Princeton: Princeton University Press, 2003.

Johnson, Mark, The Meaning of the Body, Chicago: University of Chicago Press, 2007.

Johnson, Mark, The Body in the Mind, Chicago: University of Chicago Press, 1987.

Juslin, Patrik N. and Sloboda, John A. eds. Handbook of Music and Emotion, Oxford: Oxford University Press, 2010.

Katz, Martin, Capturing Sound: How technology has changed music, Berkeley: University of California Press, 2010.

Kerman, Joseph, Opera as Drama, U.S.: Random House, 1952.

Kerman, Joseph, Contemplating Music: Challenges to Musicology, Cambridge, Massachusetts, Harvard University Press, 1985.

Kermode, Frank, Forms of Attention, London: University of Chicago Press, 1985.

Kesting, Jürgen, 2, 2011.

http://www.deutschegrammophon.com/html/special/papewagner/album.html Accessed 16/10/2014.

Kinderman, William and Syer, Katherine, eds. A Companion to Wagner's Parsifal, New York, Camden House, 2005.

Kitcher, Philip and Schacht, Richard, Finding an Ending: Reflections on Wagner's Ring. New York: Oxford University Press,.2004.

Kimbell David R. B., Verdi in the Age of Italian Romanticism, Cambridge: Cambridge University Press. 1985.

Kreutzer, Gundula, Verdi and the Germans, Cambridge:Penguin, 1993.

Koestenbaum, Wayne, The Queen's Throat, London: Penguin, 1993.

Kreiman, Gabriel, Koch Christof, Fried, Itshak, "Imagery neurons in the Human Brain", Nature, 408, 2000, 357-361.

Lakoff, George, and Johnson, Mark, Philosophy in the Flesh, New York: Basic Books, 1999.

Lamperti, Francesco, The Art of Singing, trans J.C. Griffith, New York, Schirmer 1890.

Latham, Alison and Roger Parker eds., Verdi in Performance, Oxford: Oxford University Press, 2001. 
Ledoux, Joseph, The Emotional Brain: the mysterious underpinnings of emotional life, New York: Simon and Schuster, c 1996.

Le Guin, Elisabeth, Boccherini's Body: An Essay in Carnal Musicology, California, University of California Press, 2006.

Lehmann, Lilli, How to Sing, New York: The Macmillan Company, 1916.

Leonardi, Susan J. and Pope, Rebecca A., The Diva's Mouth: Body, Voice: Prima Donna Politics, New Jersey, Rutgers University Press, 1996.

Leppert, Richard, The Sight of Sound: Music, Representation, and the History of the Body, Berkeley, University of California Press, 1993.

Lessac, Arthur, The Use and Training of the Human Voice, New York: DBS Publications, 1967.

Levin, David J. Opera through Other Eyes, ed. David J. Levin, California: Stanford University Press, 1994.

Levin, David J., Unsettling Opera, U.S.: The University of Chicago Press, 2007.

Levin, David Michael, The Listening Self: Personal Growth, Social Change and the Closure of Metaphysics, New York: Routledge, 1989.

Linklater, Kristin, Freeing the Natural Voice, London: Nick Hern Books, 2006.

Lock, Margaret and Judith Farquhar, Beyond the Body Proper: Reading the Anthropology of Material Life, Durham: Duke University Press, 2007.

Locke, Ralph P., "What are these Women doing in Opera?', En Travesti: Women, Gender Subversion, Opera, New York: Columbia University Press,1995.

McCallion, Michael, The Voice Book, London: Faber and Faber, 1988.

McClary, Susan, Feminine Endings: Music, Gender and Sexuality, Minneapolis: University of Minnesota Press, 1991.

Macarthur, Sally, Towards a Twenty-First-Century Feminist Politics of Music, Farnham: Ashgate 2010.

Macdonald, Raymond R., David Hargreaves, and Dorothy Miell, Musical Identities, Oxford University Press, Oxford and New York, 2002.

Maffei, Giovanni Camillo, Delle lettere ... libre due, un discorso della voce e del modo, d'apparar di cantar Garganta senza maestro, 1562, trans. in Carol MacClintock, Readings in the History of Music in performance, Bloomington: Indiana University Press, 1979.

Mancini, Giambattista, Practical Reflection of Figured Singing: The Editions of 1774 and 1777, trans. and ed. Edward Foreman, Champaign, Il: Pro Music Press, 1967.

Manfredini, Vicenz, Regole armoniche,o siano precetti ragionati apprendere $i$ principi della music, Venezia, G. Zerlotti, 1775. 
Marchesi Mathilde, Bel Canto: A Theoretical and Practical Vocal Method, New York: Dover, 1970.

Mauss, Marcel, "Body Techniques", Sociology and Psychology: Essays (1950), trans. Ben Brewster, London: Routledge, Kegan and Paul, 1979.

Matheopoulos, Helena, Divo, New York: Harper and Row, 1986.

Matheopoulos, Helena, Diva, London: Victor Gollancz, 1991.

Matheopoulos, Helena, Diva: The New Generation, London, Little, Brown and Co., 1998.

Matravers, Derek, Art and Emotion, Oxford: Clarendon Press, 1998.

Merleau-Ponty, Maurice, Phenomenology of Perception, trans. Colin Smith, Oxford: Routledge, 2004.

Miller, Richard, National Schools of Singing, Maryland: The Scarecrow Press, 1977.

Miller, Richard, Solutions for Singers, New York: Oxford University Press, 2004.

Millington, Barry and Spencer, Stewart, Wagner in Performance, ed. Barry Millington and Stewart Spencer, New Haven: Yale University Press, 1992.

Millington, Barry, Richard Wagner: The Sorcerer of Bayreuth, London: Thames and Hudson, 2012.

Nancy, Jean-Luc, Listening, trans. Charlotte Mandell, New York, Fordham University Press, 2007.

Nattiez, Jean-Jacques, Wagner Androgyne, trans. Stewart Spencer, New Jersey: Princeton University Press, 1993.

Noske Frits, The Signifier and Signified, Den Haag, Martinus Nijhoff, 1977.

Osborne, Charles, The Complete Operas of Verdi, New York: Da Capo Press,1977.

Parker, Roger, Leonora's last act : essays in Verdian discourse Princeton: Princeton University Press, 1997.

Parker, Roger, Remaking the song: operatic visions and revisions from Handel to Berio, Berkeley, University of California Press, 2006.

Parker, Roger, Reading critics reading : opera and ballet criticism in France from the Revolution to 1848, edited by Roger Parker and Mary Ann Smart., New York, Oxford University Press, 2001.

Parker, Roger, Reading Opera, eds Arthur Groos and Roger Parker, Princeton: Princeton University Press, 1988.

Parker Roger, "The Dramatic Structure of Trovatore”, Musical Analysis, Vol 1, no 2, July 1982.

Parly, Nila, Vocal Victories: Wagner's Female Characters from Senta to Kundry, trans. Gaye Kynoch, Copenhagen: Museum Tusclulanum Press, 2011. 
Parly, Nila, "The Cry of the Valkyrie: Feminism and Corporality in the Copenhagen Ring', The Wagner Journal, 3 ${ }^{\text {rd }}$ November 2008.

Peraino, Judith, Listening to the Sirens, Berkeley: University of California, 2006.

Petrobelli, Pierluigi, "Towards an Explanation of the Dramatic Structure of Il trovatore", trans. William Drabkin, Musical Analysis, Vol.1 No. 2, July 1982.

Petrobelli, Pierluigi, Music in the Theater: Essays on Verdi and Other Composers, trans. Roger Parker, Princeton: Princeton University Press, 2004.

Pleasants, Henry, The Great Singers, New York: Simon and Schuster, 1966.

Poizat, Michel, The Angel's Cry, trans. Arthur Denner, Paris: Métailié ,1986.

Porges, Heinrich, Wagner Rehearsing The Ring: An Eyewitness Account of the Stage Rehearsals of the First Bayreuth Festival , trans. Robert Jacobs, Cambridge: Cambridge University Press, 1983.

Rieger, Eva, Richard Wagner's Women, trans. Chris Walton, Suffolk: The Boydell Press, 2011.

Riggs, Geoffrey S., The Assoluta Voice in Opera 1797 - 1847, London: McFarland, 2003.

Risi, Clemens, "Opera in Performance-In Search of New Analytical Approaches" The Opera Quarterly, Vol 27, No 2-3, 283-295.

Risi, Clemens, "The Diva's Fans: Opera and Bodily Participation", Performance Research, 16 (3) 2011, 49-54.

Rizzolatti, Giacomo. and Corrado Sinigaglia, Mirrors in the Brain, trans. Frances Anderson, Oxford: Oxford, 2006.

Robbin, Catherine "Appoggio Demystified", York University, Ontario, Canada, http://journals.library.mun.ca/ojs/index.php/singing/article/viewFile/1 035/889, accessed 25/08/15)

Rosolato, Guy, 'La Voix: entre corps et langage" Revue Française de Psychoanalyse, ( 1; XXXV111, Janvier, 1974), 75-94.

Rosselli John, The Life of Verdi, Cambridge University Press, 2000.

Rosselli John. Singers of Italian Opera: The history of a profession, Cambridge University Press. 1992.

Rutherford, Susan, "La cantante delle passioni: Giuditta Pasta and the idea of operatic performance”, Cambridge Opera Journal, 19, 2, 107 -138, 2007.

Rutherford, Susan, “'Unnatural gesticulation' or 'un geste sublime'?: Dramatic performance in opera." Arcadia, 36.2 (2001) 236-255.

Rutherford, Susan, The Prima Donna and Opera 1815-1930, Cambridge: Cambridge University Press, 2006.

Rutherford, Susan, Verdi, Opera, Women, Cambridge, Cambridge University Press, 2013. 
Sacks, Oliver, Musicophilia, London: Picador, 2007.

Sadie, Stanley, ed. Verdi and His Operas, New York: St. Martin's Press. 2000.

Scott, Michael, The Record of Singing Vol 1 to 1914, London, Duckworth, 1977.

Senici, Emanuele, Landscape and Gender in Italian Opera, New York: Cambridge University Press, 2005.

Silverman, Kaja, The Acoustic Mirror: the female voice in psychoanalysis and cinema, Bloomington: Indiana University Press, 1988.

Sheldrake, Rupert, The Science Delusion, London: Coronet, 2012.

Shewell, Christina, Voice Work: Art and Science in Changing Voices, West Sussex, U.K: Wiley-Blackwell, 2009.

Showalter, Elaine, Hystories: Hysterical Epidemics and Modern Culture, New York: Columbia University Press, 1997.

Skelton, Geoffrey, Wagner in Thought and Practice, Oregon: Amadeus Press 1991.

Skelton, Geoffrey, Wagner at Bayreuth, London: Barry and Rockliff, 1965.

Smart, Mary Ann, Siren Songs: Representations of Gender and Sexuality in Opera, ed. Mary Ann Smart, New Jersey: Princeton University Press, 2000.

Smart, Mary Ann, Mimomania, California: University of California Press, 2006.

Smart, Mary Ann, "Dalla tomba uscita: Representations of madness in nineteenth-century Italian opera", ProQuest Dissertations and Theses, 1994.

Smith, Matthew Wilson, "Laughing at the Redeemer: Kundry and the Paradox of Parsifal," Modernist Cultures, Issue 5, 2007.

Solie, Ruth, ed., Musicology and Difference: Gender and Sexuality in Music Scholarship, Berkeley, University of California Press, 1993.

Somville, Marilyn Feller, "Vocal gesture in Macbeth" Verdi's Macbeth: A Sourcebook, Cambridge University Press, Cambridge, 1984.

Spencer, Stewart and Millington, Barry,Wagner's Ring of the Nibelungen: A Companion, London: Thames and Hudson, 1993.

Spencer, Stewart, Wagner Remembered, London: Faber and Faber, 2000.

Stark, James, Bel Canto: A History of Vocal Pedagogy, Toronto: University of Toronto Press, 1999.

Stanislavki, Konstantin, An Actor Prepares, London: Methuen, 1988.

Stern, Daniel N., Forms of Vitality, Oxford: Oxford University Pres, 2010.

Stewart, Suzanne, "The Theft of the Operatic Voice: Masochistic Seduction in Wagner's Parsifal", The Musical Quarterly, Vol 80, No 4.

Storr, Anthony, Music and the Mind, London: Harper Collins, 1992. 
Sundberg, Johan, The Science of the Singing Voice, Illinois: Northen Illinois University Press, 1989.

Titze, Ingo R., The Principles of Voice Production, New Jersey, Prentice Hall. 1994.

Toft, Robert, Bel Canto: A Performer's Guide, USA: Oxford University Press, 2012.

Tomlinson, Gary, Metaphysical Song, New Jersey: Princeton University Press, 1999.

Tosi, Pierfrancesco, Opinions of Singers ancient and modern, or Observations on Figured Singing, trans. Edward Foreman, translation of Tosi 1723, Minneapolis, Pro Music Press 1986.

Verdi, Giuseppe, Il trovatore, vocal score, ed. David Lawton, Chicago: University of Chicago Press, 2002.

Wagner, Cosima, Tagebücher Vols 1\&2. eds. Martin Gregor-Dellin and Dietrich Mack, Munich and Zurich, 1976,1977.

Wagner, Richard Actors and Singers, trans. W. Ashton Ellis, London: University of Nebraska Press, 1995.

Wagner, Richard, Opera and Drama, trans. W. Ashton Ellis, London: University of Nebraska Press, 1995.

Wagner, Richard, Parsifal, WWV 111, vocal score, Edition Peters, 1914,1942.

Wagner, Richard, Die Walküre, WWV 86B, vocal score, Edition Peters, 1914, 1942.

Waskul, Dennis and Phillip Vannini eds., Body/Embodiment, Aldershot, UK, Ashgate, 2006.

Weaver, William, Verdi: A Documentary Study, London: Thames and Hudson, 1978.

Weaver, William, Martin Chusid eds., The Verdi Companion. New York: W.W.Norton, c 1979.

Wood, Elizabeth, "Sapphonics", Queering the Pitch, eds. Philip Brett, Elizabeth Wood, Gary C. Thomas, New York: Routledge,1994.

Zinder, David, Body-Voice-Imagination: A Training for the Actor, New York: Routledge, 2002.

Žižek, Slavoj "The Wound is Healed Only by the Spear that Smote You: The Operatic Subject and its Vicissitudes" Opera Through Other Eyes, ed. David Levin, Stanford: Stanford University Press, 1994.

Zumthor, Paul, preface, Corrado Bologna Flatus Vocis: Metafisica e antropologica della voce, Bologna: Il Mulino, 2000. 